\title{
SISTEMA DE APOIO À DECISÃO NA ESCOLHA DE CONDIÇÕES OPERACIONAIS PARA \\ PROCESSOS DE USINAGEM
}

Dissertação apresentada à Escola

Politécnica da Universidade de São Paulo para obtenção do título de Mestre em Engenharia.

São Paulo 


\section{SISTEMA DE APOIO À DECISÃO NA ESCOLHA DE CONDIÇÕES OPERACIONAIS PARA PROCESSOS DE USINAGEM}

Dissertação apresentada à Escola Politécnica da Universidade de São Paulo para otenção do título de Mestre em Engenharia.

Área de Concentração:

Engenharia Mecânica

Orientador:

Prof. Dr. Nivaldo Lemos Coppini

São Paulo 
Araujo, Geraldo Accetturi de

Sistema de Apoio à Decisão na Escolha de Condições Operacionais para Processos de Usinagem. São Paulo, 1997. $148 p$.

Dissertação (Mestrado) - Escola Politécnica da Universidade de São Paulo. Departamento de Engenharia Mecânica.

1. Planejamento Auxiliado por Computador 2. Processos de Usinagem I. Universidade de São Paulo. Escola Politécnica. Departamento de Engenharia Mecânica II. t 


\section{Agradecimentos}

Ao Prof. Dr. Nivaldo Lemos Coppini, pela orientação e ânimo que sempre soube transmitir, descobrindo inovações para o trabalho e discutindo suas idéias de forma sempre tão amiga;

Ao Prof. Dr. Paulo Eigi Miyagi, pelo apoio e auxílio que manteve durante todas as fases do meu programa de mestrado;

Aos meus pais, por tudo o que fizeram e continuam fazendo por mim;

A minha esposa Adriana, pelo estímulo e incansável compreensão nos momentos de ausência devido ao trabalho;

Aos colegas da Mercedes-Benz do Brasil que direta ou indiretamente auxiliaram e incentivaram o desenvolvimento deste trabalho e, em particular, do sistema protótipo apresentado, colaborando com os testes práticos do mesmo;

Ao Eng. Odair Henrique Ribeiro pelo auxílio e instrução na programação com o Delphi;

A todos que direta ou indiretamente colaboraram na realização deste trabalho. 


\section{S U M Á R IO}

Lista de Figuras e Tabelas

Lista de Abreviaturas e Símbolos Utilizados

Resumo

Abstract

Prólogo

1 Introdução

2 O Planejamento de Processo Auxiliado por Computador 6

2.1 O CIM, o CAPP e a Fábrica do Futuro 6

2.2 A Função Planejamento da Manufatura 9

2.3 As Diferentes Abordagens dos Sistemas CAPP Quanto à Geração do Plano 14

2.3.1 O sistema CAPP variante 16

2.3.2 O sistema CAPP generativo 19

2.3.3 O sistema CAPP semi-generativo 21

2.4 Aspectos Relativos à Metodologia de Execução dos

Sistemas CAPP em Usinagem e a Especificação de

Parâmetros do Processo 23

2.4.1 Os bancos de dados tecnológicos e o projeto do produto, o planejamento de processos e a produção

2.4.2 O problema da especificação do processo de usinagem: dados de entrada, parâmetros e especificações de saída

2.4.2.1 A escolha do processo

2.4.2.2 A escolha da máquina-ferramenta

2.4.2.3 A escolha da ferramenta

2.4.2.4 A escolha da forma de fixação da peça

2.4.2.5 As restrições tecnológicas na seleção das condições de usinagem 
2.4.2.6 A escolha dos parâmetros de processo conforme diferentes critérios de otimização

2.4.3 Tendências nas metodologias computacionais empregadas nos sistemas CAPP

2.4.3.1 Sistemas algorítmicos

2.4.3.2 Sistemas baseados em conhecimento

2.4.3.3 A interface dos sistemas CAPP com o usuário e a orientação a objetos

2.5 Tendências para os Sistemas CAPP e para a Especificação de Parâmetros de Processos de Usinagem

4 Um Modelo para o Sistema de Escolha de Condições Operacionais em Processos de Usinagem 85

4.1 Aspectos Gerais do Modelo Adotado 85

4.1.1 O ambiente industrial de aplicação do modelo 88

4.1.2 Os processos de usinagem, seus parâmetros e características específicas aplicadas no Modelo

4.1.3 As etapas, as restrições e os critérios de planejamento do processo de usinagem utilizados no Modelo

4.1.4 A aplicação ao modelo e ao sistema das tendências observadas nos sistemas CAPP

4.1.5 O banco de dados relacional adotado

4.1.6 Quadro geral de especificações do sistema protótipo 102

4.2 Descrição dos Módulos do Modelo aplicados no Sistema

4.2.1 A entrada de dados da peça e a seleção do processo e operação

4.2.2 A verificação da existência de planos similares

4.2.3 A primeira pré-seleção de máquinas de usinagem

4.2.4 A primeira pré-seleção de ferramentas de usinagem

4.2.5 A primeira pré-seleção de condições de usinagem

4.2.6 A segunda pré-seleção de ferramentas de usinagem

4.2.7 A segunda pré-seleção de condições de usinagem 
4.2.8 A definição dos critérios de otimização e a seleção final da máquina, da ferramenta e das condições de usinagem: o plano final de processo (teórico)

4.2.9 A avaliação na fábrica das condições de usinagem e a verificação do intervalo de validade da velocidade de corte otimizada prática

4.3 Recursos de Software e Hardware Empregados

4.4 Considerações sobre a Utilização do Sistema numa Fábrica

5 A Simulação Numérica do Sistema e os Testes Práticos

6 Conclusões

6.1 Conclusões e Contribuições deste Trabalho

6.2 Sugestões para Pesquisas Futuras 


\section{LISTA DE FIGURAS E TABELAS}

\section{FIGURAS}

2.01 Modelo geral para um processo de manufatura [Zhang 94] 10

2.02 Classificação de alguns Domínios de Processo de Fabricação

típicos em indústrias automobilísticas [Araujo 95]

2.03 Funções de Planejamento Macro e de Operações [Rozenfeld 89, Rodrigues 93]

2.04 Formas de Geração para Sistemas de Planejamento [Zhang 94]

2.05 Um exemplo de Banco de Dados com configuração geométrica hierárquica [Zhang 94]

2.06 Uma BD de máquinas-ferramentas em rede [Zhang 94]

2.07 Um exemplo de Banco de Dados para um sistema CAPP de Usinagem, construído em ORACLE

2.08 O modelo em corrente [Eriksson 92]

2.09 Exemplo de Modelo Gráfico para um Processo de Usinagem e sua otimização sob o ponto de vista do avanço e da velocidade de corte, adaptado de [Boehs 86], [Ferraresi 85] e [Couers 90]

2.10 Exemplo de features aplicado no projeto e aplicado na manufatura [COMPLAN 95]

2.11 Diferentes materiais para ferramentas (esquemático), segundo [Reiter 89] e similar em [Kunz 94], [Stricker 90] e [Chandrasekaran 88] 43

2.12 Desenvolvimento das Velocidades de Corte, segundo [Johannsen 92] 44

2.13 Diferentes alternativas de Sistemas de Fixação e suas Características, segundo [Hargrove 94]

2.14 Diagrama ilustrando a precisão de diferentes meios de auxílio na escolha do material e condições de trabalho para ferramentas, segundo [Kunz 94]

2.15 Determinação das Condições Econômicas de usinagem e o Intervalo de Máxima Eficiência (IME) [Ferraresi 85] 
4.01 Modelo Geral Proposto para Sistema de Especificação de Condições Operacionais em Processos de Usinagem

4.02 Fluxograma com as atividades detalhadas para o modelo da figura 4.01

4.03 Tela do software Microsoft Access ${ }^{\circledR}$ com as tabelas empregadas no sistema de planejamento de processos e determinação de condições de usinagem

4.04 Tela do software Microsoft Access ${ }^{\circledR} 2.0$ com os possíveis relacionamentos entre as tabelas e os campos empregados no sistema de planejamento de processos e determinação de condições de usinagem

4.05 Processos de usinagem utilizados no sistema protótipo

4.06 Exemplo de árvore de decisão para material da ferramenta, conforme [Johannsen 79]

4.07 Algumas geometrias de insertos e ângulos de posição possíveis no sistema

4.08 Fluxograma com a rotina de verificação e correção dos valores do raio de ponta da ferramenta e do avanço máximo AMAX, com base nos valores pré-determinados do raio, do avanço máximo e da profundidade de corte máxima

4.09 Alguns casos cobertos pelo fluxograma da figura anterior, mostrando correções de raios de ponta da ferramenta e de avanços máximos, conforme posições relativas de $r_{0}$, AMAX e PMAX (para desbaste e desbaste leve)

4.10 Gráfico ilustrativo de uma possível evolução das velocidades otimizadas de corte de acordo com a sequência de ensaios e mudança no critério de otimização

5.01 Esquema simplificado para o semi-eixo utilizado como exemplo de aplicação do sistema

5.02 Máquinas selecionadas por operação/condições dimensionais e a escolha da máquina $n^{\circ} 3$ para estudo - Torno Revólver CNC TND - 360

5.03 Máquina escolhida para execução da operação (máquina 3) e os dados e tempos definidos para a mesma e para a operação

5.04 Quadro de escolha da ferramenta, com indicações de material, ângulo de saída sugerido e ângulo de posição já definido.

As sugestões iniciais do usuário foram Opção 1: DNMG 150612 => DNMG 150608 ( $n^{\circ}$ 40), e Opção 2: SNMG 120412 => SNMG 120408 ( $\left.n^{\circ} 36\right)$, alteradas pelo sistema 
5.05 Definição dos Critérios de Otimização (superior) com o botão Detalhes conduzindo aos Tempos e Custos da Operação (inferior) (valores específicos para a ferramenta 36)

5.06 Exemplo de definição da Velocidade de Corte Otimizada considerando as restrições da máquina e o cálculo de carga-máquina

5.07 Definição do Critério de Desgaste para o Ensaio com a ferramenta 36, o torno CNC TND-360 e as condições $\left(p ; a ; V_{c 1}\right)=(1,0 ; 0,64 ; 260)$

5.08 Quadro para a escolha do tipo de cavaco gerado durante o ensaio da operação

5.09 Quadro para a escolha do fluido de corte utilizado durante o ensaio da operação

5.10 Quadro para a introdução dos valores escolhido para ensaio da operação na máquina. O sistema introduz os valores teóricos e o usuário pode alterá-los, de acordo com os resultados do ensaio (na figura já estão inseridos os valores práticos obtidos no ensaio)

5.11 Definição dos Critérios de Otimização (superior) e o botão Detalhes conduzindo aos Tempos e Custos da Operação (inferior) para as condições do ensaio dessa operação

5.12 Definição da Velocidade de Corte Otimizada Prática como $260 \mathrm{~m} / \mathrm{min}$, adotando um valor conveniente por sugestão do próprio sistema e pela análise do usuário com base nos dados mostrados nas telas do sistema e contidos na fig. 5.11. O primeiro quadro mostra a validação da velocidade de corte adotada e a não necessidade de outros ensaios para determinação de $x$ e $\mathrm{K}$ de Taylor. O segundo ilustra uma comparação entre as várias velocidades discutidas e possíveis com essa máquina, ferramenta e condições de usinagem para o ensaio.

\section{TABELAS}

2.01 Quantidades aproximadas para tipos de produção diferentes [Zhang 94]

2.02 Restrições tecnológicas no processo de usinagem e sua influência nas variáveis dependentes, conforme [Boehs 86]. 


\section{LISTA DE ABREVIATURAS E SÍMBOLOS}

\begin{tabular}{|c|c|}
\hline a & Avanço (mm/rotação) \\
\hline$A B C$ & Activity Based Costing. Custeio Baseado em Atividades \\
\hline ABNT & Associação Brasileira de Normas Técnicas \\
\hline AISI & American Iron and Steel Institute \\
\hline AMAX & Avanço máximo adotado no sistema protótipo (mm/rotação) \\
\hline ASA & American Standard Association \\
\hline ASM & American Society for Metals \\
\hline ASME & American Society of Mechanical Engineers \\
\hline BD & $\begin{array}{l}\text { Banco ou Base de Dados (em geral, referindo-se a bancos de dados } \\
\text { relacionais). Database }\end{array}$ \\
\hline BDE & Borland Database Engine \\
\hline BOM & Bill of Materials. Lista de Materiais \\
\hline B-Rep & Boundary Representation \\
\hline C & Constante da Equação (2) de Taylor para a Vida da Ferramenta \\
\hline CAD & Projeto Auxiliado pelo Computador. Computer Aided Design \\
\hline CAE & Computer Aided Engineering \\
\hline CAFP & Computer Assisted / Aided Fixture Planning \\
\hline CAM & Computer Aided Manufacturing \\
\hline CAPP & $\begin{array}{l}\text { Computer Aided Process Planning. Planejamento de Processo } \\
\text { Auxiliado pelo Computador }\end{array}$ \\
\hline CAPR & Computer Aided Product Realization \\
\hline CBN & Cubic Boron Nitride. Nitreto Cúbico de Boro \\
\hline CIM & $\begin{array}{l}\text { Computer Integrated Manufacturing. Manufatura Integrada pelo } \\
\text { Computador }\end{array}$ \\
\hline $\mathrm{CM}_{\mathrm{NO}}$ & Carga-Máquina Necessária à Operação (\%) \\
\hline CMuto & Carga-Máquina Utilizada Total para a Operação (\%) \\
\hline $\mathrm{CN}$ & Controle Numérico. Numerical Control \\
\hline CNC & Controle Numérico Computadorizado. Computerized Numerical Control \\
\hline CSG & Constructive Solid Geometry \\
\hline CVD & Chemical Vapor Deposition. Deposição Química por Vapor \\
\hline D & $\begin{array}{l}\text { Relação de Taxas de Produção entre uma condição de máxima } \\
\text { produção e uma de mínimo custo }\end{array}$ \\
\hline DFMA & Design For Manufacturing and Assembly \\
\hline DIN & Deutsches Institut für Normung \\
\hline DNC & Distributed Numerical Control \\
\hline EMBRAER & Empresa Brasileira de Aeronáutica \\
\hline ESPRIT & European Strategic Program for Research in Information Technology \\
\hline FBD & Feature Based Design. Projeto Baseado em Features \\
\hline$F_{c}$ & Força de Corte para a operação de usinagem (N) \\
\hline FEA & Finite Element Analysis. Análise por Elementos Finitos \\
\hline FMS & Flexible Manufacturing System. Sistema Flexível de Manufatura \\
\hline
\end{tabular}




\begin{tabular}{|c|c|}
\hline GU & Grau de Utilização da máquina (\%) \\
\hline HB & Brinell Hardness, escala de dureza \\
\hline $\mathrm{HM}$ & Hardmetal. Metal Duro \\
\hline HSS & High Speed Steel. Aço Rápido \\
\hline IA & Inteligência Artificial \\
\hline IME & Intervalo de Máxima Eficiência \\
\hline ISO & International Organization for Standardization \\
\hline K & Constante da Equação (3) de Taylor para a Vida da Ferramenta \\
\hline $\mathrm{K}_{\mathrm{ft}}$ & Custo da Ferramenta por Vida da Aresta de Corte ( $\mathrm{R} \$$ por aresta) \\
\hline $\mathrm{K}_{\mathrm{S} 1.1}$ & $\begin{array}{l}\text { Constante específica do material para uma seção de corte de } 1 \mathrm{~mm} \text { de } \\
\text { espessura por } 1 \mathrm{~mm} \text { de largura, da fórmula de Kienzle }\left(\mathrm{N} / \mathrm{mm}^{2}\right)\end{array}$ \\
\hline $\mathrm{K}_{\mathrm{u}}$ & Custo Total de Usinagem (R\$) \\
\hline $\mathrm{K}_{\mathrm{ui}}$ & Custos Indiretos de Usinagem $(\mathrm{R} \$)$ \\
\hline $\mathrm{K}_{\mathrm{vm} \times \mathrm{p}}$ & Custo por peça para a velocidade de máxima produção $(\mathrm{R} \$)$ \\
\hline $\mathrm{K}_{\mathrm{vmc}}$ & Custo por peça para a velocidade de mínimo custo $(R \$)$ \\
\hline KT & $\begin{array}{l}\text { KraterTiefe. Profundidade da cratera na saída de cavaco da } \\
\text { ferramenta }\end{array}$ \\
\hline MFDP & Sistema Máquina-Ferramenta-Dispositivo-Peça \\
\hline MF & $\begin{array}{l}\text { Modo de Fornecimento do material da peça bruta para a operação de } \\
\text { usinagem }\end{array}$ \\
\hline MRP & $\begin{array}{l}\text { Material Requirement Planning. Planejamento de Material Requerido } \\
\text { para a Produção }\end{array}$ \\
\hline$n$ & $\begin{array}{l}=1 / x \text {, coeficiente da Equação (2) de Taylor para a Vida da } \\
\text { Ferramenta }\end{array}$ \\
\hline $\mathrm{n}_{\mathrm{t}}$ & Número de Trocas da Ferramenta \\
\hline $\mathrm{p}$ & Profundidade de Corte (mm) \\
\hline PC & Personal Computer \\
\hline PCD & Polycrystalline Cubic Diamond. Diamante Cúbico Policristalino \\
\hline$P_{\text {maxmaq }}$ & Potência Máxima da Máquina (kW) \\
\hline PMAX & Profundidade de Corte Máxima adotada no sistema protótipo (mm) \\
\hline PVD & Physical Vapor Deposition. Deposição Física por Vapor \\
\hline qpd & Quantidade Programada de peças Diariamente para a máquina \\
\hline $\mathrm{R}_{\mathrm{a}}$ & Rugosidade medida através do desvio médio aritmético (micrometros) \\
\hline Rc & Rockwell $C$, escala de dureza \\
\hline $\mathrm{R}_{\mathrm{k}}$ & $\begin{array}{l}\text { Relação de Custos entre uma condição de máxima produção e uma de } \\
\text { mínimo custo }\end{array}$ \\
\hline $\mathrm{R}_{\mathrm{m}}$ & Tensão de Ruptura à Tração $\left(\mathrm{N} / \mathrm{mm}^{2}\right)$ \\
\hline $\mathrm{R}_{\mathrm{rms}}$ & $\begin{array}{l}\text { Rugosidade medida através do desvio médio quadrático ou root mean } \\
\text { square average (micrometros) }\end{array}$ \\
\hline $\mathrm{R}_{\mathrm{t}}$ & Rugosidade Teórica (micrometros) \\
\hline $\mathrm{R} \$$ & Real, unidade monetária brasileira \\
\hline SAE & Society of Automotive Engineers \\
\hline
\end{tabular}




\begin{tabular}{|c|c|}
\hline $\mathrm{S}_{\mathrm{h}}$ & Custo ou Salário do operador ( $\mathrm{R} \$$ por hora) \\
\hline$S_{m}$ & Custo ou Salário máquina ( $\mathrm{R} \$$ por hora) \\
\hline$S_{p}$ & Custo ou Salário do preparador de máquina ( $\mathrm{R} \$$ por hora) \\
\hline SBC & Sistema Baseado em Conhecimento. Knowledge Based System \\
\hline SDB & Single Data Base \\
\hline SE & Sistema Especialista. Expert System \\
\hline SEMCON & $\begin{array}{l}\text { Sistema para Escolha de Máquinas de Comando Numérico (da } \\
\text { EMBRAER) }\end{array}$ \\
\hline SGBD & Sistema de Gerenciamento de Banco de Dados \\
\hline SIM & Sistemas Integrados de Manufatura \\
\hline SQL & $\begin{array}{l}\text { Structured Query Language. Linguagem de Consulta Estruturada a } \\
\text { tabelas de bases de dados }\end{array}$ \\
\hline$t_{a}$ & Tempos Auxiliares de Usinagem (min) \\
\hline$t_{c}$ & Tempo de Corte (min) \\
\hline$t_{\mathrm{ft}}$ & Tempo de Troca da Ferramenta (min) \\
\hline$t_{p}$ & $\begin{array}{l}\text { Tempo de Preparação da Máquina para a fabricação de um lote de Z } \\
\text { peças (min) }\end{array}$ \\
\hline$t_{s}$ & Tempos Secundários de Usinagem (min) \\
\hline$t_{t}$ & Tempo Total ou de Ciclo de Usinagem por peça (min) \\
\hline $\mathrm{T}$ & Tempo de Vida da Ferramenta na operação de usinagem (min) \\
\hline TG & Tecnologia de Grupo. Group Technology \\
\hline $\mathrm{T}_{\mathrm{PD}}$ & Tempo de Produção Disponível à máquina (min) \\
\hline $\mathrm{T}_{\mathrm{PNO}}$ & Tempo de Produção Necessário à Operação (min) \\
\hline TRCE & Torneamento Retilíneo Cilíndrico Externo \\
\hline TRCl & Torneamento Retilíneo Cilíndrico Interno \\
\hline TRCOE & Torneamento Retilíneo Cônico Externo \\
\hline TRCOI & Torneamento Retilíneo Cônico Interno \\
\hline TRCS & Torneamento Retilíneo Cilíndrico com Sangramento Axial \\
\hline TRF & Torneamento Retilíneo Radial de Faceamento \\
\hline TRRS & Torneamento Retilíneo Radial de Sangramento Radial \\
\hline $\mathrm{v}_{\mathrm{c}}$ & Velocidade de Corte (m/min) \\
\hline $\mathrm{V}_{\mathrm{c} \max }$ & $\begin{array}{l}\text { Velocidade de Corte com Restrição de Rotação Máxima da Máquina } \\
\text { (m/min) }\end{array}$ \\
\hline $\mathrm{V}_{\mathrm{c} \min }$ & $\begin{array}{l}\text { Velocidade de Corte com Restrição de Rotação Mínima da Máquina } \\
\text { (m/min) }\end{array}$ \\
\hline $\mathrm{V}_{\mathrm{C} \text { maxpot }}$ & Velocidade de Corte com Restrição de Potência da Máquina (m/min) \\
\hline $\mathrm{v}_{\mathrm{mxp}}$ & Velocidade de Corte de Máxima Produção (m/min) \\
\hline $\mathrm{v}_{\mathrm{mc}}$ & Velocidade de Corte de Mínimo Custo (m/min) \\
\hline VB & $\begin{array}{l}\text { VerschleißenBreite. Largura de desgaste na superfície de incidência da } \\
\text { ferramenta }\end{array}$ \\
\hline $\mathrm{x}$ & Coeficiente angular da reta $T-v_{c}$ no diagrama dilogarítmico \\
\hline$y, z$ & Coeficientes da Equação de Taylor Expandida \\
\hline Z & Número de peças do lote de fabricação \\
\hline$Z_{t}$ & $\begin{array}{l}\text { Número de peças produzidas por vida de cada aresta de corte da } \\
\text { ferramenta }\end{array}$ \\
\hline
\end{tabular}


$\sigma$

$\eta$

$x$

$1-z$
Desvio-padrão da distribuição da vida da ferramenta Rendimento da transmissão entre motor e fuso da máquina $(0<=\eta<=1)$

Ângulo de posição da ferramenta $\left(^{\circ}\right)$

Coeficiente da fórmula de Kienzle 
O planejamento de processos é uma atividade essencial nas diversas etapas do ciclo de manufatura, em particular nas indústrias que produzem peças através de processos de usinagem. O uso de sistemas CAPP tem implicado em uma evolução nos sistemas de planejamento. A determinação da máquina, da ferramenta e das condições operacionais adequadas visando a otimização das diversas operações é fundamental para o sucesso do processo produtivo e da empresa, podendo ser melhorado pelo uso do CAPP. Estudam-se, assim, os fatores que influenciam esse tipo de processo, propondo-se um modelo de sistema protótipo para o seu planejamento, de forma a se ter no final uma especificação teórica da profundidade de corte, do avanço e da velocidade de corte, considerando aspectos como a usinabilidade do material da peça, os tempos de fabricação secundários e auxiliares, e a própria logística aplicada ao fluxo de peças no chão-de-fábrica através da definição quanto à máquina empregada ser ou não gargalo além de considerações sobre a disponibilidade de carga-máquina. Procurou-se elaborar um critério de otimização que considere não apenas o intervalo de máxima eficiência como proposto por vários autores, mas discuta a aplicação de seus limites e as restrições do sistema máquina-ferramenta-peça. Além do planejamento teórico o sistema possui um módulo de ensaios práticos visando refinar os valores teóricos da velocidade de corte adotada para garantir a sua perfeita aplicação com a máquina e a ferramenta adotados. A proposta do sistema é semi-generativa, unindo soluções algorítmicas e baseadas em conhecimento, com uma interface simples e amigável ao usuário. 


\section{ABSTRACT}

Process planning is an essential activity in the several stages of the manufacturing cycle, particularly in industries which produce parts by means of machining processes. The use of CAPP systems has implied in a planning systems evolution. The determination of machine, tooling and suitable operational conditions looking at the optimization of the several operations is fundamental to the sucess of the productive process and of the enterprise, and can be improved by use of CAPP systems. It was studied the factors which influence this kind of process and it was proposed a prototype system model for this planning and for obtaining a theoretical specification of the depth of cut, feed and cutting speed, taking into consideration aspects like machinability of the part material, secondary and auxiliary manufacturing times, and the logistics applied to the flow of parts at the shop-floor through the definition of the used machine to be or not a production neck beyond considerations on the availability of machine capacity. It was proposed an optimization criterion which considers not only the maximum efficiency interval as quoted by many authors but also discuss the application of its limits and the restrictions of the system machine-tool-part. Besides the theoretical planning the system has a practical testing module intended to refine the theoretical values of the adopted cutting speed to garantee its application to the defined machine and tooling. The system approach is semi-generative, with algorithmic and knowledge based solutions, with a simple and user-friendly interface. 


\section{Prólogo}

Frederick Winslow Taylor (1856-1915), engenheiro mecânico, um dos pais da chamada Administração Científica a qual proporcionou grandes ganhos de produtividade industrial neste século, começou seus trabalhos analisando os processos de produção em fábricas norte-americanas e, particularmente, nos processos de corte dos metais.

Hoje os paradigmas empresariais são muito diferentes dos vigentes em sua época porém há de se reconhecer os seus méritos na declaração e no desenvolvimento dos conceitos básicos para a função Planejamento, a saber [Taylor 66]:

1. Separação das funções de preparação e execução, definindo-as com atribuições precisas;

2. A definição da finalidade do Planejamento como a de caracterizar qual o trabalho que deve ser feito, como deve ser feito, onde e por quem deverá ser executado e, finalmente, quando deverá ser feito.

As conclusões e os resultados obtidos por Taylor não foram acidentais mas consequência de um estudo sistemático de fatores que afetam a cada problema da fabricação em cada momento.

Colocados ao lado de premissas atuais como a reorganização do processo visando aliar flexibilidade e padronização da produção, controle estatístico da qualidade, necessidade da contabilidade da não-produção (versus a contabilidade da produção, preconizada por Henry Ford e pelo próprio Taylor) e as abordagens baseadas em sistemas de produção [Drucker 90], as idéias de Taylor devem sofrer evolução e adições que, no entanto, em pouco ou nada diminuem o seu valor.

Em particular no que se relaciona ao planejamento de processos de usinagem, Taylor procurou responder a uma questão ainda pesquisada e analisada hoje nos centros de pesquisa, nas universidades e nas indústrias [Taylor 66]:

- Qual a velocidade em que se deve fazer trabalhar a máquina-ferramenta?

Desde que começou o trabalho de determinar os parâmetros de corte do aço com ferramentas, seus ângulos e formas, em 1881, na oficina de construção de 
máquinas da Midvale Steel Company (Filadélfia, E.U.A.), Taylor pode concluir que havia a necessidade de se determinarem doze variáveis independentes que exerciam importante influência na solução, ou seja, na determinação da melhor velocidade da máquina e, também, do melhor avanço:

1. A dureza do material a ser cortado;

2. A composição química e o tratamento térmico que o aço sofreu;

3. A espessura do cavaco;

4. A forma da aresta cortante da ferramenta;

5. O meio de refrigeração empregado no processo;

6. A profundidade de corte;

7. A duração do corte, i.e., o tempo durante o qual uma ferramenta pode continuar cortando sem precisar novamente ser afiada (os resultados obtidos na análise desta variável com a velocidade de corte sugeriram a conhecida equação da vida da ferramenta de Taylor);

8. A elasticidade da peça e da ferramenta relativamente à vibração;

9. Os ângulos de corte e folga da ferramenta;

10. O diâmetro da peça que se vai cortar;

11. A pressão do cavaco sobre a face cortante da ferramenta;

12. A força de tração, as velocidades e as mudanças de avanço da máquinaferramenta.

Atualmente sistematiza-se de maneira um pouco diversa os influenciadores da função velocidade de corte e do avanço. Muitas das variáveis assumidas por Taylor são vistas hoje como restrições de processo e outras como fatores de pouca relevância em virtude das mudanças nos componentes tecnológicos do processo, ou seja, no material das ferramentas e nas máquinas, por exemplo.

Essas doze variáveis citadas foram coletadas durante 25 anos com métodos experimentais que consumiram 400 toneladas de aço e ferro [Trent 89]. Taylor desenvolveu, entre outros, um teste de torneamento para determinar a máxima velocidade de corte na qual uma ferramenta duraria 20 minutos antes de sua quebra. Este teste foi, então, sistematicamente utilizado para determinar o ótimo para cada uma das variáveis para valores diferentes das demais. Aliava Taylor a investigação tecnológica com a pesquisa científica através do seu método de planejamento experimental de usinagem. Tornava-se, ainda, necessário a ele achar a formulação matemática que exprimisse, rápida e simplificadamente, as leis obtidas. 
Pela inexistência de computadores, o problema de resolução rápida dessa regressão tornou-se insolúvel por muitos anos, mesmo com os recursos acadêmicos da época. A solução simplificada foi obtida no início deste século pela invenção da régua de cálculo a qual poderia ser utilizada por um mecânico treinado numa régua dedicada ao problema de usinagem. Com isso pode-se obter a velocidade de corte e o avanço da ferramenta rapidamente na fábrica, para casos específicos. A equação de Taylor que relaciona a velocidade de corte com o tempo de vida da ferramenta foi um dos corolários da sua pesquisa, continuando válida até hoje.

O problema do planejamento do processo de usinagem para diferentes operações e a determinação das condições de corte de forma otimizada continua até hoje. O auxílio do computador nos últimos 30 anos tem feito esse problema ganhar um espectro de soluções maior, com alternativas inovadoras como a utilização de sistemas baseados em conhecimento aliados a soluções algorítmicas. Os problemas e as variáveis de Taylor foram reanalisadas e ganharam abordagens diferenciadas mas, em sua essência, continuam postuladas igualmente para se determinar soluções de planejamento e de otimização de processo.

Diante do problema conhecido há tanto tempo mas que se renova a cada novo passo tecnológico nas fábricas e oficinas atuais, pretende-se colaborar nessa tarefa de se determinar soluções gerais e de auxílio ao planejamento de processos de usinagem, procurando fornecer mais uma colaboração às abordagens de análise e solução na área de especificação de parâmetros para o processo de usinagem. 


\section{Capítulo 1}

\section{Introdução}

Nas últimas três décadas muitos avanços ocorreram no desenvolvimento de sistemas de planejamento de processos automatizados. Em grande parte pelo desenvolvimento e redução dos preços dos computadores, que se tornaram menores e de fácil aquisição por qualquer empresa manufatureira. Por outro lado pela necessidade das empresas em se adequar a um novo perfil empresarial, no qual são palavras de ordem o repensar constante da organização, a busca da excelência em todas as atividades, em particular nas de fabricação, a necessidade da revisão dos conceitos tradicionais da contabilidade de custos aliada à sempre desejada redução e controle dos mesmos, e a coexistência da padronização, da flexibilidade e da simultaneidade de tarefas nas fábricas.

O Planejamento de Processo é uma atividade de ligação entre a Engenharia de Produto e a área de Produção. Sua importância reside aí: ser via obrigatória no fluxo de atividades que determinam a produção de determinada peça ou bem. Em qualquer empresa de manufatura torna-se necessário planejar para produzir um bem: a determinação do processo a ser usado, o fluxo das peças na área de produção, a especificação das máquinas, o cálculo da carga dessas máquinas para se avaliar a sua quantidade e eficiência, a especificação e o projeto das ferramentas e dos meios de produção e de controle de qualidade, além da determinação do arranjo físico para se atender a todos os condicionantes expostos.

O planejador ou processista busca, assim, várias áreas da empresa visando alcançar o seu fim. Nessa rede de informações à qual ele se liga, muitas atividades são relativamente simples e possuem algoritmos de solução. Outras, porém, dependem do conhecimento humano aplicado àquele determinado conjunto de condições de um problema de processo. O CAPP, ou Computer Aided Process Planning (Planejamento de Processo Auxiliado por Computador), tem-se tornado o responsável por avançar nessas situações, sejam elas bem definidas a priori ou necessitando da experiência de um profissional perito ou, ainda, aliando ambas as características, de forma a cumprir a função de Planejamento de uma forma melhor, mais rápida e com menor custo. 
Já se observou sistemas CAPP para processos de fabricação como a usinagem, a estampagem, a montagem mecânica e eletrônica, e a soldagem, entre outros. As abordagens, em geral, são parciais quanto à total solução do problema, com critérios variados na busca dessa solução, utilizando métodos mais ou menos determinísticos, dependendo dos critérios adotados.

Procurando avançar sobre o conhecimento que se possui dos sistemas CAPP pretende-se analisá-los sob a ótica dos processos de usinagem e, em particular, aplicados ao problema de especificação de parâmetros desse processo. Para isso far-se-á uma revisão e um posicionamento do CAPP no mundo atual, o seu estadode-técnica, preferencialmente ao que se refere à especificação de parâmetros de processo e os seus condicionantes principais. Com esses fundamentos revistos, apresentar-se-á uma proposta para um modelo de sistema para a escolha de parâmetros operacionais de processos de usinagem. Objetiva-se, assim, colaborar na obtenção de soluções práticas e exequíveis de planejamento de processo auxiliado por computador. 


\section{Capítulo 2}

\section{O Planejamento de Processo Auxiliado por Computador}

\subsection{A Fábrica do Futuro: o CIM, o Planejamento e o CAPP}

O termo CIM teria sido introduzido em 1973 por Joseph Harrington Jr. em seu livro "Computer Integrated Manufacturing" [Miyagi 90]. Dessa época até agora o termo sistemas CIM (ou SIM - Sistemas Integrados de Manufatura) teve momentos de glória e extensa difusão assim como de desilusão e descrédito de suas possibilidades previstas. A visão que se possui do conceito atualmente está mais amadurecida, fruto desses processos de difusão e desilusão sucessivos e do conhecimento neles adquiridos.

Parte do desgaste do conceito podia ser previsto em [The Economist 87] de onde se extrai o alerta que "it is the management that makes the difference" ao se comparar os ganhos que se obtém ao implantar na fábrica sistemas flexíveis de manufatura (FMS) em substituição às tecnologias convencionais de fabricação. No entanto observa-se hoje que o termo CIM retorna e volta a ser citado sem constrangimentos nas revistas técnicas e nos catálogos de empresas. Em muitos tipos de empresas, particularmente nas metalúrgicas e automobilísticas, a tecnologia CAD (Computer Aided Design) ganha um papel básico na fundamentação do CIM na empresa. Torna-se o núcleo da estrutura técnica do $\mathrm{CIM}$ e a raiz para os desdobramentos posteriores. Complementando-o e até vindo antes, conforme a empresa, os sistemas de gestão CAP (Computer Aided Production) possibilitam a ligação entre as áreas de programação de produção e o chão-de-fábrica (sistemas MRP, de Gerenciamento de Ferramentas, de Gerenciamento de Mão-de-Obra, etc.).

[Miyagi 90] coloca uma possibilidade de análise pelo chamado Modelo de Forças, o qual pode explicar o CIM pela interação de forças de atração que atuam com intensidades maiores ou menores e determinam o sentido pelo qual ocorre a evolução do CIM numa empresa ou na indústria. Quatro seriam as forças que agem procurando aproximar as três áreas Produção, Projeto e Administração, a saber: 
- forças da área de administração (programação de produção, planejamento financeiro, marketing, vendas, controle de estoques, etc.);

- forças da área de projeto do produto e planejamento ou projeto do processo (CAD/CAM/CAPP, DFMA ou Design for Manufacturing and Assembly, engenharia simultânea, etc.);

- forças da área de produção (introdução isolada de meios de produção avançados tecnologicamente como robôs, máquinas CNC, DNCs, etc.);

- forças das áreas de processamento de dados ou sistemas (cuidam do fluxo de informações).

Da interação dessas forças o conceito CIM está evoluindo, mostrando que a preponderância de uma(s) sobre a(s) outras pode gerar distorções e dificuldades na condução de uma política de manufatura coerente e de sucesso, assim como pode mostrar o caminho correto na concepção de sistemas integrados de manufatura, preenchendo lacunas técnicas que acabam, muitas vezes, por colaborar no insucesso de uma implementação.

Ainda [Miyagi 90] ressalta duas linhas de atuação que recentemente têm ganho maior importância nas introduções do CIM nas fábricas, a saber: a Realização do Produto e a Modelagem do Produto.

A primeira se origina da interação entre o projeto do produto e a área de produção. Encontram-se nessa linha atividades relacionadas ao projeto do produto e sua realimentação através das informações provenientes das áreas de produção tais como restrições de capacidade de máquinas e de maneiras para se executar determinada montagem. É no que se baseia a assim chamada Engenharia Simultânea ou Concorrente, por exemplo.

Dentro dessa linha existe a questão do projeto do processo, ou seja, do seu planejamento, o qual é fundamental ao presente trabalho. Baseia-se no encadeamento de sistemas a partir do projeto de produto: CAE/CAD/CAPP/CAM. Tem-se chamado a esta corrente de ligação entre as áreas de projeto e produção no que se relaciona ao lançamento de novos produtos de CAPR - Computer Aided Product Realization.

A segunda linha, por sua vez, incorpora o elemento Marketing ao que se chama Modelo do Produto, composto já pelas definições e dados do produto e pelas informações e dados de fabricação. Enquanto o foco da Realização do Produto está nas formas de sua implantação/fabricação, o da Modelagem do Produto localiza-se 
no projeto do produto em si, sendo este função, obviamente, das condições para a fabricação.

Embora as duas abordagens possam divergir nas ênfases adotadas, se corretamente implantadas e utilizadas na empresa podem até se complementar, obtendo um melhor efeito final. Por exemplo, num ambiente de realização do produto ocorrerá a necessidade da automatização do planejamento de processo visando terse um simulador de fabricação do produto. Isso não contraria o que se pensaria num ambiente com ênfase na modelagem do produto pois tornam-se necessários, da mesma maneira, dados de processo (ferramentas, parâmetros de máquina, etc.) de outros produtos antigos ou modelos de fabricabilidade genéricos para compor os dados de fabricação do produto atual. Enfim, ferramentas de CAPP com um ou outro enfoque. Por isso a função Planejamento de Processo e, em particular, com o auxílio do computador, torna-se, frente a essas duas linhas, uma ferramenta imprescindível e que deve ser aprimorada. É o CAPP o elo entre o projeto do produto e a sua fabricação num ambiente de fabricação automatizado [Merchant 88].

Isso leva à necessidade de se conceituar e analisar mais detalhadamente alguns objetivos que essa função Planejamento nesse ambiente moderno possui nas áreas de Produção num contexto CIM. 


\subsection{A Função Planejamento da Manufatura}

As indústrias podem ser classificadas em duas categorias principais, de acordo com a natureza das suas operações de produção: indústrias de processo contínuo e indústrias de manufatura [Araujo 87]. A primeira é representada pelas indústrias, em geral, químicas, petroquímicas, processamento de alimentos, aço, etc.. As de manufatura, por sua vez, se caracterizam pela produção de produtos discretos, tais como automóveis, peças, navios e eletrodomésticos. Na verdade uma classificação mais rigorosa feita em uma indústria tipicamente classificada como de manufatura mostra existir mesmo nessa vários tipos de operação de produção, podendo ser desde uma produção puramente de manufatura a uma que se assemelha à produção contínua [Araujo 88]. Entender-se-á por manufatura, aqui, o fato de serem produzidas peças ou seja, componentes discretos.

A forma como o trabalho na manufatura pode ser conduzido é também importante na discussão posterior quanto à função Planejamento do processo. Ele dependerá, fundamentalmente, da quantidade de produto a ser feita, podendo ser, em geral, de três tipos (produção em oficinas, em lote e em massa), com quantidades de produtos crescentes, respectivamente [Zhang 94]. A tabela 2.01 ilustra um referencial para as quantidades a serem produzidas conforme o tipo de produção.

Tamanho do Produto $\Rightarrow$

GRANDE MÉDIO PEQUENO

Tipo de Produção ת

\begin{tabular}{cccrr}
\hline em oficinas & & menos que 5 & menos que 20 & menos que 100 \\
\hline em lotes & pequenos & 5 a 100 & 20 a 200 & 100 a 500 \\
\hline & médios & - & 200 a 500 & 500 a 5.000 \\
\hline em massa & grandes & - & 500 a 5.000 & 5.000 a 50.000 \\
\hline & & - & mais que 5.000 & mais que 50.000 \\
\hline
\end{tabular}

tabela 2.01 Quantidades aproximadas para tipos de produção diferentes [Zhang 94]

A um procedimento ou atividade dedicada à produção de uma ou de um grupo de peças denomina-se processo de fabricação. Ou mais especificamente, um processo implica numa mudança nas propriedades de um objeto, incluindo geometria, dureza, estado, conteúdo de informação (dados sobre a sua forma) e assim por 
diante [Zhang 94]. Essas características permitem formular um modelo de processo simplificado como o ilustrado na figura 2.01.

ENTRADAS

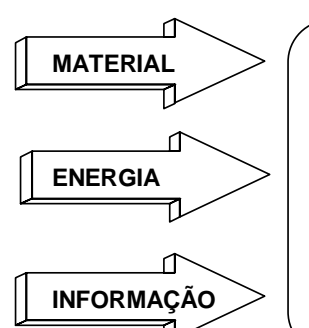

SAÍDAS

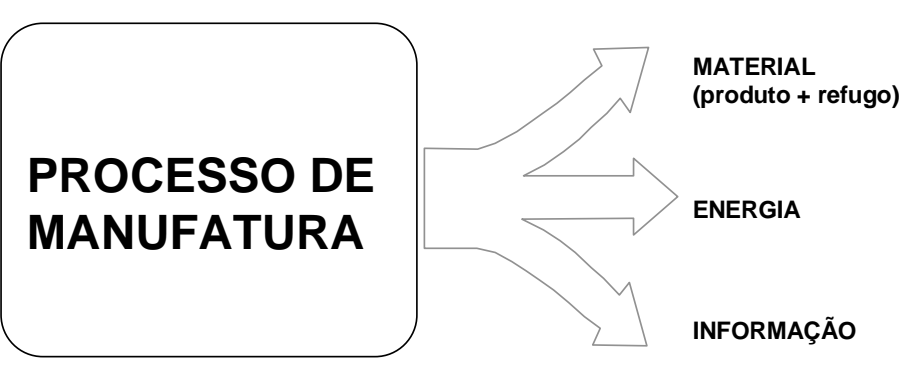

figura 2.01 Modelo geral para um processo de manufatura [Zhang 94]

Para um determinado processo pode-se definir uma ou mais operações as quais se caracterizam, cada uma, por não ter as suas condições ou parâmetros alterados antes do seu término. Assim, pode-se adotar num processo de usinagem como sendo uma operação quando não se têm alterações nas condições de velocidade de corte, avanço e/ou profundidade de corte assim como de ferramentas e de superfícies de corte, por exemplo. Numa indústria de manufatura existe, em geral, um conjunto de processos e, portanto, um conjunto ainda maior de operações, que se sequenciam visando-se obter a peça final a partir da peça bruta.

Em alguns processos e operações cabe distinguir uma outra sub-unidade existente, o corte (no caso da usinagem), passe ou passada. Um passe pode ser definido como um procedimento no qual a ferramenta "passa" usinando uma vez a superfície da peça. Assim algumas operações em processos de usinagem precisam de vários passes, com a mesma ferramenta e em condições de corte (velocidade de corte e avanço) iguais ou diferentes. Usualmente uma operação consiste de um ou mais passes, dependendo do volume a ser usinado requerido. Observe-se aqui a dependência dessas definições conforme o processo em análise.

Cada processo de fabricação possui características específicas que os fazem particulares no que concerne às formas como tratam os materiais, ou seja, como utilizam a energia através de um certo conteúdo de informação para tal. Esses conjuntos de processos, ou domínios [Rodrigues 93], deverão implicar em soluções específicas de planejamento de processo, de acordo com a pecualiaridade de cada 
um, podendo haver diferenças substanciais mesmo entre processos do mesmo domínio. Um quadro típico de domínios, os quais podem ser utilizados isolados ou agrupados, numa indústria de manufatura automobilística é mostrado na figura 2.02 [Araujo 95].

A função de Planejamento de Processo numa indústria diz respeito à definição dos parâmetros das atividades da manufatura a partir do desenho do produto e de restrições estratégicas da empresa e do mercado, tais como necessidades de materiais, planejamento e cálculo de capacidade, informações para controle de fábrica, padrões de desempenho e rendimento, etc.. Isso se torna prático e operacional sob a forma de arranjos físicos de máquinas e da configuração de postos de trabalho, da estimativa de tempos padrões e métodos, da avaliação de carga-máquina e da necessidade de compra/substituição de equipamentos, da definição de parâmetros de processo como regulagens de máquinas, capacidade de um carregador e limites para estoques intermediários, entre outros, além de especificações de ferramental empregado, dispositivos e procedimentos para controle de qualidade [Groover 88].

Além dessa, inúmeras são as definições encontradas na literatura sobre a função genérica do planejamento de processos. [Zhang 94] fornece alguns elementos os quais, juntamente com os da definição anterior, praticamente sintetizam a definição pretendida. Segundo ele o planejamento de processos pode ser definido como a determinação sistemática de métodos detalhados pelos quais peças ou partes de um conjunto maior podem ser fabricados econômica e competitivamente desde estágios iniciais (na forma de material bruto) até estágios finais (na forma do produto desejado).

Pode-se, resumidamente, dizer que a tarefa fundamental do planejamento do processo é executar o chamado Plano de Produção ou de Processo, que contêm as descrições do processo completo de fabricação com as máquinas, operações, tempos e ferramentas com as devidas regulagens. Para isso o setor de planejamento executa desde a avaliação da necessidade da aquisição de máquinas, via relatório de carga-máquina, o qual é uma folha de cálculo para verificar a capacidade da máquina em relação ao programa de vendas ou produção, até o estudo de sua disposição na fábrica, seu try-out, projeto de dispositivos, ferramentas e outros meios de produção, estimativa de tempos a priori e a posteriori da sua aquisição, etc.. $O$ setor de planejamento de processos recebe da Engenharia de Produto o chamado Plano de Produto, que seria basicamente o desenho do produto e um plano com as 
decomposições do mesmo nas suas peças componentes. Com isso ele pode verificar quais os tipos de máquina seriam necessários para fabricar cada um dos componentes ou, conforme o caso, qual o fornecedor seria capaz de fabricar de acordo com as especificações do produto. Feito isto passa-se à análise de cargamáquina e à elaboração dos roteiros e detalhes operacionais do processo [Araujo 87]. Todos esses procedimentos deverão estar inseridos num quadro que contém as diretrizes e a situação financeira e frente à concorrência da empresa, de forma que se possa especificar o tipo de tecnologia a ser empregada nos vários processos de fabricação e os seus custos [Rozenfeld 92].

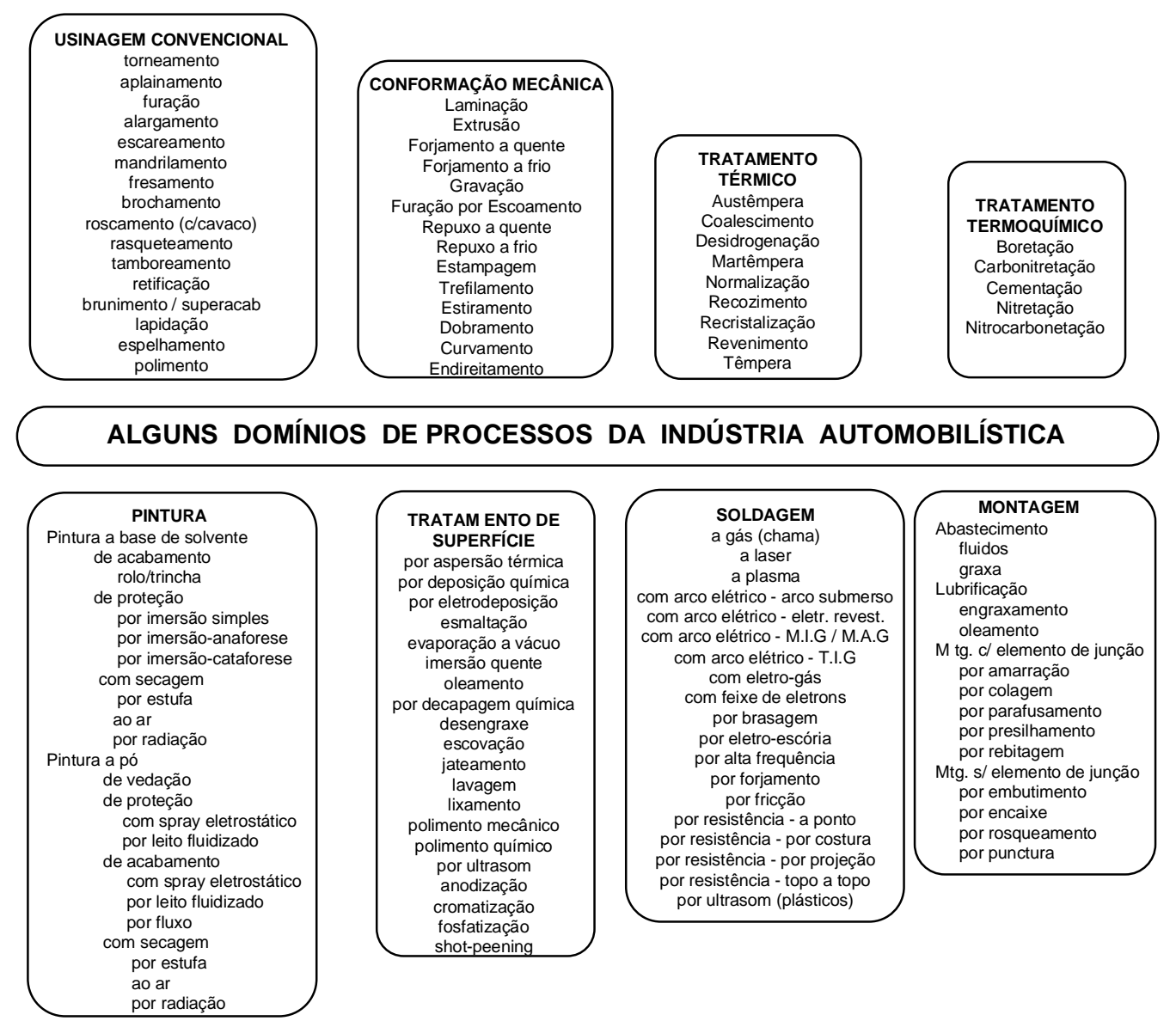

Figura 2.02 Classificação de alguns Domínios de Processos de Fabricação típicos em indústrias automobilísticas [Araujo 95].

Uma forma analítica de se estudar o Planejamento de Processo é descrita por alguns autores. [Rozenfeld 89, Rodrigues 93] adotam uma divisão das funções do Planejamento de processo em dois grupos principais (figura 2.03):

- o grupo de planejamento macro, no qual se estudam os aspectos mais externos do processo de fabricação, desde os dados da organização inerente à empresa 
em que se aplica o planejamento, até a determinação da tecnologia e maquinário necessários à manufatura;

- o grupo de planejamento de operações, quando se detalha o processo físico para obtenção da peça como é o caso da determinação de sub-operações do processo, das ferramentas a serem usadas, dos parâmetros e tempos do processo.

Outro critério estabelece uma independência na tarefa de determinação de tempos devido à sua importância no planejamento [Groover 88]. Segundo este último autor, pode-se definir três funções como típicas no planejamento do processo: a determinação da seqüência das operações, a determinação das condições apropriadas para o processo e a fixação dos tempos padrões.

$\mathrm{Na}$ verdade a classificação de [Groover 88] é mais simplificada e restrita que a adotada por [Rozenfeld 89, Rodrigues 93]. Por esta última se mostrar mais analítica e hierarquizada, o que a faz uma boa abordagem para estudo, será a adotada neste trabalho.

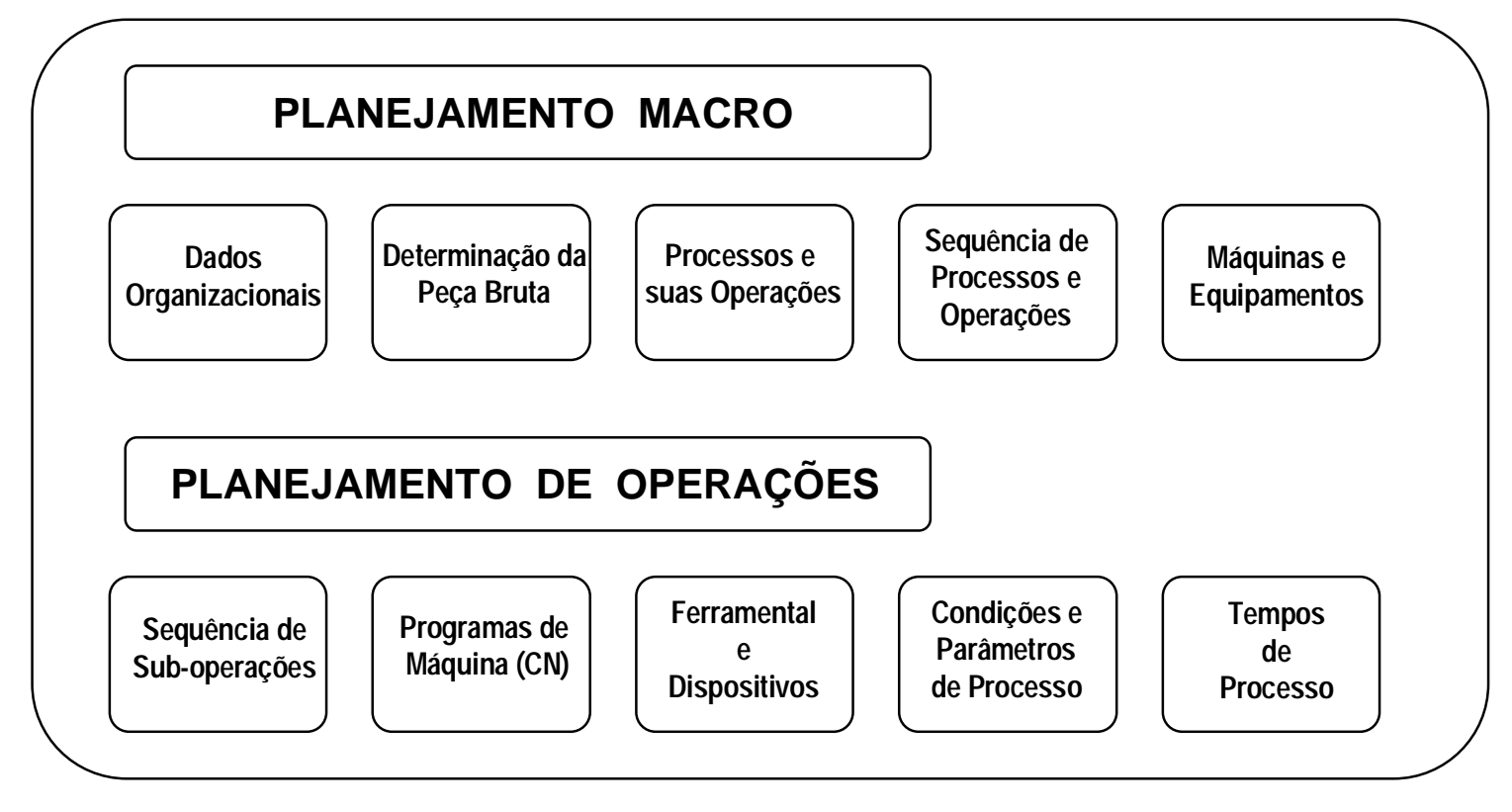

Figura 2.03 Funções de Planejamento Macro e de Operações [Rozenfeld 89, Rodrigues 93] 


\subsection{As Diferentes Abordagens dos Sistemas CAPP quanto à Geração do Plano}

O setor de planejamento tradicional de uma indústria geralmente possui um corpo de técnicos e engenheiros especializados, com grande experiência, e que são capazes de elaborar, muitas vezes rapidamente, um Plano de Processo de fabricação. A quantidade de variáveis e dados envolvidos numa avaliação de um processo de fabricação é muito grande, na dependência da complexidade tecnológica do produto e na própria quantidade de tipos de peças a serem manufaturadas. A principal questão que se pode colocar é quanto aos critérios a serem adotados por cada planejador e a sua validade de forma que conduzam, sempre ou no maior número de vezes, a soluções otimizadas de manufatura. Constata-se, contudo, que por essas e por outras razões, uma proporção significante do número total de planos de processo encontrados nas fábricas não são ótimos [Groover 88].

Neste item, embora esta dissertação se baseie nos processos de usinagem e mesmo por serem extraídas idéias de vários autores os quais as exemplificam com processos, em geral, de usinagem, pode-se adotar as abordagens como válidas para grande parte dos demais domínios ou conjuntos de processos de fabricação que necessitem de planejamento como etapa para a sua implementação na fábrica. Procura-se tratar de conceitos gerais os quais irão necessitar das características de cada domínio específico para a sua implementação, como se observará posteriormente, em particular, para a usinagem.

As soluções para o planejamento de processo visando atender os planejamentos macro e de operações são várias possíveis conforme citado na literatura [Rodrigues 93, Zhang 94]. Este último autor adota uma classificação fundamental para os sistemas de planejamento quanto à forma de sua geração, a qual está resumida na figura 2.04 .

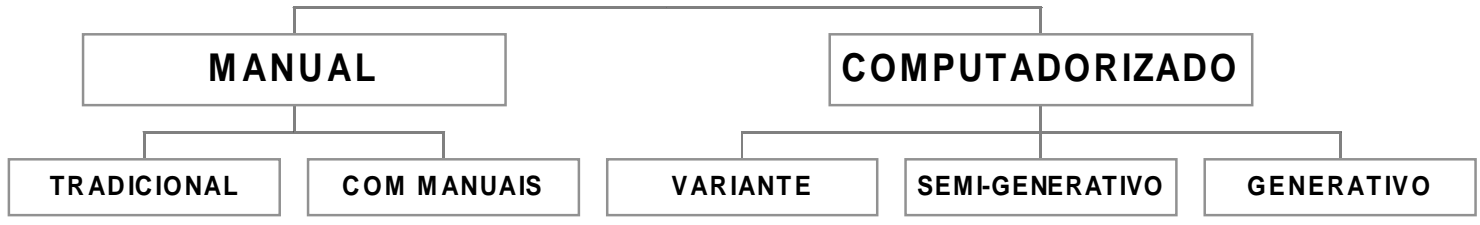

Figura 2.04 Formas de Geração para Sistemas de Planejamento [Zhang 94] 
Um plano de processo obtido de forma "manual" pode ter duas abordagens: a tradicional e a com manuais. A "tradicional" envolve o exame de informações da peça projetada por meio de desenhos, por exemplo. O planejador procura identificar peças similares através da sua própria memória ou de um livro código, recuperando os planos de processo dessas peças similares, modificando-os e adaptando-os manualmente visando atender aos requisitos do novo produto. Nestes casos não é difícil o planejador recorrer ao pessoal de chão-de-fábrica visando conhecer detalhes do processo da peça atual.

$\mathrm{Na}$ abordagem que se denominou "com manuais", utiliza-se um ou mais manuais elaborados visando a simplificação do trabalho de planejamento para um certo conjunto similar de peças. Esses manuais possuem uma seleção de sequências pré-arquivadas de operações para dados tipos de peças. Esses grupos de processos podem ser rapidamente selecionados e sequenciados pelo planejador, com essas seleções transcritas para uma folha de processos com as devidas adaptações requeridas pela nova peça. Trata-se de uma abordagem em geral mais eficiente que a primeira.

As principais vantagens das abordagens manuais são o investimento baixo e a flexibilidade obtida. Observa-se, no entanto, que a existência de planejadores experientes é crucial para a obtenção de bons planos de processo nesse caso. Além disso, outras desvantagens podem ser apontadas, principalmente quando o número de operações e de peças se elevam, tais como a falta de consistência na identificação e planejamento de peças similares, dificuldades na especificação de ferramental comum para várias peças, etc..

O planejamento computadorizado possui uma história de, ao menos, 20 anos. Desde 1965 e 1966 conhece-se tentativas de se utilizar o computador para auxiliar na geração de folhas de processo, com sucessos relativos [Zhang 94, Merchant 88].

A utilização de sistemas computadorizados conhecidos por CAPP tem se justificado, principalmente, pela busca de rapidez e de otimização na implantação e condução dos processos de fabricação na indústria. Isso, por sua vez, decorre e se vê corroborado pela crescente flexibilidade que se almeja na fabricação dos produtos sempre novos. Para suprir essa demanda de maneira eficiente planejadores de processo experientes são necessários, o que lhes exige um domínio da tecnologia do produto (geometria, materiais, especificações), dos meios de produção (máquinas, 
ferramentas, dispositivos, procedimentos de preparação) e da logística de produção (fluxo das peças, carga de máquina, arranjo físico).

Assim procura-se explicar a adoção de sistemas CAPP por alguns fatores [Rozenfeld 93]:

- integração e harmonia com outras áreas da empresa que se utilizam de computadores, tal como a Engenharia de Produto e a geração de modelos via CAD;

- existência de bases de informações que, ao serem criadas, possibilitam o reaproveitamento de informações para peças similares ou alterações para uma determinada mudança nas condições de fabricação;

- padronização de informações de processo assim como o seu domínio através de uma linguagem comum e sistemática. Por exemplo, na determinação dos valores de tempo e de custo para famílias específicas de componentes;

- aumento da produtividade na tarefa de planejamento;

- escassez de especialistas (planejadores de processo ou processistas) reais, ou seja, com conhecimento e experiência suficientes para permitir a obtenção de bons planos de fabricação;

- necessidade de consistência nos critérios de planejamento visando eliminar planos díspares para a mesma peça ou peças similares [Zhang 94].

Assim conclui-se que um sistema computacional de planejamento de processos oferece grande potencial para a redução do trabalho rotineiro dos engenheiros de manufatura. Ao mesmo tempo, fornece a oportunidade de gerar rotinas de produção mais racionais, consistentes e, talvez, até mesmo ótimas. Duas soluções alternativas para o CAPP têm sido desenvolvidas: os sistemas variantes, ou de recuperação, e os sistemas generativos [Groover 88]. Nos últimos anos uma abordagem intermediária, que possui elementos de ambas as soluções, tem sido citada: a dos sistemas semi-generativos [Zhang 94].

\subsubsection{O Sistema CAPP Variante}

Um sistema CAPP variante, em termos gerais, se utiliza de uma classificação de peças e sua codificação como base. As peças produzidas na fábrica são agrupadas em famílias de peças, distinguidas de acordo com suas características de 
fabricação. Para cada família de peças um plano de processo padrão é estabelecido. O plano de processo padrão é armazenado em arquivos de computador e, então, recuperado para peças novas que pertencem àquela família. Alguma forma de classificação das peças e um sistema de codificação é necessário para organizar os arquivos de computador e permitir uma recuperação eficiente do plano de processo apropriado para essa nova peça. Para algumas peças novas, a edição de um plano do processo já existente pode ser necessária. Isto é feito quando os requisitos de fabricação dessa nova peça são um pouco diferentes da peça padrão. Devido às alterações que são feitas no plano de processo recuperado, esses sistemas são chamados "variantes".

Uma das filosofias utilizadas como base para os sistemas variantes é a denominada Tecnologia de Grupo (TG), na qual peças similares são identificadas e agrupadas visando-se tomar a vantagem das suas similaridades tanto no seu projeto como na sua fabricação. Esta filosofia é tanto mais abrangente na medida em que não envolve o conceito de igualdade, abrigando, portanto, a perspectiva para o agrupamento em famílias. Nos sistemas CAPP variantes baseados em TG pode-se buscar a similaridade nas peças (geometria e processo de fabricação) para se obter as famílias de peças com planos de processo similares ou padrão [Rodrigues 93]. Uma família é, assim, uma coleção de peças que são similares por causa da forma geométrica ou tamanho, ou ainda por causa dos passos de processamento requeridos em sua fabricação.

Pode-se ter ainda como um sistema variante aquele que elabora planos de processo baseado em planos semelhantes, sem a necessidade da formação de famílias de peças. Isso pode ocorrer, por exemplo, em empresas que, apesar de ter planos padrões e famílias de peças definidas, têm alguns componentes que não se enquadram em nenhuma delas. Assim, se neste caso existir um plano semelhante, este será tomado como base [Rodrigues 93].

A questão fundamental que se coloca perante os sistemas variantes é como encontrar uma peça similar dentre tantas famílias, tarefa esta que pode ser difícil e levar um tempo precioso. Vários sistemas de classificação de peças e suas aplicações através de sistemas computacionais já foram propostos e utilizados, podendo-se encontrar uma síntese dos mesmos em [Groover 88] e [Zhang 94].

Uma das vantagens da TG na indústria é que, ao aplicá-la, poder-se-á utilizar de uma filosofia de planejamento de processo que independe do grau de modernidade do parque de máquinas pois muito mais importante sob o ponto de vista 
de eficiência do processo produtivo poderá ser o arranjo físico dos equipamentos o qual se adequará conforme a família de peças. Ou seja, à família de peças correlaciona-se um determinado grupo de máquinas próprias para produzi-la. Este arranjo é projetado de modo a permitir um trabalho eficiente dentro da célula de fabricação, o que implica em parâmetros de processo, ferramentas e demais condições similares que acabam possibilitando reduções no custo de produção.

A principal desvantagem dos sistemas variantes está na forma como a qualidade do processo de planejamento é determinada: ela depende, fundamentalmente, da experiência que o planejador ou processista possui para a execução do primeiro plano e para as eventuais correções no caso das peças similares, sendo o computador apenas uma ferramenta que auxilia às atividades manuais de planejamento, como a consulta a bancos de dados. O plano ótimo está vinculado aos critérios decididos no momento da formulação do primeiro plano.

Apesar disso muitas são as vantagens que fazem o CAPP variante ainda muito utilizado na indústria. Aliadas às vantagens que, da mesma forma, a TG pode trazer ao planejamento do processo produtivo, têm-se:

- simplificação e rapidez na determinação do processo de fabricação do produto, com redução nos tempos operacionais das tarefas e no número de especificações em arquivo, com aumento das facilidades de estimativa de custo, padronização de ferramentas e dispositivos, etc.;

- redução do ferramental necessário à preparação das máquinas pela sua padronização para cada família de peças;

- menor investimento em hardware e software para implantação de sistemas variantes (atualmente encontra-se mais sistemas desse tipo que dos demais);

- o tempo para desenvolvimento e implantação é menor do que o dispendido nos casos da abordagem generativa, implicando em menor necessidade de trabalho humano;

- no atual estado da técnica, os sistemas variantes são mais confiáveis para a utilização em ambientes reais de produção, especialmente em pequenas e médias empresas as quais não possuem recursos para formar um grupo de desenvolvimento de especificações de processo [Zhang 94]. Adotado determinado sistema, trata-se de classificar as peças existentes às famílias do mesmo e adaptar, na medida do possível, as condições do sistema às da fábrica (máquinas, dispositivos, arranjo físico, etc.). 
[Opas 94] salienta ainda que os sistemas variantes, embora sejam criticados por não possuirem uma tecnologia muito avançada, aplicam-se perfeitamente a alguns tipos de produção como o das fábricas que produzem peças em lotes, divididas em famílias de produtos, sendo, nestes casos, os melhores sistemas. Segundo ele, os planos podem ser gerados com base em esquemas de planos de processos de fabricação pré-definidos correspondentes às famílias de produto as quais formam a base do conceito da fábrica. Este conceito da fábrica, com suas linhas e agrupamentos de máquinas com funções pré-definidas e bem consolidadas, impõe poucas variações nas seqüências de processo. Assim o conhecimento básico é estabelecido uma vez, preliminarmente, e, para peças novas, é recuperado sem o desperdício do conhecimento existente.

\subsubsection{O Sistema CAPP Generativo}

O planejamento de processos generativo envolve o uso do computador para criar um plano de processo individual a partir do nada, automaticamente, sem a assistência do homem [Groover 88]. No entendimento de [Logan 90] um sistema generativo é todo aquele com capacidade de gerar planos de processo através da seleção de elementos em banco de dados e sua utilização na realização de cálculos, baseando-se em regras de decisão e fornecendo resultados nos formatos requeridos pelos sistemas que os utilizarão.

O computador empregaria um conjunto de algoritmos e conhecimentos tecnológicos para estabelecer, através de várias técnicas, decisões lógicas e dados geométricos da peça, um plano de processos para a fabricação da mesma. As entradas para o sistema incluiriam uma descrição completa da peça, o que pode envolver a utilização de um sistema de codificação como os aplicados com TG porém não recuperando dados como num sistema variante. Pelo contrário, o sistema generativo sintetiza o projeto ótimo da seqüência de processamento baseando-se na análise da geometria, material e outros fatores da peça, além da disponibilidade das máquinas e outros recursos para atender àquelas especificações desejadas.

Cabe fazer uma distinção a duas formas de sistemas generativos [Rodrigues 93]:

- a interativa; 
- a automática.

$\mathrm{Na}$ primeira para se gerar um plano de processo específico para uma peça específica deverá haver o envolvimento de um planejador de processo junto ao sistema computadorizado. O processista poderá responder a perguntas executadas pelo sistema sobre características da peça e do ambiente de fabricação, por exemplo. Como vantagens pode-se apontar a flexibilidade e adaptabilidade desses tipos de sistemas além da implementação mais fácil e modularidade frente a outros componentes CAPP.

$\mathrm{Na}$ forma automática a interação com o processista torna-se dispensável, sendo o plano de processo executado automaticamente pelo computador o qual possui as regras de fabricação. O sistema, por exemplo, poderá captar os seus dados geométricos e de material através de uma interface com um módulo CAD. Esta última forma implica em grande complexidade e é ainda uma área pouco desenvolvida pois trata de reconhecimento, extração e consistência de formas (features), entre outros [Zhang 94].

No desenvolvimento de sistemas generativos automáticos (ou da parte automática de um sistema interativo) houve um grande desenvolvimento pelo advento e aplicação de técnicas de inteligência artificial (IA), em particular pelo uso de diversas formas de representação do conhecimento.

No entanto os sistemas generativos atuais estão longe de serem universais nas suas aplicações. Eles tendem a perder rapidamente a sua capacidade generativa quando a peça sai do campo limitado de processos ou operações de manufatura para o qual o sistema foi projetado. Isso é particularmente limitante no caso dos sistemas automáticos. Além disso o "ótimo" estabelecido pelo sistema está na dependência dos critérios adotados no projeto do mesmo. Tais critérios podem se alterar com o passar do tempo ou, até mesmo, ter sido escolhidos de maneira equivocada inicialmente.

Outra dificuldade na aplicação de sistemas CAPP generativos automáticos está na complexidade da sistematização que engloba a aquisição de conhecimento relativo aos domínios de processos. Essa desvantagem pode inviabilizar a aplicação do sistema e afetar a qualidade dos resultados devido a uma base de conhecimento inconsistente ou incompleta.

No entanto os sistemas generativos possuem muitas vantagens, as quais os colocam no maior nível de sofisticação e automatização dentre os sistemas CAPP. 
Entre elas estão a rapidez para a execução de planos, a elevada consistência com que os mesmos são gerados, a total flexibilidade dentro do domínio tecnológico e dos critérios adotados no projeto do sistema, além da facilidade em incorporar nos planos novos processos, máquinas, dispositivos, ferramentas e métodos.

\subsubsection{O Sistema CAPP Semi-Generativo}

Observa-se na literatura mais recente uma tendência na junção dos dois tipos de sistemas, variante e generativo, aproveitando as boas qualidades de ambos, de forma a elevar a eficiência do sistema de planejamento e apoio às decisões sobre a técnica de fabricação. Pode-se afirmar que o sistema puramente generativo é de difícil execução e deve ser colocado como meta de referência no desenvolvimento de sistemas CAPP [Zhang 94]. Deve-se, assim, adotar desenvolvimentos híbridos, intermediários entre as abordagens manual, variante e generativa: a chamada abordagem semi-generativa.

Nesta abordagem um pré-plano é desenvolvido e, se for o caso, modificado antes do plano ser utilizado num ambiente de fabricação real. Isto implica que a lógica de decisão, a formulação e os algoritmos tecnológicos além dos esquemas de codificação baseados na geometria estão incorporados no sistema. Ao planejador caberá a responsabilidade da interpretação dos dados contidos nos desenho do produto. A operação do sistema é, a princípio, a mesma que no caso generativo interativo porém o plano de processo final deverá ser examinado e ter os seus eventuais erros corrigidos com base na experiência do planejador junto à fábrica.

Para se compreender melhor a transição entre os sistemas de planejamento tradicionais e os generativos totalmente automáticos, sem a intervenção humana, há vários estágios que podem ser atingidos durante esse processo. Passa-se por fases como as mostradas em [Logan 90]:

- a interativa simples, já citada em 2.3.2, na qual o computador recebe praticamente todas as informações do planejador e executa funções como busca de dados, cálculos e manipulação de textos, sendo incapaz de tomar qualquer decisão de processo e servindo apenas de meio de comunicação digital entre áreas de planejamento e o chão de fábrica; 
- a de atributos característicos, na qual alguns padrões ou atributos das peças são observados e fazem com que planos padrões comecem a ser criados, com as perguntas se baseando nesses padrões;

- a semi-automática, que aprofunda as características de atributos da fase anterior e estabelece, automaticamente, seqüências de operações através de códigos das peças. As famílias de peças podem ser buscadas como meio auxiliar ao planejamento de processo;

- a automática, também já citada em 2.3.2, finalmente, que toma apenas o desenho da Engenharia de Produto, o decompõe e, através de restrições impostas (por exemplo, excesso de sobrematerial na peça bruta), caso existam, seleciona o processo, gerando os meios de produção, programas CNC com correções, indicações de ajustes no ferramental, etc..

Apesar dos sistemas semi-generativos não serem os ideais para a integração e automatização total da fábrica, pode-se tratá-los como uma etapa intermediária sem a qual não se obteria credibilidade e mercado para futuros investimentos na área. A aplicação de tais sistemas tem possibilitado aumentar a rapidez na elaboração de planos, reduzir a participação do processista, garantir a qualidade do plano de processo pela uniformização de critérios dentro da mesma empresa. No meio acadêmico voltado para a pesquisa e desenvolvimento das abordagens CAPP, esses sistemas têm possibilitado um maior conhecimento das formas de representação de conhecimento e da análise dos processos de fabricação, em particular dos processos de usinagem, visando sistematizá-los [Rozenfeld 93]. 


\subsection{Aspectos Relativos à Metodologia de Execução dos Sistemas CAPP em Usinagem e a Especificação de Parâmetros do Processo}

Sistemas CAPP se baseiam no trato de certos conjuntos de dados para a geração ou obtenção de outro conjunto de informações na forma de planos de processo. Estes, por sua vez, deverão pertencer a outra estrutura de dados visando a sua apresentação, compreensão e arquivamento. Assim, simplificadamente, pode-se concluir que para a geração de um plano de processo, seja este pela abordagem variante, generativa ou semi-generativa, deve-se considerar:

- dados de entrada;

- métodos de execução do plano e interface com o usuário;

- arquivamento dos resultados obtidos;

- apresentação dos resultados.

Por sua vez, o conhecimento necessário à montagem de sistemas de planejamento em usinagem abrange desde a escolha do processo até a definição dos seus parâmetros, sendo organizadas estas informações em bancos de dados. Embora o termo planejar implique em ações tomadas a priori visando um determinado objetivo, essa sequência de atividades não deve ocorrer uma só vez, ou seja, finda a atividade de planejamento de processo para uma peça esse procedimento deverá ser revisto ou monitorado posteriormente pelo menos quanto à escolha dos parâmetros adotados no processo. O autor desta dissertação tem constatado pela observação da prática de planejamento em várias indústrias que o acompanhamento e a revisão do processo, por vários motivos, não ocorre sistematicamente. Isso provém desde a falta de tempo das equipes de planejamento até a falta de critérios de melhoria e otimização que justifiquem a revisão.

Pretende-se explorar e discutir nesta parte do trabalho os componentes para a decisão no planejamento do processo de usinagem assim como os critérios e métodos para tal. 


\subsubsection{Os Bancos de Dados Tecnológicos e o Projeto do Produto, o Planejamento de Processos e a Produção}

Um sistema de informações para o planejamento de processos e também para o CAPP corretamente projetado deve ser capaz de utilizar informações e fornecer serviços de especificação de ferramental, de análise e determinação do desempenho global das unidades de fabricação, de determinação das máquinas a serem utilizadas, de levantamento das estatísticas de manutenção dessas máquinas, de programas de robôs e máquinas $\mathrm{CNC}$, de sequenciamento de processo, de parâmetros desses processos, das formas de arranjo físico das máquinas, etc.. Essas informações são organizadas, em geral, através de bases de dados (BD) ou de informações. As questões mais importantes a serem feitas antes de se começar a projetar essa BD são: "quem" vai usar o BD, "quando" e "para que". Observe que "quem" pode ser qualquer sistema, máquina ou operador/administrador humano, "quando" implica em qual seqüência e se é em tempo real ou off-line, e "para que" pergunta em quais aplicações o dado ou informação será utilizada.

Antes porém de tratar a questão da geração e armazenamento de dados em sistemas CAPP, deve-se citar as estrutruras de BD que thes são auxiliares e, até mesmo, imprescindíveis, como as chamadas BD para a estrutura do produto. Nesta BD cada peça componente dos produtos de uma empresa tem seus dados cadastrados, dados esses importantes para a composição da necessidade da matéria-prima e origem de sua obtenção, dados de tecnologia de grupo, dados qualificadores e especificadores de cada peça, features, dados quanto à situação da peça (se é produzida, descontinuada ou anulada), etc.. Assim, numa empresa que possua integração entre as suas diversas atividades, a existência de um sistema de BD como o citado torna-se necessário para a execução do planejamento de processo automático, vinculando as suas informações àquelas necessárias para a determinação do processo de fabricação de maneira correta.

Após a geração do plano de processo por um sistema CAPP, essa informação, por sua vez, deverá poder ser utilizada por outros sistemas da empresa, tal como a área de produção, contabilidade (cálculo de custos), programação de produção e o próprio planejamento.

Para permitir esse funcionamento algumas tecnologias na área de informática têm sido desenvolvidas nos últimos anos conhecidas por poderem trabalhar com 
grandes bases de dados e de maneira integrada. De forma simplificada e genérica um sistema de base de dados pode ser dividido em três níveis:

- o nível interno: o mais próximo do armazenamento físico, relacionando-se com a forma como os dados são realmente armazenados;

- o nível externo: o mais próximo do usuário, relacionando-se com a forma como os dados são vistos pelos usuários individuais;

- o nível conceitual: no qual estão definidas as estruturas e o conceito de armazenamento das informações, localizando-se entre os dois níveis anteriores.

Se um conjunto de dados de determinado tipo são mantidos separadamente e acessados por programas independentes em arquivos independentes, um determinado programa não saberá em tempo quando outro atualizar o arquivo e uma situação de conflito ou erro poderá ocorrer. A utilização de Sistemas de Gerenciamento de BD (SGBD) tornou-se uma das soluções entrevistas para resolver esse problema. Hoje há muitos tipos de BD e de SGBD, com um predomínio do que se denomina bancos de dados relacionais.

Os BD relacionais foram introduzidos em 1970. São sistemas que incorporam SGBDs nos quais os dados são entendidos pelo usuário na forma de tabelas, e que contém operadores capazes de gerar novas tabelas a partir das tabelas originais conforme o emprego desejado pelo usuário [Zhang 94]. Um ponto realçado por [Jones 89] na conceituação de um BD relacional é a sua capacidade em acessar dois ou mais arquivos ou tabelas simultaneamente com o objetivo de obter certo conjunto de informações. A forma de acesso e interligação dos arquivos para tanto constituemse relacionamentos entre os diferentes arquivos via uma estrutura de campos e registros. Campos, segundo [Jones 89], são categorias, tipos de informação, enquanto registros são conjuntos de informações interligadas as quais se classificam nos diversos campos de um BD. Bancos de dados relacionais bastante conhecidos são o dBASE IV, da Ashton Tate, o ACCESS e o FoxPro, da Microsoft, o ORACLE, etc..

Outros tipos de BD podem ser categorizados também, além dos relacionais. São eles, dentre os mais expressivos, o hierárquico e o tipo rede.

Um BD hierárquico consiste num conjunto ordenado de árvores; mais precisamente, num conjunto ordenado consistindo de ocorrências múltiplas de um único tipo de árvore. Os dados são representados ao usuário na forma de um conjunto de estruturas em árvore e os operadores possuem a capacidade de 
selecionar determinada hierarquia ou nível da árvore. Uma árvore consiste de um registro de raiz única aliado a um conjunto ordenado de zero ou mais sub-árvores dependentes. Uma sub-árvore ou galho também consiste de um registro único o qual é raiz de outra(s) sub-árvore(s). Assim a árvore toda é formada por um arranjo hierárquico de registros tipo árvore e sub-árvores, os quais podem ser classificados, hierarquicamente, na forma de campos. A figura 2.05 exemplifica uma estrutura hierárquica.

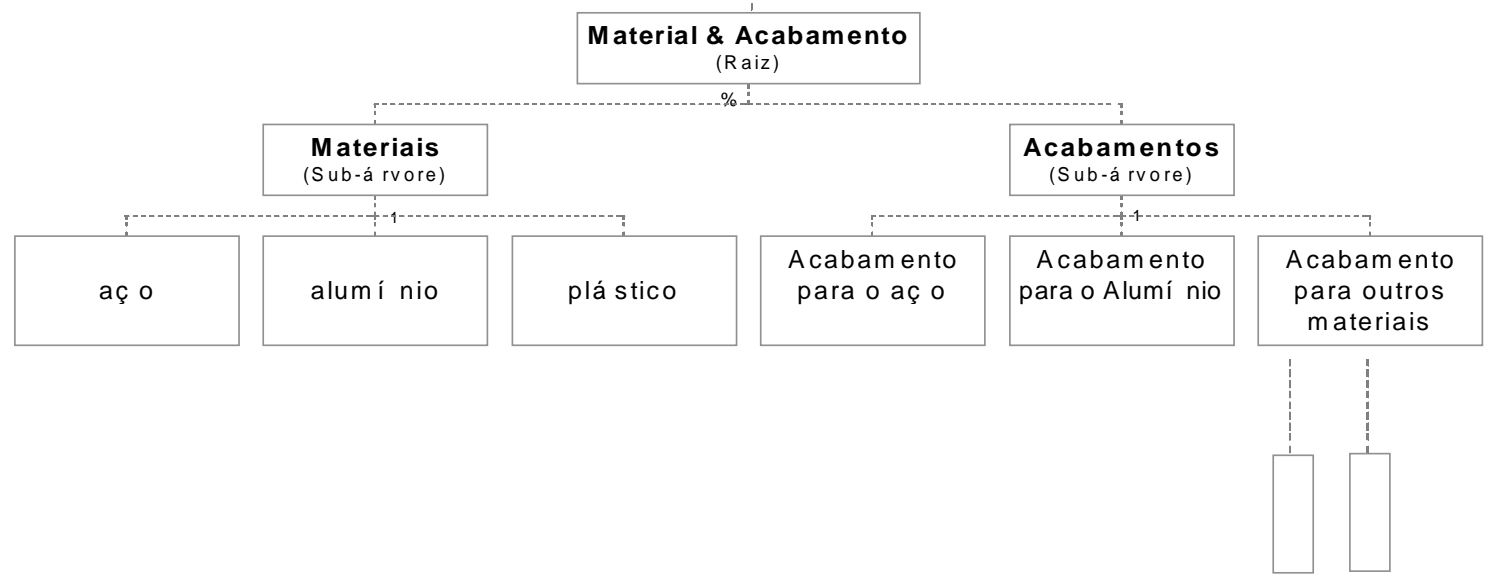

figura 2.05 Um exemplo de Banco de Dados com configuração geométrica hierárquica [Zhang 94]

Uma estrutura de BD em rede pode ser compreendida como uma forma estendida da estrutura hierárquica. A diferença entre uma e outra é que na estrutura hierárquica um registro filho tem exatamente um único pai, enquanto na estrutura em rede ele pode ter qualquer número de pais. Um BD em rede consiste de dois conjuntos: um conjunto de registros e um conjunto de ligações. Cada ligação envolve dois registros, um do pai e outro do filho, ou seja, cada ocorrência de uma dada ligação consiste de uma ocorrência isolada do registro pai com um conjunto ordenado de múltiplas ocorrências do registro filho, como se pode observar na figura 2.06 para um $\mathrm{BD}$ de máquinas-ferramentas.

A aplicação de BD se torna importante na manufatura atual especialmente devido à busca de soluções integradas para a produção. Dos diferentes tipos de BD pode-se evoluir para as chamadas estruturas distribuídas [Zhang 94], nas quais se possui o BD necessário no local em que determinada atividade ou exigência se mostra. Assim pode-se ter em diferentes locais, dados de diferentes produtos e/ou de 
diferentes processos de fabricação interligados e com transparência na obtenção das informações.

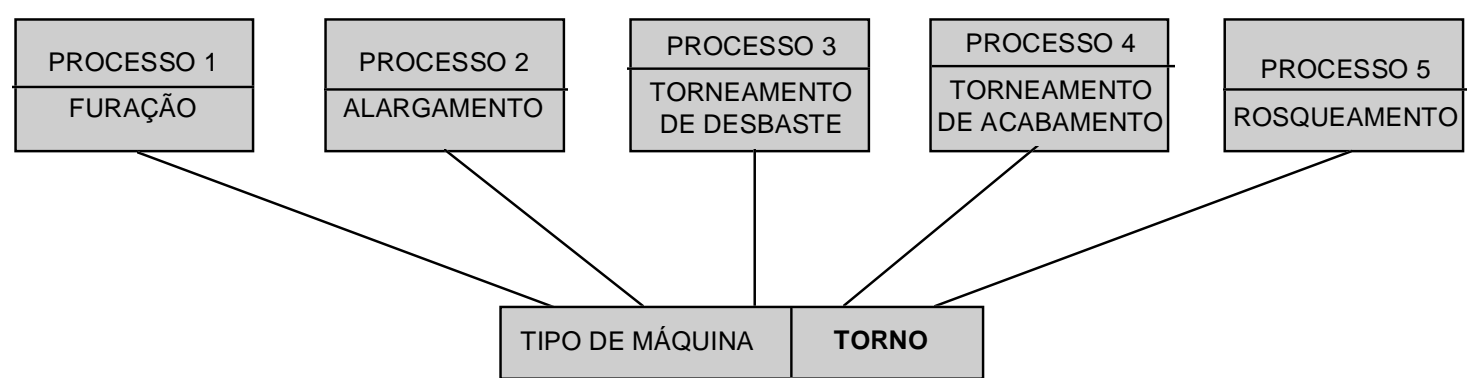

figura 2.06 Uma BD de máquinas-ferramentas em rede [Zhang 94]

Meios de acesso e de consulta rápidos e amigáveis são outros pré-requisitos. A forma de armazenamento através dos campos identificados da maneira correta (via relacional, hierárquica ou em rede) visando se tornar comum tanto à área de projeto como à de processo, à de programação, e à de produção, com a seleção de informações através de níveis hierárquicos, é outro requisito indispensável para a integração da manufatura.

O planejamento de processos é uma área na manufatura moderna na qual se encontra uma das maiores quantidades de aplicações de BD. Dentre os vários subBD possíveis aí encontra-se os BD de:

- matéria-prima;

- máquinas-ferramentas (avanços, rotações, potências, dimensões disponíveis);

- ferramentas (geometria, materiais, fabricantes);

- fixações;

- dispositivos;

- meio de controle de qualidade;

- sequência de processos;

- parâmetros de processos;

- programas $\mathrm{CN}$;

- arranjo físico;

- índices tecnológicos de processos como os de usinabilidade, de soldabilidade e de estampabilidade de materiais, por exemplo;

- ligações com BDs de projeto de produto (via TG, por exemplo), de administração da produção, de recursos humanos, etc.. 
Um exemplo simplificado de estrutura de BD para o Planejamento de Processos Auxiliado por Computador é mostrado na figura 2.07. Ele se baseia numa abordagem híbrida na qual existem BDs e sub-BDs ou tabelas

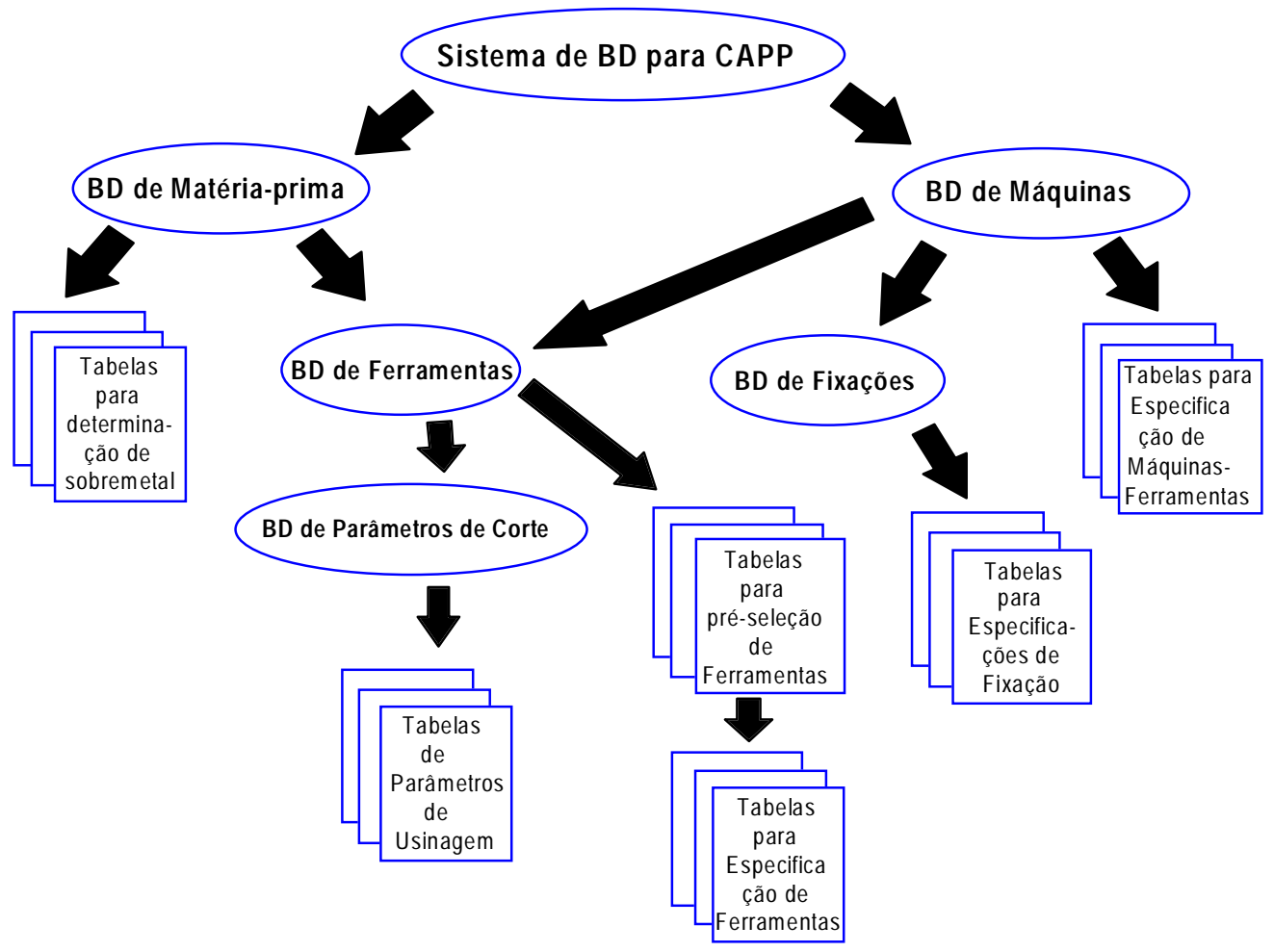

figura 2.07 Um exemplo de Banco de Dados para um sistema CAPP de Usinagem

numa estrutura em rede. Os sub-BD ou tabelas são formados numa estrutura relacional. As ligações entre os BD mostram a estrutura em rede. Por exemplo, o BD de Ferramentas é um nó filho tanto do BD de matéria-prima quanto do BD de máquinas-ferramentas, implicando que as informações relacionadas a ferramentas dependem tanto do material a ser usinado quanto das máquinas a serem empregadas no processo. Da mesma maneira, as informações relativas aos parâmetros de corte baseiam-se na ferramenta selecionada e estas, por sua vez, estão alocadas em tabelas, ou seja, em modelos de BD relacionais.

Cabe lembrar neste ponto que, devido ao objetivo de se atingir o CIM, ou a integração total, pode-se tornar necessário integrar o CAD e até mesmo o CAE com o sistema CAPP visando o auxílio ao projetista da peça na determinação de todos os condicionantes de seu projeto. Observa-se, então, grandes dificuldades no 
interfaceamento desses sistemas e, em particular, desses grandes BDs. Esse problema é colocado como de importância fundamental por [Rodrigues 93].

[Zhang 94] propõe uma saída alternativa à integração dos vários BDs de maneira funcional como se tem visto até então. Introduz um conceito de Single Data Base (SDB) o qual se destinaria a um único produto, contendo não mais relações entre $\mathrm{BD}$ funcionais como os BD de CAD, CAPP, CAM, etc. mas contendo, para determinado produto ou peça, todas as informações de projeto, análise, desenho, planejamento de processo, programas $\mathrm{CN}$, lista de materiais ou bill of materials (BOM), informações para planejamento de pós-processo, etc.. Como esse próprio autor cita, apesar dos grandes esforços feitos até então para uma solução com esse conceito, pode-se afirmar que um SDB eficaz ainda não existe.

\subsubsection{O Problema da Especificação do Processo de Usinagem: Dados de Entrada, Parâmetros e Especificações de Saída}

O domínio das operações de usinagem compreende, além de um grande número de tipos de processos específicos, uma grande quantidade de parâmetros que o condicionam, podendo-se tê-lo de forma mais ou menos otimizada conforme os critérios que se adotem para essa análise. Analisar as formas de especificação das condições em que esse processo deve ocorrer com critérios estabelecidos a priori e através do auxílio do computador é um dos objetivos deste trabalho. Para tanto, torna-se necessário caracterizar o processo de usinagem, mostrando a complexidade das interações entre os seus diversos condicionantes.

Os processos de usinagem compreendem aqueles que, ao conferir à peça a forma, ou as dimensões, ou o acabamento, ou ainda uma combinação qualquer destes três ítens, produzem cavaco [Ferraresi 85, ABNT 80]. Entenda-se por cavaco a porção de material da peça retirada pela ferramenta, caracterizando-se por apresentar, em geral, uma forma geométrica irregular.

Para os vários processos de usinagem pode-se adotar a classificação contida também em [Ferraresi 85, ABNT 80]:

- torneamento;

- aplainamento;
- fresamento;

- serramento;

- brochamento;

- roscamento;

- retificacão; 
- furação;

- alargamento;

- rebaixamento;

- mandrilamento;

- denteamento;

Cada um destes processos pode possuir sub-classificações conforme, por exemplo, a posição e a trajetória da ferramenta em relação à peça. Desta forma pode-se ter um torneamento cilíndrico ou um de faceamento, uma furação em cheio ou escalonada, e assim por diante.

Processos de usinagem envolvem interações complexas entre a peça, a ferramenta, o dispositivo de fixação e a máquina-ferramenta, componentes esses denominados como um sistema para usinagem [Coppini 87]. [Eriksson 92] relata a experiência da empresa Volvo (Suécia) em utilizar um modelo por eles denominado Modelo em Corrente para estruturação, classificação e melhor entendimento do fenômeno de usinagem como um todo, conforme mostrado na figura 2.08.

Este tipo de modelo foi utilizado visando ilustrar o fato de que os dados de corte ótimos (velocidade de corte, avanço, profundidade de corte) dependem do elo mais fraco da corrente e que qualquer melhoria só pode ser alcançada pelo fortalecimento desse elo. Esses elos ou fatores representam certas propriedades que influenciam a operação de usinagem. O autor introduz a usinabilidade, ou seja, o comportamento do material durante uma operação de usinagem, como uma das variáveis relacionadas ao material da peça, sendo uma das mais importantes.

Da observação desse modelo inicial compreende-se a complexidade envolvida ao se tentar otimizar os parâmetros de corte para uma determinada operação. [Groover 88], ainda, propõe um conjunto de características para uma operação de usinagem que se aproxima e detalha mais o modelo em corrente de [Eriksson 92]:

\section{Tipo da operação de usinagem}

- tipo de processo - torneamento, furação, fresamento, retificação, etc.;

- modo de operação - desbaste versus acabamento; 


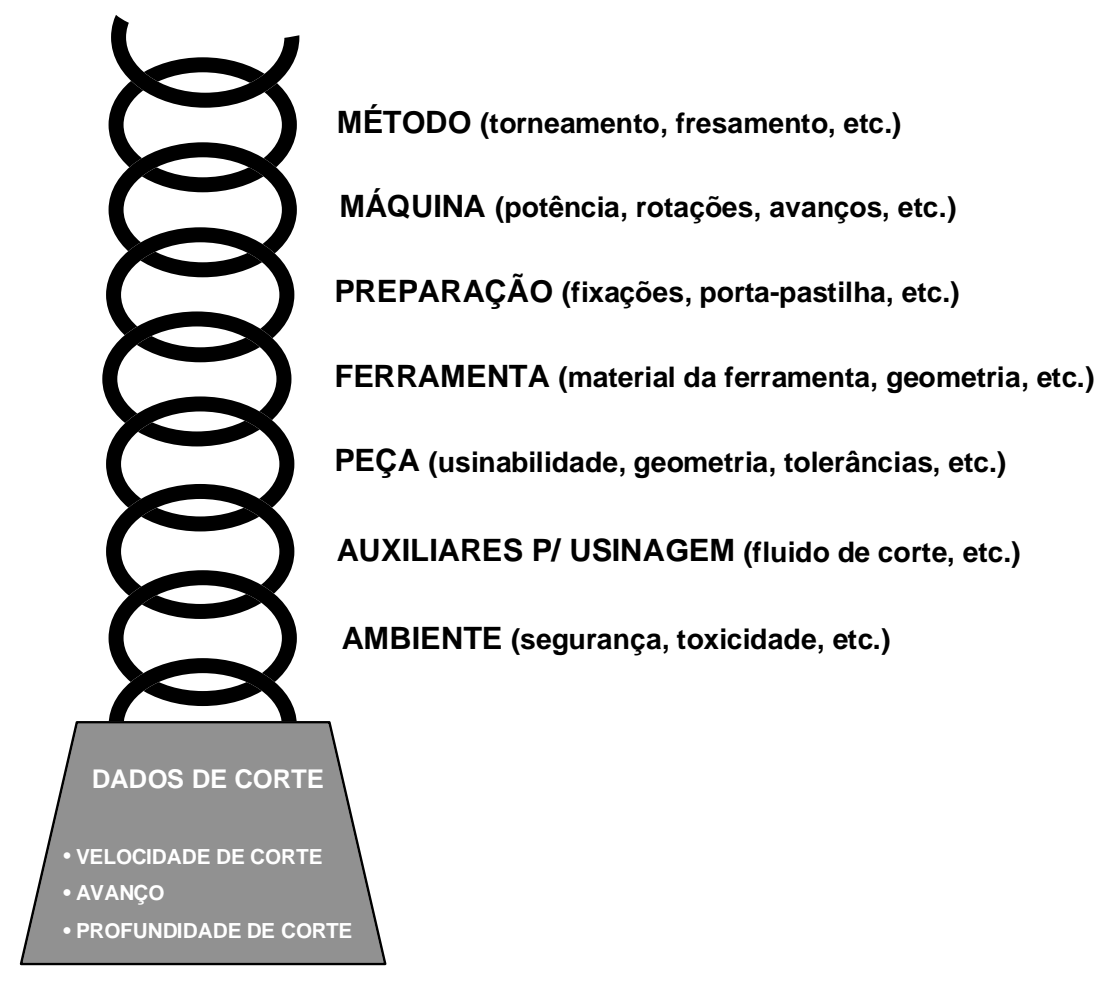

figura 2.08 O Modelo em Corrente [Eriksson 92]

\section{Parâmetros da Máquina-Ferramenta}

- tamanho e rigidez;

- potência disponível para velocidade e avanço;

- níveis de velocidade do fuso e de avanço;

- tipo da máquina - convencional ou $\mathrm{CN}$;

- capacidades de precisão e resolução de posicionamento;

- tempos operacionais.

\section{Parâmetros da Ferramenta de Corte}

- tipo do material da ferramenta (aço rápido, metal duro, cerâmica, etc.);

- composição química do material da ferramenta;

- propriedades mecânicas e físicas (dureza, resistência ao desgaste, etc.);

- tipo da ferramenta (broca de furação, pastilha de aresta única de contato, cabeçote de fresar, etc.);

- geometria da ferramenta (raio de ponta, ângulos de ataque, ângulos de alívio, número de dentes, etc.); 
- dados relacionados ao custo da ferramenta;

- dados relacionados aos tempos de troca da ferramenta.

\section{Características da Peça}

- material - tipo básico e grau específico;

- dureza e resistência mecânica;

- tamanho e forma geométrica;

- tolerâncias dimensionais desejadas;

- acabamento superficial desejado;

- condições iniciais da superfície, das dimensões e de tratamento térmico da peça (peça bruta).

\section{Parâmetros Operacionais além do Avanço e Velocidade de Corte}

- profundidade de corte;

- fluido de corte, se houver;

- rigidez da peça;

- fixações e guias.

Cabe neste ponto, utilizando a conceituação de análise sistêmica de [Asimow 68] para a análise de um problema em engenharia, fixar a diferença fundamental e as relações possíveis entre variáveis e parâmetros para o modelo matemático do processo de usinagem. Adotando um sistema CAPP, todos os atributos ou características que influem na determinação de uma condição específica de usinagem chamam-se parâmetros. No momento de uma análise, no entanto, podese fixar alguns parâmetros enquanto se trabalha com os demais, verificando os efeitos de uns sobre os outros. Define-se, assim, as variáveis dependentes ou de saída, as variáveis independentes ou de entrada, e os parâmetros, propriamente, os quais não sofrem variações para aquela determinada análise por assunção. O mesmo autor coloca a função otimização formal como a maneira de se encontrar a relação ótima entre todos os parâmetros (variáveis independentes, dependentes e parâmetros) para configurar uma determinada situação de trabalho (neste caso, uma certa operação de usinagem). Para isso os valores ótimos devem satisfazer todas as limitações do sistema, ou seja, toda a gama permitida dos parâmetros e de eventuais relações entre eles, e, principalmente, a uma função critério ou objetivo, a qual 
contém a(s) regra(s) utilizada(s) para o julgamento da situação e com que se pretende atingir um conjunto de parâmetros superior dentre os possíveis. No caso de operações de usinagem as funções critério tradicionalmente empregadas são a minimização do custo da operação, a maximização da produção, a redução do desgaste de ferramenta, a maximização do lucro da empresa [Ferraresi 89], entre outras.

[Boehs 86], por exemplo, propõe uma estruturação de um sistema CAPP que incorpora um conjunto de variáveis e parâmetros para usinagem, com suas relações. Adota como variáveis dependentes o avanço, a profundidade de corte e a velocidade de corte, e como função critério tanto o mínimo custo de usinagem como a máxima produção.

restrições impostas por:

modificam as variáveis dependentes:

\begin{tabular}{|c|c|c|c|}
\hline & AVANÇO & PROF. CORTE & VEL. CORTE \\
\hline \multicolumn{4}{|l|}{ MÁQUINA-FERRAMENTA } \\
\hline - potência disponível & $\bullet$ & $\bullet$ & $\bullet$ \\
\hline - torque admissível & $\bullet$ & $\bullet$ & \\
\hline - rotações existentes & & & • \\
\hline - avanços possíveis & $\bullet$ & & \\
\hline \multicolumn{4}{|l|}{ FERRAMENTA DE CORTE } \\
\hline - largura de corte & & $\bullet$ & \\
\hline - espessura de cavaco & $\bullet$ & & \\
\hline - força de corte & $\bullet$ & $\bullet$ & \\
\hline - desgaste admissível & $\bullet$ & $\bullet$ & $\bullet$ \\
\hline \multicolumn{4}{|l|}{ MATERIAIS: PEÇA-FERRAMENTA } \\
\hline - vida da ferramenta & & & $\bullet$ \\
\hline - forma do cavaco & $\bullet$ & $\bullet$ & \\
\hline \multicolumn{4}{|l|}{ PEÇA } \\
\hline - acabamento superficial & $\bullet$ & $\bullet$ & \\
\hline
\end{tabular}

tabela 2.02 Restrições tecnológicas no processo de usinagem e sua influência nas variáveis dependentes, conforme [Boehs 86]

Ainda, para validar a otimização, assume o que chama de restrições tecnológicas do processo, obtidas conforme disposto na tabela 2.02 .

Assim como [Boehs 86], [Groover 88] e [Eriksson 92], muitos outros trabalhos e sistemas procuram modelar o processo de usinagem visando solucionar a questão 
do CAPP voltado para esse domínio de processos. Na classificação inicial (item 2.2, citando [Rozenfeld 89, Rodrigues 93]) denominou-se a esse conjunto de funções pertencente a um sistema CAPP como grupos de planejamento macro e de

operações. É pelo estudo desses grupos e, em particular, de algumas sub-atividades nele contidas, como o caso da determinação das condições operacionais do processo de usinagem, que se desenvolverá o trabalho subseqüente. Torna-se, assim, necessário compreender com mais detalhe os principais parâmetros (i.e., os relacionados à escolha do processo, da máquina, da ferramenta e da fixação), os quais influenciarão na otimização de condições operacionais como a velocidade de corte, o avanço e a profundidade de corte. A figura 2.09 mostra simplificadamente um gráfico com uma otimização possível para o avanço e a velocidade de corte decorrente do estabelecimento de critérios como o de mínimo custo e o de máxima produção além de restrições do processo.

\subsubsection{A escolha do processo de usinagem e de seu seqüenciamento}

Decidido que o processo a ser utilizado é o de usinagem para a execução de determinada peça, a próxima etapa que um sistema CAPP ideal deve completar é a definição de quais operações dentre as diversas do domínio de usinagem serão as escolhidas. Como já citado, nas indústrias com setores de planejamento tradicionais essa atividade é exercida por uma equipe de profissionais com grande experiência na atividade e na sua implementação no chão-de-fábrica de forma que eles utilizam o seu conhecimento especialista determinando qual a melhor sequência de operações e sub-operações. Assim, por exemplo, a determinação de uma sequência hipotética faceamento - torneamento - tratamento térmico - retificação cilíndrica é feita da observação do desenho da peça, da interpretação das relações entre os seus elementos, correlacionando-os com os resultados das operações dos vários processos possíveis de serem utilizados, levando ainda em conta as exigências de tolerância dimensional, acabamento superficial, do tipo de material e de dureza da peça. 


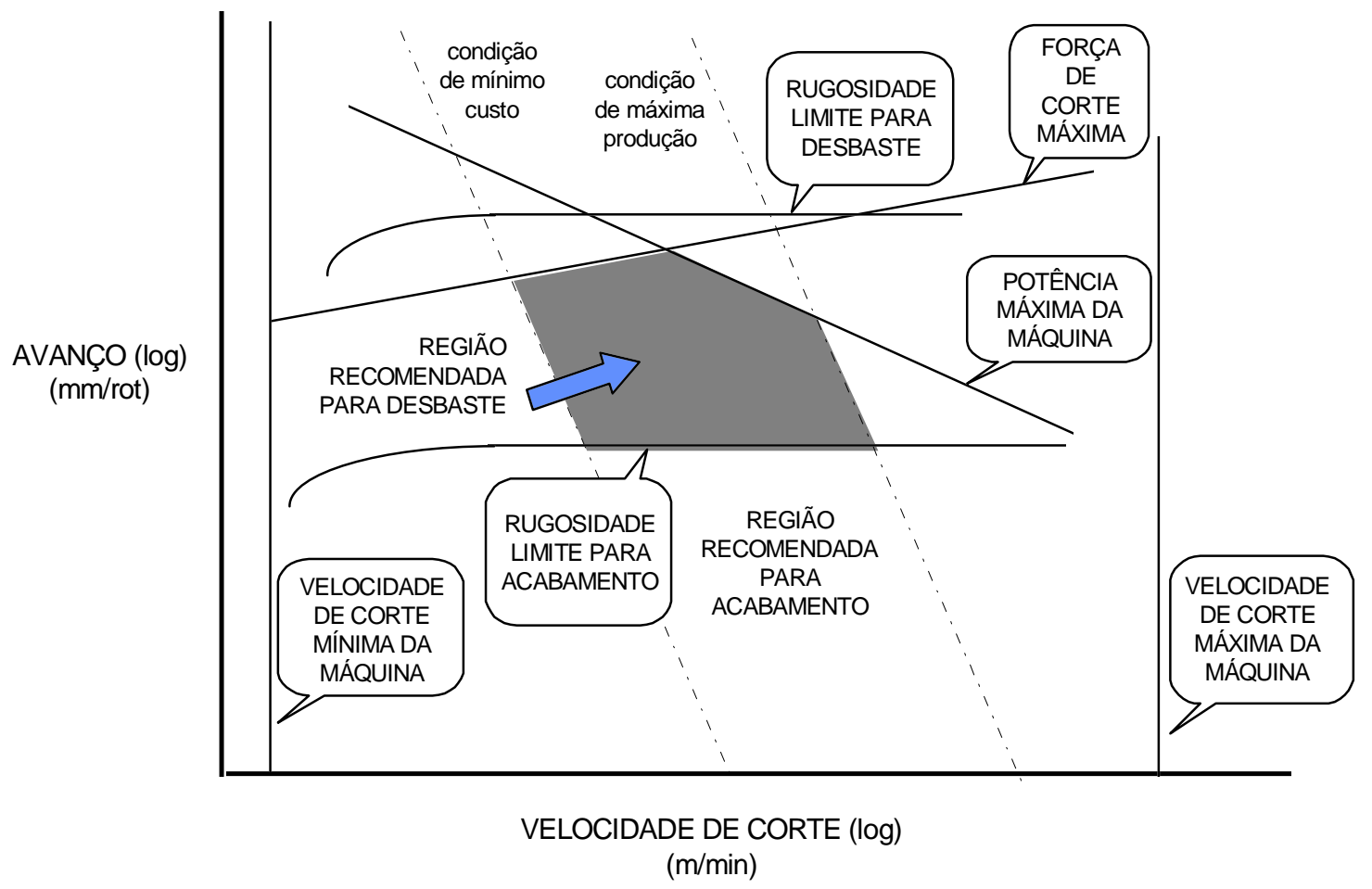

figura 2.09 Exemplo de Modelo Gráfico para um Processo de Usinagem e sua Otimização sob o ponto de vista do avanço e da velocidade de corte, adaptado de [Boehs 86], [Ferraresi 85] e [Couers 90]

Sob o ponto de vista computacional esse é um problema complexo pois envolve o reconhecimento e a interpretação de características geométricas da peça modeladas em sistemas CAD. [Lenau 88] explica que a interpretação de um modelo CAD ainda não foi resolvida satisfatoriamente devido a esses sistemas usarem primitivas geométricas como arcos, linhas e elementos mais elaborados como forma de representação (por exemplo, superfícies e sólidos), e uma estrutura de dados que apenas usa essas primitivas não pode representar relações entre elas. Nos sistemas CAD convencionais o projetista traduz as suas idéias sobre a peça, a qual inclui as relações funcionais entre as diferentes primitivas, na representação específica do $\mathrm{CAD}$, sendo a parte relacional perdida. Haverá problemas ao se tentar fazer um programa de computador que tome uma representação assim e dela extraia informações pois, ou a informação relacional não está lá ou é dada de forma implícita. Seguindo essa abordagem, encontra-se em [Teixeira Jr. 89] o desenvolvimento de uma primeira fase de um projeto de um sistema CAPP no qual procurou-se identificar através de primitivas de um modelo CAD bidimensional informações relacionais para decisão quanto ao processo de usinagem através de 
uma abordagem de sistema baseada em conhecimento (vide item 2.4.3.2) com o auxílio da linguagem OPS5, a qual é dedicada a esse tipo de sistema. Essa aplicação ilustra o que é um reconhecedor automático de features, como observar-se-á adiante.

Outra forma de se tratar o problema da interpretação de um desenho ou de um modelo CAD visando o planejamento de processo é através da utilização de Tecnologia de Grupo (TG). Como descreve [Barkocy 84] sobre o sistema CUTTECH, ele utiliza códigos de acordo com determinada abordagem de TG os quais qualificam a geometria da peça e o seu material, correlacionando-os com regras de usinagem. Uma característica desse sistema é, segundo o autor, que ele necessita da interpretação do desenho não necessariamente por um especialista em usinagem, mas por um usuário com algum treinamento.

Por essas dificuldades uma abordagem mais recente em CAD denominada Features Based Design (FBD) ou Projeto Baseado em Features vem sendo cada vez mais considerada. FBD se utiliza de um tipo diferente de primitiva, denominada feature, que se relaciona às funções do produto e a informações de manufatura. Exemplos de features: fendas, diâmetros, furos, chanfros, rasgos de chaveta, etc.. Analisada a peça com a determinação dos features existentes obtém-se a indicação das operações a serem utilizadas, visto se associar a cada feature um conjunto de operações de usinagem. Com essa abordagem pretende-se obter Sistemas de Projetos Baseados em Features ou Feature-based Design Systems (FBDS) [Schulte 92] nos quais se aliam as propriedades de tolerância (tolerâncias geométricas, acabamento superficial, etc.), propriedades do material (especificações, tratamento, etc.) e propriedades tecnológicas (parâmetros de desempenho, restrições de projeto, etc.) às entidades geométricas que definem a forma e outras características geométricas de um objeto. Estas últimas, por exemplo, têm sido pesquisadas através de sistemas de modelamento wireframe e também sólido, neste último por meio de esquemas de representação particulares como o B-rep (Boundary Representation, ou Representação de Contornos ou de Bordas), e o CSG (Constructive Solid Geometry) [Sim 89].

[Rodrigues 93] descreve a evolução das formas de interpretação de modelo CAD visando o CAPP automático, classificando-as em linguagens descritivas e representação em CAD. A aplicação de códigos por atributos utilizando os conceitos de TG, como visto, é classificada como uma linguagem descritiva. Segundo esse autor a melhor forma de representar uma peça visando o CAPP automático é através dos features ou elementos tecnológicos; estes corresponderiam a entidades 
geométricas definidas (superfícies com ou sem volume) conjugadas aos seus dados tecnológicos correspondentes visando a manufatura, como explicado por [Schulte 92]. [Rodrigues 93] ressalta, porém, que o projeto do produto baseado em features pode não ser necessariamente natural ao projetista e, dessa forma, os reconhecedores automáticos de features seriam a solução embora entenda que haja dificuldades em implementar sistemas assim para o reconhecimento de features complexos. Com o modelo definido em termos de features, vincula-se estes elementos aos processos de manufatura e pode-se partir para as etapas de CAPP posteriores.

Reforçando a idéia de [Rodrigues 93], observa-se na figura 2.10 features diferentes nas visões do projetista e do processista para uma peça funcionalmente igual conforme exposto em [COMPLAN 95]. Além da dificuldade que o projetista tem na utilização natural de features, a abordagem de uma visão mais voltada para o projeto em detrimento de outra, mais para a fabricação, pode se tornar outro problema na definição posterior do processo.

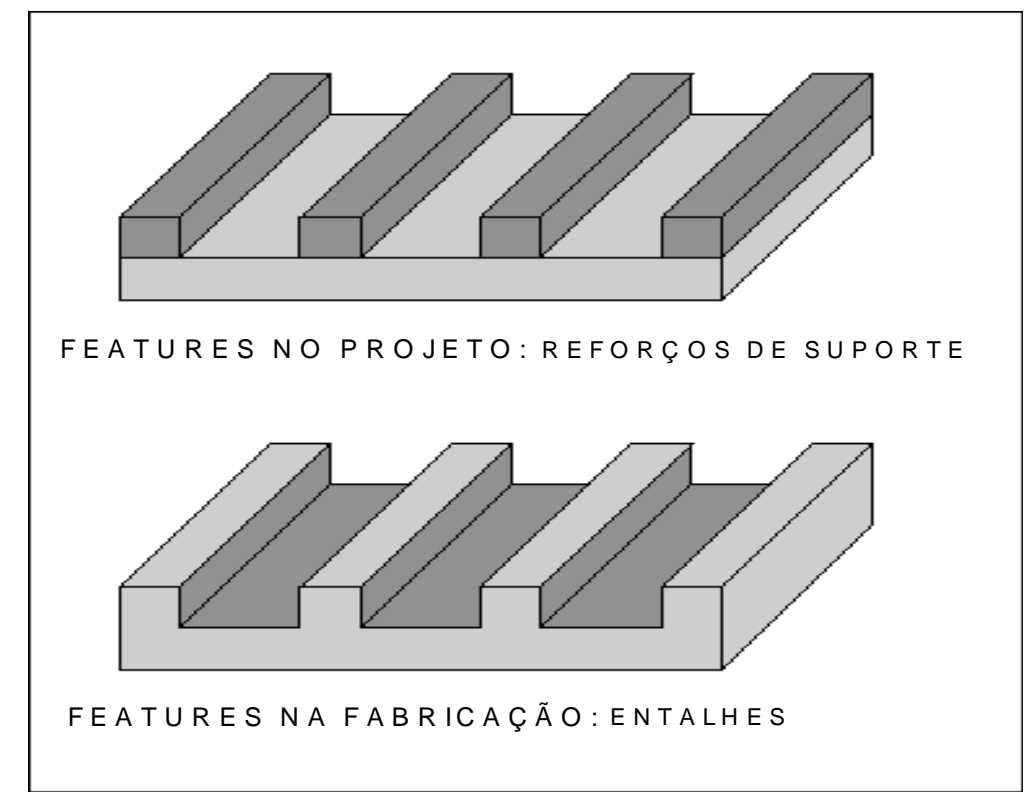

figura 2.10 Exemplo de features aplicado no projeto e aplicado na manufatura [COMPLAN 95]

Com a existência de uma interpretação do desenho ou modelo da peça, o sistema CAPP deve correlacionar essas informações com os diferentes processos de usinagem visando escolher quais aqueles que melhor se identificam para a sua execução e Ihes atribuindo uma seqüência ótima. Essas são atividades também complexas e as soluções que mais se têm mostrado eficazes são as contidas nos 
sistemas baseados em conhecimento [Sim 89, Schulte 92], utilizando-se, por exemplo, de regras baseadas em conhecimento especialista para a decisão. Em particular são muito empregados os chamados sistemas especialistas (ou Expert Systems), os quais serão analisados com mais detalhes em 2.4.3.2.

Outro aspecto importante a ser considerado na seleção de processos de fabricação é a questão do tipo de produção para o qual o processo está sendo planejado (em oficinas, em lotes e em massa, conforme item 2.2) e a arquitetura e projeto do sistema de manufatura que o sistema CAPP pretende servir [Opas 94]. Em princípio os diferentes tipos de produção poderão implicar em diferentes seleções de processos para uma mesma peça. Regras gerais mostram que a produção em oficina (ou em quantidades baixas) tende a concentrar processos, enquanto a produção em massa (ou em quantidades elevadas) tende a dispersá-los [Zhang 94]. Esse fato irá afetar uma próxima etapa do plano de processo, ou seja, a fase da escolha da máquina, quando então observar-se-á a dispersão das operações nas máquinas.

\subsubsection{A escolha da máquina-ferramenta}

Discutido o processo e as operações a serem empregadas para a fabricação, uma etapa seguinte é a da escolha da máquina-ferramenta para usinagem. Isso se faz, de partida, pela seleção das máquinas que são capazes de executar aquela determinada operação ou sequência de operações definida para a peça. Muitas vezes essas máquinas podem já estar disponíveis no chão-de-fábrica, obtendo-se um conjunto de máquinas dedicadas àquela(s) operação(ões) as quais deverão ser julgadas quanto à sua real possibilidade de executar a tarefa, de acordo com a peça, o processo e a sua disponibilidade de serem programadas para a produção.

Caso a máquina não exista na fábrica e houver a necessidade de comprá-la, as informações das máquinas com potencial de serem adquiridas poderão ser introduzidas, por exemplo, num $\mathrm{BD}$ do sistema CAPP referente às máquinasferramentas para estudo. Com isso pode-se estimar os parâmetros do processo a priori o que ajudará na definição do melhor equipamento.

O critério de disponibilidade para a programação da produção relaciona-se com a quantidade de peças que já estão sendo processadas numa determinada máquina existente [Araujo 87, Araujo 88]. Caso a máquina já esteja com 100\% de sua carga ou capacidade (tempo operacional por peça $\times$ quantidade programada de 
peças num período de tempo determinado) tomada por outras peças, a escolha deverá ser por outro equipamento ou essa informação deverá forçar uma decisão quanto à troca das atuais peças nela fabricadas. Apesar de não ser este um critério técnico que diga respeito ao processo, é fundamental a sua discussão visto poder limitar ou inviabilizar a escolha e o planejamento posterior desta e de outras peças.

Antes porém de tratar dos critérios técnicos relativos à peça, é necessário definir a peça bruta a ser usinada. A discussão aqui é quanto à seleção do material e do seu modo de fornecimento. A peça bruta pode ser originária de uma barra laminada, com várias secções transversais possíveis, de uma peça forjada ou fundida de formato específico, com sobremetal e com superfície bruta típica do seu processo de obtenção, etc.. Em termos genéricos, trata-se de definir o tipo de peça bruta, com seu correspondente sobremetal, que minimize o custo de material e o custo de retirada de cavaco na usinagem. Essa escolha será feita de acordo com uma BD padrão de materiais, com dimensões brutas e dados de custo de mercado. Por princípio o sobremetal inicial da peça deve ser o menor possível visando a redução no custo da operação de usinagem. Daí a opção que se faz na produção em massa em se ter a peça forjada ou fundida, em virtude do sobremetal poder ser calculado e/ou reduzido além de poder vir de encontro às especificações de projeto da peça quanto à resistência mecânica ou quanto a sua complexidade geométrica.

Com as dimensões da peça bruta e um conjunto de máquinas definidos, torna-se necessário verificar quais dessas máquinas são compatíveis dimensionalmente com a introdução e fixação dessa peça. Isso se faz com a comparação das dimensões principais da peça bruta com as dimensões reais do espaço de trabalho das máquinas, as quais devem estar catalogadas na BD de máquinas-ferramentas do sistema CAPP. Um sistema denominado SEMCON Sistema para Escolha de Máquinas de Comando Numérico - desenvolvido em 1986 na EMBRAER, utilizava-se desse critério dimensional para seleção de máquinas $\mathrm{CN}$. Baseado numa sessão de perguntas e respostas com um processista, o sistema decidia em quais das máquinas $\mathrm{CN}$ dentre as disponíveis era possível fabricar uma dada peça, indicando quais as máquinas mais apropriadas para isso. A parte relacionada à compatibilidade dimensional incluia 9 regras para uma avaliação inicial das máquinas candidatas à usinagem. As demais regras eram baseadas em outros critérios técnicos de usinagem (como será visto mais adiante) e na disponibilidade de programa de produção pela máquina, como já discutido. 
Com essa primeira selecão feita, as máquinas candidatas podem, então, ser ordenadas de acordo com uma estratégia de planejamento de processo. Certa estratégia pode escolher uma máquina mais rápida em preferência a uma mais lenta ou uma de menor custo operacional a uma de maior custo [Zhang 94]. Pode, ainda, decidir entre uma produção mais dispersa (operações distribuídas em mais máquinas) ou mais concentrada (utilizando-se centros de usinagem ou máquinas mais versáteis, por exemplo). A essa discussão pode-se acrescentar a decisão quanto aos conceitos de células de manufatura e de linha de produção, classificando as máquinas no BD como pertencentes a uma ou outra célula ou linha, e selecionando-as conforme haja gargalos de produção, por exemplo. As informações para decisões como essas poderão estar modeladas no BD de máquinas ou num BD auxiliar que leve em consideração, por exemplo, o seu arranjo físico, os custos de transporte de peça, o custo de preparação, etc..

Planos alternativos e/ou com máquinas opcionais também podem ser gerados, com as diferenças de custos e de tempos que podem advir. Nesse caso, porém, torna-se necessário definir-se outros conjuntos de parâmetros como os custos do processo, as ferramentas de corte e dispositivos a serem utilizados, etc., além de critérios para a sua adoção quando necessária.

Outras restrições importantes na definição final das máquinas dizem respeito aos avanços e rotações permitidas, conforme a figura 2.09 mostra. Da mesma maneira, a potência e o torque máximos permitidos, são características igualmente importantes [Ferraresi 85, Boehs 86, Groover 88] a serem catalogadas no BD de máquinas visto ser necessário, muitas vezes, trabalhar-se em condições limites visando reduzir tempo de processo.

Quanto ao tipo da máquina, convencional ou CNC, observa-se uma tendência crescente na utilização destas últimas, o que deve se consolidar nos próximos anos. Os critérios para a decisão são a flexibilidade, a necessidade técnica da operação de usinagem, a qualidade dimensional, o custo e o tempo operacionais, além da necessidade de redução do chamado time to market o que acaba por implicar na utilização de máquinas que permitam a fabricação e colocação de um novo produto no mercado consumidor num período de tempo cada vez menor. Neste caso as máquinas CNC levam uma vantagem muito grande em relação às convencionais devido à sua possibilidade de programação e flexibilidade.

Outra possível restrição tecnológica na seleção de máquinas-ferramentas é a rigidez de sua estrutura e a rigidez de seus componentes as quais poderão afetar 
diretamente a qualidade do acabamento superficial e as dimensões finais da peça. No entanto a sua avaliação objetiva apresenta dificuldades visto estar relacionada não apenas à máquina mas com os modos de vibração e as frequências naturais do sistema máquina-ferramenta-dispositivo-peça. Uma solução para a indicação de estabilidade do sistema é através de índices experimentais os quais devem ser levantados junto à máquina-ferramenta, conforme citado por [DeArdo 93, Ferraresi 85]. Nesse caso é importante também conhecer a característica da operação, se é de desbaste ou de acabamento, procurando uma regra para julgamento da capacidade da máquina para a sua execução.

\subsubsection{A escolha da ferramenta}

Definido o conjunto de operações de usinagem, associa-se a cada uma dessas operações um grupo de ferramentas que lhes é mais indicado. A escolha da ferramenta está condicionada, em geral, às existentes no mercado, podendo ser estas normalizadas ou especiais. No entanto, a cada dia novos desenvolvimentos na tecnologia de ferramentas são feitos principalmente na área de materiais e seus processos de obtenção. Além do material, entretanto, outros fatores condicionam a seleção da ferramenta ótima para o processo e para a peça, entre eles detalhes da composição química do seu material, o tipo da ferramenta (que está vinculado ao processo), a sua geometria e os custos a ela relacionados (custos de aquisição, de troca, de preparação, de estoque) [Groover 88].

- A ferramenta: seu material

A seleção do tipo de material ideal para as ferramentas de corte e de sua composição química residem na pesquisa de materiais que possuam, cada vez mais, resistência às altas temperaturas com alta tenacidade o que implica, ao final, alta produtividade [Chandrasekaran 88]. Isso é mostrado na figura 2.11. O desempenho da ferramenta, no entanto, dependerá da combinação material, processo e estabilidade [Reiter 89].

Por outro lado, a questão da produtividade na indústria metalúrgica é vista hoje sob aspectos operacionais como o da redução do tempo de preparação [Marcondes 90] e por aspectos técnicos como o do aumento da confiabilidade 
[Chandrasekaran 88] e da velocidade de corte [Johannsen 92]. O aumento da velocidade de corte, por sua vez, está relacionado com a usinabilidade do material da peça e com o material da ferramenta, refletindo-se numa redução dos tempos de processo. No caso do torneamento, por exemplo, isso ocorre pois o avanço da ferramenta, dado em mm/rotação do fuso, está correlacionado diretamente com a velocidade de corte, que é função direta da rotação do fuso. Assim aumentando-se a velocidade de corte os tempos de processo irão se reduzir, salvo outras condições limitantes como a da máxima vida da ferramenta. Além do torneamento, os exemplos fornecidos se aplicam diretamente a processos como o fresamento e a furação, mas podem ser estendidos aos demais com as devidas adaptações. Na figura 2.12 ilustrase o desenvolvimento das velocidades de corte no tempo [Johannsen 92].

Através de [Sinterconsult 94], entre outras fontes, pode-se ter uma síntese sobre o estado-da-técnica em materiais para ferramentas e as suas diversas características a serem analisadas e utilizadas pelo processista no planejamento de processos:

- Aços Rápidos (High Speed Steel, HSS)

F. W. Taylor iniciou os seus trabalhos utilizando ferramentas de aço carbono comum [Taylor 66], temperadas, com baixo rendimento devido às características desse material não o destinarem ao corte de metais. Desde o começo do século $X X$, no entanto, o aço rápido foi progressivamente tomando o lugar de ferramentas menos nobres e definindo a usinagem de alto rendimento. Aços Rápidos são atualmente uma classe de materiais de corte usados pela indústria e caracterizados por possuírem elementos de liga (em geral, W, Mo, Co, V, entre outros) que melhoram as qualidades do aço carbono conferindo-lhe condições para a usinagem de metais. Os HSS aliam alto nível de resistência ao desgaste com grande capacidade de absorção de choques (tenacidade), inclusive superior às do metal duro.

Pode-se classificar os aços rápidos para ferramentas como HSS ao molibdênio (AISI tipo M) e HSS ao tungstênio (AISI tipo T), os primeiros de aplicação geral para fresas, brocas, machos e ferramentas de torneamento, enquanto os segundos, devido ao seu alto custo, para ferramentas mais específicas. Os aços rápidos possuem boa tenacidade embora não permitam o trabalho com velocidades de corte e temperaturas elevadas devido à correspondente perda de dureza. Alguns recobrimentos tais como o PVD (Physical 
Vapor Deposition) e o CVD (Chemical Vapor Deposition) podem ser aplicados aos HSS diminuindo o coeficiente de atrito e aumentando a resistência ao desgaste. Outra tendência da indústria atualmente tem sido o desenvolvimento e a utilização do HSS sinterizado, o qual tem aumentado a confiabilidade deste material e o seu desempenho principalmente no que se refere à resistência ao desgaste e às altas temperaturas [Chandrasekaran 88]. Este último autor define confiabilidade de uma ferramenta como uma propriedade dependente do material da mesma e do processo de usinagem em que é aplicada, caracterizando-a pela estabilidade das condições do seu desgaste durante a sua vida.

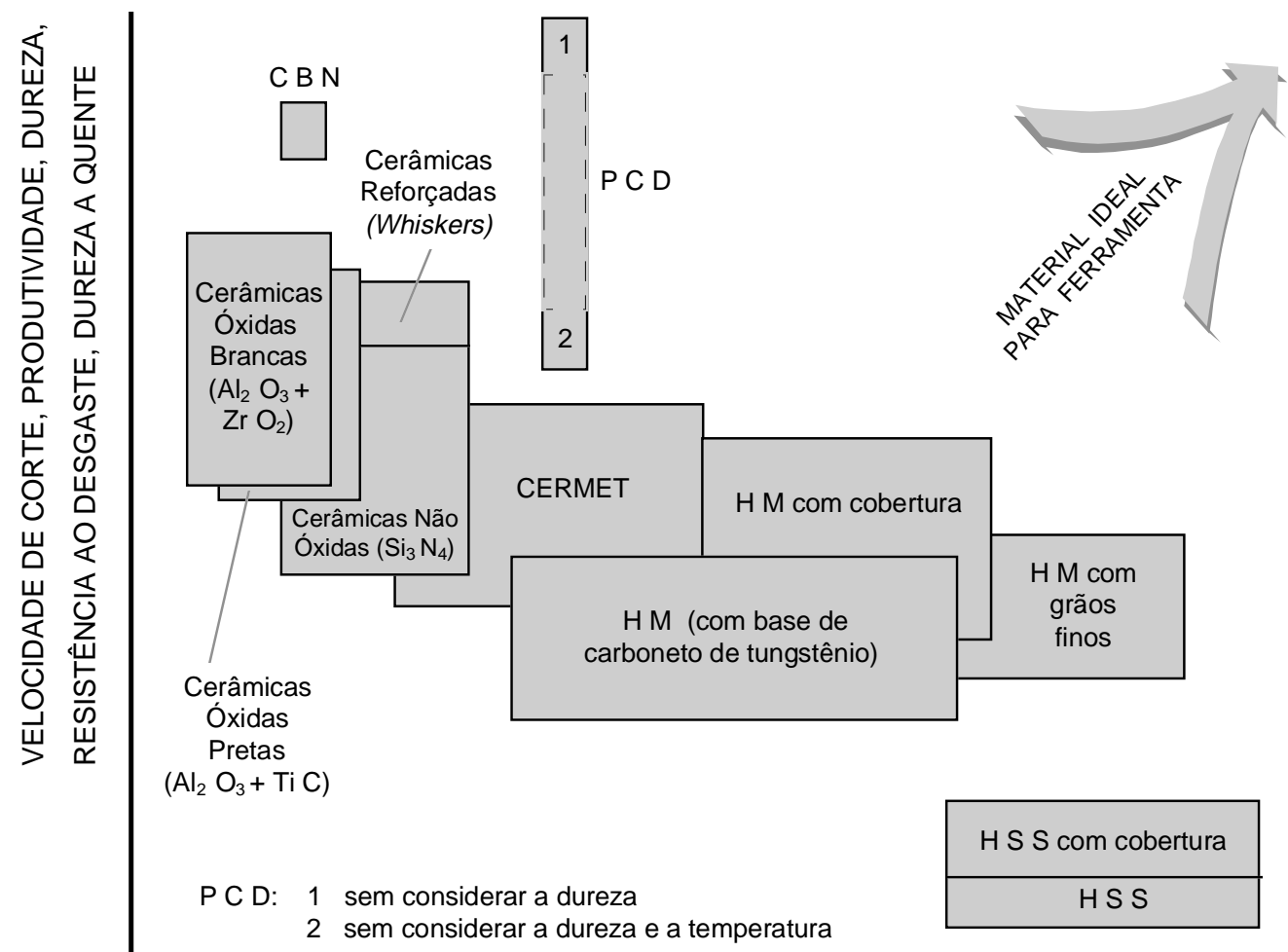

AVANÇO, CONFIABILIDADE (conforme [Chandrasekaran 88]) TENACIDADE, RESISTÊNCIA À FLEXÃO

figura 2.11 Diferentes Materiais para Ferramentas (esquemático), segundo [Reiter 89] e similar em [Kunz 94], [Stricker 90] e [Chandrasekaran 88]

Deve-se lembrar, ainda, a extensa utilização do HSS na fabricação de ferramentas especiais que exijam, para isso, usinagens complexas visando obter formas complexas o que, muitas vezes, só é possível num material como o aço. 


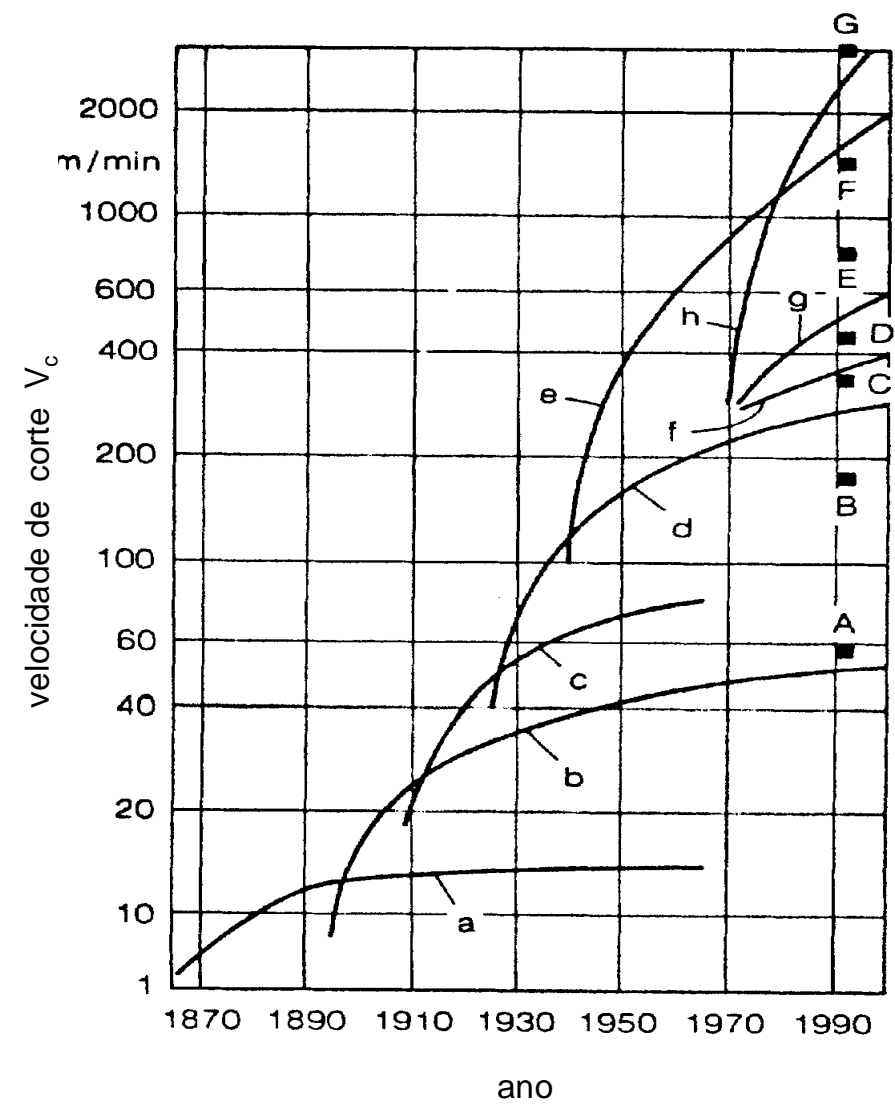

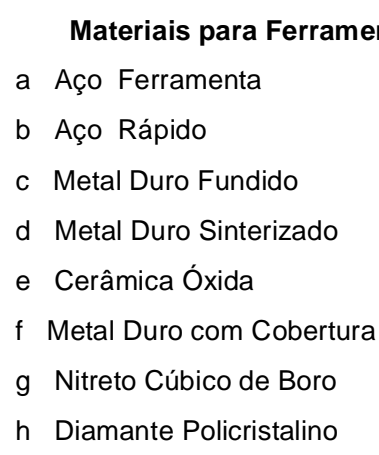

Alguns Exemplos Atuais de Aplicação:

A Furação e Rebaixamento de uma liga Alumínio-Silício

B Torneamento de Aço com Metal Duro não Recoberto

C Torneamento Curvilíneo de Aço com Metal Duro Recoberto

D Torneamento de um Eixo de Aço com CERMET

E Torneamento de um Disco de Freio em Ferro Fundido Cinzento

F Torneamento de uma Coroa de Aço

G Fresamento com Diamante

Policristalino de uma liga Alumínio-Silício

figura 2.12 Desenvolvimento das Velocidades de Corte, segundo [Johannsen 92]

- Metal Duro (Hard Metal, HM)

Metal Duro é a denominação usada para indicar o produto resultante do aquecimento em alta temperatura de compactados da mistura de pós metálicos nos quais predominam o Carboneto de Tungstênio. Começou sendo produzido pela Krupp, na Alemanha, em 1927 e com a marca Widia (Wie Diamant, como diamante). Com a adição de carbonetos duplos de Tungstênio e Tântalo, e do Carboneto de Titânio alguns anos depois, foi possível utilizar-se o HM não apenas para a usinagem do Alumínio e do ferro fundido mas também do aço. Devido à sua característica de fabricação através da metalurgia do pó e de desenvolvimentos contínuos, encontrou-se grande aplicação do HM através da fixação do inserto soldado ao porta ferramenta e, após, através de insertos intercambiáveis [Marcondes 90].

Durante a década de 60 foi desenvolvido o processo de recobrimento das pastilhas de metal duro, atingindo-se características ainda melhores para a usinagem. Iniciando pela cobertura de Carboneto de Titânio, os recobrimentos e os próprios substratos evoluíram e se apresentam atualmente de forma simples ou múltipla, com camadas de materiais variados como Carbonitreto de Titânio (TiCN), 
Carboneto e Nitreto de Titânio, de Háfnio e de Zircônia (TiC, TiN, HFC, ZrC) e também camadas de óxidos de Alumínio e Zircônia. As pastilhas revestidas possuem elevada resistência à craterização e ao desgaste frontal, bem como maior resistência à deformação plástica. No entanto as classes de metal duro convencionais (sem recobrimento) ainda continuam importantes devido, por exemplo, à sensibilidade do metal duro revestido ao corte interrompido [Marcondes 90].

Em função das diferentes aplicações do metal duro e por correlação do tipo de material que o compõe, a ISO recomenda o agrupamento do HM em três grandes grupos [Kunz 94]:

- grupo P: compreendendo as classes empregadas na usinagem de metais e ligas ferrosas, com cavacos longos e dúteis (cavacos contínuos);

- grupo M: compreendendo as classes empregadas na usinagem de metais e ligas ferrosas de cavacos tanto longos como curtos, muitas vezes de difícil usinabilidade, como lembra [Marcondes 90];

- grupo K: compreendendo as classes que se destinam à usinagem de metais e ligas ferrosas com cavacos curtos (cavaco de ruptura) e materiais metálicos.

Esses campos de aplicação são graduados segundo as exigências de usinagem e as condições mais ou menos favoráveis ao corte. Assim têm-se os graus: P 01, P 10, P20, P30, P40, P 50 / M 10, M 20, M 30, M 40 / K 01, K 05, K $10, \mathrm{~K} 20, \mathrm{~K} 30$ e K 40.

Quanto menor o valor da graduação, mais dura e resistente ao desgaste será a classe e, por este motivo, mais indicada para usinagens em condições favoráveis. Quanto maior o valor, a classe será mais tenaz e resistente a choques mecânicos e elevadas pressões de corte, sendo recomendada para usinagens em condições desfavoráveis.

As classes de HM classificam o compromisso entre a tenacidade e a dureza/resistência ao desgaste. Assim a escolha da classe de metal duro dependerá dos fatores que solicitarão a ferramenta nesses aspectos, fatores estes intimamente relacionados com o tipo de material a ser usinado e com o tipo de cavaco que se forma durante a usinagem. Os cavacos contínuos, devido ao fato de se formarem em velocidades de corte maiores (e, portanto, a temperaturas de corte maiores) além de terem um contato mais longo com a superfície de saída da 
ferramenta, podem originar uma soldagem e um desgaste maior nesta superfície, bem maior que no caso dos cavacos de ruptura [Ferraresi 85].

Assim, além do cavaco e do material a ser usinado, os fatores que influenciam na seleção do metal duro extraídos, em geral, da prática são:

- tipo de operação de usinagem: por exemplo, cortes com grandes avanços e cortes interrompidos (num fresamento, por exemplo) introduzem grandes tensões no inserto de HM exigindo-se o emprego de classes com maior tenacidade, com maior teor de Cobalto (dever-se-ia empregar, dentro de uma mesma classe, os graus de valor maior: melhor um P 30 que um P 25, por exemplo, sem considerar outros influenciadores);

- velocidade de corte: com o seu aumento, aumenta a temperatura na aresta de corte, exigindo uma classe de maior resistência ao calor, com menos Cobalto;

- condições da máquina-ferramenta: quanto menos rígidas, menos potentes e com maior tempo de utilização, menor a confiabilidade na utilização do metal duro devido à relativa fragilidade desse material. Recomenda-se então o uso de classes com maior tenacidade, com maior teor de Cobalto, à medida que a máquina se mostre menos rígida;

- fixação da pastilha: o diferencial aqui se faz principalmente entre as pastilhas soldadas em porta-pastilhas e as fixadas de forma mecânica. Nas soldadas podem surgir tensões durante o resfriamento da soldagem o que implica na escolha obrigatória de HM mais tenazes para essa operação. Com a fixação mecânica pode-se empregar classes de metal duro mais duras e de maior resistência ao desgaste [Ferraresi 85];

- tamanho do grão do HM: a presença de uma quantidade elevada de uma granulação mais fina do metal duro tem um efeito no sentido de aumentar a tenacidade da ferramenta, aumentando, igualmente, a resistência ao desgaste e à formação de cratera [Ferraresi 85, Reiter 89].

- CerMet (CER âmica + MET al, [Kunz 94])

É um material obtido através da metalurgia do pó em cuja composição química predominam os materiais cerâmicos Carboneto de Titânio (TiC) e Nitreto de Titânio (TiN), sendo o aglomerante uma matriz metálica, em geral com níquel. Outros metais são adicionados para melhorar as suas características físicas, tais como o Molibdênio, o Tungstênio, o Tântalo, o Nióbio, o Cobalto, o Alumínio, etc.. 
Com dureza em geral superior à do HM, principalmente em temperaturas elevadas, o Cermet apresenta excelente resistência à formação de crateras e ao desgaste frontal em operações de torneamento, embora a sua tenacidade seja muito baixa o que faz com que haja uma tendência na sua utilização com máquinas operatrizes isentas de vibrações, com avanços e profundidades de corte de médios para baixos. Por esses motivos a sua recomendação de uso é para o torneamento, fresamento ou mandrilamento em situações de acabamento e desbastes leves em aços e ferros fundidos maleáveis nodular, nos quais se consegue atingir velocidades de corte superiores a $500 \mathrm{~m} / \mathrm{min}$ [Kunz 94].

\section{- Cerâmicas de Corte}

Estes materiais surgiram visando atender a busca pelo limite das máquinasferramentas CNC que se caracterizam cada vez mais por elevada rigidez, altas velocidades de corte e possibilidade de troca rápida de ferramentas. Nessas condições o HM torna-se, muitas vezes, um obstáculo e as cerâmicas de corte foram desenvolvidas visando um novo patamar na evolução das ferramentas.

As pastilhas intercambiáveis de cerâmica são fornecidas conforme os formatos padrão ISO (vide geometria das ferramentas, adiante) e as ferramentas de fixação mecânica das pastilhas são iguais as que utilizam pastilhas de HM, com fixação através de grampo na superfície de saída do cavaco, ou pelo furo central da pastilha, com alavanca. No entanto, para compensar a tenacidade menor das cerâmicas em relação ao HM, em geral as pastilhas têm maior espessura e são predominantemente com ângulos de saída negativos. Para reforçar as arestas de corte é comum ter as pastilhas com uma fase negativa de $0,25 \times 20^{\circ}$.

Diferentemente dos materiais cerâmicos da década de 60 , os novos materiais possuem características melhores, com maior tenacidade e melhor confiabilidade. Da mesma maneira as cerâmicas possibilitaram um grande aumento de produtividade, permitindo a usinagem de peças endurecidas (temperadas, por exemplo), com dureza entre 65 e $35 \mathrm{Rc}$ e velocidade de corte entre 50 e 350 $\mathrm{m} / \mathrm{min}$ [Bordui 88]. Esse fato implica, inclusive, em possíveis mudanças no sequenciamento de processos de usinagem e de tratamento térmico.

Dividem-se em dois grupos principais:

- Cerâmicas Óxidas: o constituinte principal é o óxido de alumínio $\left(\mathrm{Al}_{2} \mathrm{O}_{3}\right)$, com baixa tenacidade. É classificada conforme a sua composição em: 
- cerâmicas brancas: compostas de óxido de alumínio $\left(\mathrm{Al}_{2} \mathrm{O}_{3}\right)$ e óxido de zircônio $\left(\mathrm{ZrO}_{2}\right)$, sendo as menos nobres sob o ponto de vista da tenacidade. Uma aplicação típica é no torneamento em desbaste de ferro fundido, sem incrustrações de areia e sem refrigeração;

- cerâmicas pretas: compostas de óxido de alumínio $\left(\mathrm{Al}_{2} \mathrm{O}_{3}\right)$ e carboneto de titânio (TiC), de maior tenacidade que as cerâmicas brancas. Aplica-se no torneamento em acabamento de ferro fundido e no desbaste de aços;

- cerâmicas reforçadas: compostas de uma matriz de $\mathrm{Al}_{2} \mathrm{O}_{3}$ reforçada por micro cristais de formato acicular de carboneto de silício (Whiskers de $\mathrm{SiC}$ ), conseguem manter uma elevada dureza com alta tenacidade, superior às anteriores. Aplica-se ao torneamento com corte intermitente de aço tratado, ferro fundido coquilhado e acabamento de aços.

- Cerâmicas Não Óxidas: em geral são mais tenazes e resistentes ao calor e à abrasão do que as cerâmicas do primeiro grupo, com alta dureza e boa resistência mecânica. Dividem-se em:

- cerâmicas de nitreto de silício $\left(\mathrm{Si}_{3} \mathrm{~N}_{4}\right)$ : conhece-se aplicações de torneamento em desbaste de ferro fundido cinzento e maleável, e de aços de alta liga;

- cerâmicas de oxinitreto de alumínio e silício (SiAION): aplica-se no torneamento de materiais resistentes ao calor e de ferro fundido, mesmo com incrustrações de areia.

- Materiais Ultra Duros Policristalinos (Polycrystalline Cubic Diamond, PCD; Cubic Boron Nitride, $C B N$ )

Nesta categoria estão os materiais sintéticos mais duros conhecidos. Em primeiro lugar o diamante e, em seguida, o nitreto cúbico de boro. Estes materiais, em geral, são fornecidos no mercado em plaquetas de fomato simples (retangulares, quadradas, circulares e triangulares), com espessuras que raramente ultrapassam $4 \mathrm{~mm}$ (em geral de 1 a $3 \mathrm{~mm}$ ), sendo estas plaquetas soldadas quimicamente num apoio de HM ou montada na ponta de insertos intercambiáveis de HM.

Os diamantes apresentam dureza de algumas centenas de vezes maior que o HM, com alta capacidade de dissipação de calor. Em testes de usinagem 
comprovou-se que as arestas de corte do diamante sintético são muito mais resistentes que as do diamante natural, o que faz aumentar a vida da ferramenta bem como a produtividade das máquinas, valendo o alto custo da ferramenta [Sinterconsult 94].

Os insertos de PCD, no entanto, não são recomendados para a usinagem em metais reativos com o carbono, incluindo-se a maior parte das ligas ferrosas. Segundo [Stricker 90], o PCD é, depois do HM, o melhor material para ferramenta na usinagem do alumínio, apresentando grandes vantagens econômicas em alguns casos. Recomenda-se também o PCD para torneamento, fresamento, furação, chanframento e sangramento de metais não ferrosos e suas ligas. Por exemplo: alumínio e alumínio-silício $\left(\mathrm{V}_{\mathrm{c}}\right.$ de 500 a $1500 \mathrm{~m} / \mathrm{min}$, avanço de 0,02 a 0,7 $\mathrm{mm} / \mathrm{rot}$, profundidade de corte máx. de 1,5 mm), cobre e suas ligas ( $\mathrm{V}_{\mathrm{c}}$ de $200 \mathrm{a}$ $700 \mathrm{~m} / \mathrm{min}$, avanço de 0,025 a 0,2 mm/rot, profundidade de corte máx. de 1,0 mm), materiais não metálicos abrasivos (plásticos, composites ou materiais compostos com fibra de vidro ou carbono, resinas epóxi ou poliéster $\left(V_{c}\right.$ de 300 a $2000 \mathrm{~m} / \mathrm{min}$, avanço de 0,05 a 0,4 mm/rot, profundidade de corte máx. de 1,25 mm).

Quase sempre as ferramentas de PCD são de ângulo positivo (vide geometria da ferramenta, adiante), pois são usadas para trabalhar materiais macios porém abrasivos.

O CBN foi desenvolvido através da metalurgia do pó e apresenta-se como o PCD porém voltado à usinagem de ligas ferrosas, campo em que o diamante apresentou problemas. Aplica-se na usinagem em geral de aços tratados com durezas superiores a $50 \mathrm{Rc}$, ferro fundido coquilhado e ligas de alto Níquel ou Cobalto resistente a temperaturas.

Tanto o PCD como o CBN são, muitas vezes, mais conhecidos no mercado pelos seus nomes comerciais do que pela sua denominação técnica, tal como o caso do CBN da empresa GE, de nome Borazon BZN.

Com essa suscinta descrição dos materiais e coberturas existentes para ferramentas, observa-se que a seleção do mesmo está vinculada a vários fatores relacionados ao binômio tenacidade-dureza do material, entre eles o tipo do processo de usinagem, o material a ser usinado e a estabilidade do conjunto máquina-peçaferramenta. A colocação de objetivos de produtividade, por exemplo, pode impor faixas de velocidade de corte e de avanço que acabem por limitar o material devido a outro critério como o da máxima temperatura de trabalho para que as características 
de resistência não se deteriorem. Assim observa-se que o problema da escolha otimizada do material dependerá de muitos critérios que devem ser obedecidos concomitantemente.

- A ferramenta: sua geometria e posição relativa à peça

O tipo de processo de usinagem é o principal fator determinante da geometria do conjunto ferramenta-peça. A ele pode-se adicionar o tipo do material da ferramenta, as características da máquina-ferramenta e a forma da fixação da peça.

Para a maior parte dos processos de usinagem convencionais certas características geométricas padrões das ferramentas podem existir, como é o caso da existência ou não de quebra-cavaco e as diferentes geometrias a ele associadas, a posição da superfíce de folga, a posição da superfície de saída, o raio da ponta de corte, a largura da aresta de corte, a existência ou não de chanframento da ponta, o diâmetro da ferramenta (no caso de uma broca ou uma fresa, por exemplo), o número de arestas de corte (idem), etc.. Outras características relativas à geometria existem de forma a relacionar a posição da peça com a posição da ferramenta e o movimento de corte, tais como o ângulo de posição, o ângulo de folga e o ângulo de saída da ferramenta.

Com o advento das pastilhas de HM, em particular dos insertos intercambiáveis desse material, surgiram normalizações que visavam simplificar o planejamento de processo e a própria fabricação de HM, adequando um conjunto limitado de geometrias às características do processo de usinagem pretendido. Assim padronizou-se a forma do inserto, o ângulo de folga, o tipo de quebra-cavaco, as suas tolerâncias dimensionais, a sua dimensão e espessura, o raio da ponta de corte, a direção do avanço, etc. conforme o processo de usinagem. A normalização básica possui, ainda, códigos adicionais em aberto para serem utilizados pelos fabricantes de HM, específicos a novos desenvolvimentos, melhorias e características por eles criadas. Da mesma forma que para o HM, há normalizações semelhantes que se aplicam a insertos de outros materiais como o CERMET e as cerâmicas [Marcondes 90].

Da mesma maneira que existem normalizações para insertos, deve-se lembrar que há normas para os porta-ferramentas, sejam estas de caráter geral como específicas de fabricantes. Os porta-ferramentas são os responsáveis pela fixação das pastilhas nas máquinas e pelo seu posicionamento em relação à peça. Nessas 
normas especificam-se o sistema de fixação, o tipo de suporte e as suas dimensões, entre outros. Pode-se indicar a existência de normalizações de hastes para torneamento, mandris para brocas, de cabeçotes de fresar, etc. [Marcondes 90].

Essas propriedades geométricas das ferramentas possuem muitas fontes de referência tais como a norma brasileira NB-205 (Geometria da Cunha de Corte, baseada na DIN 6581), a ISO 1832 (Denominação de Insertos Intercambiáveis, [ISO 91]), e as americanas ASA B 5.22 e B 5.36 [Ferraresi 85]. Os fabricantes também possuem seus próprios códigos embora na sua maioria eles estejam baseados nas normalizações gerais.

Em geral, muitos sistemas CAPP têm sido beneficiados pela normalização de classes de materiais e geometrias, como se observa nas descrições de sistemas CAPP em [Zhang 94]. [Yeo 88], por exemplo, procura cuidar especificamente de um sistema de apoio ao planejamento de processos no qual grande parte das decisões tomadas dizem respeito à seleção de insertos e porta-ferramentas além das condições de corte. A metodologia adotada por esse autor é a de sistemas baseados em conhecimento (vide item 2.4.3.2), cuidando inicialmente de uma forma de classificação de pastilhas e suportes disponíveis. Com isso e através do conhecimento especialista que vinculará critérios e experiências com materiais, geometrias e suportes disponíveis às diversas condições do processo de torneamento, o sistema possibilita a seleção de ferramentas, fluido de corte e parâmetros de usinagem. [Lye 92], junto a Yeo, por sua vez e visando a simplificação e o baixo custo de seu sistema CAD/CAPP/CAM, utiliza o BD de um fabricante de ferramentas, o COROPLAN (vide [Sandvik 91]). Com isso a especificação da ferramenta e dos parâmetros de corte, no entanto, ficam totalmente sujeitos às especificações desse fabricante e essa solução, como se observará em 2.4.2.5, pode não corresponder a todos os critérios desejados no sistema CAPP.

[Gopalakrishnan 89], também através de um sistema especialista, divide a seleção de ferramentas para usinagem na seleção do seu material e dos ângulos entre ela e a peça. Para o material os critérios são experimentais e abrangem desde os aços rápidos até os PCD, seguindo muitas das orientações já fornecidas anteriormente neste texto. Para a posição relativa peça-ferramenta, critérios teóricos como a influência de ângulos da ferramenta na temperatura e na resistência da mesma são aliados também a experimentações que devem ser feitas para confirmar os resultados obtidos. Assim regras como a manutenção de um bom ângulo de cunha (para aumento da resistência da ferramenta) com algum ângulo de folga (para reduzir 
o atrito na superfície de folga) impõem um compromisso destes ângulos com o valor da velocidade de corte, a qual deverá ser elevada para esses casos (isso pode implicar em ângulos de saída negativos).

Dessa forma, a questão da escolha da ferramenta tem se mostrado vinculada às informações de geometria adotadas pelos fabricantes e por normas industriais. Utilizando esse universo de possibilidades os sistemas CAPP desenvolvidos procuram incorporar conhecimento especialista sobre as restrições possíveis na maneira como se opera a usinagem e como se comporta a ferramenta quanto à sua tenacidade, dureza e vida. [Singh 92], seguindo essa tendência e diante das incertezas e das características comportamentais inerentes aos processos de usinagem, justifica em sua abordagem a necessidade de uma solução muito mais qualitativa na seleção das ferramentas e de seus parâmetros. Propõe ele, também, a utilização de um sistema especialista através da observação de condições as quais, se satisfeitas, implicam em ações que ocorrem durante o processo. Utiliza como informações tecnológicas uma BD de usinabilidade de materiais padrão (o Machining Data Handbook, da Metcut Research Associates, E.U.A.) e, dada uma determinada situação de usinagem que esteja catalogada nessa base de forma ótima, permite ensaios com diferentes valores de velocidade e avanço, fornecendo os seus efeitos em relação à seleção ótima. O sistema indica, por exemplo, a possibilidade de um aumento rápido da temperatura na superfície de saída que provocará craterização da ferramenta ou a mudança na forma de cavaco que poderá deformar a aresta de corte mais rapidamente.

\subsubsection{A escolha da forma de fixação da peça}

Não é muito frequente encontrar-se na literatura referências a sistemas de planejamento auxiliados pelo computador voltados para a escolha da forma de fixação das peças na sua usinagem. De acordo com [Mason 95], atualmente os técnicos em sistemas de fixação em países como os Estados Unidos utilizam muito pouco os recursos de modelamento CAD 3-D e sólido nesta aplicação. Apesar do relativo retardo na elaboração e na utilização de técnicas mais avançadas nessa área pela indústria, [Chang 92] declara que o interesse na pesquisa e desenvolvimento de sistemas de planejamento de meios de fixação por meio de computador ou CAFP (Computer Assisted Fixture Planning) tem crescido recentemente. 
Ainda no entender desse último autor, um dispositivo de fixação num processo de usinagem é um dispositivo único ou uma combinação de componentes de fixação para localizar e prender uma peça a ser fabricada. [Caillaud 94], mais analiticamente, define que um sistema de fixação possui três funções principais, ou seja: posicionar, manter a posição e sustentar a peça. Esta última função adquire importância, por exemplo, quando se possuem peças de grandes dimensões nas quais os elementos de localização não são suficientes para garantir a integridade geométrica da peça.

O planejamento tradicional de fixações é, em geral, baseado na experiência de engenheiros de manufatura ou de projetistas de ferramentas. Quando uma fixação não é especificada no plano de processos, ela acaba sendo escolhida, muitas vezes, pelo preparador de máquina, o qual seleciona os componentes necessários e determina a sua localização na máquina-ferramenta ou em sua mesa de trabalho.

Para [Chang 92] não há ainda uma solução sistemática disponível para o planejamento e projeto de fixações. No entanto, a experiência dos processistas indica que o plano de processo não pode ser finalizado até que se tenha um esquema de fixação determinado e que obedeça um meio-termo entre satisfação técnica quanto à qualidade e satisfação econômica. Esse meio-termo, porém, não é a única restrição. Acrescentam-se a ele: a rigidez suficiente da fixação, sua homogeneidade, a saída satisfatória dos cavacos e do refrigerante, e o respeito ao espaço disponível [Caillaud 94]. A rigidez da fixação deve evitar a sua deformação bem como as vibrações provocadas pelos esforços de corte. Uma boa saída dos cavacos e do óleo refrigerante garantirá a limpeza das regiões de posicionamento da peça na fixação. Seus elementos serão colocados em regiões livres para evitar interferências ou colisões com as ferramentas e outras partes da máquina. A homogeneidade da fixação contribui, por fim, para reduzir os atrasos e os custos de fabricação pois, com isso, pode-se ter um estoque menor de componentes na fábrica.

Dentre os vários fatores que condicionam um planejamento de fixações podese citar a geometria final da peça (dimensões, tolerâncias, acabamento superficial), geometria da peça bruta (definição do estado das superfícies, pré-usinadas ou não, e suas tolerâncias), características das operações de usinagem e das máquinasferramentas, condições para manuseio da peça, ergonomia e fatores de segurança, ferramentas selecionadas, movimentos da máquina e da ferramenta, tipos disponíveis de componentes de fixação, tipo da produção, etc. [Chang 92, Hargrove 94]. Em particular o tipo de produção (vide item 2.2) implicará em diferentes 
alternativas ou classes características de fixação conforme ilustrado através da figura 2.13 [Hargrove 94].

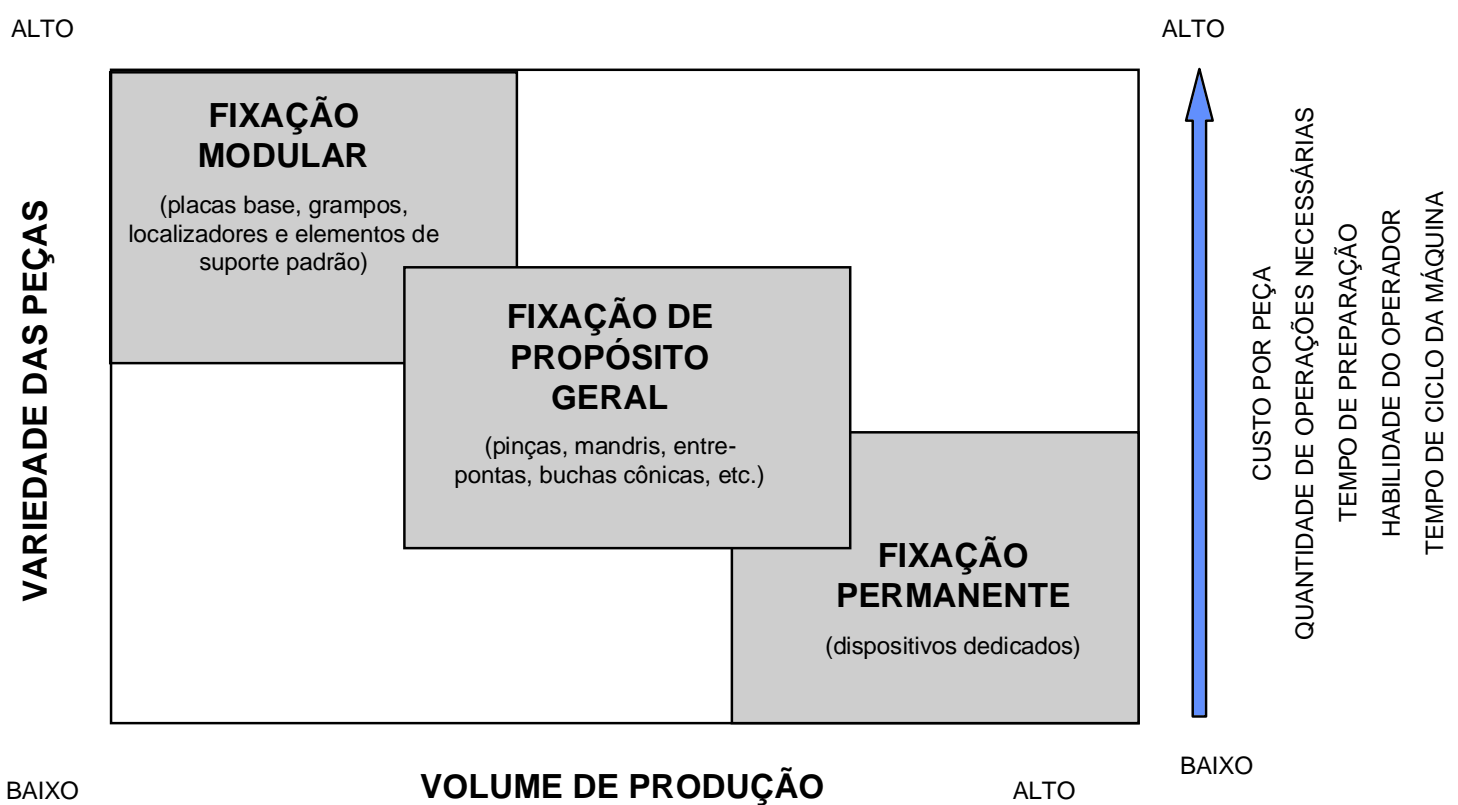

figura 2.13 Diferentes alternativas de Sistemas de Fixação e suas Características, segundo [Hargrove 94]

[Hargrove 94] explicita as ferramentas e os métodos empregados nos sistemas CAFP conhecidos como: análise de tolerâncias, sistemas especialistas, modelamento CAD 3-D e sólido, análise cinemática, FEA, features, TG, entre outros. Como se observa tratam-se de ferramentas de caráter tão distinto que a sua compatibilização para a resolução do problema integralmente é complexa. Daí os métodos de trabalho dos sistemas serem apenas, em sua maioria, interativos e semiautomáticos. Uma outra crítica encontrada em [Chang 92] sobre os sistemas CAFP é a de que, aliada à falta de estudo pela indústria dessa questão, há uma separação entre a pesquisa de sistemas CAPP e a de sistemas CAFP, fazendo com que as soluções ao problema sejam isoladas e não integradas à visão do ciclo de projeto e fabricação de produtos. As considerações de projeto que esses sistemas incorporam são, em ordem decrescente de casos encontrados: a estabilidade da fixação, a área usinada, a precisão de posição da peça e, por fim, o custo [Hargrove 94].

Observa-se atualmente uma grande tendência na utilização de sistemas especialistas (vide item 2.4.3.2) para a construção de sistemas CAFP. Apesar disso prevê-se que os desenvolvimentos devem procurar integrar mais a geometria da peça e do espaço de trabalho de usinagem com as características dos componentes da 
fixação através, por exemplo, de features e do emprego de análises cinemáticas e das deflexões que as peças e o dispositivo venham eventualmente a sofrer com a consequente influência nas tolerâncias finais da peça usinada. Além dessa tendência, autores como [Chang 92, Hargrove 94] apontam ainda a necessidade de integrar cada vez mais as etapas de planejamento e de projeto dos dispositivos de fixação. Entenda aqui o planejamento de fixações como a definição do tipo e variedade de dispositivos dentro do universo de possibilidades, ou seja, dos dispositivos existentes ou a construir, das máquinas existentes, do tipo de produção, da sua forma geral de preparação e montagem. O projeto, por sua vez, definirá detalhes do dispositivo e seu impacto sobre a qualidade da peça acabada. Isso significa trazer o CAFP mais próximo do CAPP e considerá-lo, verdadeiramente, como uma etapa do planejamento que possui um detalhamento maior ao ter o projeto do meio de fixação incorporado.

\subsubsection{Restrições Tecnológicas na Seleção das Condições de Usinagem}

Antes de discutir a questão da otimização, deve-se analisar quais serão as principais restrições a serem encontradas para as condições de usinagem conforme várias fontes.

Em [Boehs 86], por exemplo, é lembrado que, apesar de ser a velocidade de corte de importância fundamental no tempo de usinagem e na vida da ferramenta, outros parâmetros como o avanço e a profundidade de corte influenciam diretamente a força e a potência de corte, exigindo maior rigidez do sistema máquina-ferramentadispositivo-peça (MFDP) para evitar o aparecimento de trepidações nas peças usinadas.

Com relação ao volume máximo de cavaco removido por unidade de tempo, este é limitado pela potência da máquina. Quanto à força de corte, segundo [Zhou 92], a velocidade de corte não lhe é sensível numa faixa de trabalho normal. Então em otimizações de velocidade de corte não se tornaria necessária sua consideração. [Couers 90], ao analisar a teoria do diagrama Velocidade de Corte - Avanço ( $\left.v_{c}-a\right)$ para o torneamento, confirma isso apresentando um modelo no qual a baixa influência da $V_{c}$ pode ser avaliada. No entanto mostra que em modelos de usinagem mais elaborados essa influência é considerada embora, mesmo assim, seja baixa. As 
expressões para a força de corte e para a potência num diagrama $\mathrm{v}_{\mathrm{c}}$ - a podem ser encontradas em [Ferraresi 85, Couers 90] (particularmente para o processo de torneamento) e [Zhou 92], entre outros autores.

Outra restrição é o acabamento superficial da peça. Embora não haja um modelo simples que represente fielmente a geometria do corte feita pela ponta da ferramenta, adota-se muitas vezes o modelo ideal que se extrai dessa geometria no qual são considerados o avanço e o raio da ponta da ferramenta. A expressão clássica para a rugosidade teórica $\mathbf{R}_{\mathbf{t}}$ segundo [Kunz 94] e que é facilmente dedutível matematicamente pela análise da geometria de uma ferramenta de raio de ponta $\boldsymbol{r}$ avançando contra uma peça com avanço $\mathbf{a}$, pode assim ser descrita:

$$
R_{t}=r-\sqrt{r^{2}-\frac{a^{2}}{4}}
$$

onde $\mathbf{r}=$ raio da ponta da ferramenta $(\mathrm{mm})$;

$\mathbf{R}_{\mathbf{t}}=$ rugosidade teórica $(\mathrm{mm})$;

$\mathbf{a}=\operatorname{avanço~(mm/rotação).~}$

A rugosidade superficial e o problema do acabamento de peças usinadas são discutidos em [Narang 93] pela proposição de modelos alternativos ao da equação (1) para a obtenção de condições de corte ideais. Para ter valores mais fiéis à realidade observada na prática esse autor, baseando-se em diversos outros autores, adota a existência restritiva de uma região de corte estável dentro da qual se evita vibração, adesão e formação de aresta postiça de corte. São relações experimentais entre velocidade de corte, avanço e profundidade de corte que devem ser seguidas. Além disso cabe lembrar que o acabamento superficial está intimamente ligado ao número de passes com que se fabrica a peça e as condições de cada um desses passes principalmente com relação ao avanço e à profundidade de corte.

Quanto à aresta postiça de corte, sabe-se que a partir de certo valor de velocidade desaparece o seu efeito [Ferraresi 85], comum nas ferramentas trabalhando com velocidades de corte baixas e que deteriora 0 acabamento superficial da peça. Com isso a rugosidade passa a não ter dependência da velocidade de corte nessa condição (vide figura 2.09).

A velocidade de corte e o avanço utilizáveis no processo são, também, dependentes das correspondentes faixas de variação permitidas pela máquina. 
Essas e outras restrições foram tabeladas no trabalho de [Boehs 86] (vide tabela 2.2).

Uma restrição fundamental, ou talvez mais propriamente denominada condicionante do processo de corte, é o modelamento da vida da ferramenta. O seu conhecimento e discussão serão de grande importância na obtenção de modelos de custo e produtividade com os quais se pretenderá a otimização das condições operacionais do processo de usinagem.

- Modelamento da Vida da Ferramenta

Uma das mais importantes relações no processo de otimização do processo de usinagem é aquela entre a vida da ferramenta e os parâmetros ou condições operacionais do processo. O desgaste de uma ferramenta é um fenômeno complexo, abrangendo um conjunto de vários outros fenômenos como os de abrasão, difusão, deformação, fadiga e atrito [Singh 92, Ferraresi 85]. A forma predominante de desgaste depende do material da ferramenta, do material da peça e das condições de usinagem. Atualmente os aços HSS e os insertos de HM, recobertos ou não, são os materiais padrão e de uso geral na indústria. Para eles, em condições de corte usuais, as principais causas de desgaste são a difusão, a deformação e a abrasão [Zhou 92]. Quando o desgaste das ferramentas é dominado por esses mecanismos, é válida a equação de vida da ferramenta de Taylor:

$$
v_{c} \cdot T^{n}=C
$$

onde $\quad \mathbf{v}_{\mathbf{c}}=$ velocidade de corte $(\mathrm{m} / \mathrm{min})$;

$\mathbf{T}=$ vida da ferramenta $(\mathrm{min})$;

$\mathbf{n}=\mathbf{1} / \mathbf{x}$, sendo $\mathbf{x}$ o coeficiente angular da reta $T-v_{c}$ num diagrama dilogarítmico;

$\mathbf{C}=$ constante, a qual poderia ser interpretada como a velocidade de corte para a qual a ferramenta teria um tempo de vida de 1 minuto.

Essa equação é também descrita na literatura de outra forma semelhante: 


$$
v_{c}^{x} \cdot T=K
$$

onde $\mathbf{x}=$ é o coeficiente angular da reta $T-\mathrm{v}_{\mathrm{c}}$ num diagrama dilogarítmico;

$\mathbf{K}=\mathbf{C}^{\mathbf{X}}$, constante, a qual poderia ser interpretada como a vida da ferramenta para uma velocidade de corte de $1 \mathrm{~m} / \mathrm{min}$.

Depois das pesquisas de Taylor, diversos estudiosos propuseram vários modelos relativos à vida da ferramenta [Novaski 83, Novaski 91]. Dentre eles estão o modelo de Woxen (1932), o de Gilbert (1950, também denominado por modelo de Taylor expandido), o de Kronenberg (1954), o de Colding (1958/60), o de Hirsch (1969), entre outros. A equação de Taylor, por ser a mais simples, é a de maior praticidade pois a obtenção de suas constantes não exige tantos ensaios de usinagem quanto as demais [Novaski 83].

A equação de vida de Taylor mostrada em (2) e (3) admite avanço e profundidade de corte constantes. Ela pode, no entanto, ser estendida para incluir o avanço, a profundidade de corte ou outros fatores como a geometria da ferramenta. É a denominada equação expandida de Taylor [Coppini 87]:

$$
v_{c}^{x} \cdot a^{y} \cdot p^{z} \cdot T=K
$$

onde $\mathbf{a}=$ avanço ( $\mathrm{mm} /$ rotação);

$\mathbf{p}=$ profundidade de corte $(\mathrm{mm})$;

$\mathbf{x}, \mathbf{y}, \mathbf{z}, \mathbf{K}=$ constantes específicas ao processo em análise.

No entanto [Zhou 92] afirma ser o avanço, na prática, frequentemente restrito pela força de corte, pelo controle do cavaco e pelo acabamento superficial da peça. Estes outros fatores da equação de vida expandida possuem, segundo esse mesmo autor, um impacto menor na vida da ferramenta do que a velocidade de corte. Um avanço elevado tende a reduzir o consumo de potência por volume de material removido, sendo frequentemente usado um valor máximo submetidos ao controle da força, da trepidação/vibração, do acabamento superficial e do cavaco. A profundidade de corte possui, por sua vez, o menor impacto na vida da ferramenta 
dentro dos campos normais de aplicação porque ela não tem efeito considerável em um único comprimento da aresta de corte mas, ao se ter um aumento de profundidade, uma porção maior da aresta passa a ser utilizada.

Como os valores dos parâmetros nos modelos de vida da ferramenta variam devido a diversos fatores, é praticamente impossível documentar uma tabela de consulta considerando todas as variáveis independentes. Segundo [Zhou 92], ainda, a única forma de se obter boas estimativas para esses parâmetros é pela análise do processo em funcionamento. Ele acha discutível a compensação de ganho na introdução desses fatores (avanço e profundidade de corte) como variáveis independentes comparativamente às complicações adicionais na sua estimativa.

O procedimento de [Zhou 92] é praticamente o mesmo adotado por [Boehs 86, Girondi 88, Coppini 87]. [Boehs 86, Girondi 88] afirmam ainda que, ao contrário da velocidade de corte, a otimização de fatores como o avanço e a profundidade de corte não se faz por critérios de máximo e mínimo, a partir de uma diferenciação, mas são otimizações de extremo, respeitando as restrições já citadas. Eles adotam:

- o avanço ótimo - para a máxima produção ou para o mínimo custo é o máximo avanço;

- a profundidade de corte ótima - ainda mais do que para o avanço, são os valores máximos;

- para a rugosidade superficial mínima, no entanto, o avanço mínimo deverá ser usado.

[Coppini 87] escolhe o próprio ambiente de trabalho (o laboratório ou a indústria) onde está o sistema MFDP a ser analisado e não um ambiente de teste para posterior transferência dos resultados ao ambiente definitivo. Ele adota, também, o modelo simplificado de Taylor (equação 3), obtendo o avanço e a profundidade de corte a partir de bancos de dados genéricos e levando em consideração as restrições do sistema (geometria da ferramenta e peça, rugosidade superficial, rigidez do MFDP, etc.). Obedecidas as restrições, como [Boehs 86], os valores de avanço e profundidade de corte devem ser os máximos.

A equação de Taylor como mostrada em (2) e (3) tornou-se um modelo aceitável para a vida da ferramenta. É, na verdade, uma das formas mais simples de se obter resultados quanto à análise dos fatores que mais influenciam no processo de usinagem, seja na sua forma simplificada ou mesmo expandida. A sua forma de expressão pressupõe a assunção de condições de extremo, como expresso em 
\{Boehs 86], para a obtenção de condições ótimas, permitindo a criação de procedimentos relativamente simplificados como o descrito em [Coppini 87] para determinação dos valores de $x$ e $K$ de Taylor. Até mesmo mundialmente o padrão adotado para testes de desgastes de ferramenta foi baseado no modelo de Taylor, com a criação de normalização, como é o caso das normas ISO 3685 [ISO 93], para torneamento com ferramenta de ponta única, e ISO 8688 [ISO 89], para fresamento. Essas normas adotam a equação de Taylor no formato da equação (4) como modelo de vida da ferramenta.

Outro ponto importante a ser lembrado aqui, conforme colocado por [Coppini 87] e praticada em [Coppini 89], é a necessidade de se eliminar a variabilidade entre as determinações de parâmetros ótimos em laboratório e o praticado na indústria. [Coppini 87] aponta como causa das diferenças das constantes de Taylor entre os dois ambientes a variação do avanço e da profundidade de corte, as diferenças nas condições de montagem da máquina e na rigidez/precisão do sistema MFDP, a forma de utilização do fluido de corte, etc.. [Singh 92] reconhece a questão da variabilidade entre os manuais de usinagem, os ensaios de laboratório e as condições reais de fábrica, procurando uma abordagem de recomendação preliminar e qualitativa do processo de usinagem com seu sistema especialista para, após essa fase, o planejador fazer os seus testes de usinabilidade os quais determinarão as condições finais do processo.

Por fim, [Kunz 94] num trabalho mais voltado para a seleção de materiais de ferramentas fornece uma abordagem relativa não propriamente à variabilidade das condições mas à sua precisão no que diz respeito à determinação da ferramenta para determinada usinagem, como mostrou a experiência de seu grupo numa grande indústria automobilística alemã. A precisão, segundo ele, é muito baixa orientando-se apenas pelo catálogo do fabricante de ferramentas, mas eleva-se, correspondentemente, ao se utilizar os manuais de usinabilidade obtidos na própria empresa, os métodos de avaliação dos departamentos de pesquisa de materiais e processos de usinagem, e, por fim, fazendo-se ensaios de campo e no dia-a-dia da fábrica (figura 2.14).

[Colding 92] salienta que mesmo os setores avançados de engenharia das indústrias, ao construir uma nova instalação de manufatura, baseiam-se não em dados de corte otimizados, como se deveria supor, mas em especificações de usinagem dos fabricantes das máquinas operatrizes, de manuais ou na experiência prévia. Segundo ele essas considerações podem e, normalmente, estão longe dos 
valores considerados ótimos. Em sua abordagem são considerados, também, os valores de mínimo custo e de máxima produção.

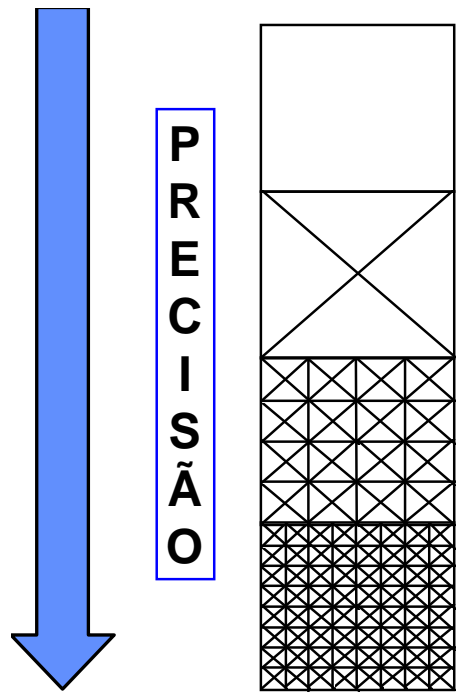

\begin{tabular}{|c|c|}
\hline I & $\begin{array}{l}\text { Catálogo do Fabricante/Catálogos } \\
\text { de Insertos Normalizados }\end{array}$ \\
\hline II & $\begin{array}{l}\text { Manuais de Usinabilidade e de } \\
\text { materiais para ferramentas obtidos } \\
\text { na própria empresa }\end{array}$ \\
\hline III & $\begin{array}{l}\text { Métodos de Avaliação dos deptos. } \\
\text { de pesquisa de materiais e } \\
\text { processos de usinagem }\end{array}$ \\
\hline IV & $\begin{array}{l}\text { Ensaios de Campo e de Fábrica } \\
\text { específicos }\end{array}$ \\
\hline
\end{tabular}

figura 2.14 Diagrama ilustrando a precisão de diferentes meios de auxílio na escolha do material e condições de trabalho para ferramentas, segundo [Kunz 94]

Estas indicações de diferentes autores mostram que, para se determinar condições de usinagem e, antes, condições da ferramenta e o tempo de sua duração, apenas obter-se-á uma solução mais precisa caso se executem testes com o sistema MFDP em que se deseja aplicar a otimização, apesar das eventuais complicações que isso acarrete.

\subsubsection{A escolha de parâmetros de processo conforme diferentes critérios de otimização}

Admitindo que tenha sido determinada para uma peça e sua forma de fabricação uma possível sequência de processos de usinagem, de máquinas, de ferramentas e de fixações, a próxima atividade implica em questionar quais condições operacionais (velocidade de corte, por exemplo) devem ser adotadas visando atingir objetivos pré-estabelecidos (como as metas financeiras, firmadas pela alta administração da empresa, ou premissas técnicas, pelo departamento de planejamento). Ou, retornando nessa sequência lógica, dada que uma determinada 
restrição (a potência da máquina, o tipo de ferramenta ou o custo elevado do processo, por exemplo) limite o tempo de ciclo de usinagem e estabeleça condições operacionais afastadas do ótimo teórico sob esse critério, o que acontecerá se houver uma alteração em alguns dos parâmetros responsáveis por essa restrição (nesse caso, no tamanho e tipo da máquina ou no material da ferramenta)? É através da análise de critérios e procedimentos de otimização para essa etapa de planejamento que se obterão os princípios que orientarão a obtenção das condições operacionais ideais.

Ao analisar o problema de otimização das condições de usinagem num ambiente com máquinas CNC, observa-se uma relevância maior desse tema devido aos custos mais elevados dessa tecnologia comparativamente a das máquinas convencionais. Nesse caso [Madl 96] lembra que quaisquer diferenças em relação à velocidade de corte ótima causam aumentos de custo significativos e que possivelmente excedem os dos processos com máquinas convencionais.

De acordo com [Zhou 92], no entanto, na prática industrial de determinação das condições operacionais de processos de usinagem observa-se um divisão de responsabilidades e uma falta de interação com o processo, o que torna mais difícil fazer boas decisões de parâmetros. As decisões de seleção de ferramentas podem ser tomadas por planejadores de processo, as condições de usinagem pelo próprio programador de CN para a peça ou pelo preparador da máquina, e o número de peças feitas antes da troca de ferramenta, em geral, é determinada pelos operadores de máquina. Além dessa partição de responsabilidades, alie-se a eventual falta de qualificação de pessoal que pode ocorrer em qualquer uma dessas três fases do planejamento e operação do processo. [Ferraresi 89] cita ter constatado fatos como esse dos quais resultou velocidades de trabalho abaixo da indicada e o emprego inadequado de ferramenta.

Os principais critérios discutidos na literatura são os econômicos pois dizem respeito ao resultado do processo de usinagem em termos de seu impacto na economia da empresa. Duas são as principais grandezas estudadas: o custo do processo e seus componentes, e os tempos de fabricação e de troca da ferramenta. Os critérios adotados utilizando essas grandezas são, comumente, a busca pelo mínimo custo, pela máxima produção e pelo máximo lucro [Ferraresi 85, Ferraresi 89].

Admitindo-se constância nas condições de avanço e de profundidade de corte para uma determinada operação, pode-se buscar a velocidade de corte de mínimo 
custo, a velocidade de corte de máxima produção e a velocidade de máximo lucro. Essas grandezas não são iguais, assim como os seus conceitos. Baseiam-se no fato de que, com o aumento da velocidade de corte, diminuem o tempo de corte, os custos relativos à máquina e ao operador. Porém diminui simultaneamente a vida da ferramenta ocasionando um aumento do tempo relativo às suas trocas e um aumento relativo à parte de custo da ferramenta [Ferraresi 89].

Assim a forma como a ferramenta se desgasta, a qual se procurou modelar em 2.4.2.5, é de importância fundamental na determinação das condições econômicas visto ser determinante de outras grandezas como a quantidade de trocas e o custo total de ferramentas consumidas.

- Ciclo e Tempos de Usinagem

Segundo [Ferraresi 85, Novaski 91], numa abordagem clássica o ciclo de usinagem de uma peça pertencente a um lote de $\mathbf{Z}$ peças é constituído por:

$$
t_{t}=t_{c}+\left[t_{s}+t_{a}+\frac{t_{p}}{Z}\right]+\left(\frac{n_{t} \cdot t_{f t}}{Z}\right)
$$

onde $\mathbf{t}_{\mathbf{t}}=$ tempo total ou de ciclo de usinagem por peça (min);

$\mathbf{t}_{\mathrm{c}}=$ tempo de corte ou de usinagem pura (min);

$\mathbf{t}_{\mathbf{s}}=$ tempos secundários (transporte, posicionamento, fixação da peça em bruto ou semi-acabada na máquina-ferramenta, acionamento da partida da máquina, inspeção da peça caso necessária, inspeção e ajustagem periódica da ferramenta, acionamento da parada e retirada da peça da máquina) (min); $\mathbf{t}_{\mathbf{a}}=$ tempos auxiliares (aproximação e afastamento da ferramenta) (min); $\mathbf{t}_{\mathbf{p}}=$ tempo de preparação da máquina para fabricação de $\mathbf{Z}$ peças do lote (min);

$\mathbf{n}_{\mathbf{t}}=$ número de trocas da ferramenta;

$\mathbf{t}_{\mathrm{ft}}=$ tempo de troca da ferramenta $(\min )$.

Como valores complementares que serão necessários posteriormente na análise e modelamento da vida da ferramenta, têm-se: 
$\mathbf{Z}_{\mathbf{t}}=$ número de peças produzidas por vida de cada aresta de corte da ferramenta;

$\mathbf{T}=\mathbf{Z}_{\mathbf{t}} \cdot \mathbf{t}_{\mathbf{c}}=$ tempo de vida da ferramenta na operação de usinagem.

O tempo de usinagem pode ser dividido, assim, em três parcelas: o tempo puro de operação da ferramenta, os tempos improdutivos da operação (colocação, fixação, preparação rateada pelo número de peças, etc.) e os tempos de troca da ferramenta.

- Custos de Usinagem

O custo total de usinagem por peça, ainda nessa abordagem clássica e na mesma situação anterior é:

$$
K_{u}=\left(S_{h}+S_{m}\right) \cdot \frac{t_{t}}{60}+K_{f t} \frac{1}{Z_{t}}+K_{u i}
$$

onde $\quad \mathbf{K}_{\mathbf{u}}=$ custo total de usinagem $(\mathrm{R} \$)$;

$\mathbf{S}_{\mathrm{h}}=$ custo ou salário do operador + encargos sociais, além de sobre-taxas rateadas (supervisão, outras áreas administrativas, etc.) como é comum em muitas empresas ( $\mathrm{R} \$$ por hora);

$\mathbf{t}_{\mathbf{t}}=$ tempo total ou de ciclo de usinagem por peça (min);

$\mathbf{S}_{\mathrm{m}}=$ custo ou salário máquina, no qual são considerados os custos anuais da máquina devido à sua depreciação, manutenção, espaço ocupado, energia e insumos consumidos na operação e a inversão feita na sua aquisição contra a o rendimento fornecido à taxa de juros do mercado ( $\mathrm{R} \$$ por hora);

$\mathbf{K}_{\mathrm{ft}}=$ custo da ferramenta por vida de cada aresta de corte, que depende de vários fatores que podem ser aplicados ou não, como o material da ferramenta, tipo de porta-ferramenta, custo de afiação, custo de armazenamento, etc. $(\mathrm{R} \$$ por aresta);

$\mathbf{Z}_{\mathrm{t}}=$ número de peças produzidas por vida de cada aresta de corte da ferramenta; 
$\mathbf{K}_{\mathrm{ui}}=$ custos indiretos de usinagem devido, por exemplo, a preparação da máquina para fabricação de um lote de peças, ao controle de qualidade das peças, etc., os quais são admitidos como constantes, ou seja, independem da velocidade de corte e do avanço $(\mathrm{R} \$)$.

- As Velocidades de Corte de Mínimo Custo, Máxima Produção e Máximo Lucro

Com um modelo de vida da ferramenta determinado, pode-se deduzir as velocidades conforme os critérios de mínimo custo e de máxima produção.

A velocidade de mínimo custo é aquela na qual o custo total de usinagem por peça é minimo. É obtida através do modelo de vida da ferramenta, para o qual será adotado o de Taylor, substituindo a expressão (2) em (5) e esta em (6). Diferenciando-se, achar-se-á o mínimo da função custo. Em [Ferraresi 85, Stipkovic Fo. 84] tem-se o desenvolvimento analítico completo para a obtenção dessa função.

A expressão final é:

$$
v_{m c}=C \cdot\left[\frac{n \cdot\left(S_{h}+S_{m}\right)}{(1-n)\left[60 \cdot K_{f t}+t_{f t} \cdot\left(S_{h}+S_{m}\right)\right]}\right]^{n}
$$

a qual também pode ser escrita, pelo uso de (3), como:

$$
\left.v_{m c}=\left[\frac{K \cdot\left(S_{h}+S_{m}\right)}{60 \cdot(x-1)\left[K_{f t}+\frac{t_{t}}{60} \cdot\left(S_{h}+S_{m}\right)\right.}\right]\right]
$$

onde $\quad \mathbf{v}_{\mathbf{m c}}=$ velocidade de mínimo custo $(\mathrm{m} / \mathrm{min})$;

n, C = coeficientes da equação de Taylor na forma (2);

$\mathbf{x}, \mathbf{K}=$ coeficientes da equação de Taylor na forma (3).

A velocidade de máxima produção é a velocidade de corte para a qual a soma dos tempos de troca de ferramenta e de usinagem é mínimo, ou seja, é a velocidade 
na qual ocorre equilíbrio entre os efeitos positivos (maior taxa de remoção de material da peça) e negativos (maior frequência de troca de ferramentas) [Coppini 89]. A sua obtenção é análoga à da equação (7), através da diferenciação e busca do ponto de mínimo de (5), chegando-se a:

$$
v_{\text {mxp }}=C \cdot\left[\frac{n}{(1-n) t_{f t}}\right]^{n}
$$

a qual também pode ser escrita, pelo uso de (3), como:

$$
v_{m x p}=\left[\frac{K}{(x-1) t_{f t}}\right]^{1 / x}
$$

onde $\quad \mathbf{v}_{\mathbf{m x p}}=$ velocidade de máxima produção $(\mathrm{m} / \mathrm{min})$;

n, $\mathbf{C}=$ coeficientes da equação de Taylor na forma (2);

$\mathbf{x}, \mathbf{K}=$ coeficientes da equação de Taylor na forma (3).

Com as velocidades ótimas determinadas por esses critérios, estabelece-se o denominado Intervalo de Máxima Eficiência (figura 2.15), que é o intervalo entre a condição de usinagem de mínimo custo e a de máxima produção. Comprova-se que o trabalho entre esses dois valores de velocidade de corte conduzem aos melhores resultados de economia industrial [Ferraresi 85].

A velocidade de máximo lucro deveria ser a grandeza mais significativa na otimização das condições de usinagem porém é de difícil utilização ainda hoje pela dificuldade na obtenção dos valores dos seus componentes. O principal valor a ser determinado proveniente da área contábil das empresas é o lucro por peça, o qual é definido como a diferença entre receita e custo na venda da mesma. Aplicado à operação de usinagem em análise, pode-se obter pela equação (6) o custo da peça relativo à operação. Porém a receita ou a proporção do preço de venda da peça rateada para cada operação de usinagem é algo mais trabalhoso e de difícil determinação [Ferraresi 89]. Recentemente alguns autores, como [Cowton 93], têm procurado fazer abordagens quanto à economia no processo de usinagem que revêem a questão dos modelos de custos e de maximização do lucro através de 
conceitos contábeis mais modernos, procurando verificar o impacto real da elevação dos custos fixos nos ambientes de manufatura mais modernos enquanto que, para análises de curto prazo, esses mesmos custos são irrelevantes. Outra dificuldade na obtenção do custo correto da operação é a sua forma de alocação, a qual, em muitas empresas, é obtida por rateios. Uma proposta que vem sendo empregada na indústria é a do custeio por atividade ou técnica $A B C$ (Activity Based Costing) [Brunstein 94]. Apesar de não ser explorada a questão da maximização do lucro no presente trabalho, pode-se lembrar que, segundo [Ferraresi 89], verifica-se estarem os valores de máximo lucro pertencendo ao intervalo de máxima eficiência antes citado.

- Análise dos Critérios de Máxima Produção e de Mínimo Custo com a influência do modelamento da vida da ferramenta

Muitos trabalhos encontrados sobre sistemas CAPP voltados à especificação de parâmetros nas operações de usinagem apresentam a busca da otimização pelos critérios apresentados. Em particular os de mínimo custo e de máxima produção são de aparecimento comum. O critério de máximo lucro, embora ideal, é de aplicação restrita devido à dificuldade de sua prática nas indústrias.

Observa-se, no entanto, que o conhecimento obrigatório de informações e de modelos para a vida da ferramenta implica na experimentação da mesma em condições que sejam iguais ou que se assemelhem aquelas em que será aplicada após o seu planejamento. Diante da enorme quantidade de variáveis que influenciam a usinagem, essa tarefa é árdua e de resultados nem sempre precisos. Talvez essa precisão jamais seja atingida visto ser o processo de usinagem dominado por muitos influenciadores não totalmente conhecidos e controláveis. Um deles é a composição e o estado de fornecimento do material da peça bruta, o qual pode variar de lote para lote e implicar em variações na vida da ferramenta. [DeArdo 93] mostra isso muito bem através de testes, alguns utilizando o mesmo material em diferentes laboratórios. Propõe então, junto a [Eriksson 92], um conjunto de índices de correção entre as diferentes condições obtidas em um laboratório e as obtidas em uma fábrica. Para a questão das diferenças de estado entre peças de lotes diferentes, [DeArdo 93] propõe um novo índice que é levantado através da análise metalográfica de inclusões não metálicas, as quais são grandes responsáveis por uma maior ou menor usinabilidade em materiais metálicos. Esses índices podem ser levantados a priori e, 
quando o lote for usinado, as condições operacionais poderiam ser recalculadas e alteradas na máquina. Esse parece ser um dos caminhos mais precisos observados na literatura desde que todas as demais condições de usinagem estejam sob controle.

$\mathrm{Na}$ indústria, porém, esse método ainda apresenta obstáculos a sua implantação. Primeiro, exige uma apuração e coordenação intensa no sentido de obter os dados e passá-los à produção, implicando na existência de uma equipe hábil tecnicamente para promover a essa atividade. Segundo, implica na existência de máquinas com variação de velocidade de corte e avanço permissíveis para se ajustar aos requisitos do lote. Essa não é, ainda, a realidade de muitas empresas e processos que possuem máquinas com rotações fixas ou escalonadas préestabelecidas no momento de sua aquisição, embora haja uma tendência de crescente utilização de máquinas $\mathrm{CNC}$, as quais possuem esses recursos.

[Madl 96] lembra que o uso de monitoração do desgaste da ferramenta através de controle adaptativo, por exemplo, é um recurso reconhecidamente de importância à medida que as máquinas de usinagem CNC e as ferramentas se tornam caras, fazendo com que qualquer desvio de uma condição de custo ótimo cause os custos se elevarem enormemente, excedendo a viabilidade do processo. Embora essas tecnologias de monitoração in-process possam responder à otimização frente a pequenas variações no processo, os valores de referência das variáveis de corte a serem adotados ainda necessitam de cálculo através de critérios de otimização pré-determinados. 


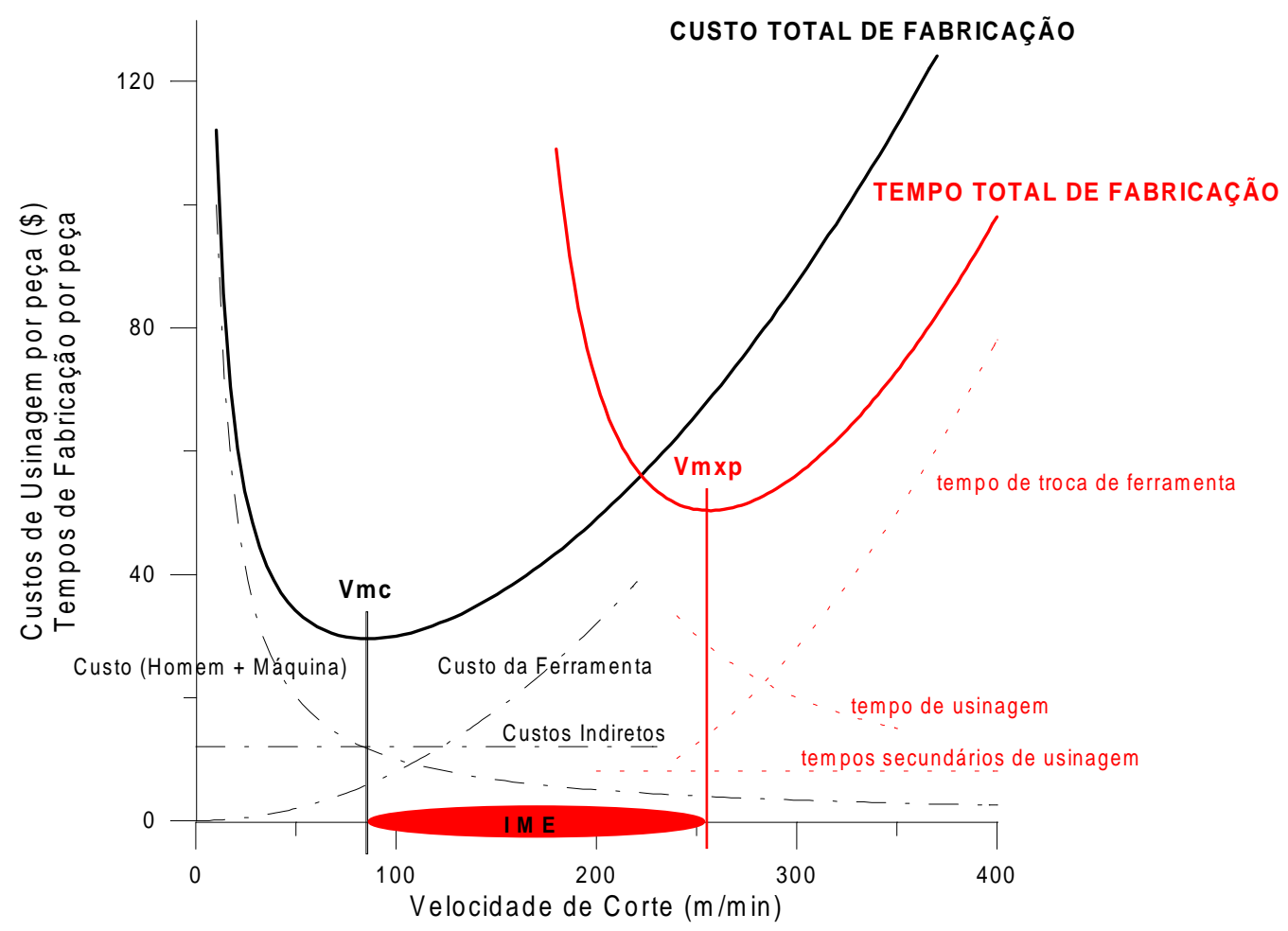

figura 2.15 Determinação das Condições Econômicas de Usinagem e o Intervalo de Máxima Eficiência (IME) [Ferraresi 85]

Considerando uma situação normal em que não se tenha tantos recursos como os citados nos parágrafos anteriores, para se obter valores de comportamento da vida das ferramentas deve-se, ou buscá-las em manuais específicos de usinabilidade, ou executar-se testes de campo. O autor [Zhou 92], numa posição razoável, utiliza-se dos dois recursos no sistema que desenvolveu: preliminarmente adota valores tabelados ou de processos existentes similares, passando a executar testes de desgaste no próprio ambiente de trabalho o que fará, após algum tempo, os parâmetros convergirem e chegarem à situação ótima de longo prazo.

[Coppini 87] partilha de posição semelhante e sugere como alternativa ao problema a determinação das constantes $\mathrm{x}$ e $\mathrm{K}$ de Taylor na própria máquina para a qual se pretende a otimização. [Zhou 92] lembra ainda que, ao se aplicar o seu método experimental na fábrica, durante o processo produtivo, deve-se prestar atenção ao tipo de produção com que se trabalha. Essa é uma observação também razoável pois, para se garantir condições mínimas de reprodução do experimento em processo fabril, que é a sua proposta, deve-se estar operando não numa produção tipo oficina mas, sim, numa do tipo em lotes ou em massa (vide item 2.2). Segundo ele, ainda, o custo de executar testes em condições de oficina para estimativas de 
otimização poderiam vir a ser maior que o ganho obtido com o resultado da análise do processo.

Tanto [Coppini 87] quanto [Zhou 92] adotam o modelo de Taylor para a vida da ferramenta porém este último especifica uma quantidade de peças a serem feitas por ferramenta antes da sua troca pelo operador da máquina e propõe funções de custo e de tempo da operação para obter os valores ótimos de forma diferente da sintetizada pelas equações (7), (8), (9) e (10) da teoria clássica, adotada por [Coppini 87]. [Zhou 92] inclui nessas funções parcelas de custo e tempo referentes às penalidades que ocorrerão quando a ferramenta quebrar antes do momento prédeterminado. Com isso os valores dos tempos, custos e velocidades de corte ótimas da sua análise diferem levemente dos obtidos de forma clássica. Além dessas parcelas, o custo e o tempo de processo são tratados de forma estatística, através de expectativas com base na distribuição do tempo de vida da ferramenta.

Para chegar aos valores de $\mathrm{x}$ e $\mathrm{K}$ de Taylor, [Zhou 92] executa preliminarmente alguns ensaios de durabilidade de ferramenta. Obtém, assim, uma sequência de tempos padrão da vida da ferramenta. Através, então, da teoria de estimação de parâmetros estatísticos, ele obtém um valor típico de $\mathrm{x}$ e $\mathrm{K}$ para o processo, pela aplicação sequencial das diferentes vidas obtidas no ensaio. Deve-se ressaltar que, ao fazer isso, [Zhou 92] assume algumas premissas como a vida da ferramenta possuir uma distribuição log-normal, o conhecimento preliminar de $\sigma$ (desvio-padrão da distribuição da vida da ferramenta), $\sigma_{1}$ e $\sigma_{2}$ (desvios-padrão relativos aos parâmetros $\mathrm{x}$ e $\mathrm{K}$ de Taylor) além de valores de $\mathrm{x}$ e $\mathrm{K}$ de Taylor obtidos em manuais de usinabilidade ou de outros casos conhecidos e similares. A base teórico-estatística para o trabalho foi extraída de [Balakrishnan 85]. [Zhou 92] afirma, concluindo, que os valores de $\mathrm{x}$ e $\mathrm{K}$ estimados convergem rapidamente dentro de uma região.

Os trabalhos de [Coppini 87] e seus desdobramentos [Coppini 89, Coppini 93] prescrevem um método simplificado para teste e avaliação de $x$ e $\mathrm{K}$ através do desgaste da aresta de corte da ferramenta ou da condição de acabamento superficial (para operações de acabamento) em, no mínimo, duas velocidades diferentes. 0 método proposto é mais simples que os das normas ISO 3685 [ISO 93] e ISO 8688 [ISO 89], para operações de torneamento e de fresamento respectivamente, podendo assim ser resumido e comentado:

- faz-se a escolha do avanço e da profundidade de corte a partir de bancos de dados genéricos, baseados em considerações restritivas do sistema. 
Com base nessas restrições, o avanço e a profundidade de corte devem ser máximos, como já explicado em 2.4.2.5;

- do mesmo banco de dados retira-se um valor orientativo para a velocidade de corte para ser adotado como valor inicial de ensaio;

- estabelece-se um critério de fim de vida da ferramenta a ser utilizado:

- desbaste: desgaste VB ou KT, quebra ou lascamento da ferramenta;

- acabamento: incapacidade do processo em manter a dimensão pelo controle estatístico do processo, controle da rugosidade superficial até um valor limite, quebra ou lascamento da ferramenta.

A norma ISO 3685 [ISO 93] sugere, ainda, outros critérios a serem aplicados conforme o caso;

- com essas condições inicia-se a operação em produção normal, computando-se o número de peças usinadas por vida da ferramenta. Da mesma maneira mede-se $o$ tempo de corte $t_{c}$ de uma peça para $a$ velocidade em teste. Após a computação de amostragem estatisticamente representativa para essas condições, varia-se a velocidade de corte da ordem de $20 \%$ da anterior, para maior ou menor, em função do resultado obtido pela estimativa inicial.

A norma ISO 3685 [ISO 93] propõe a adoção de velocidades que impliquem em, pelo menos, uma duplicação da vida da ferramenta na transição de uma para a outra condição. Esse procedimento, no entanto, nem sempre é de fácil estimativa a priori e aplicação. Assim a norma sugere a execução de um teste preliminar visando estimar as velocidades a serem utilizadas no ensaio definitivo;

- Obtém-se o valor de x e K de Taylor através das expressões (11) e (12):

$$
\begin{gathered}
x=1+\frac{\ln \frac{z_{2}}{z_{1}}}{\ln \frac{v_{c 1}}{v_{c 2}}} \\
K=z_{1} \cdot t_{c 1} \cdot v_{c 1} x=z_{2} \cdot t_{c 2} \cdot v_{c 2} x
\end{gathered}
$$


onde $\mathbf{z}_{1}$ e $\mathbf{z}_{2}$ são as quantidades médias de peças produzidas por vida da ferramenta, $\mathbf{t}_{\mathrm{c} 1}$ e $\mathbf{t}_{\mathrm{c} 2}$ são os tempos de corte de uma única peça, valores estes tomados nas velocidades $\mathbf{v}_{\mathbf{c} 1}$ e $\mathbf{v}_{\mathbf{c} 2}$, respectivamente.

Deve ser observado o intervalo de validade entre as situações 1 e 2 no cálculo das velocidades otimizadas e de referência como a $v_{m \times p}$, por exemplo. Isso acontece pois, na prática, a curva de vida de uma ferramenta não é uma reta no diagrama dilogarítmico. Assim as velocidades calculadas a partir de x e $\mathrm{K}$ experimentais apenas valem se estiverem localizadas também nesse intervalo experimental. [Coppini 89, Coppini 93] aplicam uma regra para um sistema de usinagem que testa a localização da velocidade de corte otimizada no intervalo de validade, propondo procedimentos caso essa velocidade não pertença a ele.

Embora o ensaio proposto seja o mais simples possível, um aperfeiçoamento pode ser feito se mais de duas velocidades e vidas da ferramenta forem tomadas. Nesse caso deverá ser aplicada uma regressão pelo método de mínimos quadrados visando obter os valores de $\mathrm{x}$ e $\mathrm{K}$ assim como os seus intervalos de confiança, o que é bastante detalhado nas normas ISO 3685 [ISO 93] e ISO 8688 [ISO 89], as quais são, praticamente, extensões desse ensaio visando análises diversas.

Duas são as diferenças fundamentais entre as abordagens de [Zhou 92] e [Coppini 87]. A primeira reside na forma como os valores de $x$ e $\mathrm{K}$ de Taylor são obtidos pois enquanto [Zhou 92] necessita de estimativas iniciais de $\mathrm{x}, \mathrm{K}, \sigma, \sigma_{1} \mathrm{e}$ $\sigma_{2}$ para os seus cálculos finais de $x$ e $\mathrm{K}$, [Coppini 87] os obtém sem o conhecimento dessas estimativas. $\mathrm{E}$ ainda, se mais pontos além dos dois propostos no método simplificado inicial forem tomados, os valores dos desvios-padrão poderão ser obtidos pelo método de regressão. A segunda diz respeito ao cálculo dos custos e dos tempos do processo, pois [Zhou 92] coloca as parcelas de penalidade (como explicado anteriormente) enquanto [Coppini 87, Coppini 89] assumem a teoria clássica porém questionando a necessidade e validade do cálculo da velocidade de mínimo custo. Evidencia [Coppini 87] que "o conhecimento preciso da velocidade de máxima produção aliado ao fato de que a velocidade de mínimo custo é sempre inferior, é uma ferramenta necessária e suficiente para a definição dos parâmetros operacionais, principalmente nos gargalos". Com isso faz-se uma avaliação e crítica à aplicabilidade do critério de mínimo custo na determinação das condições ótimas de usinagem. Sugere estes últimos autores, para isso, um índice D como a razão entre 
as velocidades de máxima produção e de mínimo custo clássicas, a ser expresso como:

$$
\left.D=\frac{v_{\operatorname{mxp}}}{v_{m c}}=\left[\frac{60 . K_{f t}}{t_{f t} \cdot\left(S_{h}+S_{m}\right)}+1\right]\right]^{1 / x}
$$

O valor de $D$ pode ser entendido, também, como uma relação de taxas de produção, ou seja, do quanto se usina adicionalmente entre uma situação de mínimo custo e uma de máxima produção, admitindo o avanço igual para as duas velocidades de corte.

São analisados os casos em que $D>1$, em particular aqueles em que $D$ tende ao valor unitário e ao infinito. Valores de $D<1$ não são possíveis pois implicam em se ter $K_{f t}, t_{f t}$ ou $\left(S_{h}+S_{m}\right)$ negativos, o que não é razoável em nenhum caso.

Através dessa análise esses autores mostram que apenas no caso em que o custo da ferramenta tende a valores elevados é que não se deve generalizar a escolha da $v_{\operatorname{mxp}}$ como velocidade ótima pois nessa situação o custo do processo tenderia a valores mais altos que os obtidos através de velocidades menores. De qualquer forma, quando se estudam as máquinas gargalos de produção, os valores do salário-máquina e demais custos de difícil apuração (o que faz, normalmente, com que o mínimo custo não seja corretamente calculado) tendem a se elevar. Isso pode fazer com que o custo na velocidade de mínimo custo eleve-se de tal forma que apenas na condição de máxima produção haja mínimo custo. Isso ocorre pois o tempo de produção é mínimo, o que é de importância fundamental em gargalos. [Coppini 87] defende, além disso, a dificuldade e a imprecisão na obtenção das informações de custo exigidas no cálculo da velocidade de mínimo custo, o que poderá ser resolvido, por exemplo, pela adoção da prática do método de custeio $A B C$ pelas empresas, como já citado (vide item 2.4.2.6). Assim o custo exato da atividade desempenhada na máquina com determinada peça poderá ser levantado de maneira mais precisa.

De qualquer forma, quando os valores de custo forem disponíveis, deve-se ter os seus valores calculados para ambas as condições de velocidade (ótima e de mínimo custo) para se poder julgar qual o valor a seguir. Caso ocorra ausência de informações confiáveis e o custo da ferramenta não for excessivamente elevado ou a 
máquina for um gargalo de produção, a $v_{\operatorname{mxp}}$ poderá ser adotada. Para o seu cálculo a informação necessária é originária do próprio chão-de-fábrica, ou seja, apenas o tempo de troca de ferramenta.

Em resumo, o método experimental proposto por [Coppini 87, Coppini 89, Coppini 93] é mais simplificado que a abordagem das normas citadas, necessitando de menos informações a priori que o método de [Zhou 92]. Este, no entanto, é um método que poderia ser proposto para um refinamento dos valores de $\mathrm{x}$ e $\mathrm{K}$ obtidos antes visto ser a coleta de valores de vida da ferramenta uma tarefa relativamente simples e que pode ser feita em condições normais de produção. Não será esta última proposta de conciliação e complementaridade entre os dois métodos, no entanto, a forma como será obtida a otimização da velocidade de corte no presente trabalho. Em 4.1.3 propor-se-á um método prático para se implementar o resultado desta discussão de forma a torná-lo exequível conforme padrões adotados em cada empresa, baseados em [Coppini 87] e suas extensões.

\subsubsection{Tendências nas Metodologias Computacionais Empregadas em Sistemas CAPP}

Um sistema CAPP ou, com referência mais particular à abordagem deste trabalho, um sistema que determinará os componentes e as características necessárias de um conjunto Máquina-Ferramenta-Dispositivo-Peça (MFDP) a partir do modelo ou desenho de uma peça e a subsequente determinação dos parâmetros ótimos das respectivas operações de usinagem, poderá ser programado de várias maneiras. Isso dependerá, inicialmente, da forma como o problema é colocado: tipo de produção, objetivos de planejamento, ambiente de aplicação do processo, tipo do processo, etc.. O ambiente de aplicação do processo (a fábrica), por exemplo, fornecerá a maior parte dos dados necessários à determinação do sistema MFDP e à otimização do processo.

Observa-se que para alcançar o objetivo proposto é necessário que se trate tais dados recuperando-os, comparando-os, selecionando-os e calculando, por fim, os parâmetros ótimos. Além disso o usuário precisará interagir com o sistema para introduzir informações intermediárias ou atualizar as bases de dados, razão pela qual essa interface deverá ser amiga (user friendly interface). 
Várias formas de se obter tais atividades são encontradas na literatura especializada atual baseadas em métodos algorítmicos, métodos baseados em conhecimento, programação orientada a objetos, ou uma combinação de dois ou mais desses métodos simultaneamente, solução esta que se tem mostrado bastante frequente e até necessária nos trabalhos pesquisados como mostrado em [Gopalakrishnan 89] e [Zhang 94].

\subsubsection{Sistemas Algorítmicos}

Seja num sistema CAPP variante ou generativo, o método a ser empregado para que ele resolva o problema de planejamento poderá ser do tipo algorítmico, ou seja, através de algoritmos, que são, segundo [Ferreira 86], "conjuntos predeterminados e bem definidos de regras e processos destinados à solução de um problema, com um número finito de etapas". Contrapõem-se aos métodos algorítmicos aqueles que se baseiam em conhecimento, como se discutirá em 2.4.3.2.

Visando resolver o problema de planejamento do processo de usinagem e da procura dos seus parâmetros ótimos, encontram-se autores e sistemas que se utilizam de algoritmos matemáticos bem definidos. As primeiras tentativas de $\mathrm{F}$. W. Taylor no começo deste século visavam, por exemplo, encontrar um algoritmo matemático genérico que resolvesse as equações com até 12 variáveis as quais concluiu serem as preponderantes para o corte de metais [Taylor 66]. Outros pesquisadores adotam modelos matemáticos (equações) para custo do processo, para desgaste da ferramenta, para rugosidade superficial da peça, para cálculo da potência e forças de corte, etc.. Estes modelos, obtidos muitas vezes através de regressões múltiplas (vide [Yeo 89]) possuem seus intervalos e condições de validade e nem sempre são capazes de reproduzir as situações práticas devido a alguma alteração nas condições originais como a mudança da máquina ou de algum parâmetro operacional. Com estes modelos determinados, procede-se a um processo de otimização de acordo com alguma função objetivo em que se procura determinar a velocidade de corte, o avanço e/ou a profundidade de corte mais adequado(s).

Algumas críticas que se podem fazer a essa metodologia são a rigidez do modelo matemático, a falta de avaliação de muitos influenciadores que existem mas não são controlados na máquina a ser aplicada o resultado da otimização (por 
exemplo, a frequência de ressonância da máquina e o seu impacto na vida da ferramenta) e, por consequência, uma possível generalização indevida do modelo o que pode levar a se trabalhar com ele em condições de não validade as quais ainda não foram testadas na prática. Aliando isso a uma incapacidade do algoritmo em "aprender" novas experiências, utilizando-as posteriormente, fez com que os sistemas constituídos por algoritmos puros passassem, nos últimos anos, a incorporar o conhecimento de especialistas ou planejadores de processo.

\subsubsection{Sistemas Baseados em Conhecimento}

Os sistemas computacionais baseados em conhecimento possuem sua origem nas técnicas denominadas por cognitivas ou de inteligência artificial (IA). [Mill 87] relata algumas abordagens de IA que procuraram resolver o problema de planejamento de processo. Segundo esses autores a utilização de IA vem de encontro a problemas como a preservação do conhecimento de planejadores experientes assim como a manutenção de uma linha coerente de planejamento. É sabido, da prática, que se for pedido o planejamento de processo para uma peça num mesmo ambiente a dois planejadores, dificilmente a solução apontada por ambos será a mesma devido ao grande número de possibilidades existentes para a tarefa.

Por IA entende-se atualmente a parte da ciência computacional preocupada com a criação de sistemas computacionais inteligentes, isto é, sistemas que tenham características associadas à inteligência no comportamento humano, como por exemplo: a compreensão de linguagem, a aprendizagem, o raciocínio, a solução de problemas, a indução e dedução lógicas.

Dentre as várias áreas da IA, uma que se tem mostrado bastante pesquisada e utilizada para resolver problemas de planejamento de processos é a dos sistemas baseados em conhecimento (SBC), ou seja, aqueles nos quais o conhecimento é explícito e separado do restante do sistema. Dentro da classificação de SBC's, encontram-se o que se denomina sistemas especialistas (SE). A diferenciação básica entre um SBC e um SE é que, enquanto no primeiro o conhecimento especializado pode se originar de várias fontes, como livros, manuais, especialistas humanos, por exemplo, incorporando tópicos de assuntos que não requerem aptidão ou educação especiais, os SEs tratam de uma classe particular de SBC na qual o 
conhecimento provém de uma autoridade reconhecida em um determinado campo. Nos SEs o conhecimento perito é codificado na forma de regras e fatos obtidos através da observação e/ou entrevista do especialista por um engenheiro de conhecimento e, após essa etapa, é processado num computador que repete as análises e estratégias de solução de problemas [Genaro 86]. Ou, ainda baseando-se na conceituação deste último autor, um SE é um programa não convencional de computador que se propðe a resolver problemas do mundo real de razoável complexidade e que requerem para a sua aplicação a interpretação de um especialista ou perito, entendido como um profissional com suficiente conhecimento dos problemas de sua área de atuação e que é capaz de resolver a maioria deles através de uma sessão de perguntas e respostas, quando consultado por uma pessoa com pouco conhecimento da área.

Segundo [Liu 85], a maioria dos SEs e SBCs emulam o mecanismo de síntese humana numa estrutura denominada sistema baseado em regras (rule-based system) composto de três blocos: uma base de conhecimento, onde estão representados os conhecimentos necessários para a solução de problemas, adquiridos de um ou mais especialistas na área na forma de fatos e regras, uma máquina de inferência, responsável pela geração de conhecimentos deriváveis a partir de conhecimentos armazenados, ou seja, pela decisão de como aplicar as regras e em que ordem para deduzir novos conhecimentos, e uma interface que atua de modo a facilitar ao usuário do sistema a comunicação com a base de conhecimento e com a máquina de inferência (vide figura 2.16). As chamadas regras de produção são regras do tipo "SE... ENTÃO..." e são mais adequadas à representação de conhecimento dedutivo, como situação/ação, premissa/conclusão, antecedente/consequente e causa/efeito. Daí a sua utilização no auxílio aos sistemas CAPP. Um exemplo de regra [Zhang 94]:

$$
\begin{array}{ll}
\text { SE: } & \text { É um diâmetro externo, e } \\
& \text { o diâmetro é menor que } 100 \mathrm{~mm} \\
\text { ENTÃO: } & \text { Um processo de torneamento é sugerido, e } \\
& \text { um torno de tamanho médio é necessário. }
\end{array}
$$

As regras de produção são a forma de representação de conhecimento mais utilizada atualmente, conforme [Zhang 94].

A máquina de inferência é a responsável pelo processamento de informaçðes contidas na base de conhecimento, como as regras do tipo "SE... ENTÃO...". Ela 
decide como aplicar as regras e em que ordem, a fim de deduzir novos conhecimentos. Observe que estando o conhecimento especializado separado, tornase fácil para o engenheiro de conhecimento projetar procedimentos para manipulá-lo. O analista de aplicação não é um projetista de código procedural, mas perito no domínio específico que cria a tabela de regras para simular o conhecimento desejado.

Há muitas estratégias utilizadas para a inferência, sendo muito conhecidas a forward-chaining (encadeamento para frente) e a backward-chaining (encadeamento para trás). Na primeira as regras são utilizadas para frente, deduzindo-se todas as conclusões lógicas a partir de um conjunto de dados de entrada ou fatos. Quando a regra mais adequada é encontrada, a regra é aplicada, a base de conhecimento é atualizada e a procura recomeça. Este processo continua até um estado objetivo ser atingido ou não se encontrar mais regras aplicáveis. Os sistemas CAPP CUTTECH [Barkocy 84], o SEU [Coppini 93] e o SEDCU (Sistema Especialista para Determinação das Condições de Usinagem) [Bernardo 96], utilizam esta técnica.

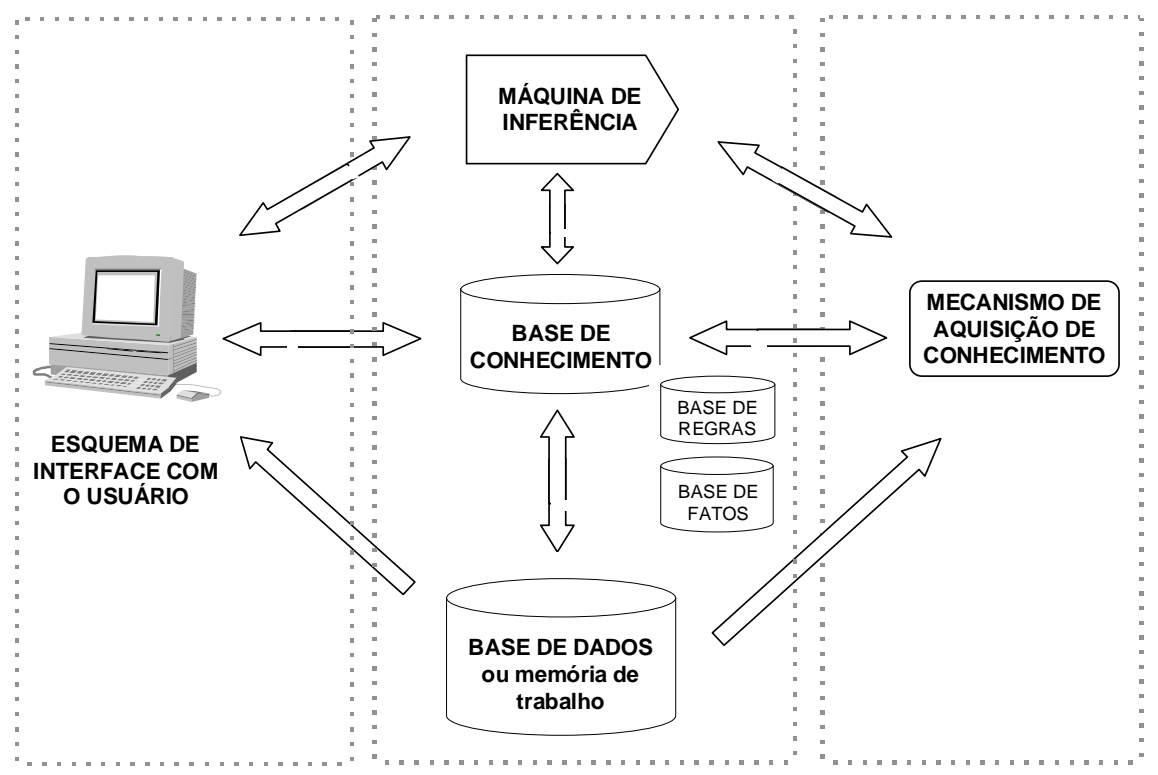

figura 2.16 Arquitetura genérica de um sistema especialista, conforme [Zhang 94]

$\mathrm{Na}$ estratégia backward-chaining inicia-se com a meta a ser verificada, tentando estabelecer os fatos necessários para prová-la através do exame das regras que a atendem. Se nesse processo chegar-se a uma situação em que não existam regras para o estabelecimento da nova sub-meta, então o sistema questiona o usuário sobre mais informações [Mital 94]. 
Quanto às linguagens de programação dos SBCs e dos SEs, estes podem ser desenvolvidos em qualquer linguagem de computador, seja esta procedural, como o FORTRAN, O PASCAL e o C, como específicas para manipulação de símbolos como - LISP e o PROLOG ([Genaro 86, Mital 94]). Há, no entanto vantagens claras na utilização do segundo tipo visto a facilidade na manipulação de expressões simbólicas. Encontram-se hoje ambientes ou shells para desenvolvimento de sistemas baseados em conhecimento. Estes ambientes possuem já mecanismos de inferência pré-determinados assim como uma forma sistemática de representação do conhecimento facilitando a implementação dos sistemas.

Quanto à aplicação de SBCs e SEs no CAPP, [Zhang 94] relata que até 1988 cerca de 50 SEs foram desenvolvidos em todo o mundo. As soluções utilizando este conceito partem do desenho (CAD), com o reconhecimento de features automático, e chegam até a especificação de parâmetros de usinagem. Outros sistemas abordam as metodologias de IA apenas em parte do problema como a escolha da máquina, a seleção de ferramentas e fixações assim como os parâmetros de usinagem e a sequência de processos. Em sistemas variantes a interpretação do desenho da peça é fundamental e as regras podem ser aplicadas na determinação de peças similares. $\mathrm{Na}$ abordagem generativa a aplicação de SBCs pode iniciar-se no desenho computadorizado e chegar até a seleção de parâmetros de processo, conforme os objetivos desejados ([Liu 85]).

[Zhang 94] possui uma coletânea de 187 sistemas CAPP desenvolvidos e conhecidos até 1992 dos quais conclui serem 23,6\% baseados em SBCs ou SEs. Não inclui nessa amostragem, no entanto, soluções brasileiras como a do SEMCON (vide item 2.4.2.2) e a de [Teixeira Jr. 89] (vide item 2.4.2.1). Mais recentemente [Coppini 93] mostra o desenvolvimento de um sistema especialista que utilizou algumas regras de verificação da validade de resultados com base na metodologia de otimização buscando a velocidade de corte de máxima produção proposta em [Coppini 87, Coppini 89]. [Bernardo 96] apresenta um sistema que estende a aplicação dos sistemas especialistas em usinagem com critérios e metodologia similar à de [Coppini 93].

\subsubsection{A interface dos sistemas CAPP com o usuário e a orientação a objetos}


Com as diversas abordagens já existentes para o CAPP deve-se considerar uma importante característica desses sistemas e que pode representar o sucesso ou não de sua implantação numa empresa: a capacidade de possuir uma interface amiga com o seu usuário. [Zhang 94], no entanto, declara a dificuldade em se determinar padrões para medir essa característica. Por exemplo, no caso de um SBC haverá a interação deste com pelo menos três tipos de usuários distintos: o processista, o engenheiro de conhecimento e o operador de sistema.

Uma facilidade que os sistemas comerciais muitas vezes possuem é a capacidade de introdução e modificação fácil de regras de produção. Com isso o especialista (processista) pode vir a substituir o engenheiro de conhecimento o qual teria a tarefa de montar a estrutura básica e inicial do sistema, deixando que o conhecimento especialista fosse introduzido diretamente pela sua fonte.

As atividades envolvidas no CAPP podem, por outro lado, ser analisadas com o conceito de orientação a objetos, conforme mostrado por [Rodrigues 93]. Isso implica numa abordagem modular das diversas atividades dentro de um CAPP (determinar processo, selecionar máquina, determinar condições de usinagem) podendo tais etapas ser padronizadas, como objetos, e aptas a serem utilizadas como módulos em um ou mais sistemas. A orientação a objetos pode, porém, implicar na relação do sistema com o usuário ao possibilitar, por exemplo, uma sistematização de nomenclatura e de elementos (operações, equipamentos, ferramentas, etc.) necessários para a consistência das diversas fases de planejamento.

Por fim, as linguagens de programação mais recentes que trabalham com orientação a objetos possibilitam, por si só, o projeto de ambientes gráficos de utilização agradável. Podem incorporar recursos como janelas, desenhos e multimídia os quais são importantes auxiliares ao planejador de processo e elementos atrativos e facilitadores nessa interação. 


\subsection{Tendências para os Sistemas CAPP e para a Especificação de Parâmetros de Processos de Usinagem}

Apesar da tendência na utilização cada vez maior do computador na fábrica e, em particular, no planejamento de processos, a realidade observada ainda se afasta das primeiras propostas de automatização total dessa atividade. Isso ocorre pelas suas características próprias como o alto grau de complexidade existente, o seu caráter subjetivo visto depender, muitas vezes, do processista e das condições e facilidades disponíveis no ambiente de produção aplicado [Rodrigues 93]. Conforme este último autor, observa-se, mesmo, uma tendência ao abandono quanto a se tentar fazer o plano completo automaticamente.

Aliada a essas dificuldades, encontra-se uma barreira técnica nas metodologias computacionais a serem aplicadas. Ainda não se possui um sistema de features abrangente e que satisfaça todas as exigências de manufatura de forma a integrar as áreas de projeto com o planejamento de processo. Quanto aos SBCs e SEs, comenta-se em [Zwicker 93] a existência de um hiato de aplicabilidade dos mesmos na indústria devido à dificuldade da sua implementação através das técnicas atuais de IA, da eventual ocorrência de falta de capacitação do pessoal envolvido nesses projetos assim como de abordagens errôneas que se faz, muitas vezes, ao problema em questão. Apesar disso as técnicas dos SBCs se aplicam bem ao trabalho com bancos de dados e devem continuar sendo pesquisadas e utilizadas no caso do CAPP, conforme resultados já obtidos [Coppini 93, Zhang 94, Bernardo 96].

Outra tendência é tornar o CAPP cada vez mais dinâmico, flexível, planejando continuamente 0 processo de fabricação a fim de corrigir quaisquer restrições impostas pela matéria-prima, pelo conjunto de máquinas ou pelas necessidades de venda do produto, enfim, pela programação cotidiana de produção [Zhang 94]. Com isso gerou-se uma nova abordagem conhecida por Planejamento de Processos Não Linear na qual a transferência de informações às áreas de produção ocorre de maneira mais uniforme permitindo desvios dos planos nominais e gerando rapidamente um conjunto de alternativas de processos para as peças [COMPLAN 95]. Essa abordagem vem sendo testada em alguns sistemas, conforme relatado em [Zhang 94] e [COMPLAN 95].

Da observação da extensa literatura a respeito do tema, concluem-se algumas tendências nas pesquisas de sistemas CAPP visando a sua maior flexibilidade e integração, condições normais exigidas nas empresas hoje: 
- serem generativos, em essência, com a possibilidade de utilização da recuperação de planos quando necessário;

- utilizarem features como interface tecnológica e de comunicação entre o projeto e o planejamento de processos;

- serem aptos a extrairem automaticamente todos os dados do produto;

- suportarem todas as tarefas de planejamento incluindo o planejamento de capacidade e a programação de peças, incorporando informações de restrições a priori e estabelecendo os sistemas de planejamento como solucionadores de problemas de forma cooperativa entre vários ambientes;

- tomarem decisões baseados em técnicas de otimização, inclusive com SBCs;

- terem habilidades de realimentação com informações da produção e outras resultantes das saídas do sistema de forma a manter as bases de dados e informações constantemente atualizadas e melhorando a qualidade dos planos elaborados;

- permitirem uma interface com o usuário simples e de fácil compreensão que habilite e estimule o trabalho dos processistas junto ao sistema e à fábrica, em particular na especificação de parâmetros e condições de processo o qual é tratado, muitas vezes, de forma secundária nas atividades de planejamento.

Com base nas análises realizadas, pretende-se observar algumas das tendências na execução dos sistemas CAPP, aplicando-as num sistema voltado à especificação de parâmetros de usinagem, em particular à determinação da velocidade de corte otimizada para o processo. 


\section{Capítulo 3}

\section{Objetivos do Trabalho}

Dentro do âmbito de planejamento de processo, macro e de operações, pretende-se desenvolver um sistema CAPP que vise auxiliar o planejador na tarefa de determinar as condições operacionais $\left(v_{c}, a, p\right)$ iniciais e finais para um determinado processo de usinagem. Entenda-se por condições iniciais aquelas necessárias para uma avaliação preliminar do trabalho de usinagem com a máquina, baseada em informações teóricas ou obtidas de bases de dados genéricas, e condições finais aquelas obtidas através de um processo de otimização experimental e prática nas condições reais em que o processo ocorre. Pretende-se ter o sistema, inicialmente, para alguns processos dentre os classificados como de torneamento retilíneo.

Busca-se com esse sistema a facilidade de uso, seja na especificação inicial, através de uma interface de utilização fácil pelo usuário, como na final, por um método experimental que seja reproduzível com facilidade em condições de fábrica.

O sistema deverá possuir três funções principais: uma de pré-seleção dos componentes do sistema MFDP e das condições operacionais, outra de seleção otimizada desses mesmos componentes porém teórica (ou com dados recuperados) e, por fim, outra de otimização com realimentação através de experiências na fábrica.

$\mathrm{Na}$ primeira função, dever-se-á poder selecionar alguns dos componentes principais do sistema MFDP através de um sistema baseado em conhecimento que leve em conta os dados geométricos, o material e o modo de fornecimento da peça, condições esperadas para $\circ$ processo, recomendações de ferramentas e possibilidades de máquinas existentes nas bases de dados de uma fábrica hipotética. A determinação do processo e informações quanto à geometria da peça, por ser um sistema protótipo, serão introduzidas pelo próprio usuário. As regras heurísticas basear-se-ão em conhecimento especialista de acordo com vários critérios já analisados antes. O conhecimento de um usuário especialista é fundamental visando a seleção final de máquinas, ferramentas e condições de usinagem, com o auxílio de decisões automáticas tomadas pelo sistema quando possível. 
No segundo bloco, deve-se proceder à otimização para determinar as condições operacionais. O avanço e a profundidade de corte a serem utilizadas serão as limites, conforme recomenda [Boehs 86] e [Coppini 87]. As ferramentas e máquinas escolhidas, da mesma forma, obedecerão a limites de velocidade de corte, avanço e potência de corte, além de outras restrições impostas e citadas no capítulo 2. O fato de ser uma situação de escolha de meios e condições de produção na fábrica, critérios como o de carga-máquina disponível e necessária para cada máquina e em cada condição de usinagem também deverão ser observados. Finalmente, pela especificação correta de critérios para a adoção da velocidade de corte otimizada, conforme [Coppini 87, Coppini 89], e sua aplicação visando o cálculo de tempos e custos de usinagem, determinar-se-á a combinação máquina / ferramenta / condições operacionais que possibilitem o trabalho em condições otimizadas. Dar-se-á ênfase à aplicação da velocidade de máxima produção, observando e discutindo as restrições nessa adoção, conforme analisado e discutido no item 2.4.2.6. Da observação dessas restrições dever-se-á apresentar um critério geral para a otimização situacional, ou seja, de acordo com as condições encontradas em determinada situação abrangendo a usinabilidade do material, a geometria da operação, a logística da fábrica e outras características inerentes ao caso em planejamento e apresentadas como tendência nos sistemas CAPP.

No terceiro bloco, determinados os componentes e a seleção de condições de operação, o sistema permitirá uma realimentação com os dados originários da fábrica utilizando-se os valores teóricos determinados no bloco anterior aplicados à máquina, no chão-de-fábrica. Nessa função o sistema deverá, em termos finais, servir para conjugar o procedimento experimental contido em [Coppini 87, Coppini 89], além das normas relacionadas como [ISO 89, ISO 93], visando determinar os valores de $\mathrm{x}$ e $\mathrm{K}$ de Taylor práticos, com as regras especialistas de [Coppini 93, Bernardo 96] para verificar o seu intervalo de validade. Pretende-se, ao final, testar o sistema na prática. 


\section{Capítulo 4}

\section{Um Modelo para o Sistema de Escolha de Condições Operacionais em Processos de Usinagem}

\subsection{Aspectos Gerais do Modelo Adotado}

O planejamento de processos costuma ser, em indústrias com muitas máquinas, uma atividade feita, em geral, anterior à produção da peça planejada. $O$ próprio termo planejar implica em execução de planos e programas visando o futuro. Tomando-se o conceito de planejamento de forma mais ampla, compreende-se que ele sempre visa o estabelecimento de situações futuras e, com isso, a sua execução só terminaria quando a peça também termina, ou seja, é descontinuada. Isso, no entanto, costuma não ocorrer, com a atividade de planejamento acabando-se ao se determinar em que condições as peças serão fabricadas pela primeira vez.

As condições do ambiente econômico e, em particular, da indústria, se alteram, assim como as condições técnicas de fornecimento das peças, ferramentas, fixações e demais acessórios. Aliado a isso existe o desgaste e consequente envelhecimento das máquinas, as mudanças de geometria e material das ferramentas e das próprias peças, o melhor aperfeiçoamento do pessoal que executa a preparação das máquinas, entre outros fatores que se modificam com o tempo. Assim o planejamento torna-se tarefa de revisão constante e a sua não execução implica em possíveis perdas na economia industrial.

O modelo a ser proposto para a escolha de condições operacionais em processos de usinagem é baseado em se ter um conhecimento relativamente bom e simplificado das condições e restrições do processo a priori. Com isso pode-se fazer as primeiras análises de viabilidade de processo para a peça planejada. Porém só se poderá confirmar ou corrigir os valores propostos inicialmente pela experimentação do próprio sistema MFDP. 
A idéia de simplificação contida na proposta é fundamentada na escolha do avanço e profundidade de corte limites para a operação, o que poderá provir de planos recuperados, do banco de dados padrão de usinabilidade ou de testes práticos feitos posteriormente à montagem do sistema MFDP na fábrica. Além disso, fundamenta-se também na adoção da equação de Taylor simplificada como modelo de vida da ferramenta. O modelo de Taylor é interessante porque pode ser aplicado a qualquer processo de usinagem que contenha uma ferramenta com gume cortante usinando e retirando cavaco de uma peça bruta. Respeitadas as pecualiaridades de cada tipo de processo, como a geometria da ferramenta, tipo de máquina, tipo de fixação, movimento relativo entre peça e ferramenta, consegue-se aplicar a equação de Taylor e os seus coeficientes para determinar a $v_{m \times p}$ específica, por exemplo. Da mesma maneira, consegue-se adequar as restrições como a potência de corte, a rugosidade superficial, etc. para vários processos de usinagem na mesma condição pedida pela equação de Taylor. Ao final o modelo, a ser aplicado inicialmente para o torneamento de diâmetros internos e externos, poderá também ter o fresamento e a furação, por exemplo, como possíveis extensões. Neste caso as maiores mudanças, certamente, ocorrerão no primeiro módulo, ou seja, no do conhecimento técnico especialista necessário a cada processo.

Uma característica interessante ao se ter um modelamento como o proposto, é a oportunidade que o processista tem de estudar alternativas para a escolha de uma situação final (máquina e/ou ferramenta e/ou condição de usinagem) de acordo com os tempos e custos desejados. Na prática industrial essas alternativas se limitam bastante pois, além do nem sempre fácil cálculo de custo do processo, o processista se vê limitado pela máquina e/ou pela ferramenta, muitas vezes. Na verdade, muitas vezes essa busca de alternativas que visem otimizar o processo de usinagem não é feita de forma sistemática pelo processista, distante das propostas apresentadas nesta dissertação.

A figura 4.01 fornece uma visão geral desse modelo de sistema para planejamento proposto. Na figura 4.02 está um fluxograma do sistema mostrando as diversas atividades previstas, suas entradas e saídas assim como os critérios utilizados para decisão e seleção dos vários componentes e condições do sistema MFDP. 


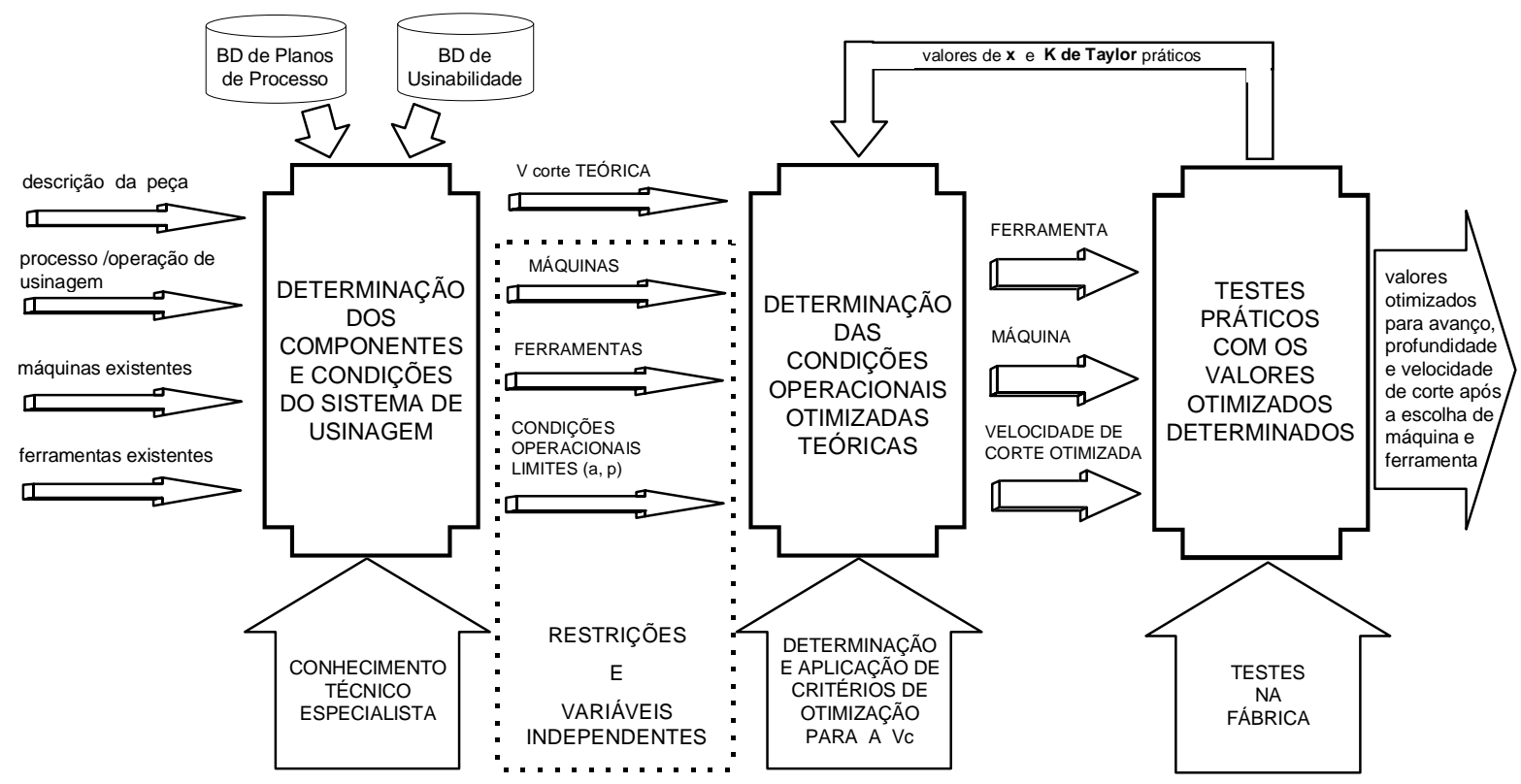

figura 4.01 Modelo Geral Proposto para o Sistema de Especificação de Condições Operacionais em Processos de Usinagem

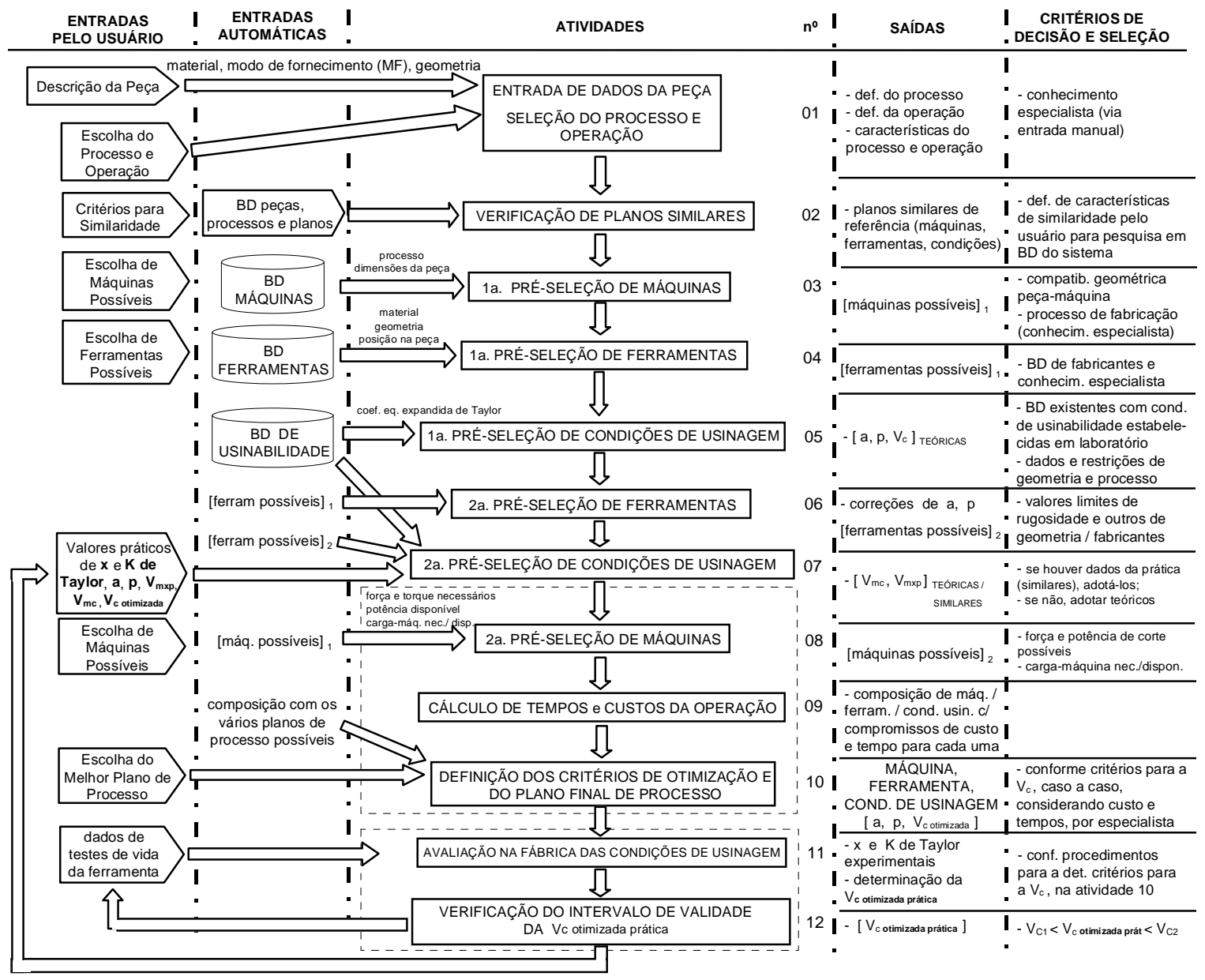

figura 4.02 Fluxograma com as atividades detalhadas para o modelo da figura 4.01 


\subsubsection{O Ambiente Industrial de Aplicação do Modelo}

Alguns requisitos são necessários para a aplicação do modelo, em particular para o sistema protótipo. O seu funcionamento se dá nas áreas de Planejamento de Processos de Fabricação de uma fábrica voltada à usinagem de peças em aço e ferro fundido, embora outros materiais possam ser utilizados apenas necessitando de informações para as bases de dados de usinabilidade e ferramentas. Pode ser aplicado tanto para peças novas, que ainda não tenham plano de processo de fabricação, como para peças já existentes e nas quais se deseje checar as condições atuais de trabalho comparativamente às otimizadas, para eventual correção. Admitese a existência de um sistema de codificação de peças o qual não necessita obrigatoriamente basear-se nos conceitos de tecnologia de grupo.

Nessa fábrica todas as máquinas têm permissão para participar do processo seletivo de execução da peça, embora isso não corresponda a uma realidade generalizada na indústria.

Admite-se, também, a existência de um sistema de contabilidade capaz de fornecer dados como custo da ferramenta, salário máquina e salário homem para o processista ou técnico de ferramenta responsável pela tarefa, como sugerido em [Coppini 89]. Da mesma forma a existência de um almoxarifado organizado de ferramentas disponíveis na fábrica e cadastradas nas bases de dados do sistema é fortemente recomendado, apesar de se poder manter informações sobre ferramentas não existentes visando estudos alternativos e simulações de cálculo de tempos e custos. Essa possibilidade de simulação também existe para o caso de máquinas ainda não existentes mas em estudo para aquisição, por exemplo.

O tamanho do lote deverá ser o suficiente visando possibilitar a aquisição de dados práticos através de ensaios de fábrica. Pode-se afirmar que o modelo é ideal para fabricação em massa e discutível, conforme o caso, para a produção em lotes. A parte de determinação teórica de condições de usinagem do sistema pode ser aplicada, também, para lotes menores observadas as restrições já citadas em 2.4.2.5.

Quanto à sequência de operações, o sistema permite que cada operação seja feita em uma máquina diferente da anterior, embora isso não seja uma atitude usual na indústria devido às eventuais perdas com tempo de preparação e de transporte de peças. Para auxiliar no processo de seleção de máquinas, o sistema informa a máquina utilizada na operação imediatamente anterior visando uma tomada de decisão do usuário. 


\subsubsection{Os Processos de Usinagem, seus Parâmetros e}

\section{Características Específicas Aplicadas no Modelo}

Os processos de usinagem com retirada de cavaco possuem um conjunto de características comuns que possibilita a aplicação do modelo proposto para o planejamento de condições de usinagem com apenas algumas modificações. Isso implica que, embora as alternativas de processo utilizadas para o protótipo sejam baseadas no torneamento retilíneo, com adequações feitas conforme o caso, o modelo também pode ser utilizado para o fresamento, a furação, o brochamento, o alargamento, etc.

A principal condição que se necessita para isso no modelo é o respeito à expressão de Taylor [equações (2) e (3)] para o desgaste ou vida da ferramenta, desgaste este que possa ser medido adequadamente através de experimentos simplificados, como os prescritos em [Coppini 87, Coppini 89], ou mais elaborados, como os mostrados em [ISO 89, ISO 93]. Deve-se, nessas medições, levar em consideração o fenômeno que está ocorrendo influenciando o desgaste: abrasão, difusão, lascamento, fissuramento transversal, existência de aresta postiça de corte, etc. que ocorrem tipicamente dependendo do processo e de suas condições (corte interrompido ou não, velocidade excessivamente baixa, etc.), da ferramenta, entre outros, como lembrado em [König 94, Ferraresi 89].

Dependendo de cada processo as definições de profundidade de corte, de avanço e de velocidade de corte podem ser aplicadas, com valores, geometria e movimentos típicos adequados a cada caso. Dessa forma seus valores podem ser tabulados e arquivados em BDs. Da mesma maneira, as máquinas que se utilizam para cada processo podem ter seus valores limites arquivados (potência, rotações, velocidades lineares, dimensões limites, custos, etc.) assim como é possível arquivar as características das ferramentas utilizadas. Para cada processo ter-se-á uma geometria típica a qual dependerá em grande parte da máquina e da forma como a ferramenta retira material da peça. Dessas relações geométricas obtém-se as expressões para a determinação da rugosidade e das forças de corte, além dos cálculos da velocidade de corte, por exemplo.

No protótipo, como já citado, utilizou-se o processo de torneamento como

base, obtendo-se as expressões para o seu modelamento de várias fontes como 
[Pallerosi 73, Stipkovic Fo. 84, Ferraresi 85, Sandvik 91, König 94], entre várias outras contidas nas Referências Bibliográficas.

Por se tratarem de máquinas $\mathrm{CNC}$ as contidas nesse ambiente de planejamento, pode-se adotar mais facilmente a velocidade de corte constante o que implica que a rotação varia à medida em que o diâmetro da peça se altera. Apesar dessa premissa estar sendo aplicada no sistema protótipo ao processo de torneamento, pode-se aplicá-la também ao de furação e de fresamento, visto serem as rotações e, portanto, as velocidades de corte constantes mesmo em máquinas convencionais. Isso simplifica o uso e cálculo da velocidade de corte. Caso no torneamento se tivesse uma condição de rotação constante, isso implicaria no cálculo de uma velocidade equivalente devido à mudança de diâmetro da peça para representar a mesma condição de desgaste da ferramenta, formulação esta encontrada em [Pallerosi 73].

\subsubsection{As Etapas, as Restrições e os Critérios de Planejamento do Processo de Usinagem Utilizados no Modelo}

Quanto ao processo de planejamento adotado, utiliza-se um sistema de seleção hierárquica dos diferentes componentes e condições dos meios de produção. Assim, partindo-se de uma definição da peça, através de sua geometria e material, define-se a operação que Ihe será aplicada (processo, modo de fornecimento da peça para a operação, geometria de usinagem, etc.). Essas são as condições de entrada do modelo.

Entenda-se por seleção hierárquica a definição de conjuntos de máquinas, ferramentas e condições de usinagem através de restrições impostas pelo usuário ou pela própria situação da fábrica através de níveis nos quais se obtém valores de parâmetros a serem utilizados nos níveis seguintes de seleção, visando chegar a uma máquina, a uma ferramenta, a uma profundidade de corte, a um avanço e a uma velocidade de corte finais que correspondam a situação otimizada dentro do conjunto de todas as opções disponíveis.

Nesse processo de seleção hierárquica, algumas ações são automáticas e outras feitas pelo usuário. As ações automáticas são tomadas pelo conhecimento especialista embutido no algoritmo do sistema através de regras "SE... ENTÃO..." e consulta às bases de dados (fatos) existentes (informações sobre máquinas, 
ferramentas, materiais, etc.). As ações tomadas pelo usuário decorrem da necessidade de outros conhecimentos além dos existentes no sistema para a definição de uma determinada situação ou escolha. A sequência natural adotada inicialmente na seleção - MÁQUINA $\Rightarrow$ FERRAMENTA $\Rightarrow$ CONDIÇÕES DE USINAGEM - não é sempre esta pois várias pré-seleções são necessárias em virtude da não disponibilidade de todas as informações no momento da escolha de cada item. Assim, como poder-se-á compreender mais adiante na descrição dos módulos, uma primeira etapa de pré-seleção tem a sequência MÁQUINA $\Rightarrow$ FERRAMENTA $\Rightarrow$ CONDIÇÕES DE USINAGEM (em particular entendendo, aqui, a escolha de profundidade de corte e de avanço). Numa segunda e última etapa a sequência fica FERRAMENTA $\Rightarrow$ CONDIÇÕES DE USINAGEM $\Rightarrow$ MÁQUINA $\Rightarrow$ DEFINIÇÃO DE CRITÉRIOS DE OTIMIZAÇÃO $\Rightarrow$ DEFINIÇÃO FINAL DE MÁQUINA / FERRAMENTA / VELOCIDADE DE CORTE OTIMIZADA. Informações como tempo de processo podem ser indispensáveis para a definição, por exemplo, de qual máquina possui capacidade para a produção da peça; no entanto só se obterá esse valor de tempo após a definição da ferramenta e, por consequência, do avanço e da velocidade de corte finais. Essa interatividade é permitida pelo sistema, podendo-se chegar a uma situação em que não existam soluções possíveis devido a seleções já feitas, a posteriori. Nesses casos o sistema permite um retrocesso de ações e decisões tomadas para se efetuar nova escolha que venha a ser viável.

Quanto às restrições adotadas como forma das ações citadas, utilizou-se compatibilidades geométricas peça-máquina e peça-ferramenta, compatibilidade de carga-máquina, compatibilidade máquina-processo de usinagem, limitações por características das máquinas (máximas velocidades alcançadas, máxima potência e máxima força de corte possíveis), limitações pelos campos de validade dos dados experimentais (coeficientes das equações de Taylor), limitações pelo intervalo de máxima eficiência para a velocidade de corte, limitações pela existência ou não da máquina ou ferramenta na fábrica, entre outras descritas com detalhe no item 4.2.

Com referência aos critérios de otimização, procura-se o que se denominou Intervalo de Máxima Eficiência (vide item 2.4.2.6) considerando, porém, as observações de [Coppini 89] e respeitando as restrições de máxima velocidade de corte e de máxima potência da máquina utilizada. Os valores de profundidade de corte e de avanço são tomados por extremos, observadas as restrições de acabamento superficial da peça e sugeridos ao usuário (o qual tem a possibilidade de alterar os seus valores em virtude de alguma necessidade não prevista), conforme 
descrito e discutido em 2.4.2.5. Assim a velocidade de corte otimizada que se procura estará dentro do intervalo de máxima eficiência, podendo tender à velocidade de mínimo custo ou à velocidade de máxima produção, dependendo das características da logística de produção da fábrica, da máquina e da ferramenta em estudo.

Muito importante na tomada de decisão é a observação da influência da logística de produção da fábrica quanto à definição da máquina em seu contexto fabril, junto a outras máquinas, de maneira a se determinar se ela é ou não um gargalo de produção. Define-se por gargalo de produção à máquina ou ao conjunto de máquinas que, devido às características que possui e às condições em que o processo foi projetado e é mantido, acaba por fabricar peças no maior tempo das máquinas pertencentes a um determinado fluxo de fabricação, conforme [Toledo Jr. 79, Araujo 88]. Por essa definição é a máquina que controla o processo e o seu custo de ineficiência é facilmente subestimado pois, em geral, baseia-se em regras contábeis gerais, enquanto a ineficiência num gargalo cria custos indiretos, de contabilização nem sempre fácil (vide item 2.4.2.6). Um gargalo num fluxo de produção pode ser classificado por dois tipos:

- gargalo permanente ou principal: é a máquina cujos motivos que a tornam gargalo não são temporários. Dentre esses motivos aponta-se o tempo elevado de processo, o excesso de carga-máquina e o excesso de paradas por manutenção ou geração de refugo e reparo de forma crônica. É a máquina que efetivamente controla o fluxo produtivo;

- gargalo temporário ou secundário: os motivos que tornam essa máquina um gargalo são temporários. Ocorrem, por exemplo, devido a necessidade de manutenção preventiva, a problemas de manutenção corretiva anormal prolongada, a oscilação de programa de produção ou a existir uma distância grande entre os diferentes pontos gargalos numa linha de produção.

No modelo adotado para o protótipo utiliza-se uma definição quanto à máquina ser ou não gargalo de produção (vide figura 5.03). Adota-se aqui o gargalo permanente embora gargalos temporários também possam, eventualmente, gerar custos indiretos elevados.

Necessita-se também, para aplicar os critérios, o valor de duas relações: $\mathbf{D}$, já descrita pela equação (13), e $\mathbf{R}_{\mathbf{k}}$, uma relação de custos definida por: 


$$
R_{k}=\frac{K_{v \operatorname{mxp}}}{K_{v m c}}
$$

onde $\mathbf{R}_{\mathbf{k}} \quad=$ relação de custos entre a situação de velocidade de máxima produção e a de mínimo custo;

$\mathbf{K}_{\mathbf{v m x p}}=$ custo por peça para a velocidade de máxima produção $(R \$)$;

$\mathbf{K}_{\text {vmc }}=$ custo por peça para a velocidade de mínimo custo $(R \$)$.

Com esses valores determinados, propôs-se a seguinte interpretação do critério adotado por [Coppini 89], através de regras especialistas:

- SE a máquina é gargalo de produção,

ENTÃO sugere-se adotar como velocidade de corte otimizada a mais próxima e possível da velocidade de máxima produção;

- SE a máquina não é gargalo de produção,

ENTÃO $\left\{\right.$ SE $\quad D<1,5$ e $R_{k}<1,3$,

ENTÃO como a velocidade de máxima produção está relativamente próxima da velocidade de mínimo custo e a diferença de custo de operação é menor que $30 \%$, sugere-se a adoção da velocidade de corte otimizada como tendente à de máxima produção;

SE $\quad \mathrm{D}<1,5$ e $\mathrm{R}_{\mathrm{k}}>=1,3$,

ENTÃO como a velocidade de máxima produção está relativamente próxima à velocidade de mínimo custo porém a diferença de custo de operação é maior que $30 \%$, sugere-se a adoção da velocidade de corte otimizada como tendente à de mínimo custo visando reduzir o custo da operação. O limite para essa redução, no entanto, é a velocidade que faça o tempo da operação elevar-se de tal forma que a máquina se 
transforme num gargalo de produção, o que

naturalmente elevaria os seus custos de fabricação;

SE

$\mathrm{D}>=1,5$ e $\mathrm{R}_{\mathrm{k}}<1,3$,

ENTÃO com a velocidade de máxima produção elevada em relação à de mínimo custo e a diferença de custo de operação menor que $30 \%$, sugere-se a adoção da velocidade de corte otimizada como tendente à de máxima produção. Caso se desejem custos ainda menores deve-se procurar uma velocidade menor que a de máxima produção, procurando compatibilizar os custos e os tempos de fabricação mas precavendo-se para que o tempo de fabricação elevado não transforme a máquina em gargalo de produção, o que elevaria os seus custos de fabricação;

SE $\quad \mathrm{D}>=1,5$ e $\mathrm{R}_{\mathrm{k}}>=1,3$,

ENTÃO com a velocidade de máxima produção elevada em relação à de mínimo custo e a diferença de custo de operação maior que $30 \%$, sugere-se a adoção da velocidade de corte otimizada como tendente à de mínimo custo visando manter os custos da operação baixos, mas, simultaneamente não comprometendo o tempo de fabricação o que pode fazer a máquina tornar-se um gargalo de produção \}.

Como se pode observar, para a escolha da velocidade de corte otimizada assume-se que há um compromisso entre capacidade de produção e custo, o qual deverá ser levado em conta sempre avaliando não apenas o processo na máquina em questão, isolada do processo produtivo, mas a operação de fabricação como um todo, dessa peça e de outras que a acompanham nas máquinas por que passa. Assim a questão da definição se a máquina é gargalo ou não se torna fundamental no modelo, aplicando-se a diversas formas de organização de produção como linhas de fabricação ou células, nas quais o aparecimento de gargalos que se destacam é 
extremamente nocivo à sua economia, gerando estoques intermediários e ociosidades.

Outra contribuição deste trabalho ao critério esboçado em [Coppini 89] é a possibilidade de opção entre a adoção dos valores de $\mathbf{D}$ e de $\mathbf{R}_{\mathbf{k}}$ com maior ou menor extensão. Entenda-se por menor extensão (utilizado em [Coppini 89]) os valores de custos e tempos tomados apenas na etapa de usinagem pura, enquanto que por maior extensão entendam-se os tempos e custos tomados no ciclo total de usinagem, envolvendo a troca de ferramenta, a preparação da máquina, os tempos auxiliares e secundários além do tempo de corte puro. Enfatiza-se o uso dos valores de maior extensão visto representarem a realidade mais fiel do processo de usinagem na fábrica e seus influenciadores. O valor de $\mathbf{D}$, por exemplo, torna-se mais significativo se for calculado como uma relação entre o ciclo total na condição de mínimo custo e o ciclo total na condição de máxima produção, e não apenas como uma relação entre os tempos de usinagem pura nas condições de mínimo custo e de máxima produção (equação 13). Isso ocorre pois é possível ter-se tempos auxiliares e secundários maiores que os tempos de corte puro, mostrando que outros fatores são tão ou mais importantes na otimização que a etapa de usinagem pura simplesmente. Da mesma maneira isso ocorre com o valor de $R_{k}$. No sistema protótipo pode-se fazer uma opção pela adoção do critério de maior ou menor extensão através do arquivo de configuração USINAGEM.INI.

A respeito da adoção dos valores limites de $50 \%$ para a relação de velocidades e de $30 \%$ para a relação de custos, são valores experimentais e que deverão ser assumidos de acordo com a empresa em que se aplica o modelo e seu parque de máquinas e ferramentas disponíveis, além do nível de produção vigente e o grau de ociosidade gerado por isso. A adoção do critério de maior ou menor extensão também influi no resultado, observando-se que para a "maior extensão" os valores limites podem ser menores visto poderem diminuir as diferenças de custos e tempos entre as condições de máxima produção e de mínimo custo. No sistema protótipo esses valores limites podem ser alterados através do mesmo arquivo de configuração citado (USINAGEM.INI).

A utilização de informações de planos já existentes ocorre em duas atividades do modelo. Na atividade 02 - Verificação de Planos Similares - é estabelecido pelo usuário um conjunto de critérios para verificar a existência de planos de fabricação já desenvolvidos similares ao que será estudado agora, com as condições da peça e da operação recém-definidas na atividade 01 - Entrada de Dados da Peça e Seleção do 
Processo e Operação. Dentre os possíveis ítens para a similaridade estão o código da peça, o processo de usinagem, o material da peça, a geometria da peça, etc.. Escolhido o plano similar dentre os eventualmente possíveis, o usuário sempre poderá consultá-lo durante o desenvolver do estudo para a elaboração do novo plano visando uma orientação a ele nesse processo.

$\mathrm{Na}$ atividade 07 - Segunda Pré-seleção de Condições de Usinagem - buscase a similaridade por usinabilidade, ou seja, optar-se-á nessa fase pela adoção de valores de $\mathrm{x}$ e $\mathrm{K}$ de Taylor teóricos ou práticos, dependendo da existência ou não destes últimos. Entenda-se por usinabilidade um conceito mais estendido que o disposto em 2.4.2: é o comportamento do material durante uma operação de usinagem levando em conta os efeitos da máquina, ferramenta e demais condições de usinagem, em particular da profundidade de corte e do avanço. Naturalmente os resultados de experimentos feitos para se obter $x$ e $\mathrm{K}$ de Taylor no chão-de-fábrica deverão ser os preferidos pelo usuário devido ao exposto em 2.4.2.5, em particular pelas explicações e experiências contidas em [Coppini 87, Zhou 92, Kunz 94].

\subsubsection{A Aplicação ao Modelo e ao Sistema das Tendências Observadas nos Sistemas CAPP}

Observou-se no capítulo 2. desta dissertação uma série de tendências para o desenvolvimento dos sistemas CAPP, as quais procurou-se utilizar no modelo e, em particular, no sistema protótipo apresentado.

O modelo é, em seu fundamento, generativo embora se utilize de informações recuperadas de outros planos de processo. Isso o caracteriza como tipicamente semi-generativo, baseado na interação com o processista a quem auxilia, tomando algumas decisões independentemente e lhe deixando a decisão ou entrada de dados em situações mais complexas, como a entrada de dados geométricos.

O modelo permite a sua implementação como um sistema baseado em conhecimento (SBC) porém não se utilizaram as metodologias de projeto de sistemas especialistas (SE) na sua execução. O sistema emprega regras de produção porém não com uma base de regras e uma máquina de inferência que a consulta. A metodologia básica empregada foi a algorítmica com critérios de decisão "SE... ENTÃO..." que incorporam o conhecimento de um especialista. 
O modelo também não se utiliza de recursos como features ou mesmo CAD para a transmissão automática do modelamento da peça da área de projeto de produto para a de planejamento de processos. Esse processo é feito pelo processista ou usuário do sistema. No entanto partes do modelo podem ser reconhecidas como módulos possíveis de serem aplicados na estratégia de planejamento contida em [Rodrigues 93]. Pode-se, para isso, citar os módulos contidos pelas atividades: 08 Segunda Pré-Seleção de Condições de Usinagem; 09 - Cálculo de Tempos e Custos da Operação; 10 - Definição dos Critérios de Otimização e do Plano Final de Processo; e pelas atividades 11 e 12 - Avaliação na Fábrica das Condições de Usinagem e Verificação do Intervalo de Validade da Velocidade de Corte Otimizada Prática, estas duas últimas devendo ser adotadas conjuntamente devido às premissas do ensaio e à necessidade de validação das velocidades obtidas com o seus resultados.

O modelo considera, ainda, a carga-máquina e a definição de gargalos de produção, incluindo o planejamento de capacidade, na estratégia de planejamento adotada.

Por fim, quanto à interface com o usuário, procurou-se um ambiente baseado em janelas (Microsoft Windows ${ }^{\circledR}$ ) para implementação do modelo com suas atividades. Algumas dessas atividades, numa versão com mais recursos, poderiam ser mais automáticas visando auxiliar ainda mais o trabalho do processista. No entanto a facilidade de opções foi enfatizada durante todo o sistema, possibilitando que um usuário com apenas algum conhecimento de processos de usinagem e da fábrica para a qual se planeja seja capaz de tomar as decisões corretas. Uma característica do sistema é a capacidade de retroação do sistema, ou seja, além de se poder colocar diversas condições para a simulação de situações, o sistema permite a correção dessas condições de entrada caso se chegue a uma solução impossível. Casos como esse implicariam, por exemplo, numa nova escolha de profundidade de corte ou de máquina-ferramenta. 


\subsubsection{O Banco de Dados Relacional Adotado}

A utilização de um SGBD com banco de dados relacional é uma das principais características do sistema pois em todas as atividades busca-se ou introduz-se valores nessas tabelas.

Adotou-se, em princípio, o software Microsoft Access ${ }^{\circledast} 2.0$ para a introdução de dados e o gerenciamento pelo usuário. O sistema, porém, trabalhou com uma versão migrada desse $\mathrm{BD}$ para $\mathrm{o}$ ambiente de desenvolvimento da Borland denominado Delphi ${ }^{\circledR}$ 1.0. A seguir descrevemos suscintamente as tabelas e os seus principais campos, conforme as figuras 4.03 e 4.04 :

1. Peças: contém as informações básicas sobre a peça a ser planejada (nome da peça, código da peça e material) e depende de informações do usuário;

2. Peças - Operações \& Processos: contém informações sobre a operação de usinagem e as condições da peça para essa operação (código da peça, processo de usinagem empregado, modo de fornecimento da peça para a operação, descrição geométrica da operação e da peça, rugosidade final requerida, tipo de corte, tipo de trabalho, estado da superfície da peça para a operação, e a dureza Brinell ou tensão de ruptura à tração), dependendo também de informações do usuário;

3. Processos - Características: contém informações de consulta para auxílio ao usuário no momento de especificar o processo de usinagem da operação (relação de todos os processos possíveis, com seus esquemas geométricos e faixas típicas quanto ao tipo de trabalho como desbaste, desbaste leve e acabamento);

4. Peças / Materiais: contém todos os materiais para a peça possíveis de serem utilizados para a determinação dos valores teóricos de $\mathrm{x}$ e $\mathrm{K}$ de Taylor, além da classe de cada material (aço comum, carbono, para beneficiamento, para cementação, ligado para ferramenta, de corte fácil e fundido; ferros fundidos cinzento, nodular e maleável) e seus equivalentes em outras normas e outras características (a denominação básica originase da normalização DIN e as equivalências para referência são $A B N T, S A E$ e AISI); 
5. Peças / Materiais - Modos de Fornecimento: contém uma relação com descrição dos modos de fornecimento (tratamentos térmicos) isolados ou combinados para os materiais da peça ao entrar na operação, com a faixa de valores de tensão de ruptura possíveis;

6. Peças / Materiais - Índices de Usinabilidade: baseada na tabela anterior, relaciona os materiais aos seus modos de fornecimento possíveis, o índice de usinabilidade respectivo, conforme [Johannsen 79], e os valores dos coeficientes de Kienzle para o material nessa condição, também pelo mesmo autor e por [König 94];

7. Parâmetros da Equação de Taylor Expandida: de acordo com o índice de usinabilidade da tabela anterior e com o tipo de material da ferramenta (metal duro ou metal duro recoberto), esta tabela possui os coeficientes citados e sua faixa de validade (conforme [Johannsen 79]);

8. Máquinas: contém os dados das máquinas existentes na fábrica hipotética, seus códigos, as dimensões limites das peças nelas usinadas, limites de rotação e avanço, potência máxima disponível para corte, rendimento do motor-transmissão do eixo árvore, salário-hora-homem (operador da máquina), salário-hora-máquina, salário-hora-preparador da máquina, carga-máquina utilizada, grau de utilização da máquina;

9. Máquinas - Processos: relação dos processos de usinagem possíveis de serem executados em cada máquina existente na tabela anterior;

10. Máquinas - Pré-seleção: contém a seleção de máquinas conforme diferentes critérios adotados em cada etapa, incluindo valores de cargamáquina calculados com os tempos da operação atual;

11. Ferramentas - Materiais: contém todos os materiais possíveis das ferramentas a serem utilizadas na operação (metal duro e metal duro recoberto), com sua descrição;

12. Ferramentas - Geometria: contém uma sequência de geometrias possíveis e adotadas na fábrica e no mercado (formato, tamanho, espessura, esquema geométrico e foto) conforme norma ISO 1832 ([ISO 91, Sandvik 91]) com uma codificação sequencial além dos custos de cada uma confeccionada com metal duro;

13. Ferramentas - Ângulo de Posição: contém os ângulos de posição e o número de arestas de corte possíveis de acordo com o formato da pastilha e o processo de usinagem da operação; 
14. Ferramentas - Pré-seleção: lista um sumário das ferramentas selecionadas, indicando para cada uma a sua geometria, material, ângulo de posição, custo, valores de profundidade de corte e de avanço otimizados, além de valores de x e $\mathrm{K}$ de Taylor teóricos;

15. Ferramentas Existentes / Utilizadas: idem à tabela anterior, a menos dos valores de profundidade, avanço, x e $\mathrm{K}$ de Taylor os quais não são colocados, apenas com as ferramentas que estão sendo utilizadas na fábrica e/ou foram escolhidas pela utilização do sistema. A diferença básica em relação à tabela anterior é que esta fica residente para futuras consultas de ferramentas enquanto a primeira é limpa a cada operação;

16. Condições de Usinagem - Pré-seleção: lista um sumário das condições de usinagem selecionadas, indicando máquina, ferramenta, velocidades de corte limites, de mínimo custo e de máxima produção, tempo de troca de ferramenta previsto, tempo puro de usinagem, tempo total da operação, número de peças feitas por aresta de corte, custo da operação de acordo com a velocidade de corte adotada (mínimo custo, máxima produção ou otimizada) e cargas-máquinas, sendo todos esses valores teóricos;

17. Dados e Tempos do Processo / Operação: contém uma série de informações fornecidas pelo usuário para a peça, operação e máquina, tais como distância de movimentação rápida da ferramenta, tempos de transporte e retirada da peça, fixação, inspeção, troca de ferramenta, preparação da máquina, tamanho do lote, quantidade programada diária e uma indicação se a máquina é ou não um gargalo de produção;

18. Fluidos de Corte Disponíveis: contém uma lista dos possíveis fluidos de corte para utilização na operação com uma recomendação para cada tipo visando auxiliar o usuário na escolha;

19. Ensaios de Usinagem: contém uma descrição dos ensaios de usinagem realizados para a operação indicando o número do ensaio, o critério de desgaste de ferramenta adotado, o fluido de corte, o tipo de cavaco obtido, as velocidades de corte, os tempos de usinagem e os números de peças por vida da ferramenta para cada ensaio, além dos valores das velocidades de corte e custos de mínimo custo, máxima produção e otimizada obtidos pelos dados do ensaio. Todos os valores citados são práticos.

20. Planos Finais de Processo: contém um sumário dos Planos Finais de Processo adotados na fábrica, com valores teóricos e práticos, para 
determinada peça, máquina, ferramenta, condições de usinagem, custos e tempos.

$\mathrm{Na}$ figura 4.04 pode-se observar um quadro com as vinte tabelas citadas e os possíveis relacionamentos entre campos de diferentes tabelas. O sistema utiliza algumas tabelas para consulta, outras para a introdução de dados da peça e da operação, e outras para pré-seleções de máquinas, ferramentas e condições de usinagem; por fim três tabelas são para o armazenamento de informações finais Ferramentas Existentes/Utilizadas, Ensaios de Usinagem e Planos Finais de Processo.

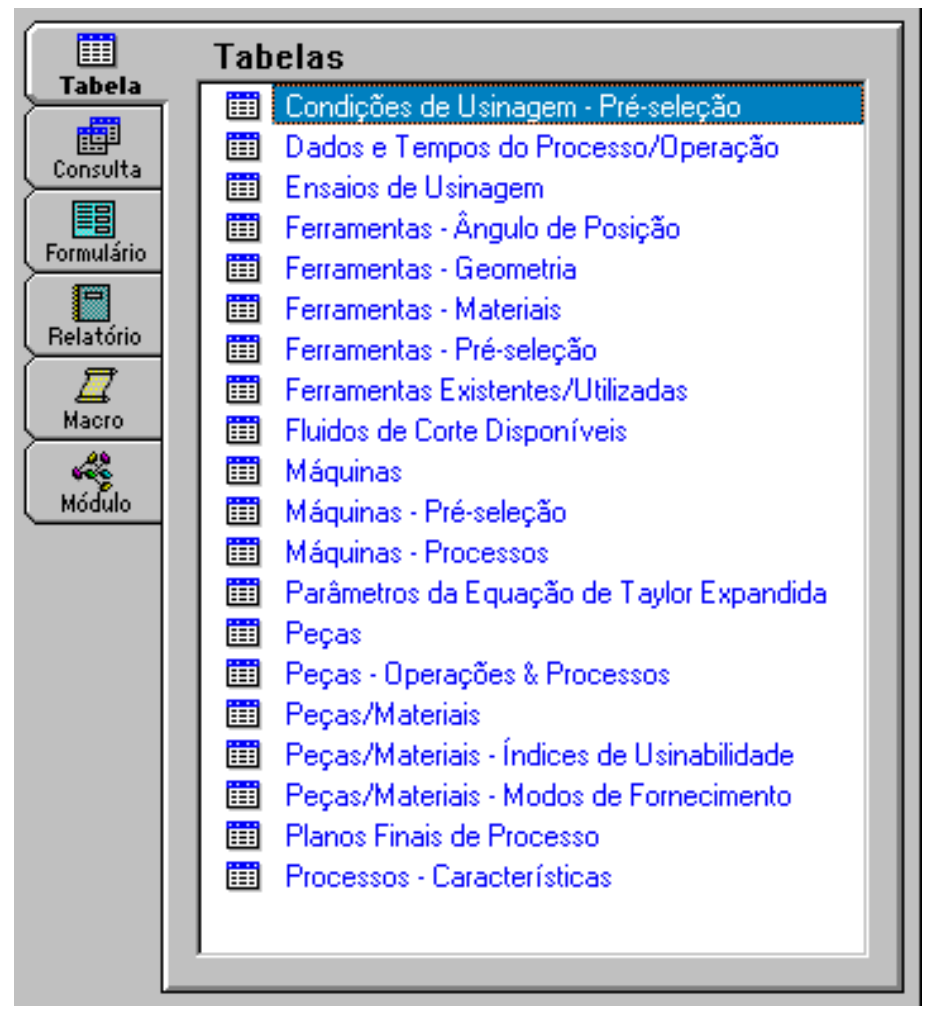

figura 4.03 Tela do software Microsoft Access ${ }^{\circledR} 2.0$ com as tabelas empregadas no sistema de planejamento de processos e determinação de condições de usinagem

\subsubsection{Quadro Geral de Especificações do Sistema Protótipo}

\section{Peças}


- geometria:

cilíndrica ou prismática (dimensões D1 a D4, com a rugosidade em 3 escalas diferentes)

- classes de materiais e materiais: aço comum (4), aço carbono (4), aço para cementação (7), aço para beneficiamento (8), aço ligado para ferramentas (1), aço de corte fácil (5), ferro fundido cinzento (7), ferro fundido nodular (5), ferro fundido maleável (5), aço fundido (6) (total: 52 materiais)

- modos de fornecimento (aço): sem tratamento térmico, descascado, recozido, coalescido, beneficiado, trefilado a frio, conformado a frio, normalizado, beneficiado

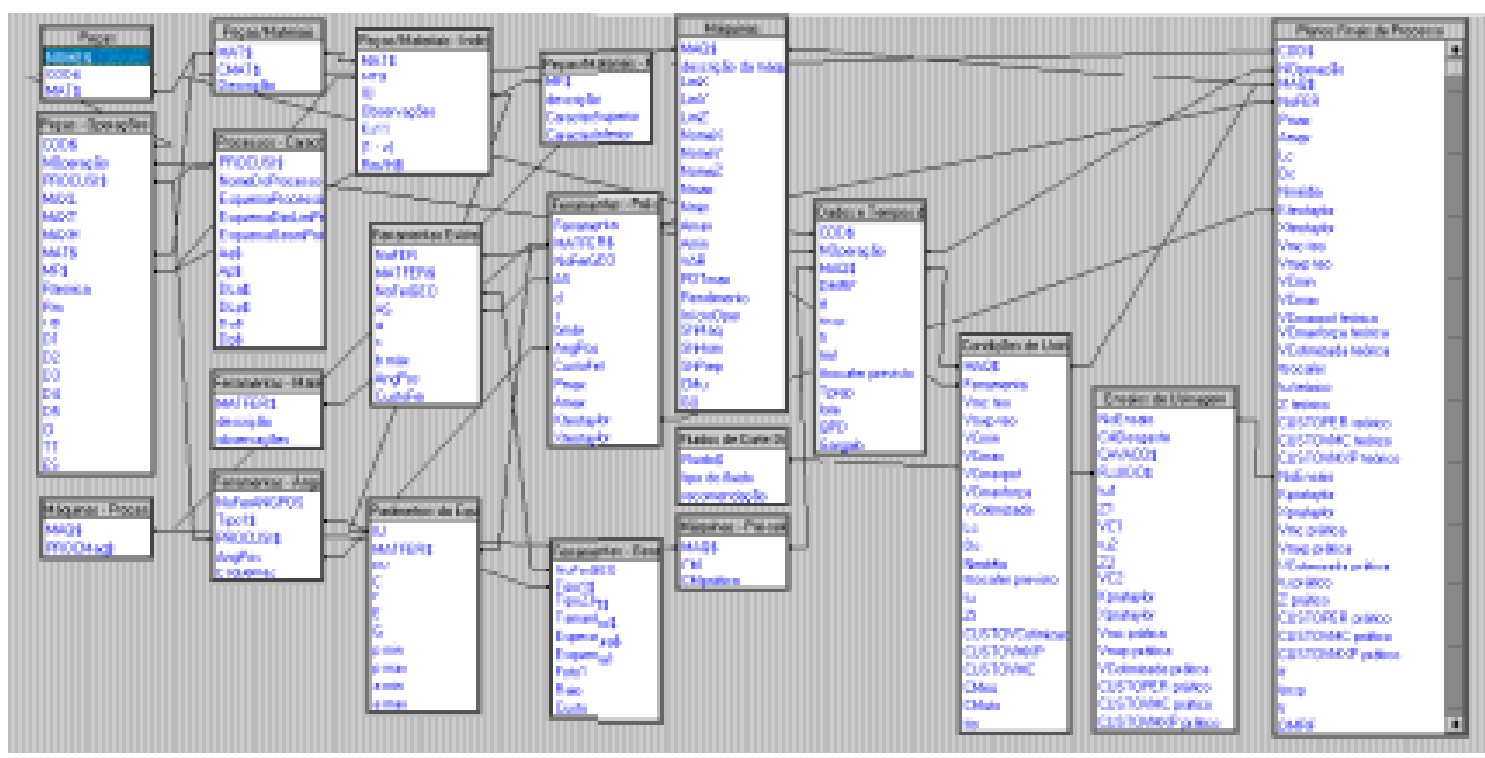

figura 4.04 Tela do software Microsoft Access ${ }^{\circledR}$ com os possíveis relacionamentos entre as tabelas e os campos empregados no sistema de planejamento de processos e determinação de condições de usinagem

\section{Processos de Usinagem}

- denominações (fig. 4.05):

torneamento retilíneo cilíndrico interno (TRCl) torneamento retilíneo cilíndrico externo (TRCE) torneamento retilíneo cilíndrico com sangramento axial (TRCS) 
torneamento retilíneo radial de faceamento (TRF)

torneamento retilíneo radial de sangramento radial (TRRS)

torneamento retilíneo cônico interno (TRCOI)

torneamento retilíneo cônico externo (TRCOE)

- tipo de corte:

interrompido e não interrompido
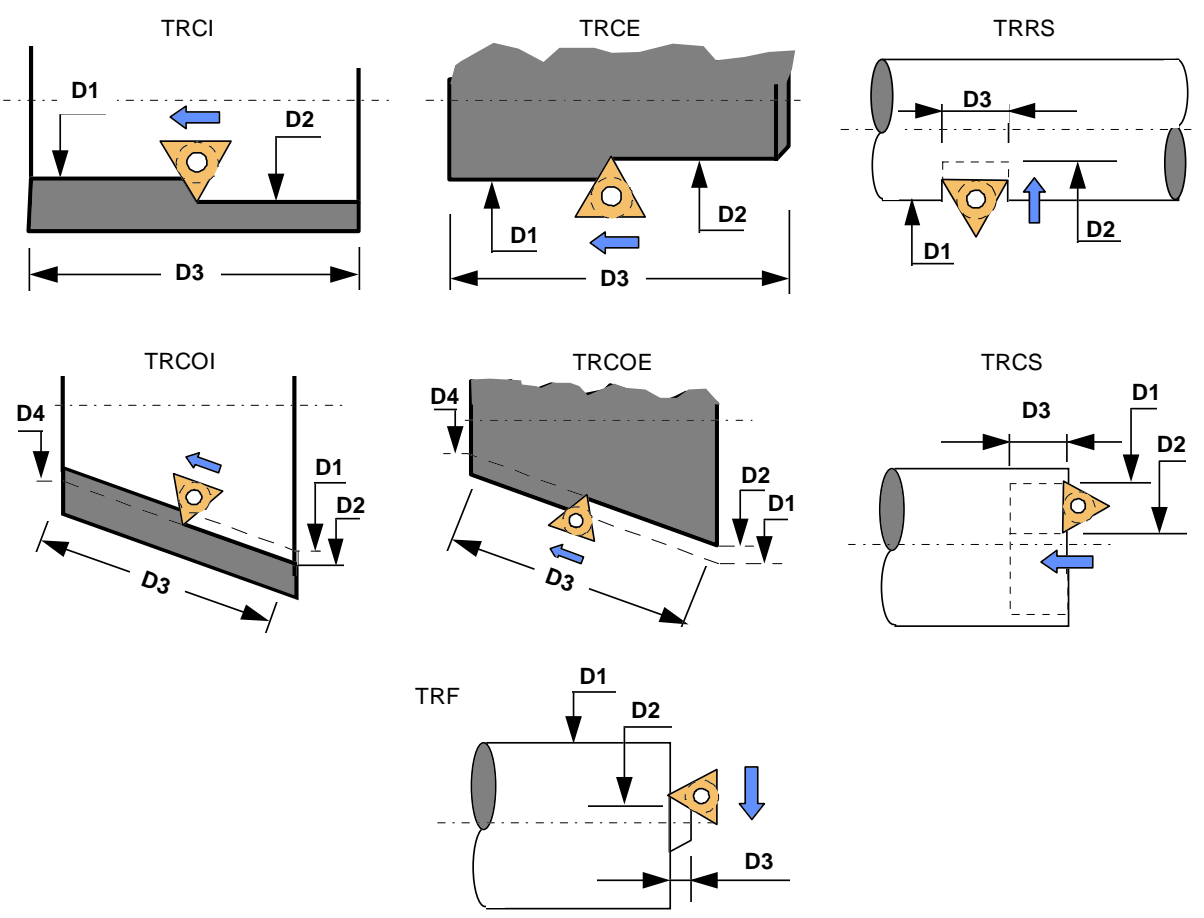

figura 4.05 Processos de usinagem utilizados no sistema protótipo

\section{Máquinas}

- tipo:

- dimensão limite $X$ :

- dimensão limite Y:

- dimensão limite Z:

\section{Ferramentas}

- material:

- tipo de ferramenta: tornos CNC: verticais e horizontais, universais ou não

curso longitudinal do carro

diâmetro máximo torneável

não utilizada no processo de torneamento

metal duro com e sem cobertura $(P, K, M)$ inserto padrão ISO 1832 ([ISO 91]) 
- geometrias possíveis:

SCMT, SPMT, SNMG, CCMT, DCMT, TCMT, CNMG, DNMG

- tamanhos possíveis:

$06 / 07 / 09 / 11 / 12 / 15$ (conforme ISO [91])

- espessuras possíveis:

02 / 03 / T3 / 04 / 06 (conforme ISO [91])

- raios de ponta possíveis:

02 / 04 / 08 / 12 / 16 (conforme ISO [91]) ou, respectivamente, 0,2 / 0,4 / 0,8/1,2/1,6 mm

- ângulos de posição possíveis: $45^{\circ} / 60^{\circ} / 62,5^{\circ} / 75^{\circ} / 90^{\circ} / 91^{\circ} / 93^{\circ} / 95^{\circ}$

(conforme a geometria da ferramenta)

\section{Condições de Usinagem}

- faixas de avanço admitidas conforme o tipo de trabalho (valores máximos sugeridos inicialmente em negrito):

$\begin{array}{ll}\text { desbaste } & \mathbf{1 , 2} \text { a } 0,4 \mathrm{~mm} / \text { rotação } \\ \text { desbaste leve } & \mathbf{0 , 7} \text { a } 0,2 \mathrm{~mm} / \text { rotação } \\ \text { acabamento } & \mathbf{0 , 3} \text { a } 0,1 \mathrm{~mm} / \text { rotação }\end{array}$

- faixas de profundidade de corte admitidas conforme o tipo de trabalho (valores máximos sugeridos inicialmente em negrito):

desbaste

desbaste leve

acabamento
10,0 a $4,0 \mathrm{~mm}$

3,0 a $1,0 \mathrm{~mm}$

1,0 a $0,3 \mathrm{~mm}$

\section{Banco de Dados Utilizado}

- tipo:

- quantidade de tabelas:

- descrição das tabelas: relacional

20

vide item 4.1.5. 


\subsection{Descrição dos Módulos do Modelo Aplicados no Sistema}

Para a descrição dos módulos de atividades, adotam-se os seguintes ítens para melhor caracterização:

- descrição do modelo geral aplicado no módulo, com objetivos e resumo das atividades;

- informações de entrada e de saída para cada módulo no sistema protótipo, com indicação da(s) tabela(s) utilizada(s) entre parênteses;

- processamento adotado no sistema protótipo.

A figura 4.02 possui um fluxograma de referência para as explicações que serão fornecidas a partir do item 4.2.1.

\subsubsection{A Entrada de Dados da Peça e a Seleção do Processo e Operação}

- Descrição do Modelo Geral: permite a introdução de dados da peça e da operação para a BD, com o início do processamento.

- Entradas: denominação e código da peça (Peças), material (Peças / Materiais), modo de fornecimento (tratamento térmico) do material da peça para a operação (Peças / Materiais - Modos de Fornecimento), código e processo de usinagem da operação (Processos - Características), dimensões da peça bruta e da peça usinada para a operação, incluindo a qualidade superficial requerida (rugosidade superficial), tipo de corte, tipo de trabalho (Processos Características), estado superficial da peça bruta, valores de resistência mecânica do material da peça bruta para a operação.

- Processamento: dois blocos de atividades se encontram neste módulo:

a) definição da peça, no qual o usuário consulta o sistema e verifica se há alguma peça idêntica à que pretende planejar. Em seguida escolhe (entra) o seu nome, código, material, modo de fornecimento do material da peça para a operação;

b) definição da operação, no qual o usuário verifica as operações existentes e decide pela próxima, introduzindo os seus dados como o tipo de processo de usinagem, dimensões limites para a peça (conforme 
o processo de usinagem escolhido), dimensões características para o processo (com verificação de validade para os valores entrados), rugosidade superficial final desejada, com valores em $R_{a}$ (desvio médio aritmético, em micrometros), $\mathrm{R}_{\mathrm{rms}}$ (root mean square average ou desvio médio quadrático, em micrometros) ou $R_{t}$ (rugosidade teórica, em micrometros), com conversão automática para $R_{t}$ e verificação de faixa de validade, conforme [Sandvik 91]. O usuário deve ainda informar o tipo de corte (interrompido ou não), o estado superficial da peça bruta (prétorneado/descascado ou bruto de forjamento/fundição), os valores de resistência mecânica do material no estado de fornecimento de acordo com a classe do material (tensão de ruptura à tração, $R_{m}$, para aços $e$ dureza Brinell, HB, para ferros fundidos) e uma estimativa do tipo de trabalho a ser feito (desbaste, desbaste leve ou acabamento).

- Saídas: todos os dados indicados são armazenados em tabelas (Peças; Peças - Operações \& Processos).

\subsubsection{A Verificação da Existência de Planos Similares}

- Descrição do Modelo Geral: permite a seleção de planos com condições similares às propostas no primeiro módulo conforme diferentes critérios de similaridade, para auxílio ao usuário.

- Entradas: critérios de similaridade (código da peça, processo de usinagem da operação, material da peça, classe do material da peça, modo de fornecimento do material da peça, geometria da peça, rugosidade final desejada na operação, tipo de trabalho).

- Processamento: o usuário opta pelo(s) critério(s) de similaridade que deseja e o sistema pesquisa por peças com essa(s) característica(s) (Peças; Peças - Operações \& Processos). Se houver peças que atendam a similaridade desejada, o usuário pode consultar os seus planos de processo (Planos Finais de Processo). Isso pode ser feito a qualquer momento do processo de planejamento através do botão PLANO SIMILAR disposto na tela.

- Saídas: planos similares ao da situação em planejamento. 


\subsubsection{A Primeira Pré-seleção de Máquinas de Usinagem}

- Descrição do Modelo Geral: possibilita a primeira seleção de máquinas possíveis para a operação através de dois critérios: tipo de processo de usinagem e valores das dimensões da peça compatíveis com a máquina.

- Entradas: dados fornecidos através do módulo 4.2.1 (Peças - Operações \& Processos), tais como o processo de usinagem da operação e a geometria limite da peça típica para o processo/máquina, e os processos e dimensões permitidas por cada máquina (Máquinas - Processos; Máquinas). $O$ usuário também deverá introduzir valores pertinentes a cada máquina escolhida tais como: distância para movimentação rápida da ferramenta, tempos de fixação, inspeção e retirada da peça, tempo de preparação da máquina entre operações, tempo de troca da ferramenta, lote de fabricação, quantidade programada diária de peças e uma indicação quanto à máquina ser ou não um gargalo de produção (Dados e Tempos do Processo / Operação).

- Processamento: este módulo permite ao usuário determinar se há máquinas na fábrica capazes de fabricar a peça, considerando o tipo de processo e as dimensões de sua área de trabalho [Machado 87]. Outras considerações como a qualidade do acabamento superficial e a precisão dimensional possíveis poderiam também ser feitas aqui, no que se relaciona à influência da máquina na operação.

O sistema admite até três dimensões limites possíveis conforme o processo e a máquina. Neste caso as máquinas adotadas foram os tornos $\mathrm{CNC}$ e as dimensões limites o máximo curso longitudinal do carro e o máximo diâmetro torneável, dados comuns em catálogos de fabricantes de máquinas.

- Saídas: pré-seleção de máquinas para a operação (Máquinas - Pré-seleção).

\subsubsection{A Primeira Pré-seleção de Ferramentas de Usinagem}

- Descrição do Modelo Geral: permite a definição de até duas ferramentas possíveis (insertos intercambiáveis) com seu material, geometria e posição 
em relação à peça, de acordo com catálogos e informações de fabricantes ([Marcondes 90, Sandvik 91]), normas de usinagem ([ISO 91]), valores orientativos para usinagem de usuários e especialistas ([Johannsen 79, König 94]) e interação com o próprio usuário.

- Entradas: dados fornecidos através do módulo 4.2.1 (Peças; Peças Operações \& Processos) e de outras BDs (Ferramentas - Materiais; Ferramentas Geometria; Ferramentas - Ângulo de Posição).

- Processamento: três blocos de atividades se encontram nesse módulo:

a) definição do material da ferramenta, em que o sistema sugere a adoção de metal duro, metal duro recoberto ou cerâmica, embora seja feita uma especificação detalhada apenas para os dois primeiros. Os critérios adotados são a classe do material da peça, o seu estado da superfície, o tipo de corte e de trabalho, além da resistência mecânica do material (HB ou tensão de ruptura à tração $R_{m}$ ). Na figura 4.06 podese observar uma árvore de decisão típica para a seleção de material da ferramenta adotado em [Johannsen 79]. O sistema indica as alternativas e deixa a escolha final ao usuário, sugerindo, também, o ângulo de saída (positivo ou negativo);

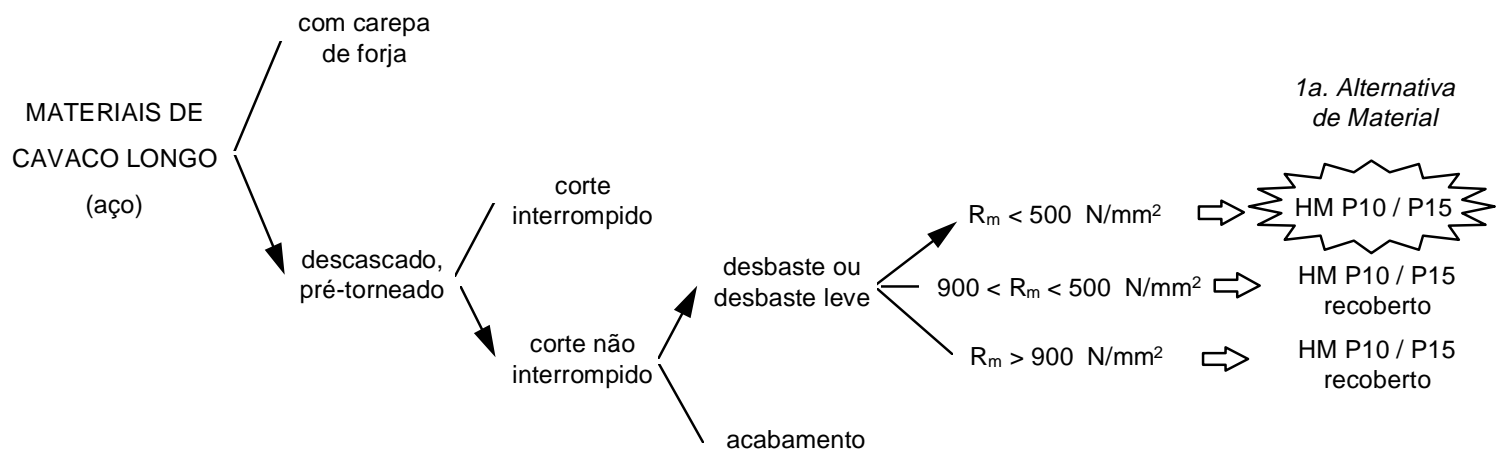

figura 4.06 Exemplo de árvore de decisão para material da ferramenta, conforme [Johannsen 79]

b) definição da geometria da ferramenta, quando o usuário decide entre as várias geometrias disponíveis, escolhendo de acordo com o código contido na norma ISO 1832 [ISO 91] e o seu custo, dimensões e tipo de trabalho para o qual se destina. São determinados o formato geométrico do inserto, ângulo de incidência, tolerância dimensional, tipo da pastilha, 
seu tamanho e espessura. Neste caso utiliza-se, fundamentalmente, o conhecimento especialista do usuário;

c) definição do ângulo de posição, para o qual o sistema orienta o usuário pré-selecionando os ângulos possíveis de acordo com 0 processo de usinagem e o formato geométrico do inserto. Tanto nesta etapa quanto na anterior, o usuário é auxiliado por figuras para a sua escolha. Esse procedimento se assemelha, em muitos aspectos, aos existentes nos recentes bancos de dados eletrônicos para ferramentas [Mason 96]. Vide figura $4.07 \mathrm{com}$ algumas alternativas possíveis. $O$ número de arestas de corte também é definido de acordo com o processo, o formato do inserto e o ângulo de posição adotado.
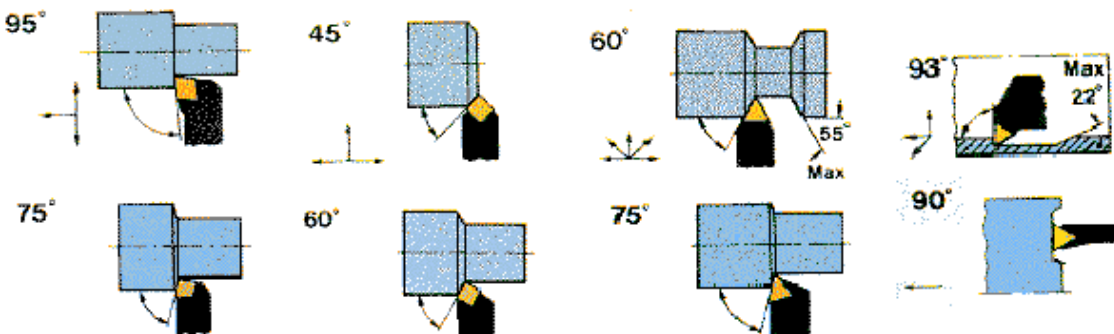

$60^{\circ}$

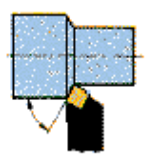

$75^{\circ}$
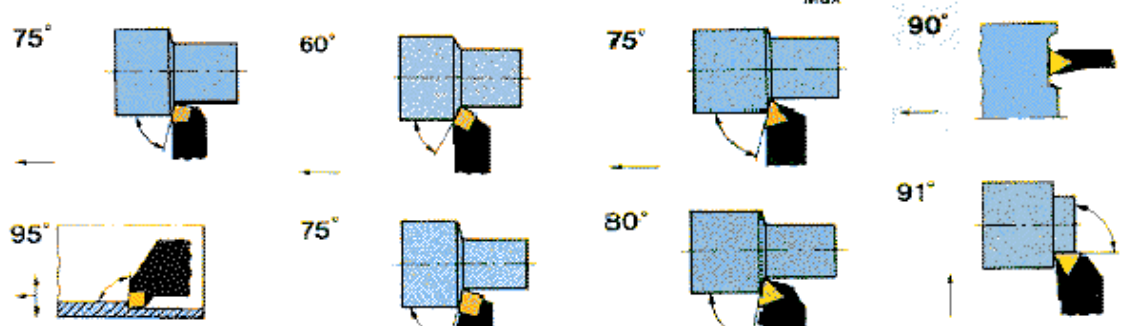

$75^{\circ}$

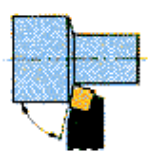

$80^{\circ}$

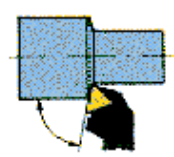

$91^{\circ}$
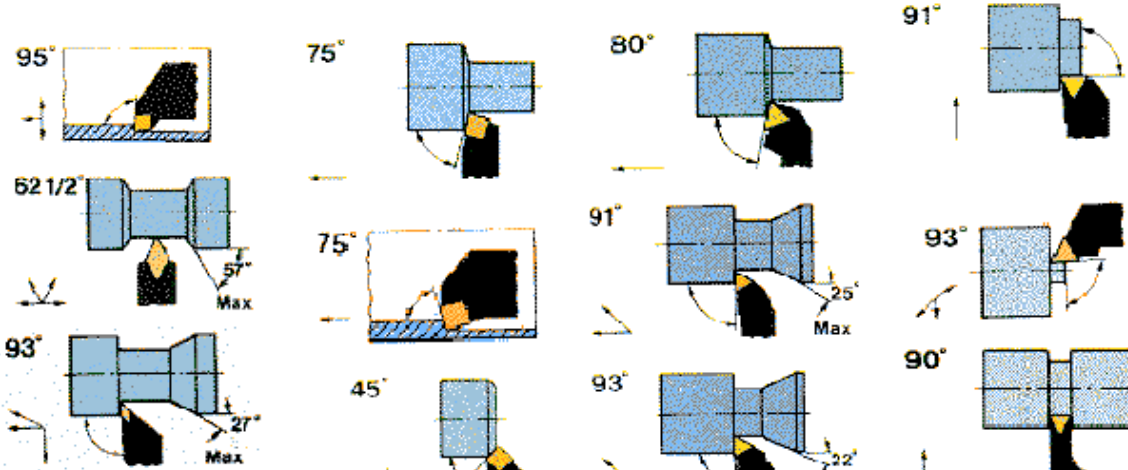

45

5

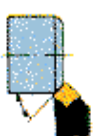

$91^{\circ}$
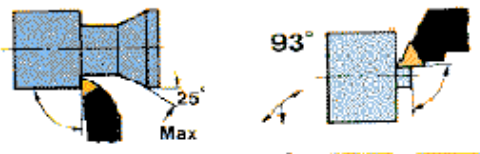

$93^{\circ}$

$90^{\circ}$
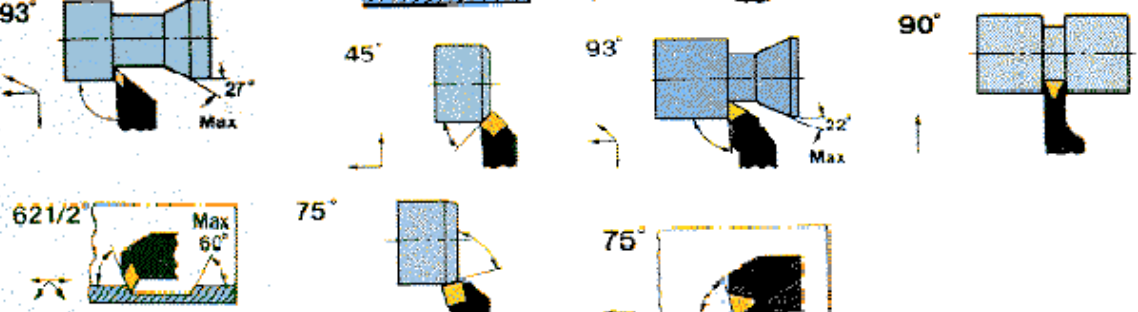

$75^{\circ}$
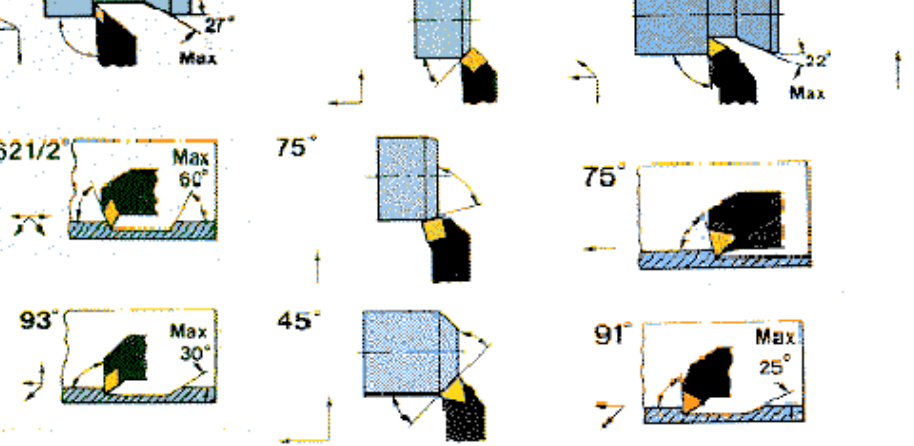

figura 4.07 Algumas geometrias de insertos e ângulos de posição possíveis no sistema 
- Saídas: duas ferramentas alternativas definidas com o mesmo material porém diferentes geometrias e posições relativas à peça (Ferramentas - Préseleção).

\subsubsection{A Primeira Pré-seleção de Condições de Usinagem}

- Descrição do Modelo Geral: determina os valores iniciais de profundidade de corte e avanço, além de consultar a BD de Usinabilidade para estabelecimento das condições teóricas para o cálculo da velocidade de corte.

- Entradas: dados da peça e da operação fornecidos através do módulo 4.2.1 (Peças; Peças - Operações \& Processos), informações quanto aos índices de usinabilidade dos materiais (Peças / Materiais - Índices de Usinabilidade; Parâmetros da Equação de Taylor Expandida) e informações quanto às ferramentas escolhidas em 4.2.4 (Ferramentas - Pré-seleção).

- Processamento: feito em três módulos:

a) determinação da profundidade de corte da operação, no qual o sistema parte de valores tabelados limites (máximos) conforme o tipo de trabalho desejado (vide item 4.1.6) e o restringe por limitações da geometria da ferramenta (aresta de corte) e da geometria da peça (sobremetal a ser retirado). Caso haja necessidade de mais que um passe de usinagem, o sistema informa ao usuário e solicita uma nova geometria da operação. Isso ocorre porque cada passe deve corresponder a uma operação;

b) determinação do avanço máximo, no qual o sistema parte de valores tabelados limites (máximos) conforme o tipo de trabalho desejado para posterior verificação de restrições (vide item 4.1.6);

c) determinação das condições teóricas de usinabilidade, que se baseia na metodologia e dados experimentais contidos na BD de usinabilidade de [Johannsen 79], e no qual se obtém índices de usinabilidade (com base no material da peça e no seu modo de fornecimento) e de correção para a velocidade de corte (devido ao processo de usinagem, ao estado da superfície da peça, ao tipo de 
corte, ao material e à geometria da ferramenta), além dos coeficientes da equação expandida de Taylor. Cabe ressaltar que os dados de usinabilidade são para usinagem a seco, conforme definido em sua fonte, [Johannsen 79].

- Saídas: valores de profundidade de corte e avanço preliminares para cada ferramenta (Condições de Usinagem - Pré-seleção) e valores dos índices pesquisados e calculados.

\subsubsection{A Segunda Pré-seleção de Ferramentas de Usinagem}

- Descrição do Modelo Geral: determina o valor do raio de ponta das ferramentas escolhidas, verificando os valores da profundidade de corte e do avanço, e compatibilizando todos pela busca da qualidade superficial da peça e do menor tempo de usinagem (maior avanço).

- Entradas: valores de profundidade de corte e de avanço (Condições de Usinagem - Pré-seleção), da rugosidade superficial da peça após a operação (Peças - Operações \& Processos), e das ferramentas selecionadas (Ferramentas - Pré-seleção; Ferramentas - Geometria).

- Processamento: de acordo com o tipo de trabalho da operação (desbaste/desbaste leve ou acabamento), o sistema procura garantir a situação em que o raio da ponta do inserto seja menor que a profundidade de corte, alterando os valores do raio conforme disponibilidade, assim como a situação em que o raio e o avanço estejam compatíveis de acordo com o previsto na equação (1), item 2.4.2.5. Neste último caso, primeiramente os valores do raio de ponta são maximizados e, caso a rugosidade desejada não seja atingida, o avanço é reduzido. Por outro lado, caso a rugosidade esteja melhor do que a possível com o avanço definido, o valor do avanço é aumentado até o limite do raio de ponta. A equação (1) foi aplicada para o avanço maximizado predeterminado em 4.2.5 conforme indicações e adaptações contidas em [Sandvik 91, Kunz 94]. O fluxograma de decisão destas adequações está na figura 4.08 e alguns casos de aplicação do algoritmo na figura 4.09. Ao usuário cabe, ao final, a decisão por aceitar ou alterar os valores estimados do raio de ponta, avanço e profundidade de corte. 
- Saídas: valores finais de profundidade de corte, avanço (Condições de Usinagem - Pré-seleção) e raio de ponta para cada ferramenta (Ferramentas Pré-seleção). A ferramenta é, então, efetivamente definida.

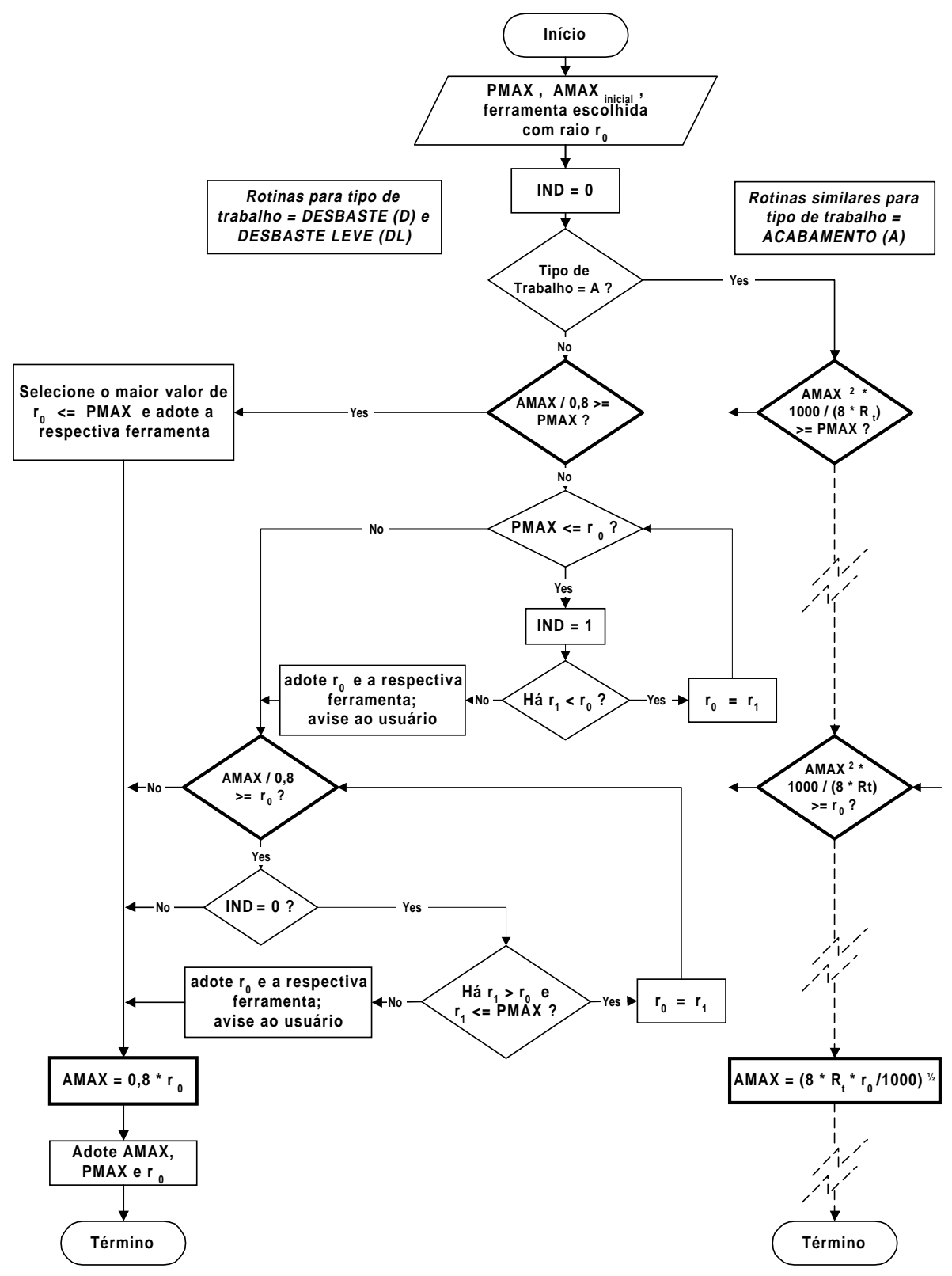

figura 4.08 Fluxograma com a rotina de verificação e correção dos valores do raio de ponta da ferramenta e do avanço máximo AMAX, com base nos valores pré-determinados do raio, do avanço máximo e da profundidade de corte máxima 


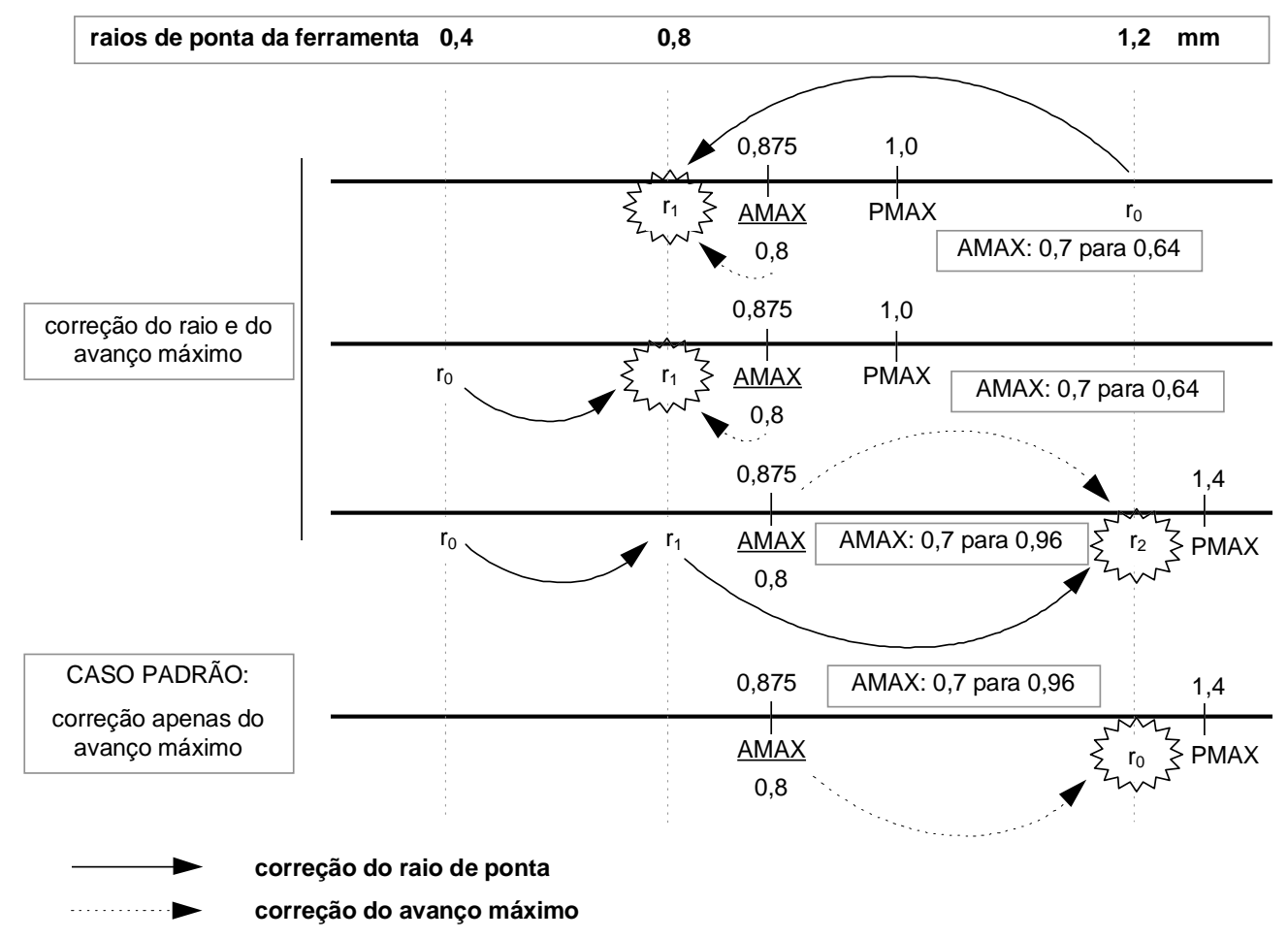

figura 4.09 Alguns casos cobertos pelo fluxograma da figura anterior, mostrando correções de raios de ponta da ferramenta e de avanços máximos, conforme posições relativas de $r_{0}$, AMAX e PMAX (para desbaste e desbaste leve)

\subsubsection{A Segunda Pré-seleção de Condições de Usinagem}

- Descrição do Modelo Geral: com os valores dos coeficientes da equação expandida de Taylor, da profundidade de corte e do avanço definidos nos módulos 4.2.5 e 4.2.6, o sistema calcula os valores de $\mathrm{x}$ e $\mathrm{K}$ de Taylor teóricos e fornece ao usuário a opção entre ( $\mathrm{x}$ e $\mathrm{K}$ de Taylor práticos) ou ( $\mathrm{x}$ e $\mathrm{K}$ de Taylor teóricos) através da busca de planos similares com valores obtidos em ensaios de fábrica. Com a definição de $x$ e $\mathrm{K}$, o sistema calcula as velocidades de corte de mínimo custo e de máxima produção.

- Entradas: critérios de similaridade por usinabilidade adotados (material da peça e seu modo de fornecimento, processo de usinagem da operação, resistência mecânica do material da peça, rugosidade final desejada na operação, tipo de trabalho, tipo de corte, estado da superfície da peça, 
máquina utilizada, material e geometria da ferramenta, valores de profundidade de corte e de avanço), conforme item 4.1.3. Provenientes dos dois módulos anteriores: valores dos coeficientes da equação expandida de Taylor, além de valores auxiliares como o custo da ferramenta, customáquina, custo-homem e o tempo de troca da ferramenta (Ferramentas - Préseleção; Máquinas; Máquinas - Pré-seleção; Condições de Usinagem - Pré-seleção).

- Processamento: o usuário opta entre os valores de x e K de Taylor teóricos ou práticos, caso estes últimos estejam disponíveis através de planos similares. Com esses valores definidos, o sistema calcula os valores de mínimo custo e de máxima produção para a velocidade de corte. Com relação à busca por similaridade de planos de processo, permite-se uma variação de $\pm 1,0 \mathrm{~mm}$ para a profundidade de corte e de $\pm 0,1 \mathrm{~mm} /$ rotação para o avanço.

- Saídas: valores da velocidade de mínimo custo e de máxima produção, teóricas ou práticas (por similaridade).

\subsubsection{A Definição dos Critérios de Otimização e a Seleção Final da Máquina, da Ferramenta e das Condições de Usinagem: o Plano Final de Processo (teórico)}

Os módulos numerados de 08 a 10 no fluxograma da figura 4.02 , embora possuam atividades distintas, muitas delas não ocorrem exatamente em sequência como ilustrado no fluxograma. O resultado final, porém, é único e na forma de duas telas subsequentes: a de definição do critério de otimização e a da determinação da velocidade de corte otimizada e do par máquina/ferramenta. Por isso serão descritos conjuntamente neste item.

- Descrição do Modelo Geral: define o critério de otimização a ser adotado através do cálculo da taxa horária de produção (D) e da relação de custos entre as situações de mínimo custo e de máxima produção $\left(\mathbf{R}_{\mathbf{k}}\right)$, possibilitando a escolha final da velocidade de corte dentro do campo de restrições de potência, rotações e carga-máquina da máquina-ferramenta. Esses módulos do sistema se aplicam a uma situação teórica, proveniente 
de dados de usinabilidade genéricos, ou a uma situação de similaridade da operação, ou, ainda, a um ensaio feito na fábrica (vide item 4.2.9).

- Entradas: dados das máquinas, ferramentas e condições de usinagem préselecionadas (Máquinas - Pré-seleção; Ferramentas - Pré-seleção; Condições de Usinagem - Pré-seleção), com consultas aos dados gerais da operação (Dados e Tempos do Processo / Operação; Peças - Operações \& Processos) e ao arquivo de configuração do sistema USINAGEM . INI (vide item 4.1.3).

- Processamento: pode ser dividido em quatro rotinas (cálculo de tempos e custos; cálculo de carga-máquina; definição do critério de otimização; cálculos auxiliares para as máquinas), as quais também serão utilizadas nos procedimentos de teste na fábrica para a determinação da velocidade de corte otimizada prática (item 4.2.9):

a) cálculo de tempos e custos da operação ${ }^{1}$, na qual se calculam os tempos unitários de usinagem $\left(\mathbf{t}_{\mathrm{t}}, \mathbf{t}_{\mathrm{c}}, \mathbf{t}_{\mathrm{s}}, \mathbf{t}_{\mathrm{a}}, \mathbf{t}_{\mathrm{p}} / \mathbf{Z}, \mathbf{n}_{\mathbf{t}} \cdot \mathbf{t}_{\mathrm{ft}} / \mathbf{Z}\right)$ e os custos da operação de usinagem visando fornecer estas informações ao usuário. Os valores de tempo calculados, baseados na equação (5), são: $\mathbf{t}_{\mathbf{t}}=$ tempo total de usinagem ( $\left.\mathrm{min}\right)$; $\mathbf{t}_{\mathrm{c}}=$ tempo de corte ou de usinagem pura $(\min ) ;$

$\mathbf{t}_{\mathbf{s}}=$ tempos secundários (transporte, fixação, retirada, adicionais da máquina-ferramenta) (min);

$\mathbf{t}_{\mathbf{a}}=$ tempos de aproximação e afastamento da ferramenta (min);

$\mathbf{t}_{\mathbf{p}} / \mathbf{Z}=$ tempo de preparação por peça do lote (min);

$\mathbf{n}_{\mathbf{t}} \cdot \mathbf{t}_{\mathrm{ft}} / \mathbf{Z}=$ tempo de troca de ferramenta por peça do lote (min).

1 Um dos principais determinantes no cálculo de tempos de processo é o próprio tipo de processo de usinagem e a consideração quanto à velocidade de corte ser ou não constante. Adotou-se essa velocidade como constante visto as máquinas serem CNC o que lhes permitem trabalhar nessa condição. Assim para os processos TRCE, TRCI, TRCOE, TRCOI e TRCS calcula-se facilmente um diâmetro equivalente de corte [Pallerosi 73]. Para os processos TRF e TRRS admite-se que a máquina CNC trabalhe com velocidade constante até determinada redução de diâmetro, quando atinge a sua máxima rotação permitida visando manter a velocidade de corte constante. A partir desse ponto a rotação permanece constante e a velocidade de corte decresce até o centro da barra em torneamento, quando se anula. [Pallerosi 73] estuda esse caso de rotação constante e propõe uma fórmula que compensa a variação de velocidade de corte no desgaste da ferramenta enquanto [Johannsen 79] sugere uma fórmula simplificada (por média quadrática dos diâmetros) e que aproxima a de [Pallerosi 73]. No entanto verificou-se que os desvios dos valores obtidos pela média linear dos diâmetros inicial e final são apenas levemente superiores aos valores das fórmulas dos autores citados, o que nos leva, por simplificação, a adotá-la no sistema protótipo sem causar erros consideráveis nos valores dos tempos. Isso ocorre, principalmente, devido ao $\mathrm{CNC}$ da máquina compensar a rotação para manter a velocidade de corte constante na maior parte do percurso da ferramenta, sendo o percurso com rotação constante, em geral, pequeno. 
Quanto aos custos, adota-se a fórmula (15) que difere da equação (5) apenas pela introdução de um salário diferenciado (preparador de máquina $-\mathbf{S}_{\mathbf{p}}$ ), o qual, em geral, é superior ao do operador normal. Observa-se, no entanto, uma tendência em se ter o operador de máquina também executando a função de preparador, tornando-se um operário polivalente com um nível de salário igual ou pouco superior ao seu atual. Na equação (15), mostrada a seguir, as três parcelas correspondem, respectivamente, ao custo homem/máquina da operação, ao custo homem/máquina da preparação e ao custo da ferramenta.

$$
K_{u}=\left(S_{h}+S_{m}\right) \cdot \frac{t_{c}+t_{s}+t_{a}}{60}+\left(S_{p}+S_{m}\right) \cdot \frac{t_{p}}{60 \cdot Z}+\frac{K_{f t}}{Z_{t}}
$$

b) cálculo de carga-máquina ${ }^{2}$, na qual, através dos diversos valores de tempo da operação calculados em (a) e adotando-se a $\mathbf{v}_{\operatorname{mxp}}$ como a velocidade para a menor carga máquina possível (pois este valor implica no menor tempo de usinagem e, assim, na maior produção), calcula-se a carga-máquina necessária para a operação. Esse valor advém da relação calculada para um dia de produção:

$$
C M_{N O}(\%)=\frac{T_{P N O}}{T_{P D}}=\frac{t_{t} \cdot q p d}{960 \cdot G U} \cdot 100
$$

$$
\text { onde } \begin{aligned}
\mathbf{C M}_{\mathrm{NO}} & =\text { carga-máquina necessária à operação (\%); } \\
\mathbf{T}_{\mathbf{P N O}} & =\text { tempo de produção necessário à operação (min); } \\
\mathbf{T}_{\mathbf{P D}} & =\text { tempo de produção disponível (min); } \\
\mathbf{t}_{\mathbf{t}} & =\text { tempo total de usinagem (min) (vide equação (5)); } \\
\mathbf{q p d} & =\text { quantidade programada de peças diariamente; } \\
\mathbf{G U} & =\text { grau de utilização da máquina (\%). }
\end{aligned}
$$

Adotou-se para o tempo de produção disponível $\left(\mathbf{T}_{\mathbf{P D}}\right)$ dois turnos de

\footnotetext{
${ }^{2}$ Entenda-se por carga-máquina o valor percentual do tempo disponível de trabalho da máquina para o qual ela realmente possui programação de peças para fabricação e por Grau de Utilização (GU) ou Eficiência Média da máquina o percentual do tempo total disponível realmente possível de utilização para a produção da peça (retirando-se os tempos de manutenção e outros motivos de parada não previstos) [Toledo Jr. 79].
} 
trabalho, cada um com oito horas ou $480 \mathrm{~min}$, totalizando $960 \mathrm{~min}$ por dia, equivalente a uma carga-máquina disponível de 100\%.

c) definição do critério de otimização, já explicada no item 4.1.3, baseiase em informações dos limites do intervalo de máxima eficiência, ou seja, das velocidades de corte de mínimo custo e de máxima produção, analisando-as com base em suas relações $\mathbf{D}$ e $\mathbf{R}_{\mathbf{k}}$, que correspondem, respectivamente, à capacidade de produção e aos custos da operação entendido nos conceitos de maior ou menor extensão citados. A escolha da velocidade de corte otimizada para cada par ferramentamáquina só ocorrerá após a definição do critério de otimização específico para esse par.

d) cálculos auxiliares para as máquinas, na qual, após a definição do critério de otimização para o par ferramenta-máquina, calculam-se os valores da força de corte necessária e da velocidade de corte máxima devido à restrição de potência e de rotação da máquina-ferramenta utilizada na operação. Para o cálculo da força de corte $\mathbf{F}_{\mathbf{c}}$, utiliza-se a expressão simplificada (equação (17)), não dependente da velocidade de corte, e uma que incorpora a dependência da velocidade contida em [Couers 90]. A expressão simplificada da força de corte é oriunda da formulação de Kienzle [Ferraresi 85]. A equação (18) mostra a expressão da velocidade de corte com a restrição da máxima potência. Os valores das velocidades de corte com a rotação mínima também são mostrados no conjunto de gráficos de velocidades do sistema. Com isso o sistema calcula e mostra graficamente as restrições de potência e de rotação, limitando a velocidade de corte otimizada quando for o caso. $\mathrm{O}$ resultado final é um valor dessa velocidade perfeitamente adequado ao campo de restrições da máquina, ao campo de restrições de custo e da capacidade de fabricação, e à logística da fábrica. Quanto a este último aspecto da velocidade otimizada, são mostrados os valores da cargamáquina necessária à operação e total da máquina, além de uma indicação quanto a ela ser ou não gargalo de produção, tornando-se a decisão final quanto à escolha do conjunto ferramenta-máquinacondições de usinagem pertencente ao usuário.

Equações utilizadas para a Força de Corte e a Restrição de Potência: 


$$
\begin{aligned}
& F_{c}=\frac{p}{\sin \chi} \cdot(a \cdot \sin \chi)^{(1-z)} \cdot K_{S 1.1} \\
& v_{\text {cmaxpot }}=\frac{P_{\text {maxmaq }} \cdot \eta \cdot 60000}{F_{c}} \\
& \text { onde } \mathbf{F}_{\mathrm{c}} \quad \text { = força de corte para o torneamento }(\mathrm{N}) \text {; } \\
& \text { p = profundidade de corte }(\mathrm{mm}) \text {; } \\
& \text { a } \quad=\operatorname{avanço~}(\mathrm{mm} / \mathrm{rot}) \text {; } \\
& x \quad=\text { ângulo de posição da ferramenta }\left({ }^{\circ}\right) \text {; } \\
& \mathbf{K}_{\mathrm{S1.1}}=\text { constante de força de corte específica do } \\
& \text { material para uma seção de corte de } 1 \mathrm{~mm} \text { de } \\
& \text { espessura por } 1 \mathrm{~mm} \text { de largura }\left(\mathrm{N} / \mathrm{mm}^{2}\right. \text { ) (fórmula } \\
& \text { de Kienzle); } \\
& \text { (1-z) = coeficiente da fórmula de Kienzle; } \\
& \mathbf{v}_{\mathrm{c} \text { maxpot }}=\text { velocidade de corte com restrição de potência } \\
& \text { da máquina }(\mathrm{m} / \mathrm{min}) \text {; } \\
& \mathbf{P}_{\text {maxmaq }} \quad=\text { potência máxima da máquina }(\mathrm{kW}) \text {; } \\
& \eta \quad=\text { rendimento da transmissão entre o motor e o } \\
& \text { fuso da máquina }(0<=\eta<=1) \text {. }
\end{aligned}
$$

- Saídas: valor da velocidade de corte otimizada, com o conjunto ferramentamáquina-condições de usinagem determinado pelo usuário (Planos Finais de Processo; Ferramentas Existentes / Utilizadas).

\subsubsection{A Avaliação na Fábrica das Condições de Usinagem e a Verificação do Intervalo de Validade da Velocidade de Corte Otimizada Prática}

Os módulos 11 e 12 do fluxograma da figura 4.02 são considerados conjuntamente devido à integração entre as duas atividades e descritos a seguir. 
- Descrição do Modelo Geral: módulo de orientação geral para os ensaios de usinagem na fábrica, baseado na metodologia de [Coppini 87, Coppini 89] (vide item 2.4.2.6) modificada, com registro de dados dos mesmos e cálculo das condições de usinagem práticas assim obtidas.

- Entradas: dados fornecidos através do módulo 4.2.1 (Peças - Operações \& Processos), além de informações finais deduzidas e contidas no Plano Final de Processo (Planos Finais de Processo; Ferramentas Existentes / Utilizadas), tais como profundidade de corte, avanço, velocidade de corte otimizada teórica, características da ferramenta e da máquina escolhida, etc.. Os possíveis fluidos de corte também são provenientes de uma tabela existente (Fluidos de Corte Disponíveis).

- Processamento: este módulo orienta o usuário na preparação e registro do ensaio de chão-de-fábrica, fornecendo alternativas para a definição do critério de fim de vida da ferramenta conforme o tipo de trabalho, alternativas para o registro do tipo do cavaco obtido (baseado na norma ISO 3685 [ISO 93]) e do tipo de fluido de corte utilizado, se for o caso. O sistema descreve os procedimentos para o ensaio e permite o registro dos valores previstos nas equações (11) e (12) para cálculo de x e K de Taylor práticos. Como default, o sistema calcula e deixa na forma de orientação ao usuário os valores das velocidades de corte a serem adotadas no ensaio, os tempos teóricos de usinagem pura e os números de peças teóricos por aresta de corte, sendo esses valores substituíveis pelos definidos/obtidos no ensaio. Baseado nesses valores, o sistema calcula as velocidades de mínimo custo e de máxima produção, permitindo a entrada na rotina de definição de critérios de otimização. Definida a velocidade de corte otimizada prática para a operação, o sistema verifica o seu intervalo de validade antes de permitir a sua adoção. Para isso é adotado o intervalo de validade, ou seja, o intervalo entre as duas velocidades empregadas no ensaio ( $\mathbf{V}_{\mathbf{C} 1}$ e $\mathbf{V}_{\mathbf{C}_{2}}, \mathbf{V}_{\mathbf{C}_{1}}>\mathbf{V}_{\mathbf{C}_{2}}$ ), de forma que a velocidade otimizada prática deverá pertencer a ele. Esse processo de decisão é mostrado a seguir e baseia-se na adoção de variações progressivas de $\pm 20 \%$ nas velocidades de corte dos ensaios objetivando obter valores da velocidade otimizada dentro do intervalo de validade e das restrições do sistema máquina-ferramenta: 


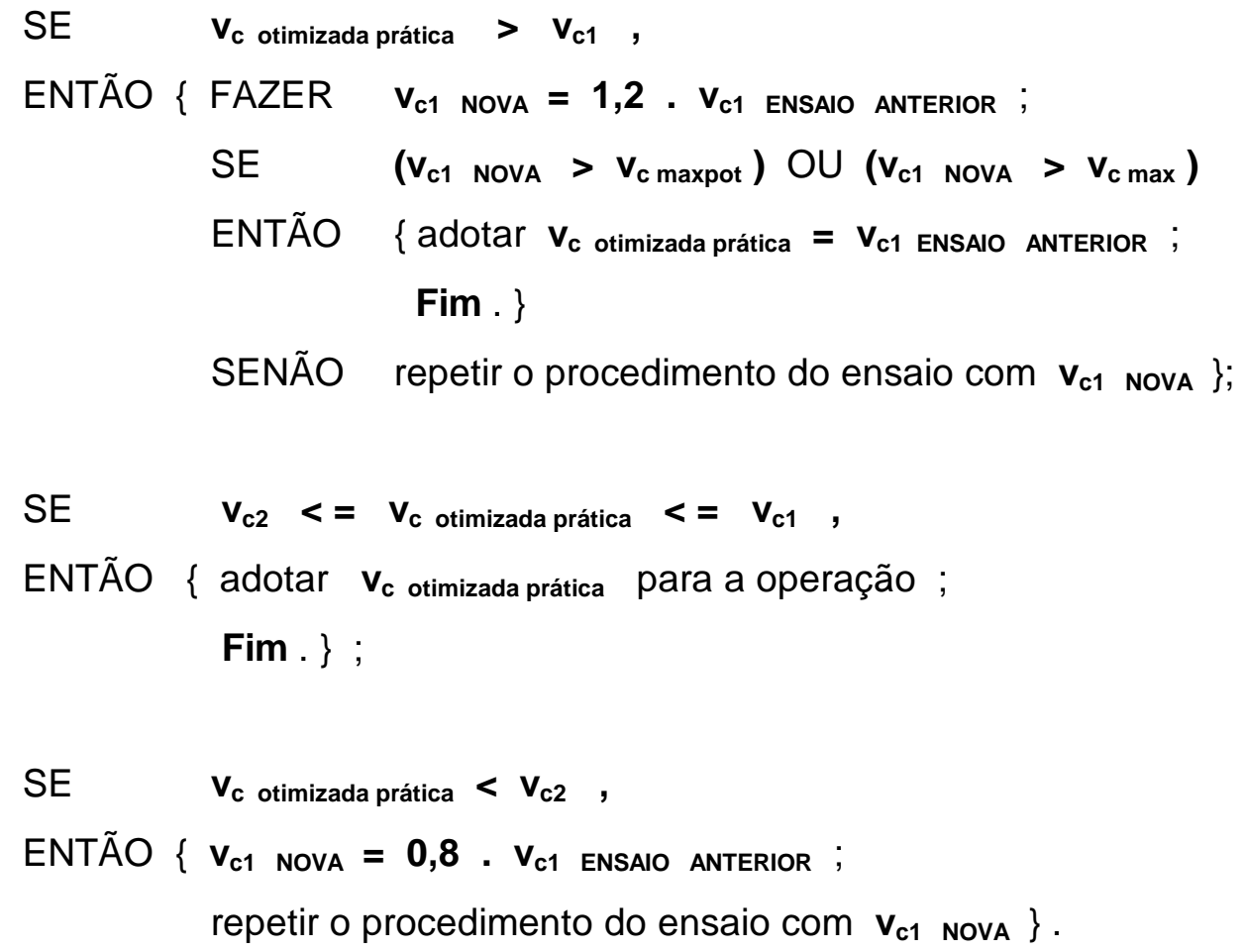

O valor da velocidade otimizada pode ser definido pelo usuário, visto o sistema indicar uma faixa de valores com uma tendência. Ao se decidir por determinado valor, o sistema julga a sua validade e, caso não seja válido, o procedimento de ensaio se repete até a velocidade de corte otimizada estar dentro do respectivo intervalo de validade.

Os valores das velocidades $\left(\mathrm{v}_{\mathrm{c}}\right)$, números de peças usinadas por aresta de corte $\left(Z\right.$ ) e tempos de usinagem do ensaio $\left(t_{c}\right)$ são verificados quanto à sua coerência $\left(v_{c 1}>v_{c 2} \Rightarrow Z_{1}<Z_{2} \Rightarrow t_{c 1}<t_{c 2}\right)$.

Há algumas diferenças entre esta metodologia de validação e a de [Coppini 89], principalmente quanto ao tipo de velocidade em discussão. Enquanto em [Coppini 89] a velocidade discutida era a $v_{m \times p}$, aqui ela é denominada velocidade de corte otimizada a qual pode ser tanto a $\mathrm{v}_{\mathrm{mxp}}$, como a $\mathrm{v}_{\mathrm{mc}}$, como algum valor intermediário entre ambas, respeitando os critérios de custo e produção sugeridos em 4.1.3. Outro ponto de diferença é quanto à maximização da velocidade devido à restrição de potência ou rotação que pode existir na sequência dos ensaios. Propõe-se a adoção da última velocidade de corte ensaiada $\left(\mathrm{v}_{\mathrm{c} 1}\right)$ como a velocidade otimizada devido à posição do ensaio estar numa evolução positiva o que implica estar a velocidade válida acima da $\mathrm{v}_{\mathrm{c} 1}$ atual e que não poderá ser aumentada pela restrição existente. 
Devido a essa extensão no conceito da velocidade discutida, merece uma observação a adoção de critérios de convergência desse processo de validação. Pela observação do gráfico contido em [Coppini 87] com uma curva típica de vida de uma ferramenta com expoente $\mathrm{x}$ de Taylor variável, a convergência do método poderá não ocorrer caso o passo de evolução dos ensaios seja muito elevado relativamente ao intervalo entre as duas velocidades do ensaio. No entanto, pelos resultados obtidos por [Coppini 89, Bernardo 86], o valor de $20 \%$ para o intervalo entre velocidades do mesmo ensaio e entre ensaios tem se adequado, aliando praticidade e convergência para a metodologia de ensaio.

A figura 4.10 ilustra uma possível evolução das velocidades de corte otimizadas de acordo com a sequência de ensaios. No ponto 1 observa-se a velocidade otimizada teórica a qual será sugerida pelo sistema como velocidade inicial do ensaio. O ponto 2 define a velocidade otimizada calculada pelo sistema baseado nos resultados do ensaio. Observa-se que a velocidade 2 está fora do intervalo de validade, sendo a única velocidade válida a de número 1 , mas que pode estar, ainda, abaixo da otimizada ideal. Ao se executar um novo teste, no entanto, os resultados obtidos poderão indicar a velocidade 3 como otimizada, a qual, porém, está abaixo da faixa de validade. Em casos como esse não se deve continuar executando as indicações do sistema pois isso poderá gerar um ciclo ou looping de sugestão de velocidades otimizadas e de ensaios de difícil saída. Pode-se sugerir, nesse caso, a adoção pelo usuário da última $\mathrm{v}_{\mathrm{c} 1}$ (velocidade 1 da figura 4.10) como velocidade otimizada preferencialmente às velocidades 2 ou 3 . Outra sugestão é redução no fator de progressão de velocidades de $20 \%$ para $10 \%$, por exemplo, de forma a se ter uma evolução mais gradual das velocidades otimizadas calculadas e propostas pelo sistema. O usuário deverá, assim, fazer essa análise e ponderar sobre a utilização de uma ou outra velocidade como otimizada ou para o ensaio. Outro fato que poderá acontecer é o resultado da sequência de ensaios fazer atingir a denominada velocidade de corte limite para criação de gargalo. Esta velocidade, como lembrado em 4.1.3, resulta da adoção de valores reduzidos de velocidade otimizada de forma que a máquina se transforme num gargalo de produção na sua célula ou linha de fabricação. No entanto essa discussão é algo difícil de se introduzir no sistema pois 
depende não apenas da peça que se analisa e de todas as suas operações, mas também das demais peças que são fabricadas pela máquina. Também deverá o processista aqui, tendo uma noção geral do tempo necessário para a fabricação na sequência de máquinas, fazer uma análise e ponderar sobre esse limite de velocidade.

Também poderá ocorrer uma mudança nos valores de $\mathbf{D}$ e de $\mathbf{R}_{\mathbf{k}}$ que faça com que o sistema altere a forma de sugerir ao usuário a tendência nos valores da velocidade otimizada. Este é mais um fato a ser ponderado na análise do usuário e as mesmas considerações feitas no parágrafo anterior podem ser aplicadas aqui.

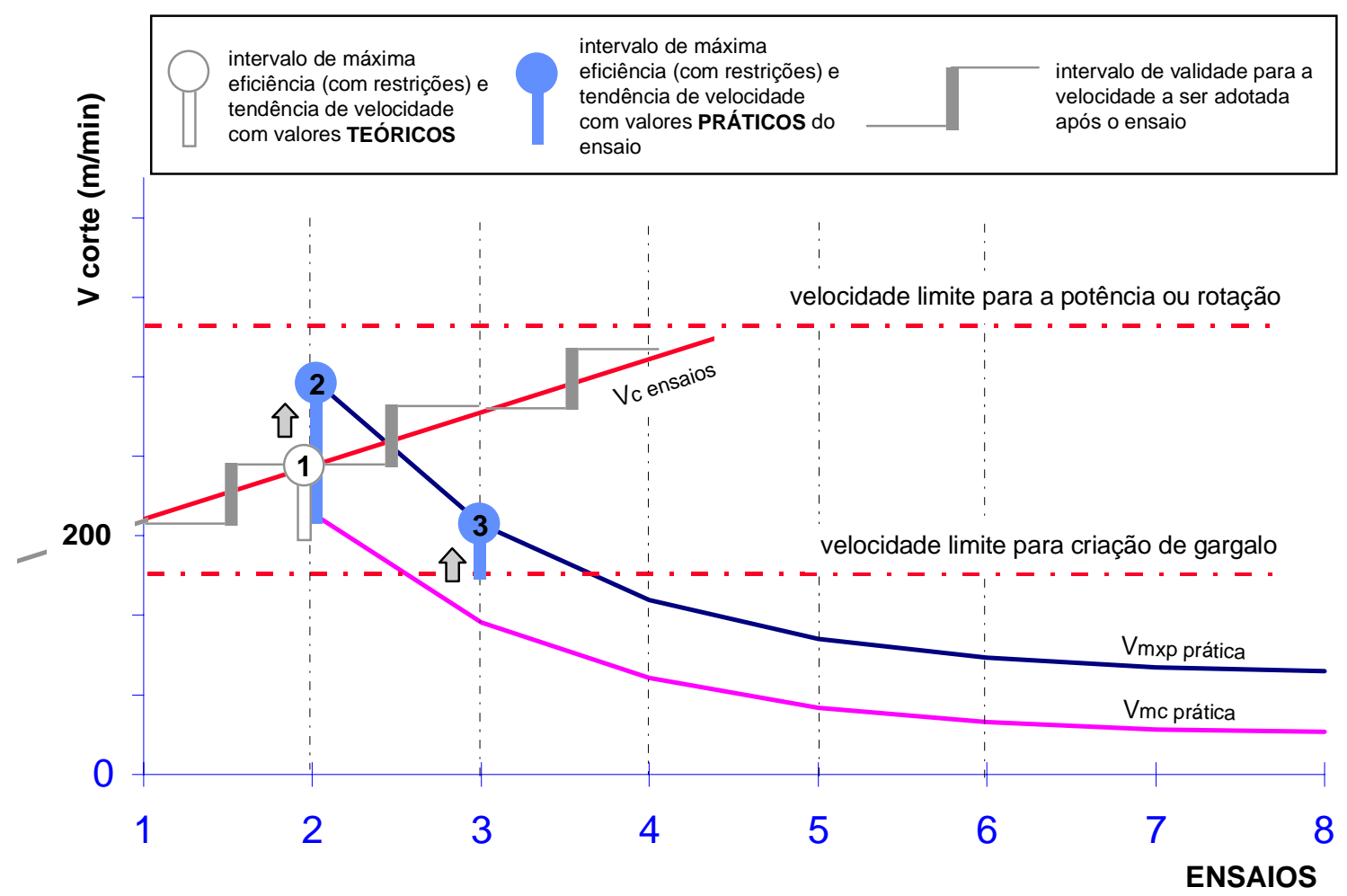

figura 4.10 Gráfico ilustrativo de uma possível evolução das velocidades otimizadas de corte de acordo com a sequência de ensaios e mudanças no critério de otimização

Deve-se, por fim, observar que a precisão da base de dados de usinabilidade exerce um papel importante na convergência dos resultados dos ensaios para a velocidade de corte otimizada prática. Quanto mais imprecisa seja a velocidade otimizada teórica, mais ensaios serão necessários para se alcançar a velocidade otimizada prática. Para a visualização desse efeito, basta observar e estender a linha de ensaios da 
figura 4.10 para a esquerda, o que aumenta o número de ensaios necessários.

Propõe-se para o futuro um estudo mais especializado quanto à introdução dessas alterações no critério proposto em [Coppini 89], suas novas restrições e a questão da convergência do método, de maneira a se ter uma implementação facilitada no sistema protótipo, garantindo a uniformidade na aplicação desses critérios. Uma proposta para a base desse estudo pode estar contida em [Almeida 96] pela utilização de lógica nebulosa ou fuzzy.

- Saídas: dados do(s) ensaio(s) (Ensaios de Usinagem), incluindo os valores de $x$ e K de Taylor práticos além das velocidades de corte de mínimo custo, de máxima produção, de máxima potência, de máxima/mínima rotação e otimizada prática, disponíveis para o trabalho na máquina. 


\subsection{Recursos de Software e Hardware Empregados}

Visando dotar o usuário com um sistema de interface mais amigável e moderna, com recursos gráficos e que possibilitasse o trabalho com bases de dados relacionais, escolheu-se o ambiente Microsoft Windows ${ }^{\circledR} 3.1$ (podendo ser utilizado, também, no Microsoft Windows $\left.{ }^{\circledR} 95\right)$. Dentro desse ambiente de janelas, optou-se pela utilização do Delphi ${ }^{\oplus} 1.0$ da Borland, que é uma linguagem orientada a objetos e que se utiliza de código em Pascal para o desenvolvimento dos programas [Rubenking 96]. O programa pode ser executado sem a ajuda do ambiente de desenvolvimento Delphi ${ }^{\circledR}$.

Junto à utilização do Delphi ${ }^{\oplus} 1.0$ e pela necessidade de um gerenciador de base de dados relacionais, foi empregado o BDE - Borland Database Engine - que acompanha o pacote Delphi ${ }^{\circledR}$. Pela facilidade de uso, no entanto, optou-se por começar a geração do BD de Usinagem, composto por vinte tabelas, com o Microsoft Access $^{\circledast}$ 2.0, conforme explicado em 4.1.5, migrando-se posteriormente para $\circ \mathrm{BDE}$ para a utilização pelo sistema Delphi ${ }^{\circledR}$. No sistema protótipo a inclusão, retirada ou edição de informação das tabelas da BD deverão ser feitas através do BDE devido ao vínculo necessário deste com o Delphi ${ }^{\circledR}$. Para o trabalho com as tabelas dentro do sistema utilizou-se o recurso do Delphi ${ }^{\circledR}$ que permite trabalhar com SQL (Structured Query Language) para selecionar registros e campos das tabelas. Esse recurso foi um facilitador na utilização do banco de dados relacional empregado.

Quanto ao tipo de computador empregado, o sistema pode ser processado em micros tipo PC que suportem o ambiente Microsoft Windows ${ }^{\circledR}, 3.1$ ou superior. Todo o desenvolvimento foi feito num microcomputador Pentium de $133 \mathrm{MHz}$, com 16 Mb RAM e sistema Microsoft Windows ${ }^{\circledR} 3.11$.

Embora não tenha sido utilizada uma ferramenta computacional própria para o desenvolvimento de sistemas especialistas, o que permitiria uma separação mais clara entre os fatos e as regras do modelo, o sistema protótipo poderia ter sido implementado nesse tipo de software visando facilitar a introdução e alteração de regras e conhecimento adquirido pela utilização do sistema. Para fins de obtenção de um protótipo, no entanto, a solução adotada atendeu perfeitamente às premissas iniciais. 


\subsection{Considerações sobre a Utilização do Sistema numa}

Fábrica

O sistema protótipo não possui embutido um gerenciador de base de dados para a introdução ou eliminação de registros das tabelas diretamente. Essa função é importante pois o planejador pode operar em duas situações com o sistema:

a) a fábrica já possui a máquina e/ou a ferramenta para a operação com a peça - neste caso o sistema consulta as tabelas de máquinas e de ferramentas existentes e as utiliza para a composição do plano de processo para a peça;

b) a fábrica não possui a máquina e/ou ferramenta para a operação com a peça - este caso pode ocorrer quando se estuda a viabilidade da aquisição de uma máquina, por exemplo, e o seu impacto em termos de logística de produção, tendo-se alguns dados funcionais sobre a mesma (dimensões para trabalho, potência, rendimento, rotações, avanços), uma estimativa dos custos a ela vinculados (salário-máquina, salário-homem, salário-preparador) e outras informações relativas propriamente à logística (grau de utilização previsto, carga-máquina potencial). Neste caso torna-se necessário o acesso às tabelas para a mudança das condições mais fácil e rapidamente.

As informações relativas às ferramentas dependem, fundamentalmente, da base de dados de usinabilidade que contém os parâmetros da equação de Taylor e uma avaliação dos índices de usinabilidade para cada material e seu modo de fornecimento. Observa-se que esses valores são tanto mais precisos quanto mais se aproximem dos ensaios de fábrica, conforme mostrado na figura 2.14 [Kunz 94]. Assim pode-se afirmar que a precisão da avaliação teórica da velocidade de corte otimizada está muito ligada a essa fonte de informações. No caso do sistema protótipo os parâmetros da equação de Taylor, originários de [Johannsen 79], não estão sendo correlacionados com qualidades de material de ferramentas de fornecedores específicos, o que pode implicar em valores diferenciados quando da adoção de determinado material similar a outro porém obtido de outro fornecedor e/ou especificação. Assim, um metal duro P05 de um determinado fornecedor ou lote de fabricação poderá ser diferente do fabricado por outro ou de outro lote. Essa realidade, pela experiência do autor, ocorre na fábrica e muitas vezes implica em 
variações do processo significativas, principalmente no que diz respeito à vida da ferramenta. Para o caso do metal duro, por exemplo, a explicação para isso está na porosidade, microestrutura e composição química que cada fabricante adota e que faz o segredo comercial do seu produto, aliadas às diferenças que também existem entre os diversos tipos de recobrimento de cada um. Por outro lado, determinado material específico de um fabricante de insertos de metal duro pode pertencer a várias classes de HM. [Kunz 94] possui várias tabelas correlacionando as classes ISO de material ( $\mathrm{P}, \mathrm{M}$ e $\mathrm{K})$ com os materiais de diversos fabricantes e que poderiam ser utilizadas como tabelas de recorrência no sistema protótipo. Cabe lembrar que a especificação ISO de materiais citada em 2.4.2.3 é voltada mais a aplicação do material do que à sua composição química.

Quanto ao tempo de troca de ferramenta, adotou-se apenas um valor específico, seja para a situação teórica seja para a prática pois, uma vez medido e definido o tempo padrão de troca pelo operador, esse valor deverá ser posto como meta e seguido. Assim pode-se afirmar que esse valor de tempo de troca provém da área de produção, é adotada como dado de planejamento e volta para a produção como meta a ser obtida ou melhorada. Neste último caso a informação deve ser retornada à área de planejamento para reavaliação do plano de processo. Isso concorda com o exposto em 2.2 ao se afirmar que a função de planejamento visa uma determinação sistemática de métodos de fabricação que sejam econômicos e competitivos, tornando-se uma tarefa que não ocorre uma única vez mas é constante.

Apesar do fluxograma da figura 4.02 mostrar a avaliação na fábrica das condições de usinagem (atividades 11 e 12) como uma atividade sequencial ao planejamento teórico, isso nem sempre é possível em virtude das duas realidades em que ocorrem as etapas teórica e prática, a primeira normalmente num escritório e a outra no chão-de-fábrica. Além disso, o processo de planejamento, como já citado no início deste item, pode iniciar se sem a existência física de determinada máquina na fábrica, por exemplo. Posteriormente, ao se adquirir a máquina, executa-se o ensaio para se obter os valores mais precisos de $\mathrm{x}$ e de $\mathrm{K}$ de Taylor e, por consequência, da velocidade de corte otimizada prática. Assim, visando possibilitar o prazo correto de aplicação a cada uma das etapas, o sistema tem uma opção inicial de planejamento teórico e outra de ensaio de fábrica, podendo cada uma ser feita a seu tempo para a mesma peça e operação. 


\section{Capítulo 5}

\section{A Simulação Numérica do Sistema e os Testes Práticos}

Para teste do sistema, adotou-se uma peça genérica: um semi-eixo para caminhão. Deseja-se planejar uma sequência de operações de torneamento externo para se chegar a uma condição de acabamento que possibilite o tratamento térmico (beneficiamento). Não se fará o plano completo de processo mas apenas o que se refere à operação inicial de desbaste.

\section{- Semi-eixo Genérico}

Pode-se observar um esquema simplicado da peça e das suas especificações dimensionais na figura 5.01. A peça bruta é fixada no torno através de um sistema com contra-pontas e arrastador. São previstos dois passes: um de desbaste e outro de desbaste mais leve. As informações passadas pelo processista ao sistema são:

\section{DADOS DE ENTRADA}

peça:

código da peça:

operações:

material:

modo de fornecimento:

estado da superfície:

tipo de corte:

tipo de trabalho:

\section{semi-eixo de teste}

T001

duas (10. e 20. passes)

aço DIN 42 Cr Mo 4

sem tratamento térmico

bruto, forjado

não interrompido

$1^{\circ}$ passe - desbaste

( $2^{\circ}$ passe - desbaste leve)

dimensões limites da peça: MÁX $L=1070 \mathrm{~mm} ; \quad$ MÁX $T=50 \mathrm{~mm}$

geometria para a operação: $1^{\circ}$ passe - $\quad \mathrm{D} 1=49 \mathrm{~mm}$; D2= $47 \mathrm{~mm}$; D3=1035,5 mm

Rugosidade final $=\mathrm{Rt} 30 \mu \mathrm{m}$

$\left(2^{\circ}\right.$ passe - $\quad \mathrm{D} 1=47 \mathrm{~mm} ; \mathrm{D} 2=46 \mathrm{~mm} ; \mathrm{D} 3=1035,5 \mathrm{~mm}$

Rugosidade final $=$ Rt $10 \mu \mathrm{m}$ )

tensão de ruptura à tração da peça bruta: $\quad 300 \mathrm{~N} / \mathrm{mm}^{2}$ 
quantidade diária programada:

tamanho do lote de fabricação:
150 peças/dia

300 peças

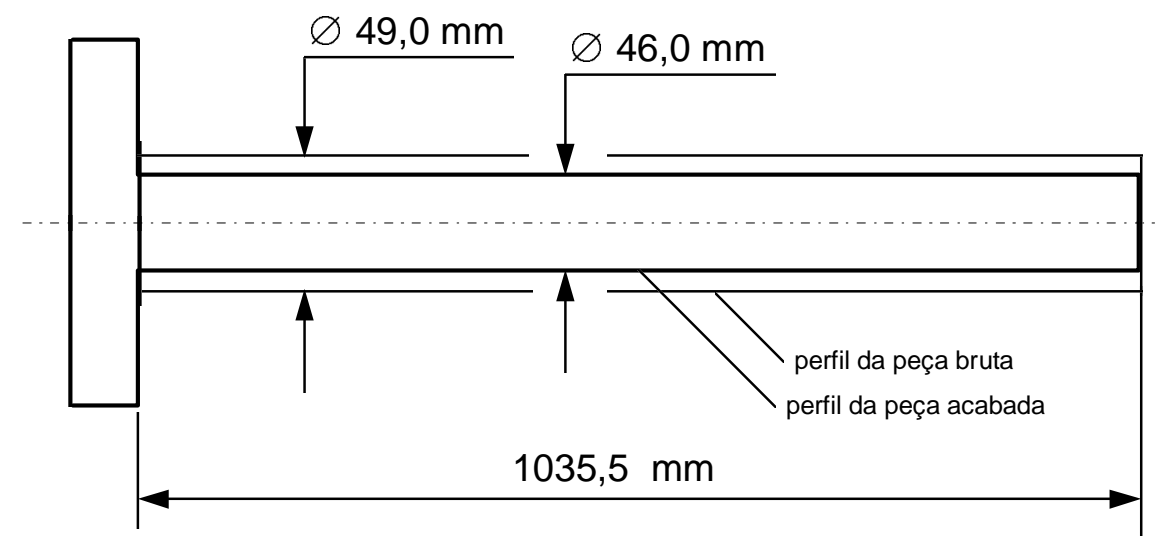

figura 5.01 Esquema simplificado para o semi-eixo utilizado como exemplo de aplicação do sistema

\section{INTERAÇÃO COM O PROCESSISTA NO PRIMEIRO PASSE (Operação $\mathbf{n}^{\circ}$ 1)}

$\Rightarrow$ não foram encontrados planos similares para acompanhamento de referência.

Dentre as máquinas possíveis por operação e por condições dimensionais (vide figura 5.02), foi escolhida apenas a máquina 3 (torno revólver CNC TND - 360) e introduzidos os dados adicionais relativos a ela e a operação (vide figura 5.03);

$\Rightarrow$ material da ferramenta: dentre os quatro possíveis selecionados pelo sistema, foi escolhido o metal duro da classe P05, sem cobertura;

$\Rightarrow$ seleção da geometria (vide figura 5.04): para estudo foram escolhidas duas ferramentas, a DNMG 150612 e a SNMG 1204 12. O avanço e a profundidade de corte inicialmente adotadas devido ao tipo de trabalho (desbaste) foram, respectivamente: 1,2 mm/rotação e 10,0 mm. Esses valores foram corrigidos, para ambas as ferramentas, para 0,64 mm/rotação e 1,0 $\mathrm{mm}$, com raio de ponta de $0,8 \mathrm{~mm}$, visando atender às condições dimensionais e de rugosidade da peça. Por sua vez as ferramentas foram alteradas para DNMG 150608 e SNMG 1204 08, respectivamente, pelo mesmo motivo;

$\Rightarrow$ não foram encontrados planos similares por usinabilidade, assumindo-se, então, os valores de x e K de Taylor teóricos; 


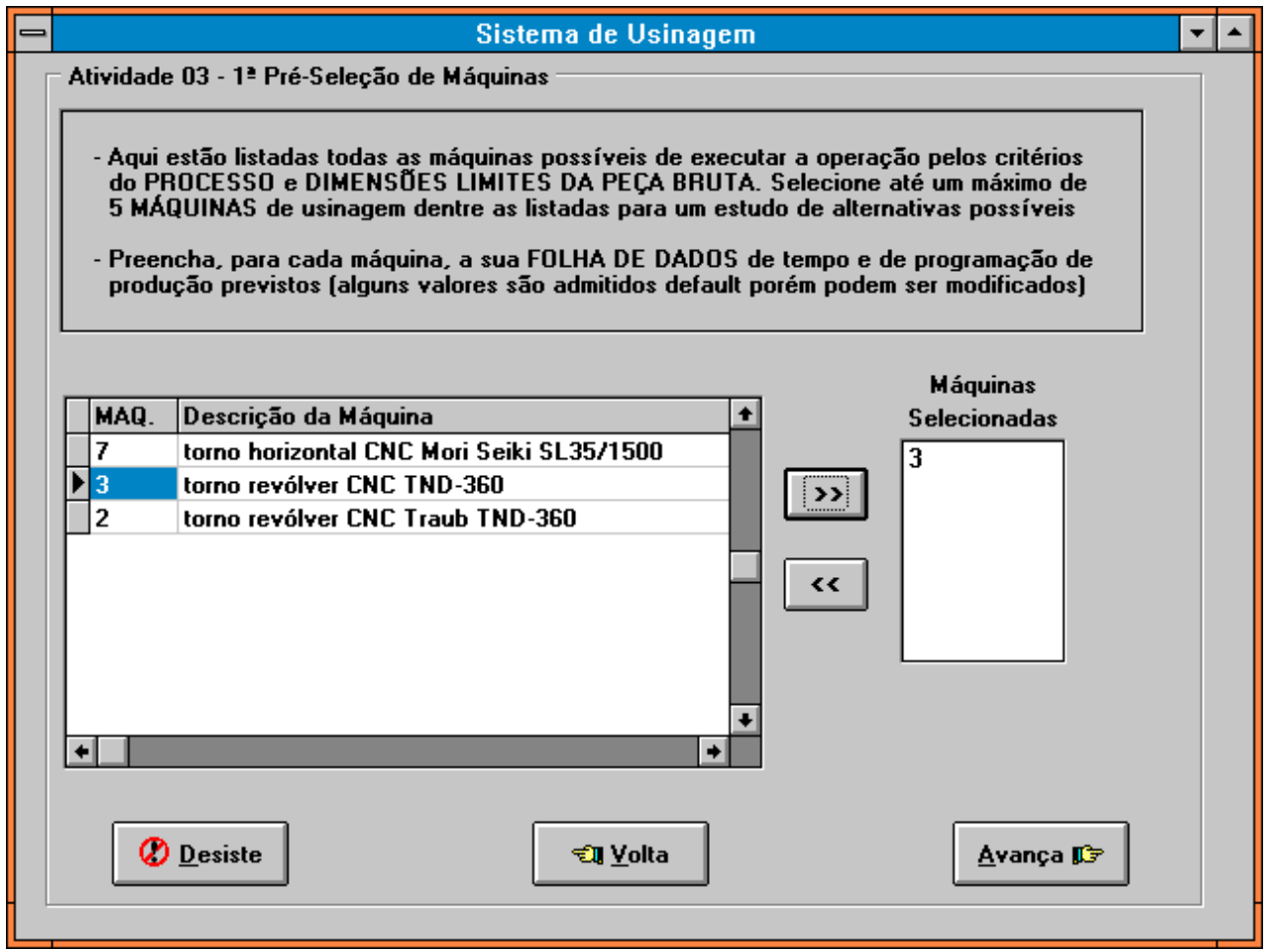

figura 5.02 Máquinas selecionadas por operação/condições dimensionais e a escolha da máquina ${ }^{\circ} 3$ para estudo - Torno Revólver CNC TND-360

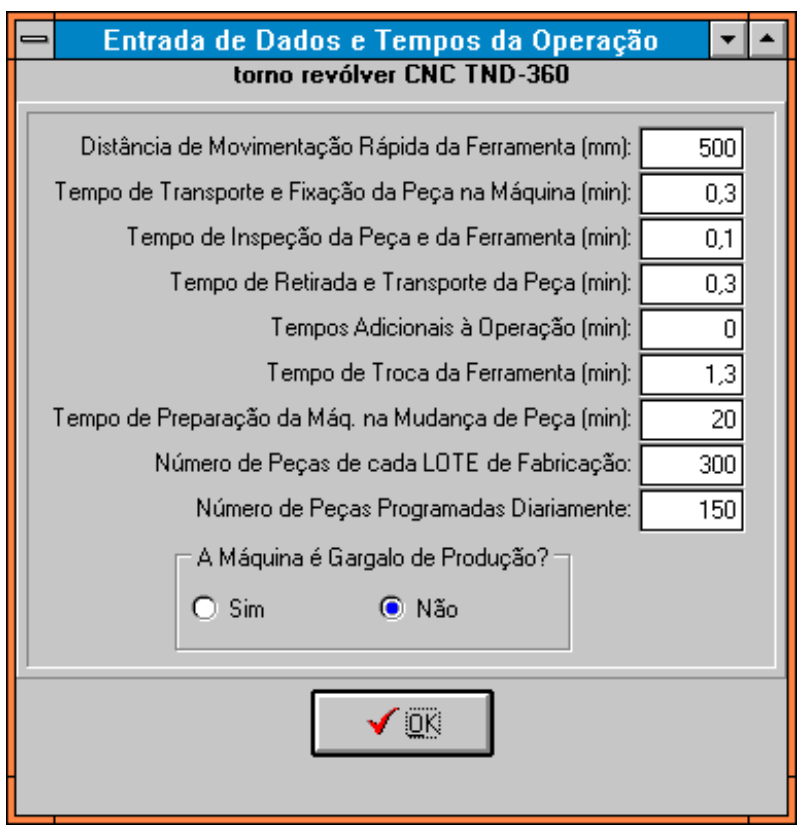

figura 5.03 Máquina escolhida para execução da operacão (máquina 3) e os dados e tempos definidos para a mesma e para a operação 


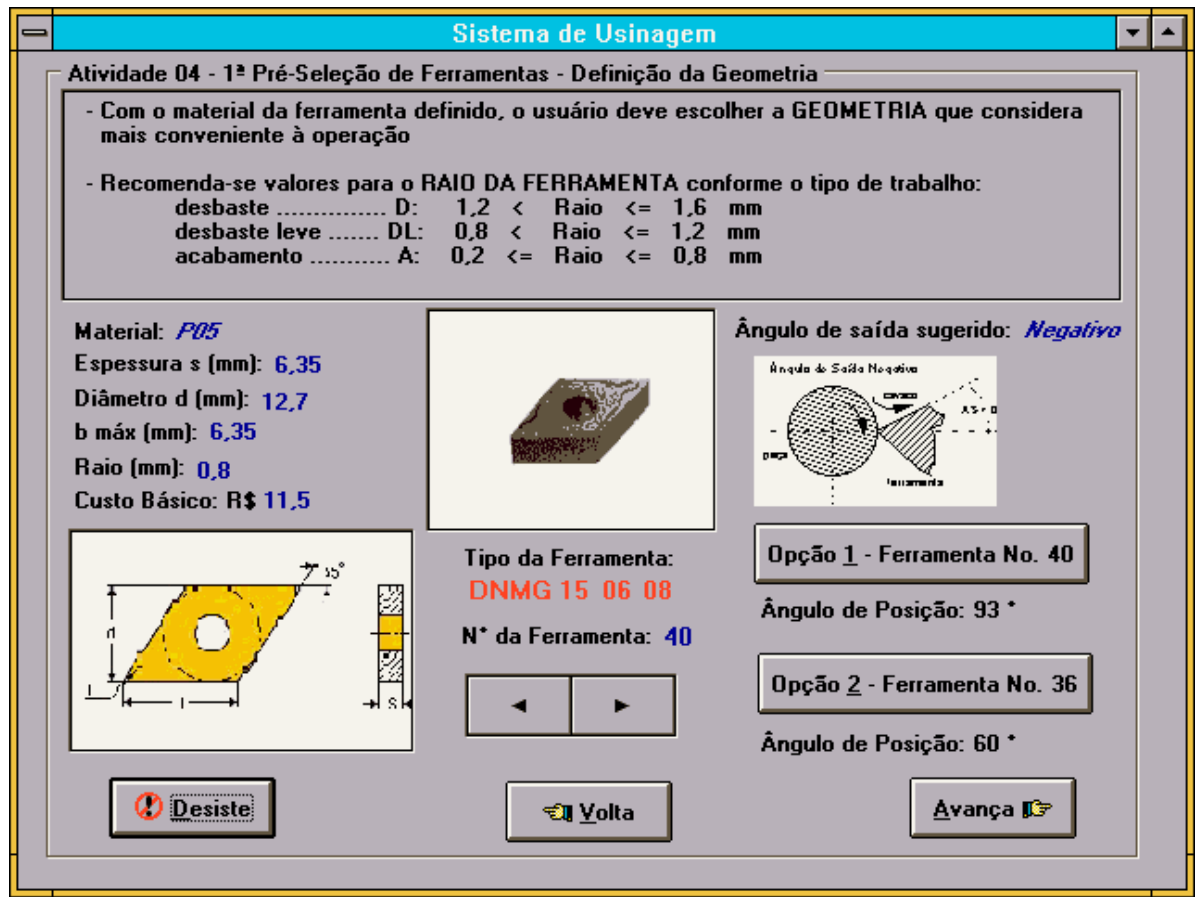

figura 5.04 Quadro de escolha da ferramenta, com indicações de material, ângulo de saída sugerido e ângulo de posição já definido. As sugestões iniciais do usuário foram Opção 1: DNMG 150612 => DNMG 150608 (n40), e Opção 2: SNMG 120412 => SNMG 120408 ( $\left.n^{\circ} 36\right)$, alteradas pelo sistema

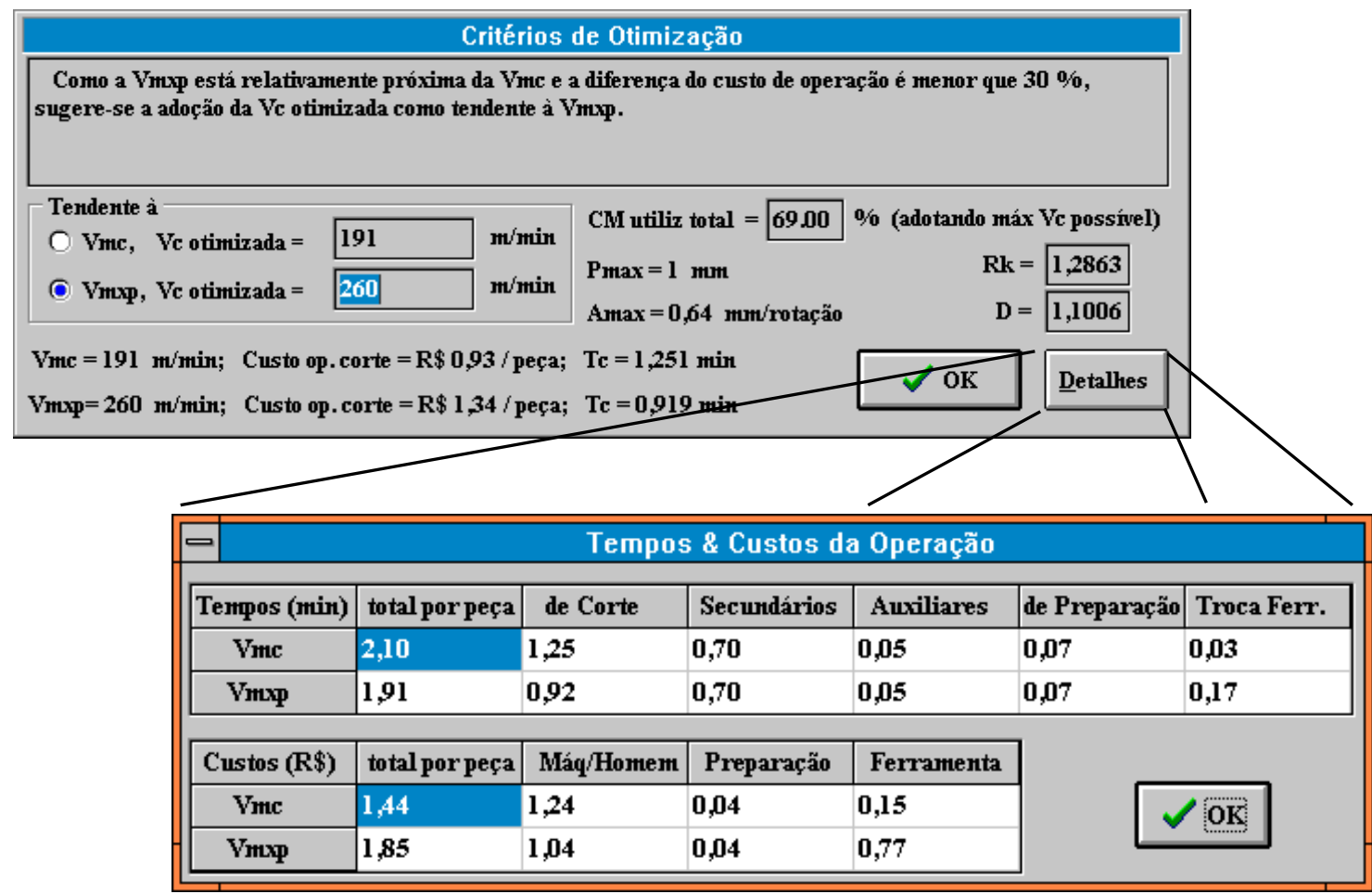

figura 5.05 Definição dos Critérios de Otimização (superior) com o botão Detalhes conduzindo aos Tempos e Custos da Operação (inferior) (valores específicos para a ferramenta 36) 
$\Rightarrow$ na etapa de definição do Critério de Otimização a ser adotado para o torno CNC TND - 360 e a ferramenta 40 (DNMG 1506 08), o sistema sugere utilizar uma velocidade de corte tendente à $v_{m \times p}$ devido aos valores de $D$ e $R_{k}(1,1159$ e 1,2854, respectivamente) serem inferiores aos adotados como limite $(1,50 \mathrm{e}$ 1,30 , respectivamente). Aceitou-se essa sugestão $\left(v_{c}=260 \mathrm{~m} / \mathrm{min}\right)$;

$\Rightarrow$ como segunda opção de ferramenta (SNMG 1204 08) com o mesmo torno (vide figura 5.05), o sistema sugere utilizar uma velocidade de corte tendente à $v_{m \times p}$ devido aos valores de $D$ e $R_{k}(1,1006$ e 1,2863 , respectivamente) serem inferiores aos adotados como limite (1,50 e 1,30, respectivamente). Aceitou-se essa sugestão $\left(v_{c}=260 \mathrm{~m} / \mathrm{min}\right.$ ) (figura 5.06 );

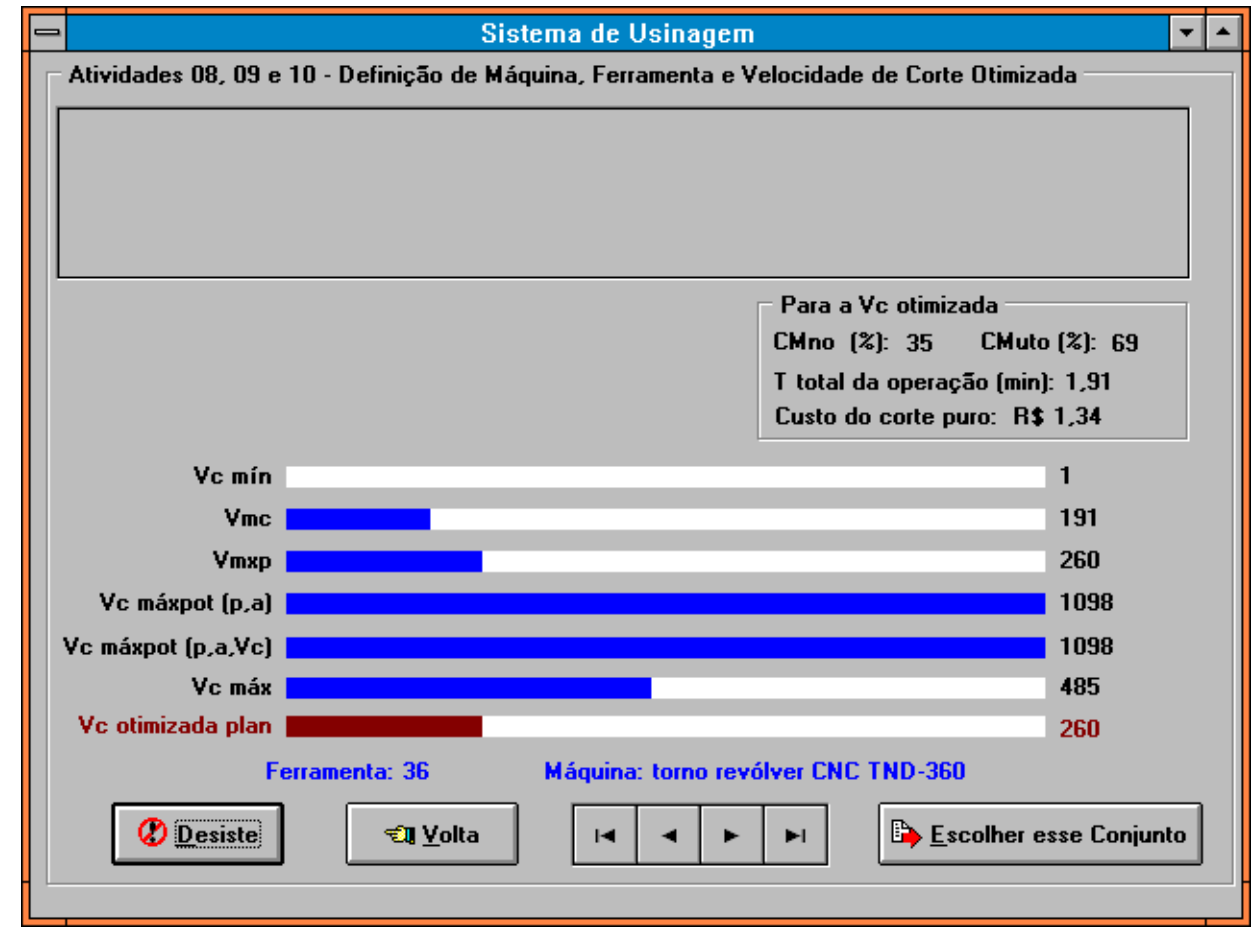

figura 5.06 Exemplo de definição da Velocidade de Corte Otimizada considerando as restrições da máquina e o cálculo de carga-máquina

$\Rightarrow$ quanto à análise de carga-máquina, como o sistema sugeriu para ambas as ferramentas a velocidade de máxima produção, a qual foi aceita, e estas eram iguais $(260 \mathrm{~m} / \mathrm{min})$, a carga-máquina necessária à operação $\left(\mathrm{CM}_{\mathrm{NO}}\right)$ também foi a mesma, ou seja, 35\%. Não houve sobrecarga da máquina pois, em ambos os casos, o valor da carga-máquina utilizada total na máquina ( $\mathrm{CM}_{\text {Uто) }}$ foi $69 \%$, não excedendo os dois turnos de trabalho ou $100 \%$; 
$\Rightarrow$ devido à pouca diferença entre os resultados econômicos das duas ferramentas aplicadas à mesma máquina, escolheu-se o conjunto que incluia a ferramenta 36 (SNMG 1204 08) devido ao custo ligeiramente inferior da ferramenta e maior robustez da mesma (pastilha quadrada) o que é aconselhável para operações de desbaste (figura 5.06).

\section{ENSAIOS DE FÁBRICA PARA O PRIMEIRO PASSE (Operação $\mathrm{n}^{\circ}$ 1)}

$\Rightarrow$ adotando-se a velocidade de corte otimizada de $260 \mathrm{~m} / \mathrm{min}$ com a ferramenta 36 operando na máquina $\mathrm{n}^{\circ} 3$ e as condições de $\operatorname{AMAX}=0,64 \mathrm{~mm} /$ rotação e $P M A X=1,0 \mathrm{~mm}$, fêz-se uma descrição rápida das condições do ensaio para a operação através da descrição do tipo de cavaco obtido, do tipo de fluido de corte empregado e do critério de desgaste adotado para a ferramenta (figuras $5.07,5.08$ e 5.09$)$;

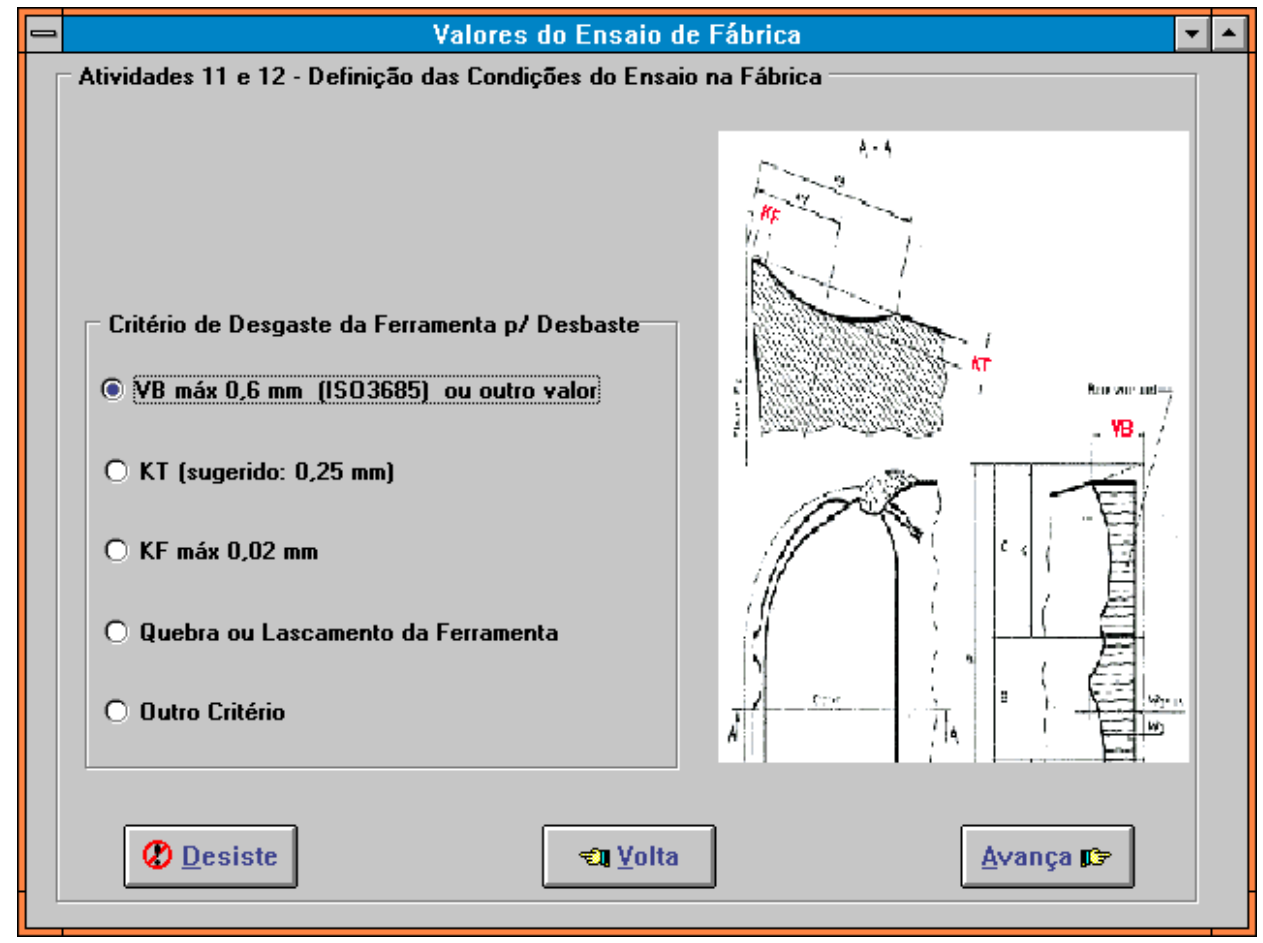

figura 5.07 Definição do Critério de Desgaste para o Ensaio com a ferramenta 36, o torno CNC TND - 360 e as condições $\left(p ; a ; V_{c 1}\right)=(1,0 ; 0,64 ; 260)$ 


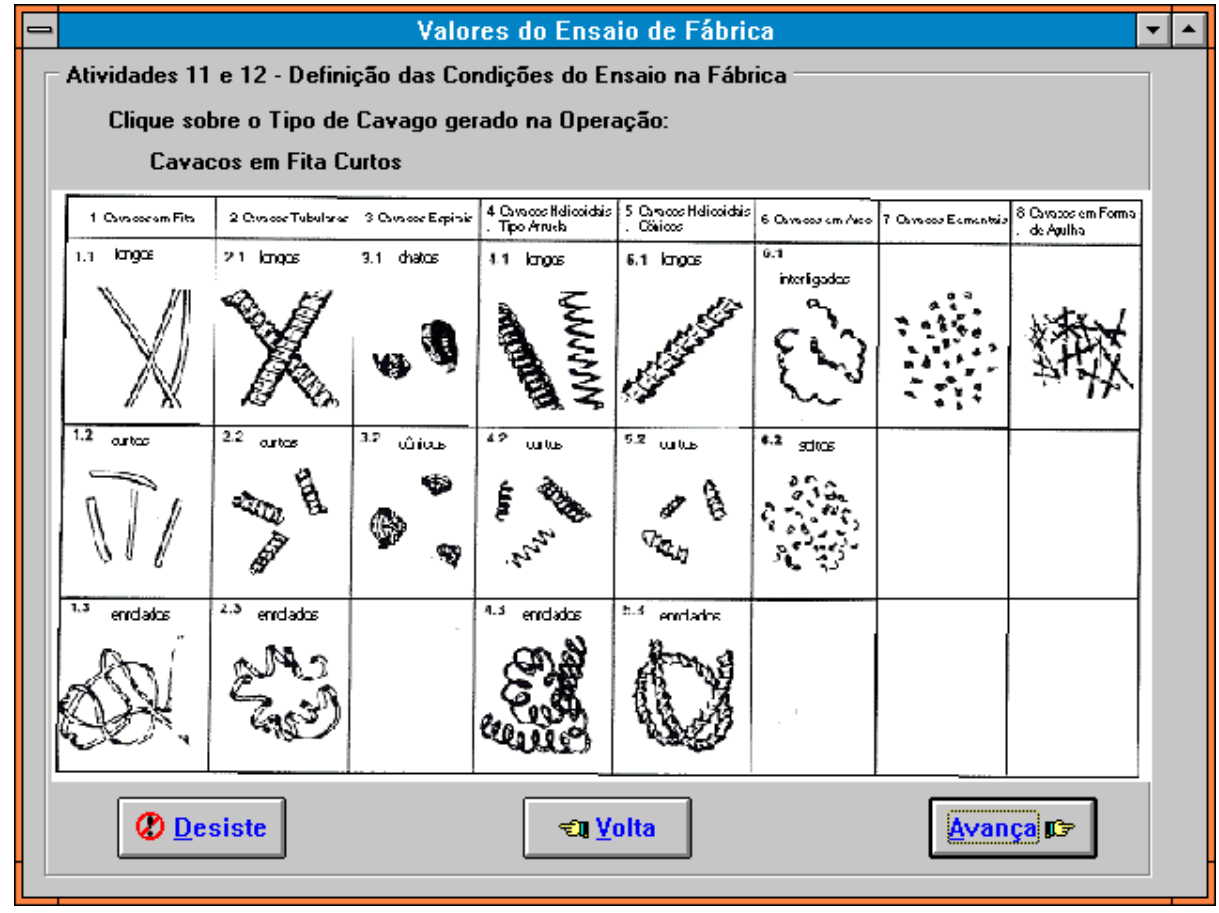

figura 5.08 Quadro para a escolha do tipo de cavaco gerado durante o ensaio da operação

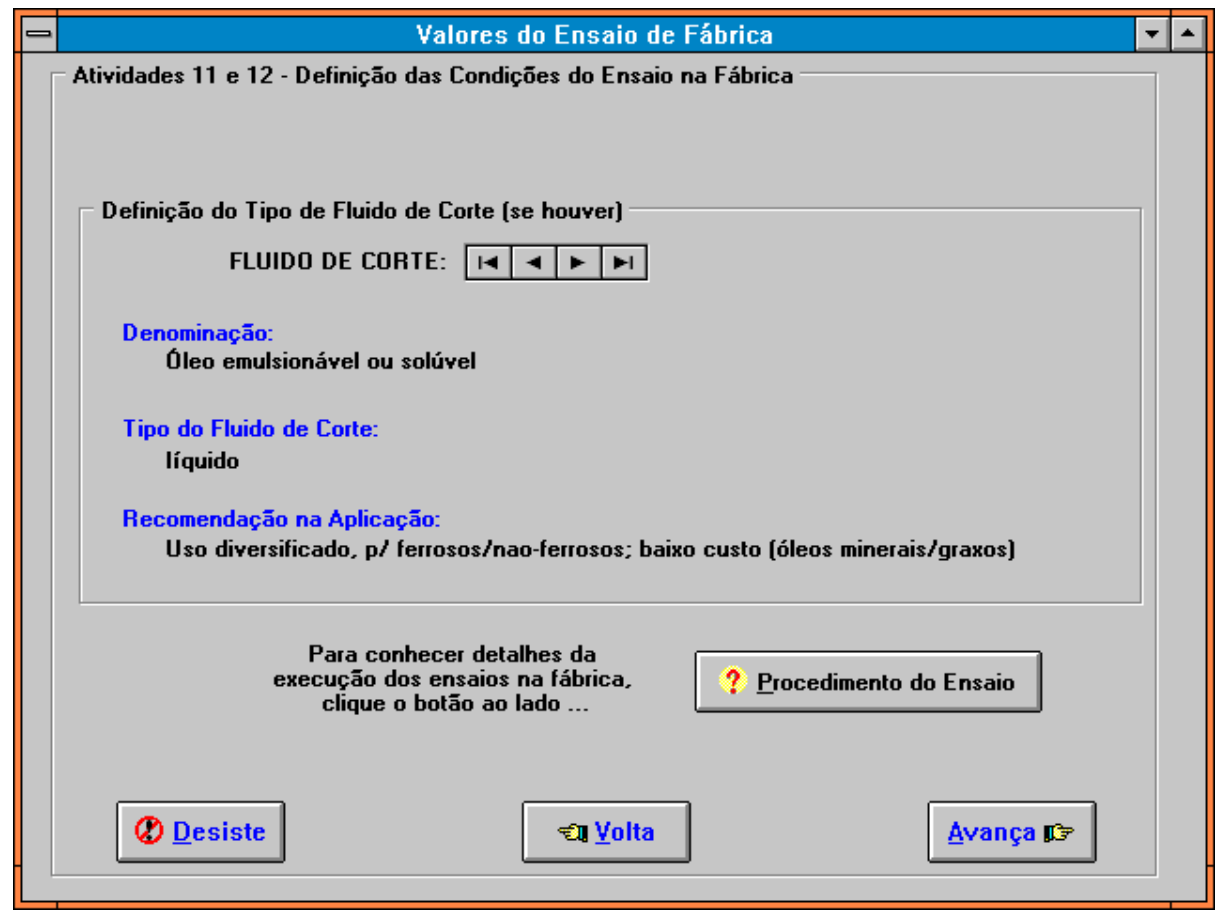

figura 5.09 Quadro para a escolha do fluido de corte utilizado durante o ensaio da operação 
$\Rightarrow$ em seqüência preencheu-se a tabela de resultados do ensaio, com os valores de $\left(Z_{1} ; T_{c 1} ; V_{c 1}\right)=(25$ peças; $1,0 \mathrm{~min} ; 260 \mathrm{~m} / \mathrm{min})$ e $\left(Z_{2} ; T_{c 2} ; V_{c 2}\right)=(45$ peças; 1,4 $\mathrm{min} ; 208 \mathrm{~m} / \mathrm{min}$ ), feitos com os valores de AMAX e PMAX já definidos (figura 5.10);

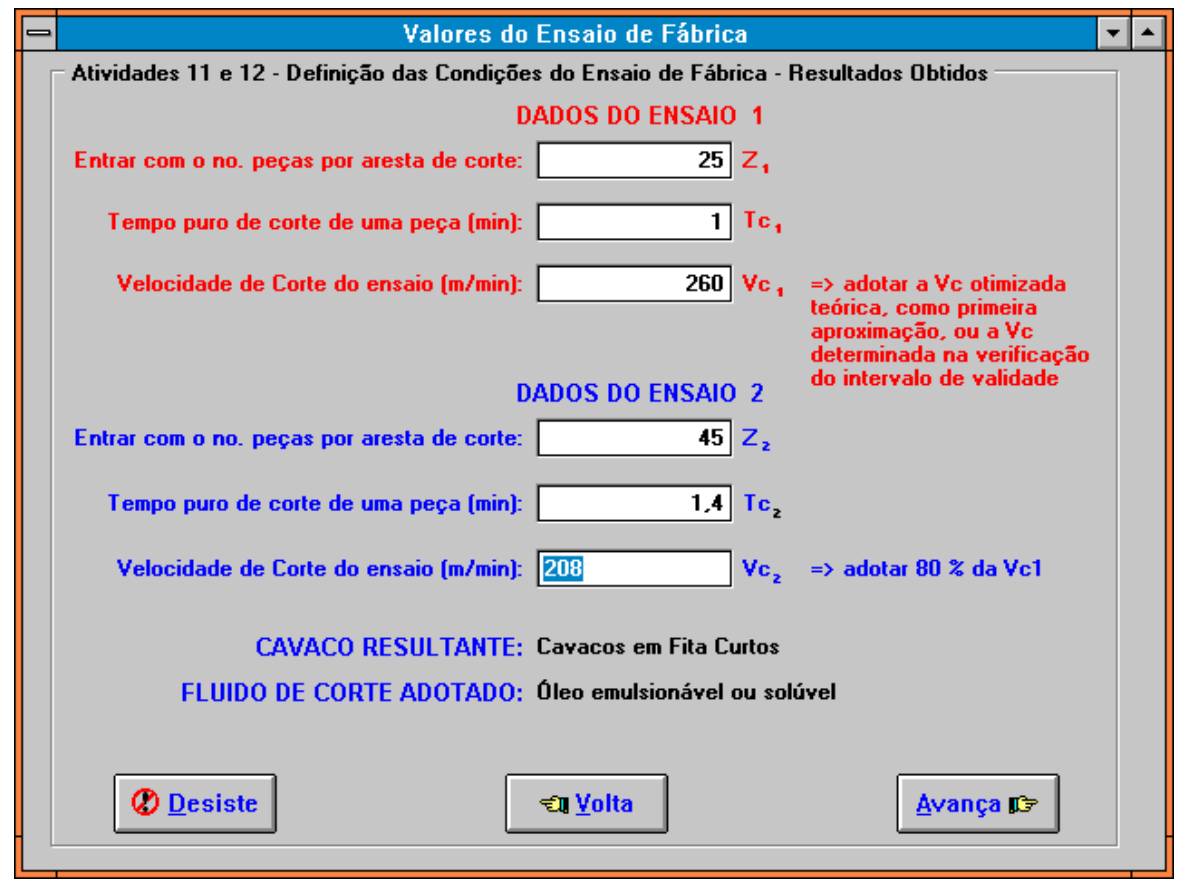

figura 5.10 Quadro para a introdução dos valores escolhidos para ensaio da operação na máquina. O sistema introduz os valores teóricos e 0 usuário pode alterá-los, de acordo com os resultados do ensaio (na figura já estão inseridos os valores práticos obtidos no ensaio)

$\Rightarrow$ o sistema protótipo, então, utiliza a mesma conceituação empregada na fase de planejamento teórico da operação para definir o critério de otimização a ser adotado na escolha da velocidade de corte (figura 5.11). Embora sem a informação da carga-máquina, a qual não foi implementada nesta etapa, o usuário deve escolher a velocidade de corte observando as indicações que o sistema the fornece. Caso a velocidade escolhida esteja fora dos limites de validade experimentais, ou seja, fora do intervalo entre $V_{c 1}$ e $V_{c 2}$, o sistema utilizará as regras mostradas em 4.2.9 para decidir por novas velocidades de ensaio de forma a se obter $\mathrm{x}$ e $\mathrm{K}$ de Taylor válidos, com uma velocidade de corte otimizada que esteja nesse intervalo e seja, assim, válida. 
$\Rightarrow$ visando obter uma redução grande no custo da operação sem comprometer o tempo de fabricação, adotou-se a velocidade de corte otimizada como igual a $260 \mathrm{~m} / \mathrm{min}$. Com isso consegue-se não elevar demasiadamente o custo da operação (o custo estabelece-se próximo ao mínimo custo, ou seja, inferior à diferença de 34,02\% existente entre as condições de mínimo custo e de máxima produção), obtendo-se um tempo total da operação relativamente baixo (até, no máximo, 16,56\% maior que o tempo obtido em condições de máxima produção) o que mantém a velocidade dentro do intervalo de máxima eficiência e numa situação em que a taxa de produção e a relação de custos são aceitáveis pela empresa.

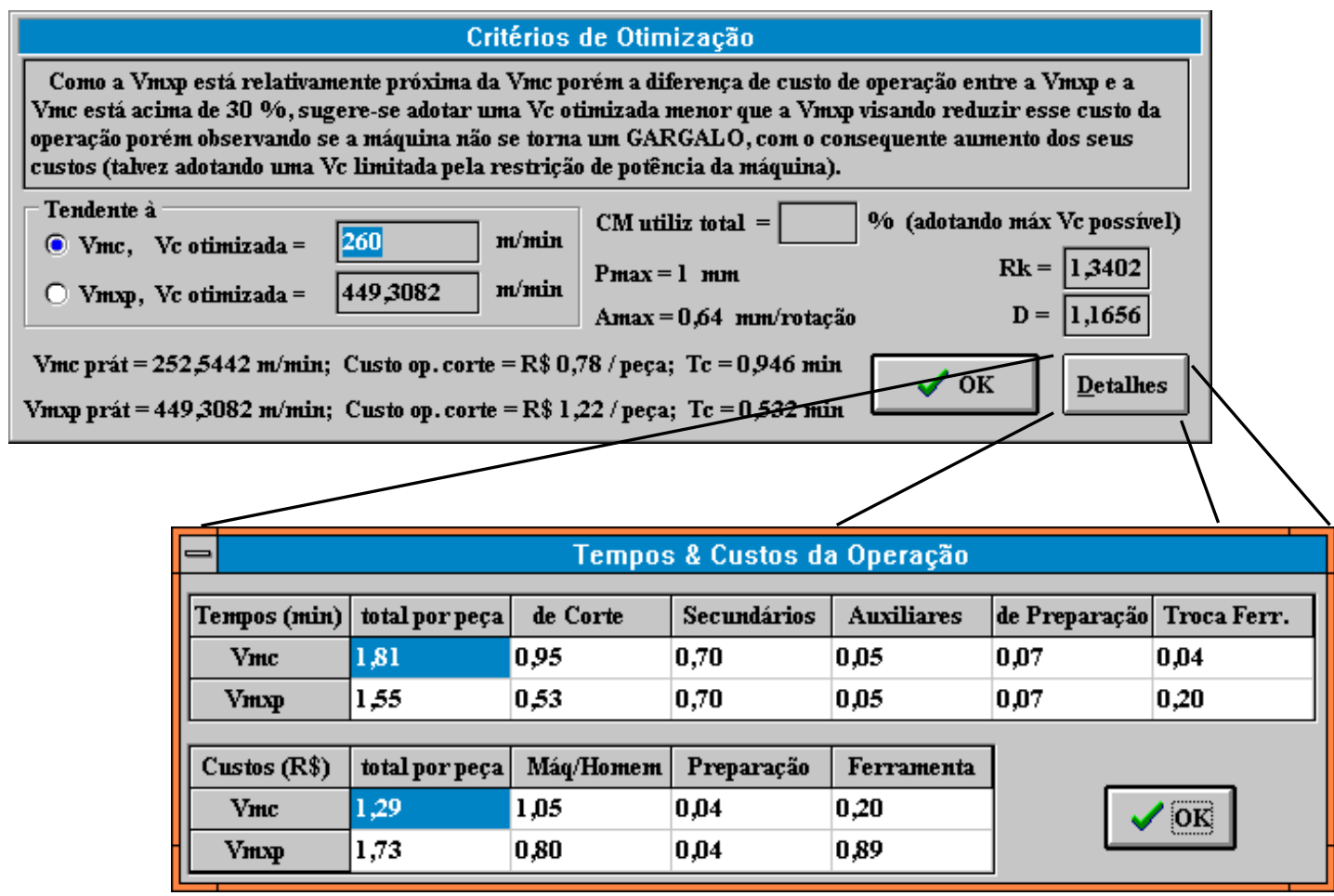

figura 5.11 Definição dos Critérios de Otimização (superior) e o botão Detalhes conduzindo aos Tempos e Custos da Operação (inferior) para as condições do ensaio dessa operação

$\Rightarrow$ caso fosse escolhida uma velocidade acima de $260 \mathrm{~m} / \mathrm{min}$, por exemplo, o sistema verificaria o intervalo de validade e sugeriria a adoção de uma nova velocidade de ensaio de $312 \mathrm{~m} / \mathrm{min}$. Com esse novo ensaio, novos valores de $\mathrm{x}$ e $\mathrm{K}$ de Taylor seriam calculados e, portanto, das velocidades de mínimo custo e de máxima produção, sugerindo valores mais refinados para a faixa 
de velocidades de corte possíveis de serem adotadas. Observando o item 4.2.9, onde há uma discussão sobre a evolução dos ensaios e as possíveis velocidades otimizadas a serem adotadas pelo usuário, conclui-se que a adoção da velocidade de $260 \mathrm{~m} / \mathrm{min}$ compatibiliza o intervalo de validade dos ensaios com as relações de custos e de produção, embora um ajuste fino nesse valor ainda possa ser feito através de um ou mais novos ensaios.

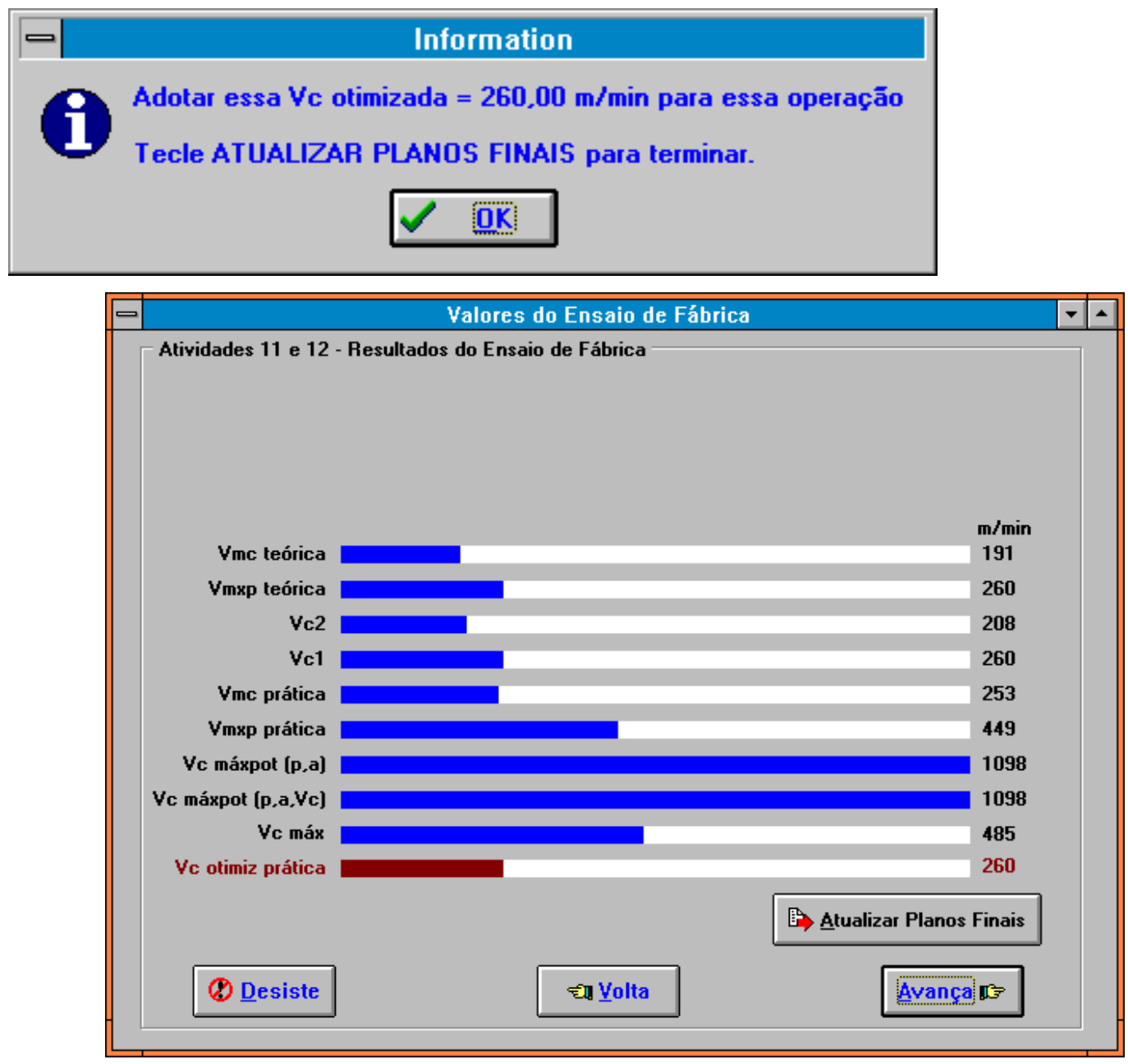

figura 5.12 Definição da Velocidade de Corte Otimizada Prática como $260 \mathrm{~m} / \mathrm{min}$, adotando um valor conveniente por sugestão do próprio sistema e pela análise do usuário com base nos dados mostrados nas telas do sistema e contidos na figura 5.11. O primeiro quadro mostra a validação da velocidade de corte adotada e a não necessidade de outros ensaios para determinação de $x$ e K de Taylor. O segundo ilustra uma comparação entre as várias velocidades discutidas e possíveis com essa máquina, ferramenta e condições de usinagem para o ensaio 


\section{Capítulo 6}

\section{Conclusões}

\subsection{Conclusões e Contribuições deste Trabalho}

Neste trabalho discutiu-se a questão do planejamento de processo dentro de uma indústria moderna, visando a sua integração, automatização e otimização por meio de computadores e particularmente para o caso de processos de usinagem. Procurou-se mostrar a grande quantidade de condicionantes existentes e que determinam a forma como se faz esse planejamento. Analisou-se o processo de planejamento distinguindo-o por dois grupos principais: o planejamento macro e o planejamento de operações. Visando executar a última etapa do planejamento global de processo, a determinação de condições e parâmetros de processo, concluiu-se quais os principais condicionantes desse problema. Isso conduziu a uma discussão dos aspectos específicos ao processo de usinagem a ser aplicado, assim como da usinabilidade do material da peça e do material e geometria da ferramenta. Por fim os aspectos relacionados à logística de produção, ou seja, à forma como se programa a quantidade produzida pelas máquinas na fábrica e os seus influenciadores, também se mostrou de elevada importância, sendo um dos principais aspectos a serem considerados em todo o processo de otimização. Junto a todas essas características, os valores dos tempos e dos custos de produção mostraram-se necessários para se avaliar e obter a otimização final.

Além da análise dos condicionantes do processo de determinação e otimização de parâmetros de usinagem, discutiu-se e sintetizou-se as tendências atuais nas metodologias computacionais empregadas em sistemas de planejamento CAPP. Concluiu-se que há uma tendência em se ter sistemas que fundem algoritmos bem definidos ao conhecimento especialista, além de uma busca de interfaces amigáveis com o usuário. A utilização de bancos de dados relacionais para sistematização dos dados necessários mostrou-se, da mesma forma, uma tendência. Por fim a adoção de uma abordagem semi-generativa, o que não descarta o uso de recuperação de informações advindas de outras peças e operações, mostrou-se uma 
alternativa viável e necessária para a simplificação e complementação do procedimento de otimização durante a fase de planejamento, seja teórico ou prático.

Este trabalho contribuiu, além da análise das restrições, influenciadores e métodos para a otimização em sistemas de planejamento, com a execução de um sistema protótipo que procurou considerar muitas das conclusões apontadas e, em particular, o caráter dinâmico e experimental do processo de otimização quando aplicado na fábrica. O conhecimento especialista, embora não se tenha empregado uma linguagem de programação dedicada à construção de sistemas baseados em conhecimento, foi empregado e mostrou-se eficaz nos resultados, particularmente na escolha do material da ferramenta, entre outros. A interface com o usuário simplificada permitiu uma fácil discussão pelo processista de alternativas de planejamento, podendo-se, ao final, escolher-se a melhor conforme os critérios de tempo e custo adotados.

A utilização de duas alternativas para escolha da velocidade de corte otimizada, uma tendente à velocidade de mínimo custo e outra à velocidade de máxima produção, mostrou que a busca por velocidades sempre maiores é, em geral, uma tendência só não ocorrendo quando os custos se elevam demasiadamente, caso este em que o sistema orienta para a adoção de velocidades menores. Para isso assumiu-se valores empíricos para os coeficientes $D$ e $R_{k}$ de forma que sejam indicadores do grau de transição de velocidade desejado.

Outras contribuições deste trabalho podem ser citadas:

- proposta de uma arquitetura geral e básica para o planejamento de processos de usinagem, como a contida na figura 4.01 ;

- detalhamento da estrutura citada, como mostrado na figura 4.02. Esse fluxograma, em termos gerais, pode ser aplicado a qualquer processo de usinagem convencional com pequenas modificações de acordo com o tipo de processo (geometria do processo, usinabilidade do material, tipo da máquina, etc.);

- o estudo de um modelo de usinabilidade como o adotado, mostrando que, quanto maior a sua correspondência à realidade do processo mais fiel será o plano de processo teórico, implicando em menor número de ensaios práticos visando atingir a velocidade otimizada prática no chão-de-fábrica;

- a proposição de um novo critério de otimização para condições de usinagem que considera aspectos como as atividades complementares à atividade de corte ou usinagem pura (movimentação rápida da ferramenta, fixação e retirada da peça na máquina, preparação da máquina, etc.) de maneira a recalcular os valores de $D$ e 
$R_{k}$ com base nas taxas de produção e de custos globais da operação e não apenas da atividade de corte pura. Com isso considera-se o que realmente importa à fábrica, ou seja, o tempo e o custo total das operações;

- a proposição de um algoritmo para a determinação/refinamento dos valores de avanço e raio de ponta da ferramenta levando em consideração as situações de desbaste e de acabamento, assim como a rugosidade superficial final desejada para a peça;

- a proposição de uma aliança entre o planejamento teórico e o acompanhamento/refinamento práticos do valor da velocidade de corte a ser adotada para a operação, sugerindo e esboçando modificações no procedimento de validação adotado em [Coppini 89]. 


\subsection{Sugestões para Pesquisas Futuras}

Entre os possíveis trabalhos futuros, pode-se destacar:

- aplicar e validar o presente sistema para outros processos de usinagem além do torneamento e utilizando um número maior de casos reais;

- um complemento ao trabalho atual através do estudo e da utilização de features de usinagem, procurando uma maior integração entre projeto de produto e planejamento de processo para se ter não apenas a geração do programa CNC ao final, mas também a determinação das condições de corte otimizadas, fazendo uma junção CAD/CAPP/CAM mais completa;

- o estudo da aplicação deste sistema de planejamento quando se tratar de lotes de fabricação menores, para os quais nem sempre é possível executar os procedimentos de ensaio propostos;

- utilizar para o desenvolvimento do sistema proposto linguagens específicas ao trabalho com sistemas especialistas, tais como os possibilitados por shells, ou ambientes de desenvolvimento baseados na introdução de regras e fatos, com inferência própria;

- estudar e propor formas de maior interação entre sistemas CAPP e sistemas CAFP;

- a aplicação de outros modelos de otimização e a avaliação comparativa entre cada um e o proposto no presente trabalho tais como o das normas ISO 3685 [ISO 93] e ISO 8688 [ISO 89] (no que diz respeito à forma de avaliação do desgaste da ferramenta), o modelo estatístico utilizado em [Zhou 92], o qual considera a estimação sequencial na fábrica como fonte de informações de usinabilidade do material da peça e propõe uma função de custo que considera as penalidades decorrentes de uma troca tardia da ferramenta, os modelos presentes em catálogos e sugeridos pelos fabricantes de ferramentas, etc.;

- estudar e propor soluções para os casos de múltiplos passes ou de várias operações com a mesma ferramenta;

- estudar e propor critérios teóricos e práticos de seleção de material para a ferramenta visando a sua aplicação em sistemas de planejamento;

- estudar e comparar modelos alternativos para a qualidade de acabamento superficial em usinagem, obtendo-se valores que se aproximem mais da realidade observada na prática. Sugere-se, por exemplo, o estudo das restrições de rigidez 
da máquina que influenciam na qualidade superficial de forma a se poder incorporar essas informações de maneira simples num sistema de planejamento (vide [Narang 93]);

- estudar e propor modelos de custos de fabricação baseados na abordagem ABC citada para o sistema mostrado neste trabalho, de forma a se ter uma estrutura de custos que se aproxime mais da realidade do processo que se deseja planejar;

- estudar e propor soluções para a determinação de valores otimizados alternativos de profundidade de corte e de avanço, discutindo a adoção dos máximos como proposto em parte da literatura atual;

- utilizar bancos de dados de usinabilidade com materiais além do aço e do ferro fundido, visando estender o campo de aplicação do sistema protótipo;

- estudar e aplicar os conceitos de planejamento de processo integrados ao de programação de produção, a exemplo do que o sistema protótipo faz porém com maior grau e possibilitando a atualização rápida das novas condições otimizadas para usinagem, como descrito em 2.5;

- aplicar a estrutura geral do sistema de planejamento defendido para o domínio de processos de usinagem em outros domínios, tais como o de processos de soldagem, adequando os modelos de utilizados porém mantendo os requisitos de otimização das condições de processo que se baseiam em tempos, custos e qualidade finais da peça;

- aprimorar o critério de validação das velocidades otimizadas obtidas por meio de ensaios de usinagem adotado no presente trabalho, definindo-o em termos do critério situacional dos valores de $D$ e de $R_{k}$ utilizado, das restrições de velocidade existentes e da convergência do processo de teste, seja através de regras especialistas ou por lógica nebulosa, como proposto em [Almeida 96]. 


\section{Referências Bibliográficas}

[ABNT 80] ASSOCIAÇÃO BRASILEIRA DE NORMAS TÉCNICAS. Processos Mecânicos de Usinagem - NBR 6175. São Paulo, 1980.

[ABNT 90] ASSOCIAÇÃO BRASILEIRA DE NORMAS TÉCNICAS. Geometria da cunha de corte - NB 205. Rio de Janeiro, 1990.

[Almeida 96] ALMEIDA, S. L. R. et al. Aplicação de Lógica Fuzzy e Redes Neurais para a Otimização de Condições de Usinagem. Máquinas e Metais, no. 365, p. 98-106, junho, 1996.

[Araujo 87] ARAUJO, G. A.; TRAVITSKY, O. Conceitos de Programação e Controle da Produção. São Bernardo do Campo, Mercedes-Benz do Brasil, 1987. 22 p. (publicação para uso interno).

[Araujo 88] ARAUJO, G. A. A Antecedência de Produção. São Bernardo do Campo, Mercedes-Benz do Brasil, 1988. 50 p. (publicação para uso interno)

[Araujo 95] ARAUJO, G. A. Orientações para um Plano Diretor de Manufatura. São Bernardo do Campo, Mercedes-Benz do Brasil, 1995. (trabalho interno, de uso restrito).

[Asimow 68] ASIMOW, M. Introdução ao Projeto de Engenharia. 1a. ed. traduzida. São Paulo, Brasil. Ed. Mestre Jou, 1968. 171p.

[Barkocy 84] BARKOCY, B. E.; ZDEBLICK, W. J. A Knowledge Based System for Machining Operation Planning. Proceedings of SME Autofact 6. Arlington, Texas, U.S.A.. 1984, p. 2.11-2.25.

[Balakrishnan 85] BALAKRISHNAN, P., DEVRIES, M.F. Sequential Estimation of Machinability Parameters for Adaptive Optimization of Machinability Data Base Systems. Transactions of ASME, Journal of Engineering for Industry. E.U.A. Maio, 1985, vol. 107, p. 159-166.

[Bernardo 96] BERNARDO, V.; COPPINI, N. L. Inteligência artificial aplicada à otimização das condições de usinagem. Máquinas e Metais, no. 369, p. 76-87, outubro, 1996.

[Billatos 91] BILLATOS, S. B.; KENDALL, L. A. A General Optimization Model for Multi-Tool Manufacturing Systems. Transactions of ASME, Journal of Engineering for Industry. E.U.A. Fevereiro, 1991, vol. 113, p. 10-16.

[Boehs 86] BOEHS, L. et al. Seleção de Condições Otimizadas de Corte - "Software" Apoiado por Banco de Dados. In: 6o. Seminário de Comando Numérico no Brasil. Anais. Sobracon, São Paulo. Agosto, 1986. Vol. I, p. 01.01-01.17.

[Bordui 88] BORDUI, D. Hard Part Machining with Ceramic Inserts. Ceramic Bulletin. E.U.A., 1988, vol. 67, no. 6. (Reimpresso in: Advances in Materials 
Technology: MONITOR - Materials for Cutting Tools. UNIDO, Austria, 1988, no. 12 , p. 12-15).

[Brunstein 94] BRUNSTEIN, I. Análise de Custos no Projeto e Manufatura no Contexto da Engenharia Simultânea. 1a. ed., São Paulo, Brasil. AEAAssociação Brasileira de Engenharia Automotiva, 1994. 60 p.

[Caillaud 94] CAILLAUD, E. et al. Sistema de fixação de peças: um conhecimento especializado. Máquinas e Metais, no. 346, p. 26-33, novembro, 1994.

[Chandrasekaran 88] CHANDRASEKARAN, H. Material Development and its Role in Advanced Machining Situations. Journal of Mechanical Working Technology. Amsterdam, 1988, vol. 17, p. 119-136.

[Chang 92] CHANG, C. Computer-Assisted Fixture Planning for Machining Processes. Manufacturing Review. E.U.A., A.S.M.E., 1992, vol. 5, no. 1, p. 1528.

[Colding 92] COLDING, B. N. A boa escolha de parâmetros de usinagem leva a muitos ganhos. Máquinas e Metais, no. 313, p. 86-94, fevereiro, 1992.

[COMPLAN 95] COMPLAN, ESPRIT 6805. COMPLAN Process Planning and Workshop Scheduling - Public Domain Report. Bélgica. Http://www.mech. kuleuven.ac.be/pma/project/complan. 1995. 21 p.

[Coppini 87] COPPINI, N. L. et al. Análise das Condições Operacionais visando a Obtenção das Condições de Usinagem Otimizadas. In: 7o. Seminário de Comando Numérico no Brasil. Anais. Sobracon, São Paulo. 1987. Vol. I, p. 03.01-03.06.

[Coppini 89] COPPINI, N. L. et al. Otimização de Condições de Usinagem em Células de Fabricação. In: 10. Simpósio Brasileiro sobre Tecnologia de Usinagem. Anais. Sobracon, São Paulo. Março, 1989. Vol. I, p. 17.01-17.20.

[Coppini 93] COPPINI, N. L.; BATOCCHIO, M. C. A. Sistema Especialista de Banco de Dados em Usinagem para Aplicações em Ambiente Fabril. In: Seminário de Usinagem e Automação para a Competitividade e a Qualidade. Anais. São Caetano do Sul, SP, Brasil, Senai, JICA, Sebrae. 1993, 6p.

[Couers 90] COUERS, D. Schnittgeschwindigkeits-Vorschub-Diagramm beim Drehen. Werkstattechnik. Springer-Verlag, Deutschland. 1990, vol. 80, p. 411414.

[Cowton 93] COWTON, C. J.; WIRTH, A. On the economics of cutting tools. International Journal of Production Research. London, U.K., outubro, 1993, vol. 31 , no. 10 , p. 2441-2446.

[DeArdo 93] DEARDO, A. J. et al. A Better Way to Assess Machinability. American Machinist. E.U.A. Maio, 1993, p. 33-35.

[DIN 85] DEUTSCHES INSTITUT FÜR NORMUNG. Bezugssysteme und Winkel am Schneidteil des Werkzeuges - DIN 6581. Berlin, Alemanha, 1985. 
[Drucker 90] DRUCKER, P. F. The Emerging Theory of Manufacturing. Harvard Business Review, v. 68, no. 3, p. 94-102, maio/junho, 1990.

[Eriksson 92] ERIKSSON, U. The Quantitative Assessment of Machinability. Processing, Microstructure and Properties of Microalloyed and other Modern High Strength Low Alloy Steels. ISS-AIME, Warrendale, Pa., E.U.A., 1992, 4p.

[Ferraresi 85] FERRARESI, D. Fundamentos da Usinagem dos Metais. 1a. ed., vol. 1. São Paulo, Brasil. Edgard Blücher, 1985. 751p.

[Ferraresi 89] FERRARESI, D. Otimização das condições de usinagem em produção seriada. Máquinas e Metais, no. 286, p. 24-37, novembro, 1989.

[Ferreira 86] FERREIRA, A. B. H. Novo Dicionário da Língua Portuguesa. Rio de Janeiro, Brasil, Nova Fronteira, 2a. Ed.,1986, 1838p.

[Genaro 86] GENARO, S. Sistemas Especialistas: o Conhecimento Artificial. Rio de Janeiro, Brasil, LTC Editora, 1a. ed., 1986. 192p.

[Girondi 88] GIRONDI, A. C.; FERREIRA, A. C.; BOEHS, L. Determinação automática de condições de usinagem. Máquinas e Metais, no. 265, p. 134-139, janeiro, 1988.

[Gopalakrishnan 89] GOPALAKRISHNAN, B. Computer Integrated Machining Parameter Selection in a Job Shop using Expert Systems. Journal of Mechanical Working Technology. Amsterdam, Netherlands, Elsevier Science Publishers, 1989, vol. 20 , p. 163-170.

[Groover 88] GROOVER, M. P.; ZIMMERS, E. W. CAD/CAM: Computer Aided Design and Manufacturing. New Jersey, NJ, USA, Prentice-Hall, 1988.

[Hargrove 94] HARGROVE, S. K.; KUSIAK, A. Computer-aided fixture design: a review. International Journal of Production Research. London, U.K., 1994, vol. 32, no. 4, p. 733-753.

[ISO 89] INTERNATIONAL ORGANIZATION FOR STANDARDIZATION. Tool-life testing in milling (part 1: face milling - part 2: end milling) - ISO 8688. 1a. ed. Switzerland, 1989.

[ISO 91] INTERNATIONAL ORGANIZATION FOR STANDARDIZATION. Indexable inserts for cutting tools - Designation - ISO 1832. Genebra, Suiça, 1991.

[ISO 93] INTERNATIONAL ORGANIZATION FOR STANDARDIZATION. Tool-life testing with single-point turning tools - ISO 3685. 2a. ed. Switzerland, 1993.

[Johannsen 79] JOHANNSEN, P., KUNZ, H. et al. Zerspanungrichtwerte Schnittdaten für Drehen von Eisenwerkstoffen mit Hartmetall-Werkzeugen. Ünterturkheim, Alemanha, Daimler-Benz AG, 1979.60 p. (publicação para uso interno). 
[Johannsen 92] JOHANNSEN, P. Anwendung hoher Schnitt-geschwindigkeiten im

Fahrzeugbau. Werkstatt und Betrieb, vol. 125, no. 3, p. 179-182, 1992.

[Jones 89] JONES, E. dBASE IV: Guia do Usuário. 1a. ed. traduzida. São Paulo, Brasil. McGraw Hill, 1989. 705 p.

[König 94] KÖNIG, W. Tecnologia da Fabricação - Tornear, Fresar e Furar. Trad. de Walter L. Weingaertner. 1.ed., vol. 1. Florianópolis, Santa Catarina, 1994. 409 p. (texto manuscrito)

[Kunz 94] KUNZ, H. et al. Leistungspotentiale von Werkzeugwerkstoffen nutzen Zerspanung. 1a. ed., vol. 1. Untertürkheim, Deutschland. Zentralen Werkstoff und Prozeßtechnik - Mercedes-Benz AG, dezembro, 1994. 274p.

[Lenau 88] LENAU, T.; ALTING, L. Artificial Intelligence for Process Selection. Journal of Mechanical Working Technology. Amsterdam, 1988, vol. 17, no. 1.

[Liu 85] LIU, C. R.; WU, M. C. Automated Process Planning and Expert Systems. In: 1985 IEEE International Conference on Robotics and Automation. IEEE Computer Society Press, St. Louis, Mlssouri, E.U.A., 1985. 1a. ed., p. 186-191.

[Logan 90] LOGAN, F. A Evolução para Planejamento de Processo Automático através de Sistema Especialista Generativo. Boletim SOBRACON. São Paulo, no. 48, p. 43-48, 1990.

[Lye 92] LYE, S. W.; YEO, S. H. Development of an integrated CAD/CAPP/CAM system for turning operations. Journal of Materials Processing Technology. Amsterdam, Netherlands, Elsevier Science Publishers, 1992, no. 29, p. 103-117.

[Machado 87] MACHADO, A. Comando Numérico Aplicado às MáquinasFerramenta. 2.ed. São Paulo, ĺcone, 1987. 396 p.

[Madl 96] MADL, J. Optimization of Cutting Conditions in Machining. Prague, Czech Republic. Http://wwwift.tuwien.ac.at/ www311a/1995/m1.asc. 1996.

[Marcondes 90] MARCONDES, F. C. A História do Metal Duro. 1a. ed. São Paulo, Brasil. Sandvik do Brasil, março de 1990. 240p.

[Mason 95] MASON, F. Computer Aided Fixture Design. Manufacturing Engineering. E.U.A., S.M.E., 1995, vol. 114, no. 6, p. 41-45.

[Mason 96] MASON, F. Electronic Tool Selection. Manufacturing Engineering. E.U.A., S.M.E., 1996, vol. 116, no. 1, p. 57-59.

[Merchant 88] MERCHANT, M. E. CIM Systems Integration - Problems and Trends. Journal of Mechanical Working Technology. Amsterdam, 1988, vol. 17, no. 1, p. $1-10$.

[Mill 87] MILL, F.; SPRAGGETT, S. Artificial intelligence for production planning. In: Smart Manufacturing with Artificial Intelligence. SME, Dearborn, MI, E.U.A., 1987. 1a. ed., p. 71-75. 
[Mital 94] MITAL, A.; ANAND, S. Handbook of Expert Systems Applications in Manufacturing Structures and Rules. 1a. ed., London, U. K. Chapman \& Hall, 1994. 396 p.

[Miyagi 90] MIYAGI, P. E.; BARRETO, M. R. P. Sistemas Integrados de Manufatura. In: 8ํㅡㄹ Congresso Brasileiro de Automática. Anais. Belém, PA, Sociedade Brasileira de Automática. 1990, v. 1, p. TC81-TC87.

[Narang 93] NARANG, R. V., FISCHER, G. W. Development of a framework to automate process planning functions and to determine machining parameters. International Journal of Production Research. London, U.K., 1993, vol. 31, no. 8, p. 1921-1942.

[Novaski 83] NOVASKI, O. Uma Contribuição ao estudo das condições econômicas de usinagem. Campinas, 1983. Tese (Mestrado) - Universidade de Campinas.

[Novaski 91] NOVASKI, O. Custos de Usinagem. 1a. ed. Campinas, SP. Editora da Universidade Estadual de Campinas - UNICAMP, 1991. 149p.

[Omar 86] OMAR, N. Sistemas Especialistas: uma Nova Ferramenta para Automatização Industrial. Anais do $6^{\circ}$ Seminário de Comando Numérico no Brasil. São Paulo, SOBRACON. 1986, vol. I, p. 22.01-22.17.

[Opas 94] OPAS, J. et al. Automatic process plan generation in an operative process planning system. International Journal of Production Research. London, U.K., 1994, vol. 32, no. 6, p. 1347-1363.

[ORACLE 92] Oracle Manufacturing. Catálogo. Oracle Corporation, 1992, E.U.A. $16 p$.

[Pallerosi 73] PALLEROSI, C. A. Formulação de um método geral de análise das condições econômicas de usinagem. Campinas, 1973. 264p. Tese (Doutorado) - Departamento de Engenharia Mecânica, Universidade Estadual de Campinas.

[Reiter 89] REITER, N. Neue Werkstoffe und Bearbeitungstechnologien. Werkstattechnik. Springer-Verlag, Deutschland. 1989, vol. 79, p. 513-516.

[Rodrigues 93] RODRIGUES, S. R. Criação e Aplicação de Módulos Automáticos para o Planejamento de Processo Assistido por Computador em Soluções Híbridas de Planejamento. São Carlos, 1993. 163p. Tese (Doutorado) Escola de Engenharia de São Carlos, Universidade de São Paulo.

[Rozenfeld 89] ROZENFELD, H. Sistema Modular de Planejamento de Processo (CAPP) Aplicado ao Contexto Nacional. In: IV Simpósio sobre "CAE/CAD/CAM". Anais. Sobracon, São Paulo. 1989.

[Rozenfeld 92] ROZENFELD, H. et al. Modelamento de Empresas: Requisito para a Manufatura Integrada por Computador (CIM). In: V Congresso Nacional de Automação Industrial (CONAI). Anais. São Paulo, SP. 1992, p. 75-94. 
[Rozenfeld 93] ROZENFELD, H. Planejamento de Processo Auxiliado por Computador, uma Solução Acessível. In: Seminário de Usinagem e Automação para a Competitividade e a Qualidade. Notas das Palestras. São Caetano do Sul, SP, Brasil, Senai, JICA, Sebrae. 1993, 20p.

[Rubenking 96] RUBENKING, N. J. Programação em Delphi Para Leigos. 5a. ed. traduzida. São Paulo, Brasil. Berkeley Brasil, 1996. 372 p.

[Sandvik 91] SANDVIK COROMANT. Herramientas Y Plaquitas para Tornear. Suécia, 1991. (Catálogo)

[Schulte 92] SCHULTE, R. M. et al. Feature-driven, process-based approach to the integration of CAD/CAM in wireframe models. International Journal of Production Research. London, U.K., 1992, vol. 30, no. 5, p. 1005-1028.

[Sim 89] SIM, S. K., LEONG, K. F. Prototyping a Feature Based Modelling System for Automated Process Planning. Journal of Mechanical Working Technology. Amsterdam, 1989, vol. 20, p. 195-204.

[Singh 92] SINGH, R., RAMAN, S. METEX - An expert system for machining planning. International Journal of Production Research. London, U.K., 1992, vol. 30 , no. 7 , p. 1501-1516.

[Sinterconsult 94] SINTERCONSULT TECNOLOGIA LTDA. Materiais para Ferramentas de Corte. São Paulo, setembro, 1994.

[Stipkovic Fo. 84] STIPKOVIC FILHO, M. Usinagem. São Paulo, Apostila EPUSP, 1984. 220p.

[Stricker 90] STRICKER, R. Aluminium Specific Tools in Application. Industrial \& Production Engineering, vol. 14, no. 2, p. 55-61, 1990.

[Taylor 66] TAYLOR, F. W. Princípios de Administração Científica. Trad. de Arlindo Vieira. 6.ed. São Paulo, Atlas, 1966. 157 p. (Série Administração-vol. XIII)

[Teixeira Jr. 89] TEIXEIRA JÚNIOR, A. et al. Sistema para Planejamento de Processos de Usinagem. Máquinas e Metais, no. 278, p. 44-49, março, 1989.

[The Economist 87] Factory of the Future: A Survey. The Economist. 30 de maio, 1987.

[Toledo Jr. 79] TOLEDO JÚNIOR, I. B., KURATOMI, S. Cronoanálise. 4.ed. São Paulo, Nobel, 1979. 414 p.

[Trent 89] TRENT, E. M. The Role of Scientific Research in Development of Cutting Technology. In: 10. Simpósio Brasileiro sobre Tecnologia de Usinagem. Anais. Sobracon, São Paulo. Março, 1989. Vol. I, p. 01.01-01.09.

[Yeo 88] YEO, S. H. et al. Development of an Expert System for Machinability Data Selection. Journal of Mechanical Working Technology. Amsterdam, Netherlands, Elsevier Science Publishers. 1988, no. 17, p. 51-60. 
[Yeo 89] YEO, S. H. et al. Towards Enhacement of Machinability Data by Multiple Regression. Journal of Mechanical Working Technology. Amsterdam, Netherlands, Elsevier Science Publishers. 1989, no. 19, p. 85-99.

[Zhang 94] ZHANG, H. C.; ALTING, L. Computerized Manufacturing Process Planning Systems. 1a. ed., London, U. K. Chapman \& Hall, 1994. 336p.

[Zhou 92] ZHOU, C.; WYSK, R. A. An Integrated System for Selecting Optimum Cutting Speeds and Tool Replacement Times. International Journal of Machine Tools \& Manufacture - Design, Research \& Application. Pergamon

Press, Great Britain, 1992, vol. 32, no. 5, p. 695-707.

[Zwicker 93] ZWICKER, R.; REINHARD, N. Sistemas especialistas: um hiato de aplicabilidade. Revista de Administração. Instituto de Administração, FEAUSP, São Paulo, 1993, vol. 28, no. 4, p. 111-116. 